\title{
Differences among standardized test scores due to factors of Internet access at home and family affluence
}

Steve Macho

West Virginia University

Follow this and additional works at: https://researchrepository.wvu.edu/etd

\section{Recommended Citation}

Macho, Steve, "Differences among standardized test scores due to factors of Internet access at home and family affluence" (2005). Graduate Theses, Dissertations, and Problem Reports. 2667.

https://researchrepository.wvu.edu/etd/2667

This Dissertation is protected by copyright and/or related rights. It has been brought to you by the The Research Repository @ WVU with permission from the rights-holder(s). You are free to use this Dissertation in any way that is permitted by the copyright and related rights legislation that applies to your use. For other uses you must obtain permission from the rights-holder(s) directly, unless additional rights are indicated by a Creative Commons license in the record and/ or on the work itself. This Dissertation has been accepted for inclusion in WVU Graduate Theses, Dissertations, and Problem Reports collection by an authorized administrator of The Research Repository @ WVU.

For more information, please contact researchrepository@mail.wvu.edu. 
Differences Among Standardized Test Scores Due to Factors of Internet Access at Home and Family Affluence

Steve Macho

\author{
Dissertation submitted to the \\ College of Human Resources and Education \\ at West Virginia University \\ in partial fulfillment of the requirements \\ for the degree of \\ Doctor of Education \\ in \\ Technology Education \\ John Wells, Ph.D., Chair \\ Sebastian Diaz, Ph.D., J.D. \\ Stacy Gartin, Ph.D. \\ Edward Pytlik, Ph.D. \\ Richard Walls, Ph.D. \\ Department of Technology Education \\ Morgantown, West Virginia \\ 2005
}

Keywords: Internet at home, Educational Technology, SES

Copyright 2005 Steve Macho 


\begin{abstract}
Differences Among Standardized Test Scores Due to Factors of Internet Access at Home and Family Affluence
\end{abstract}

Steve Macho

The purpose of this study was to examine differences among the standardized test scores of students due to factors of Internet access at home, household income, and the highest level of education attained by mother, father or guardian. If students with Internet access at home have a different academic standing, is it the result of the Internet connection or confounding factors of family affluence?

The San Miguel GEAR UP program at New Mexico Highlands University, located in Las Vegas, New Mexico had existent data on program participants for Internet access at home, household income, highest level of education in the household, and standardized test data. The population of the participants consisted of students from two public school districts in northern New Mexico. These students were in grades six to ten, and standardized test data and demographic data were from the 2003-2004 school year. The independent variables were: A) Internet access grouped as yes versus no, B) highest level of education of the parent and/or guardian grouped as those with or with out a bachelor's degree, and C) household income in three categories $(\$ 0-\$ 20,00, \$ 20,001$ $\$ 30,000$, and $\$ 30,001+$ ) of annual income. The dependent variable was the NCE total score from Spring 2004 CTB/McGraw-Hill -TerraNova. The method of analysis was a 3-way factorial ANOVA.

There were two significant differences in the primary analysis students NCE total scores: 1) the main effect for the education level of the parent and/or guardian, $F(1,544)$ $=20.412, p<0.001$, and; 2 ) the three way interaction of the factors of Internet access at home, household income and highest level of parent education, $F(2,560)=3.234, p=$ 0.040 . Only the education level of the parent and/or guardian proved to far exceed the level of rejection in this study.

Outlying data were removed for further analyses. An unbalanced factorial ANOVA, fully crossed and balanced factorial ANOVA, and two sets of one-way ANOVAs were performed. Findings were consistent among all further analyses performed. The highest level of education within the household was the only determinant factor of student NCE total score performance. 


\section{Acknowledgements}

In the closing of a process, I must acknowledge that while I have put forth due effort, this is not the result of a single individual. I wish to express my gratitude for the examples set by others, their enduring patience \& encouragement the support - their efforts must be acknowledged.

The life long learning example of my father, Vernon Macho, -- while he achieved the "normal" eighth-grade education of rural-Minnesota in the early 1940's - in the 1970s he brought me along to his night classes when he became an engineer. And, of course, for being raised the fourth generation on the family farm, which provides lessons far beyond the scope of any formal education experiences.

At West Virginia University: Dr Ed Pytlik (Chair \#1), Dr John Wells (Chair \#2), Dr Dick Walls, Dr Sebastian Diaz, Dr Stacy Gartin, Dr Ernest Goeres -- Dr Dave McCrory, Dr Paul DeVore, \& Dr George Maughn. I am grateful for the excellence of the faculty at WVU.

Because I have lived this process so well, I have had two excellent advisors. Dr Pytlik was an excellent mentor and continues to hold a revered place. His inspiration, insight and honesty - his character guided me through the major portion of this farmboys dream. Dr Wells has done an excellent job of mentoring me back to the rites of a doctoral student. His profoundly precise insight and guidance have made this possible. (and I will remember to "put my best foot first").

In the New Mexico \& other various places: Jose C'de Baca "saint Joe" (New Mexico Highlands University -GEARUP), Abad Sandoval (Los Alamos National Laboratory - STB/UO), Dr Chris Nelson (New Mexico Highlands University - School of Education), Dr Pat \& Rosena Romero (retired NMHU Technology Education Chair), Dr David West, Dr Jim Abreu, (both at NMHU), Dr Bill Robertson (University of Texas at El Paso - School of Education), Joe Vigil (Los Alamos National Laboratory - SEO), \& Dr Paul Siciliano (of the entire world). Paul, thanks.

The example set by others, in earlier years -- Dr Andy Horton (of his beloved Appellations) - Andy set this all in motion by removing the barriers I had made. Dr "Bud” Nestle \& Dr Anthony Akubue (St Cloud State University), \& Dr Stan Edin (Staples Technical Institute) who reminded me that I was a sum of my choices.

Perhaps Cate Macho deserves an entire chapter ... essentially; this document would not exist without her influences - the dream would have been abandoned.

To all -- Thank you.

: ) Steve 
Table of Contents

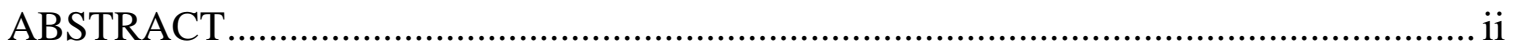

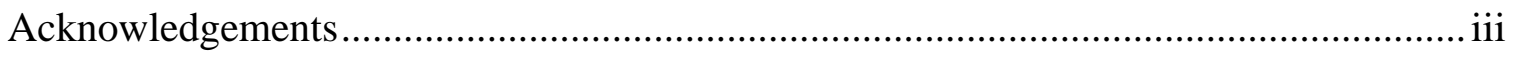

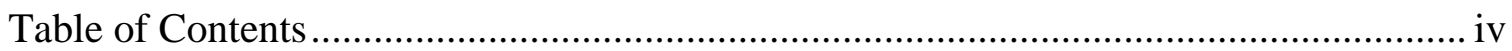

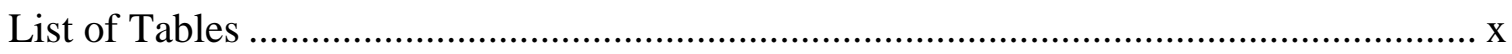

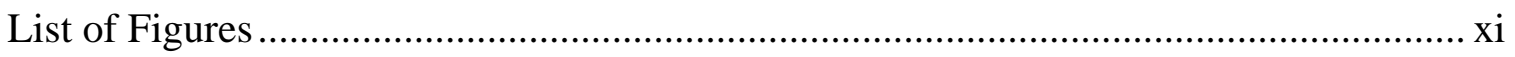

List of Appendixes .............................................................................................

CHAPTER 1 - INTRODUCTION....................................................................... 1

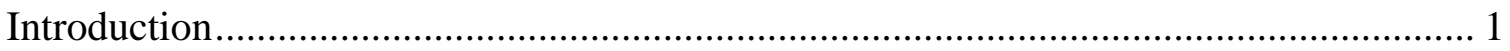

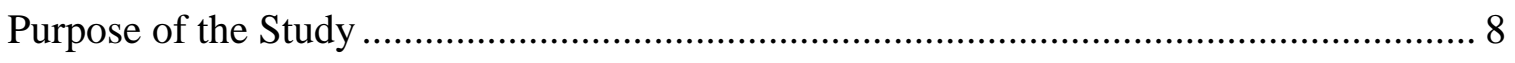

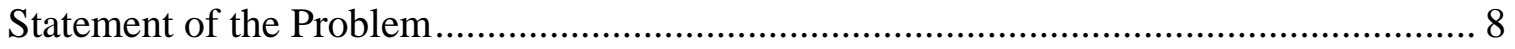

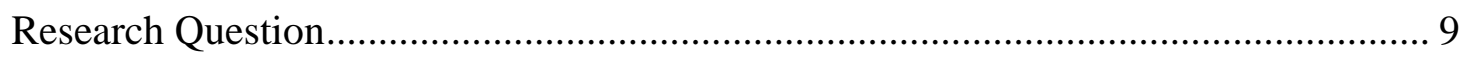

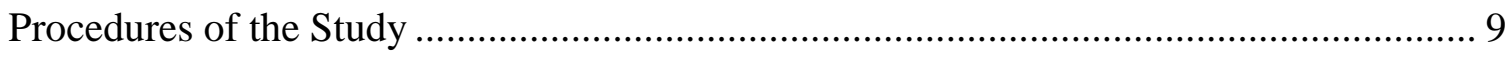

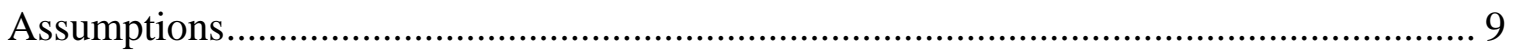

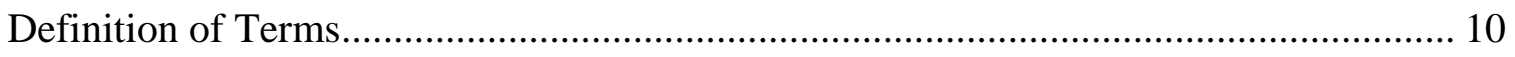

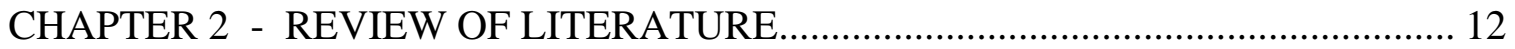

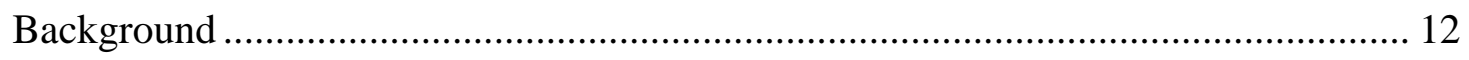

Magnitude of Student Use of the Internet ......................................................... 14

Assumption that Technology in the Home has an Effect on Academic Standing ............ 16

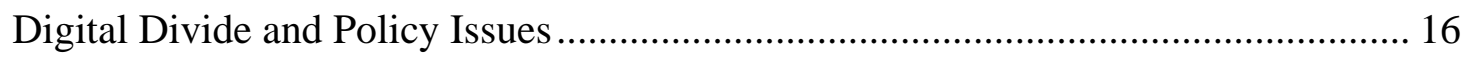

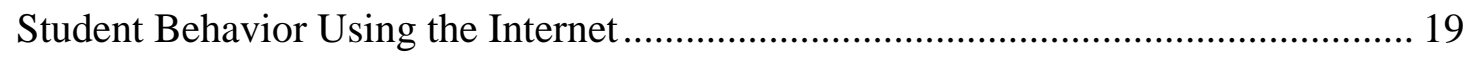

Internet Access at Home and Student Use ..................................................... 21

Affluence Effect on Student Performance .................................................................. 24 
Household Income and Internet Access .................................................................... 25

Household Income and Academic Standing .............................................................. 28

Parent Education Level and Academic Standing ........................................................ 31

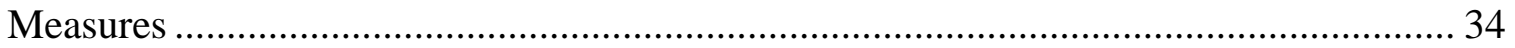

San Miguel GEARUP Partnership Application Form ................................................. 35

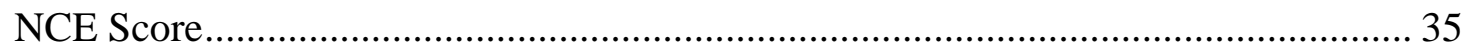

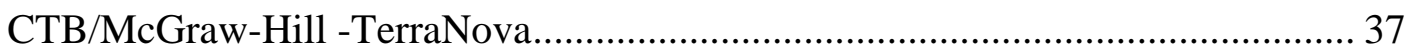

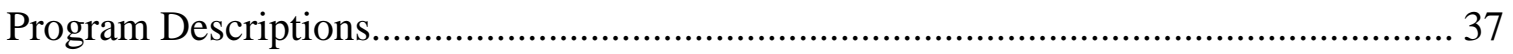

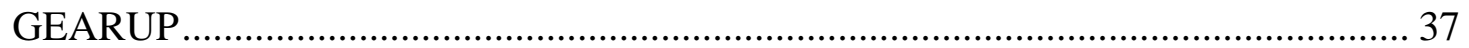

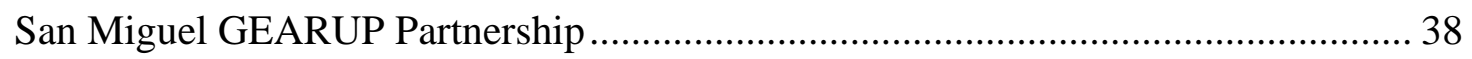

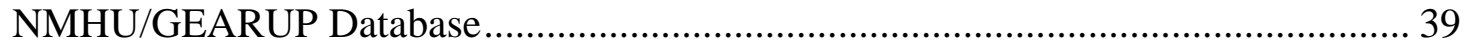

Prior and Related Research......................................................................................... 40

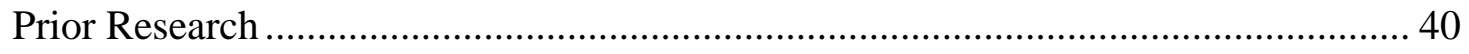

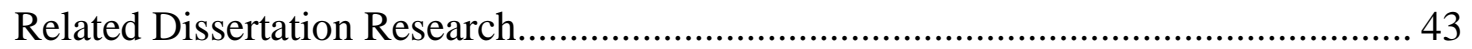

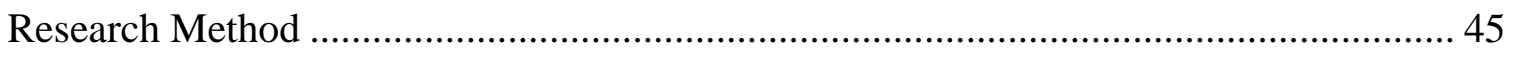

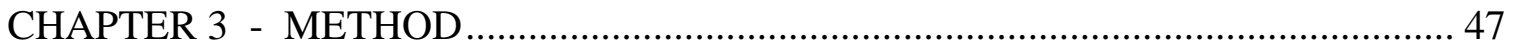

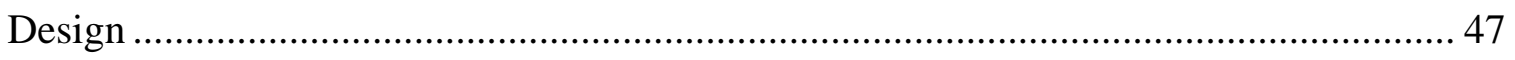

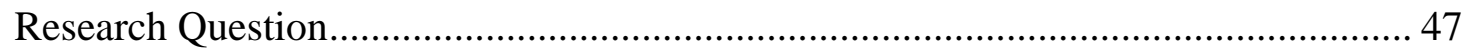

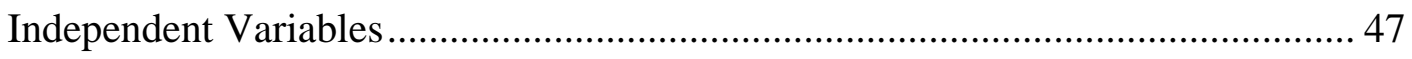

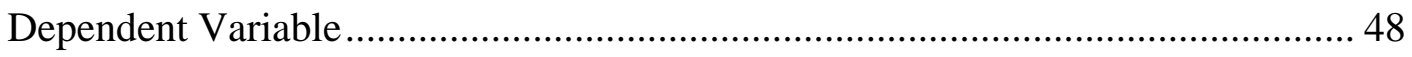

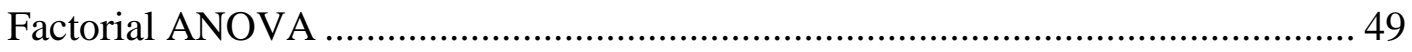

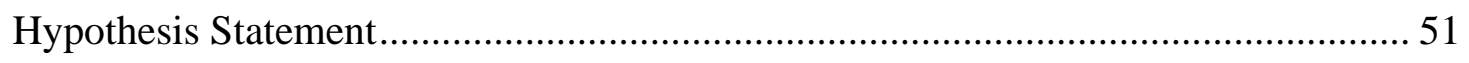

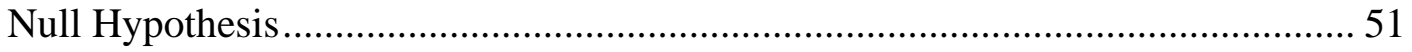




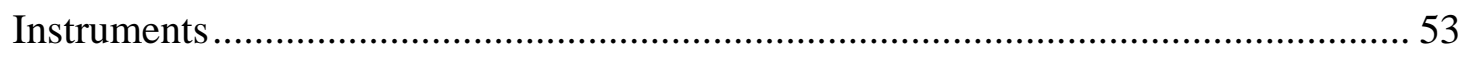

Matrix of Analysis ........................................................................................... 54

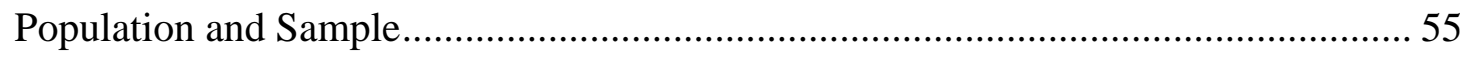

Human Subjects Clearance ......................................................................... 56

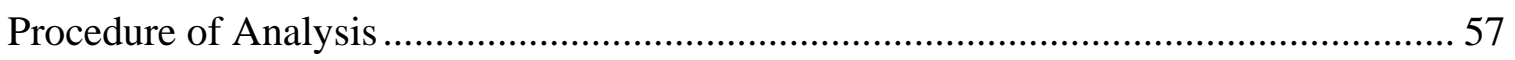

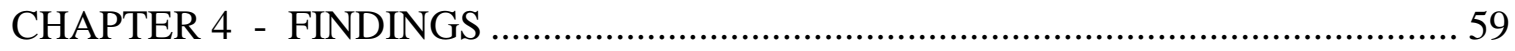

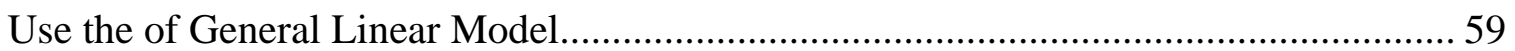

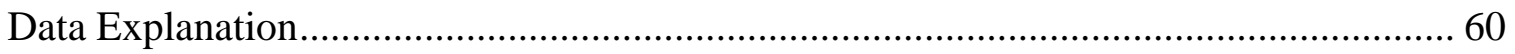

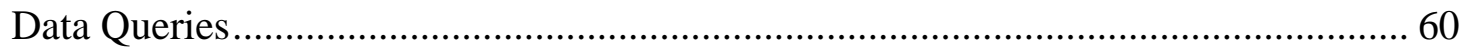

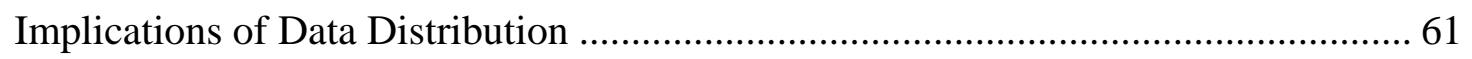

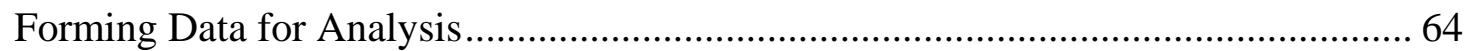

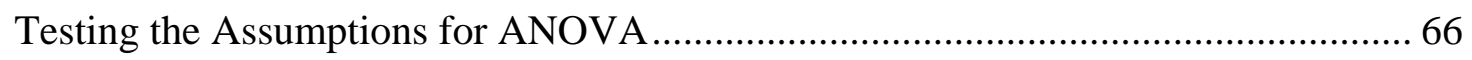

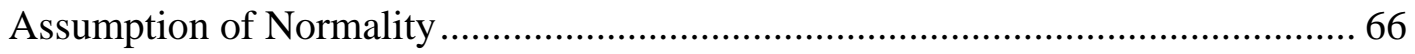

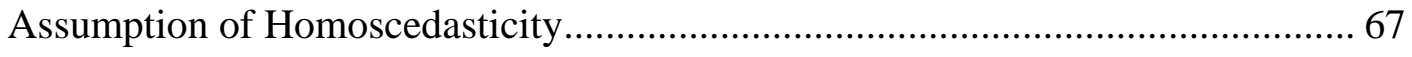

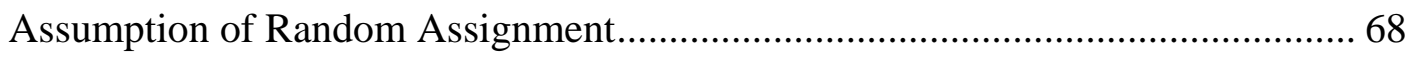

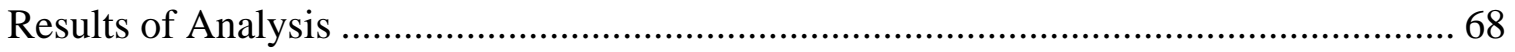

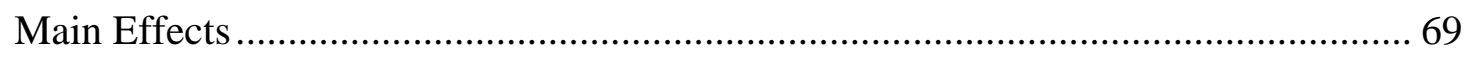

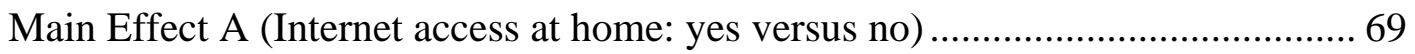

Main Effect B (Income of household: three categories) ................................... 70

Main Effect C (Highest level of education attained: two categories) .................... 70

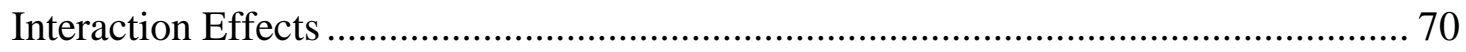

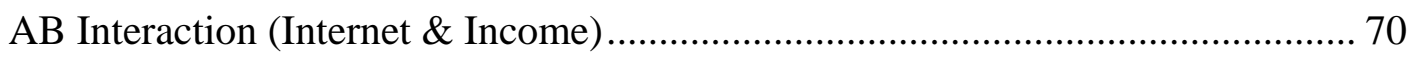

AC Interaction (Internet \& Education) ..................................................... 71 
BC Interaction (Income \& Education) ....................................................... 71

ABC Interaction (Internet \& Income \& Education) ........................................... 72

Measures of Association ............................................................................... 73

Summary of Primary Factorial ANOVA ….................................................... 73

One-way ANOVAs on Uncategorized and Categorized Data .................................. 73

One-Way ANOVA on Uncategorized Full Set Data ........................................ 74

One-Way ANOVA of Uncategorized Internet Access on Full Data Set............ 75

One-Way ANOVA of Uncategorized Income on Full Data Set ...................... 75

One-Way ANOVA of Uncategorized Education Access on Full Data Set........ 76

One-Way ANOVA on Categorized Full Set Data ........................................... 77

One-Way ANOVA of Categorized Income on Full Data Set .......................... 77

One-Way ANOVA of Categorized Education Access on Full Data Set............ 78

Summary of One-way ANOVAs on Uncategorized and Categorized Data .......... 78

Results of Further Analysis with Outliers Removed .............................................. 78

Assumption of Homoscedasticity Part 2 ....................................................... 79

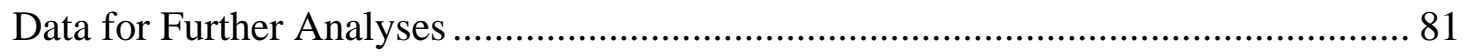

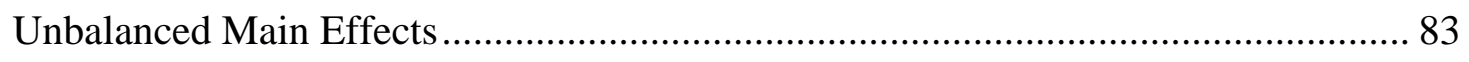

Unbalanced Main Effect A (Internet access at home: yes versus no) .................... 83

Unbalanced Main Effect B (Income of household: three categories) .................... 83

Unbalanced Main Effect C (Highest level of education attained: two categories) . 84

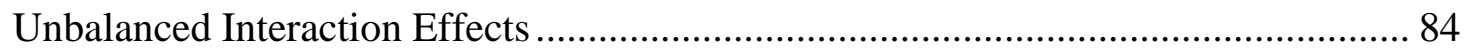

Unbalanced AB Interaction (Internet \& Income) ............................................ 84

Unbalanced AC Interaction (Internet \& Education)......................................... 85 
Unbalanced BC Interaction (Income \& Education) ………...................................... 85

Unbalanced ABC Interaction (Internet \& Income \& Education).............................. 86

Unbalanced Measures of Association .................................................................. 86

Summary of Unbalance Factorial ANOVA ……………....................................... 87

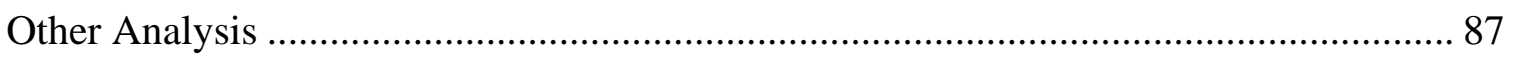

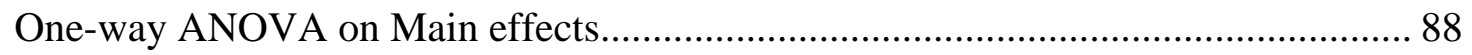

One-Way ANOVA for Internet Access ................................................................. 88

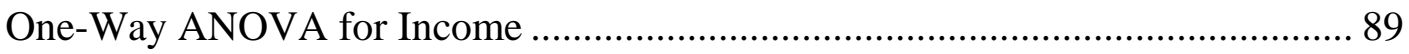

One-Way ANOVA for Education of Parent/Guardian ............................................ 90

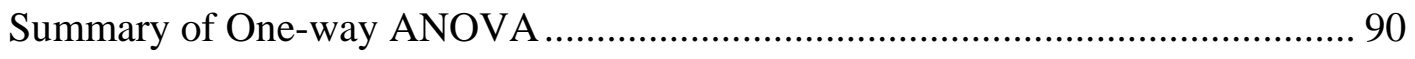

Results of the Fully Crossed and Balanced Factorial AVOVA ..................................... 91

Main Effects of the Fully Crossed and Balanced Factorial AVOVA ............................ 91

Fully Crossed and Balanced Main Effect A (Internet)............................................ 91

Fully Crossed and Balanced Main Effect B (Income) ……..................................... 92

Fully Crossed and Balanced Main Effect C (Education) ........................................... 92

Interaction Effects of the Fully Crossed and Balanced Factorial AVOVA .................. 92

Fully Crossed and Balanced AB Interaction (Internet \& Income)........................... 93

Fully Crossed and Balanced AC Interaction (Internet \& Education)....................... 93

Fully Crossed and Balanced BC Interaction (Income \& Education) ....................... 93

Fully Crossed and Balanced ABC Interaction (Internet \& Income \& Education).. 94

Fully Crossed and Balanced Measures of Association ............................................. 94

Summary of the Fully Crossed and Balanced Factorial AVOVA ............................ 95

One-Way ANOVA Results with Fully Crossed and Balanced Data ............................ 95 
One-way ANOVA for Internet Access With Fully Crossed and Balanced Data.... 96 One-way ANOVA for Income With Fully Crossed and Balanced Data.................. 96 One-way ANOVA for Education of Parent/Guardian With Fully Crossed and

Summary of One-way ANOVA Results with Fully Crossed and Balanced Data .. 97

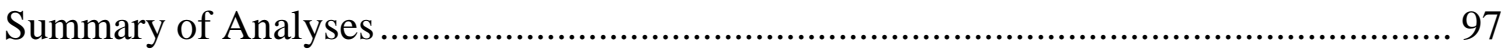

Findings Related to Hypotheses \& Research Question ................................................... 99

Contrast of Findings from Analyses ................................................................... 100

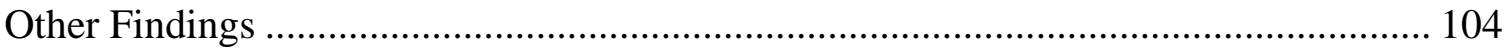

Discussion of the One-Way ANOVA Findings ............................................................ 104

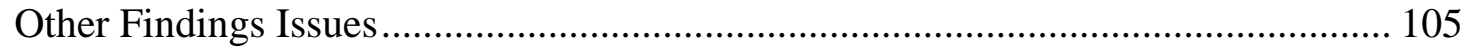

CHAPTER 5 - CONCLUSIONS, IMPLICATIONS AND RECOMMENDATIONS 106

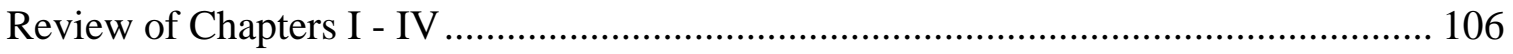

Conclusions Related to Hypothesis \& Research Questions............................................ 108

Highest Level of Education Within the Household .................................................... 108

Interaction of Internet, Income and Education......................................................... 109

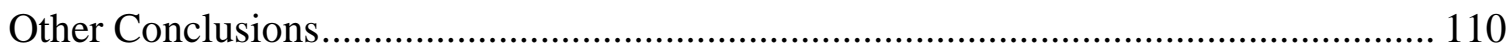

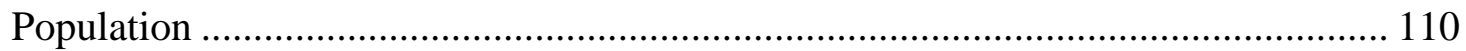

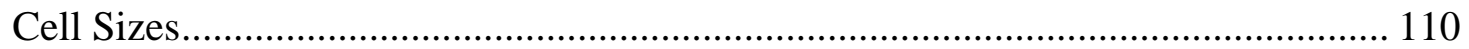

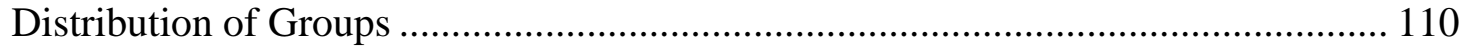

Education Stratification..................................................................................... 111

Unaccounted Variability ……………………………............................................. 111

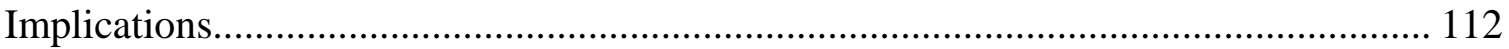


Highest Education Within the Household Matters................................................ 112

Confounding Factors Reveal Better Results ...................................................... 112

Larger Population Would Improve Quality ....................................................... 113

Unaccounted Variability .............................................................................. 113

Gifting Internet Access Would Be Imprudent ................................................. 114

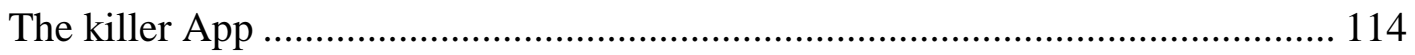

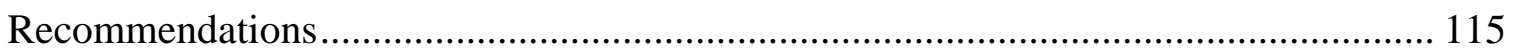

Confounding Factors ................................................................................... 115

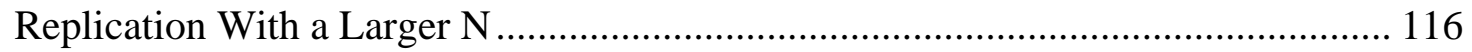

Replication With a Randomly Assigned Fully Crossed and Balanced Design.......... 116

Gifting Internet Access Must be Accompanied ................................................... 117

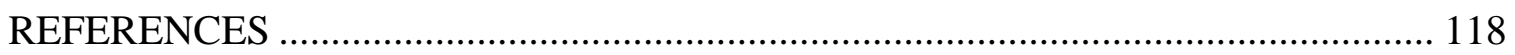

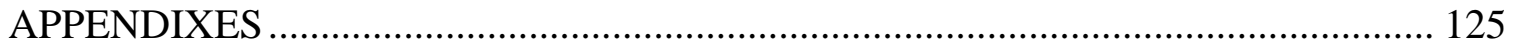

\section{List of Tables}

Table 1. Scholastic Assessment Test Score Averages by Family Income, 1995-96, 1997-

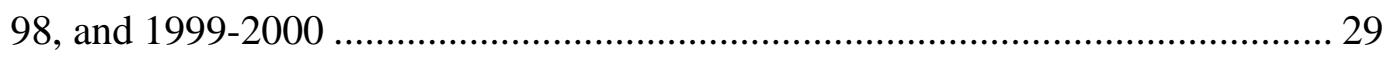

Table 2. Scholastic Assessment Test Score Averages by Parent Education, 1995-96,

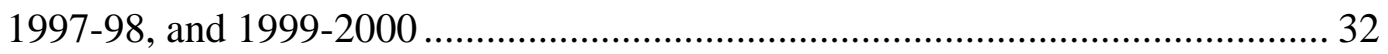

Table 3. Quasi-Experimental Research Design: 3 Way ANOVA - 2 x 4 x 4 Factorial

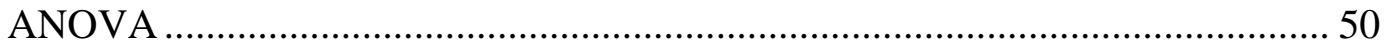

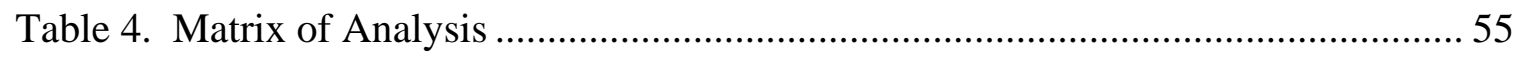

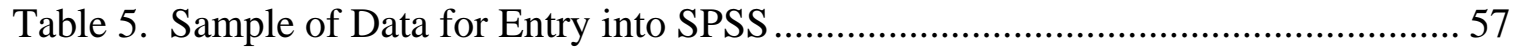


Table 6. Distribution of data - Internet access at home ………….................................. 62

Table 7. Distribution of data - No Internet access at home ............................................. 63

Table 8. Distribution of data - Count of data in each cell.............................................. 64

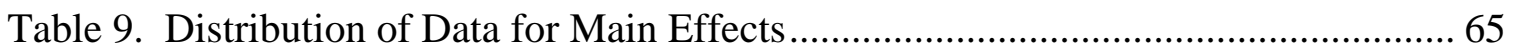

Table 10. Distribution of Data for Main Effects 2nd Trim............................................ 82

Table 11. Distribution of data - Count in each cell........................................................... 83

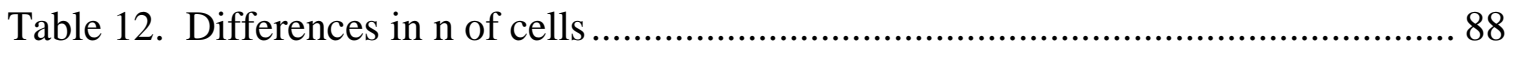

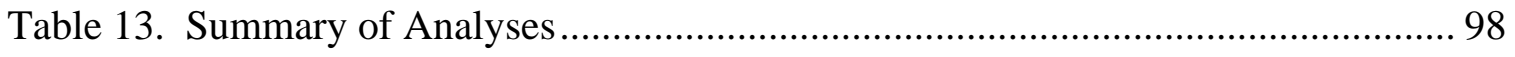

Table 14. Detailed Summary of Findings, Main Effects and One-Way ANOVAs....... 101

Table 15. Detailed Summary of Findings, Interactions in Primary Factorial ANOVAs102

Table 16. Detailed Summary of Findings, Interactions in Unbalanced and Fully Crossed \& Balanced Factorial ANOVAs ........................................................................ 103

List of Figures

Figure 1. Internet Use Among Children at Home / Any Location, 2001 as a Percent of

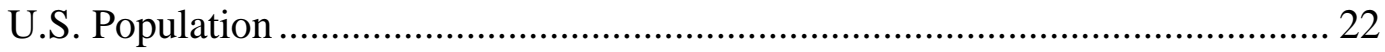

Figure 2. Internet Use by Age and Location, 2001 ...................................................... 23

Figure 3. Internet Use Among 10 to 17 Year-Olds By Income and Location, 2001 ....... 26

Figure 4. Scholastic Assessment Test Score Averages by Family Income, 1995-96, 1997-

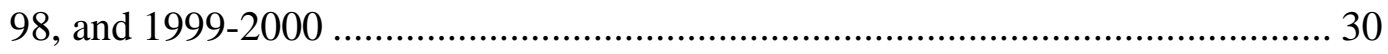

Figure 5. Average Student Scale Score in Reading, age 9: Selected Years, 1971 to 1999 
Figure 6. Scholastic Assessment Test Score Averages by Parent Education, 1995-96, 1997-98, and 1999-2000

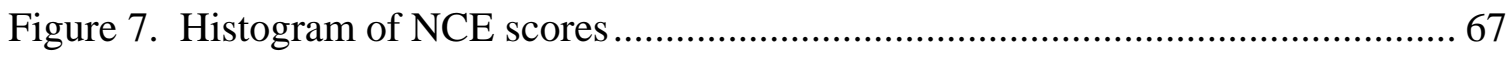

Figure 8. Histogram of NCE scores after second trim 81

\section{List of Appendixes}

APPENDIX A - Student Application ................................................................ 126

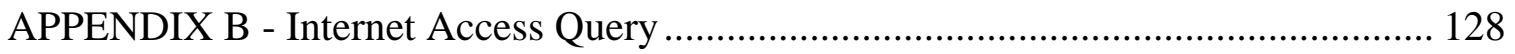

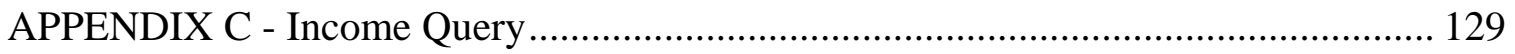

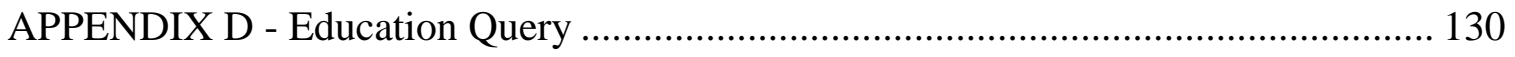

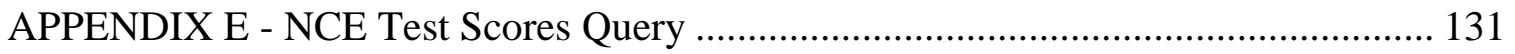

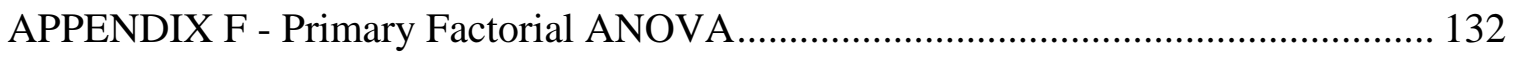

APPENDIX G - Primary Interaction Graphs for Factors A\&B................................... 139

APPENDIX H - Primary Interaction Graphs for Factors A\&C.................................. 141

APPENDIX I - Primary Interaction Graphs for Factors B\&C ................................... 143

APPENDIX J - Primary Interaction Graphs for Factors A\&B\&C .............................. 145

APPENDIX K - Tukey’s Post Hoc Comparison on Primary ABC Interaction.............. 148

APPENDIX L - One-way ANOVA on Uncategorized Full Set Data ........................... 152

APPENDIX M - One-way ANOVA on categorized full set data................................. 158

APPENDIX N - Analysis: First Trimmed Dataset ................................................ 161

APPENDIX O - Unbalanced Factorial ANOVA...................................................... 168

APPENDIX P - Unbalanced Interaction Graphs for Factors A\&B ............................. 175

APPENDIX Q - Unbalanced Interaction Graphs for Factors A\&C ............................. 177 
APPENDIX R - Unbalanced Interaction Graphs for Factors B\&C ............................. 179

APPENDIX S - Unbalanced Interaction Graphs for Factors A\&B\&C ......................... 181

APPENDIX T - One-Way ANOVA for Factors A, B, \& C ........................................ 184

APPENDIX U - Fully Crossed and Balanced A\&B\&C Factorial ANOVA ................. 189

APPENDIX V - One-Way ANOVA - Balanced Data............................................... 196 


\section{CHAPTER 1 - INTRODUCTION}

\section{Introduction}

Technologies in the home, such as computers and Internet access, have become common in the past decade. In 2002, over half of all Americans were using the Internet (U.S. Department of Commerce, 2002). Nearly every student in the United States has used the Internet for schoolwork (Lenhart, Simon, \& Graziano, 2001, Levin \& Arafeh, 2002, U.S. Department of Commerce, 2002, U.S. Department of Education, 2005). Many parents purchase computers expressly for their children's educational use. Access to the Internet has been one of the driving forces for this growth which is expected to continue in the coming years, especially as options for faster connections to the Internet become more common, through cable services and high speed telephone access. Greater access to home computers is being encouraged by increasingly less expensive computers (below $\$ 1,000$ ) that invite moderate income families, often first-time users, to acquire technology. (Kafai, Fishman, Bruckman \& Rockman, p.53, 2002)

How are students using this resource for educational purposes? “Approximately 9 out of 10 high school students who have access to a home computer use that computer to complete school assignments” (Fairlie, p. 3, 2003). The National Center for Educational Statistics published, Computer and Internet Use by Children and Adolescents in 2001 Statistical Analysis Report (2003) and reports of 5-17 year old students: 68\% indicate they have accessed the Internet from the school, 78\% indicate they have accessed the Internet from home, and $46 \%$ connect to the Internet to complete school assignments (pp. vi, \& 22). 
A survey of 754 students, who were 12-17 year olds, performed by for the Pew Internet \& American Life Project, reports that 94\% of those who have Internet access state they use it for school research and 78\% state they believe the Internet helps them with schoolwork. Most students (71\%) report that they have used the Internet as a "major source for their most recent major school project or report (Lenhart et al, 2001 p. 2).” About half (41\%) use email for school purposes, and about one third (34\%) have downloaded a study guide. Roughly three in five (58\%) have used web sites made for one of their classes. About one in five (17\%) have created web pages for school projects, and (18\%) know of someone who has "used the Internet to cheat on a paper or test (Lenhart et al, 2001 p. 2).” These data support the notion that Internet usage by students would have an impact upon student learning, and hence, measured performance.

Schoolwork is not the only use of the Internet resource within the home. The U.S. Department of Commerce (2002) and the U.S. Department of Education (Rathbun, West \& Hausken, 2003) rank educational uses of home Internet access as the second most popular use, behind gaming. Is the secondary use of the Internet, homework, of consequence to student performance? A September 2004 publication, Technology and Equity in Schooling: Deconstructing the Digital Divide (Warschauer \& Knobel, 2004), questions the contribution of technology access in the home. Specifically, Warschauer \& Knobel state, “Although home access to computers has long been regarded as important for supporting students' academic achievement, research suggests that home ownership of computers alone does not level out inequalities in terms of technology's contributions to student learning” (p. 563). 
The common perception questioned by Warschauer \& Knobel is a vision of students refining their homework at home with the new marvel. "Public school children who had access to home computers used them an average of 3 to 4 days a week. Over 85 percent of young children with home computers used them for educational purposes” (Rathbun et al, p. 12, 2003). "Some may believe that inexpensive computing devices will provide ubiquitous access for all students, at home and in school” (Kafai et al, p. 65, 2002). With more computers placed in homes, should we expect students to perform better in school? It appears that it is not quite that simple.

... we recognized (as previous researchers did) that computers alone are not the central factor in making educational computing at home and its connection to school work. Any effort needs to consider not only activities and resources in schools but also families and their available resources both at home and in their communities (Kafai et al, p. 65, 2002).

Some research has indicated there is an association between the availability of a computer and Internet access in the home and student performance. As stated in a The Information Society article by Attewell and Battle of City University of New York, Home Computers and School Performance (1999), "We find that having a home computer is associated with higher test scores in mathematics and reading” (p. 1). Sweeping statements such as home computers are being associated with higher test scores may be true, but the depth of that truth may be an issue. The particular issue with this reasoning is the danger of putting forth conclusions based upon a spurious association.

Milo Schield, Professor at Augsburg College in Minneapolis, has published numerous articles on the topic of critically considering the use of statistics and the 
appropriate inferences that can be made from their application. Schield provides the following definition of a spurious association:

To understand a spurious association, one must understand Simpson’s Paradox. A spurious association is both true and false - but in different ways. It is true given what one has (or has not) taken into account (controlled for). It is 'false' or at least accidental because it does not persist after one takes into account (controls for) a more important confounding factor (Schield, p. 5, 1999).

When trying to correctly qualify -- or quantify -- if there is an effect of home Internet access on student academic standing, other factors must be taken into consideration. Schield advises the consideration of three explanations of the factors being considered to explain a phenomenon:

... one must review three different kinds of explanations for any association obtained from an observational study. In interpreting an observational association between A and B, the three causal explanations are (1) A causes B, (2) B causes A, and (3) C (some confounding factor) causes both A and B. Once all three explanations are expressed, one can work at eliminating one and supporting another (Schield, p. 5, 1999).

To determine if there is an association of Internet access at home and academic standing, other factors need to be included in the research design. The research design should determine differences and potential interactions among factors such as Internet access at home, family affluence, and academic achievement. Applying these three tests to the design of the study can lead to the following statements:

1. the presence of Internet access in the home causes a higher test score; 
2. higher test scores cause the presence of the Internet at home; or

3. other factors such as family affluence (family income, parents level of education), explain both differences in academic standing and the presence of Internet access at home.

Each of these three explanations, patterned after Schields' explanations, has potential and supporting arguments with varied degrees of merit -- or legitimacy. To declare that the presence of Internet access at home is the sole cause of academic standing is denying all other potential mitigating factors. The second explanation could be that the students with greater academic standing place a higher value on the use of computers and Internet access, and have therefore manipulated their environment to include that resource in their home. The third explanation seems like the most likely and is a model for the research question proposed within this study. With the third explanation in mind, a statistical method can be chosen which will examine the differences and interactions among the contribution of the factors; i.e., the independent variables' effect on the dependent variable.

There are bodies of evidence to support the notion of family affluence being associated with student performance and Internet access. The National Center for Educational Statistics Scholastic Assessment, Test score averages, by selected student characteristics: 1995-96, 1997-98, and 1999-2000 (Table 135, 2004) clearly illustrates the trend that student scores tend to increase relative to household income. The association of parent education and student academic performance are supported by nearly 30 years worth of data from the National Center for Educational Statistics, Average student scale score in reading, by age and selected student and school 
characteristics: Selected years, 1971 to 1999 (Table 110, 2004). The notion that household income and Internet access are related are supported by data from the U.S. Department of Commerce, Internet use among 10 to 17 year-olds by income and location, 2001 (2002). These factors of family affluence impact upon academic standing are already established.

An optimal research design would control for all other potential factors; such as an experimental design. In an ideal experimental design, all variables would be quantified; i.e., factors ranging from the attitude and physical condition of the students, situational circumstances in a classroom, availability of computer and Internet resources in the home, assurance those resources are in proper working condition, that all parents would treat all students equally, and that each teacher would treat each student equally. Everything a student encounters would be equitable with all other students with the only exception being Internet access within the home. It would be exceedingly difficult to use an experimental design where households would be controlled and randomly assigned to have or not have computer and Internet access. Therefore, an experimental design would be difficult to employ to determine the effect of home and Internet access on student standing.

Data utilizing established factors of family affluence and standardized test results are available from the San Miguel GEARUP Partnership. The San Miguel GEARUP Partnership is conducted in Las Vegas, New Mexico, at New Mexico Highlands University. Parents of participants complete an application form annually. The Appendix NMHU/San Miguel GEAR-UP Student Application, 2003-2004 School Year, contains a reproduction of the survey form. The data collected from this instrument are 
used to conduct the GEARUP program and complete an annual performance review. There is a high rate of return on the applications because completed applications are required before any students can obtain their earned reward. The participant's application form contains questions that are within the scope of the objectives of GEARUP. e.g., Do you plan to go on to college? What college? What major? Data gathered by the San Miguel GEARUP partnership includes information on Internet access at home and family affluence. The San Miguel GEARUP partnership has collected the results of standardized tests on participants.

Using data from the San Miguel GEARUP partnership is in the interest of the partnership because findings of this study could be used to seek support to provide Internet access to San Miguel GEARUP partnership participants in hopes of improving their academic standing. Findings of this research could be generalized to other underrepresented populations similar to those of the San Miguel GEARUP partnership.

A quasi-experimental research design can be selected to determine if there is a difference in the academic standing for those who have Internet access at home compared to those who do not have Internet access at home. Although those with Internet access at home may have a different academic standing, is that an indication of family affluence or a benefit of that technology, or some combination of both? Therefore, the effect of family affluence will be examined to determine if a potential difference in academic standing is an independent factor, or if it follows family affluence. Affluence for the purposes of this study will be defined as the income level of the household the student resides within, and the highest attained education levels of the mother, father or guardian. 
Purpose of the Study

Prior research (Attewell \& Battle, 1999, Becker, 2000, Warschauer \& Knobel, 2004) indicates relationships between technology access at home and a difference in standardized test scores. There are also data that associate family affluence with differences in standardized test scores (Levin \& Arafeh, 2002, National Center for Educational Statistics Scholastic Assessment, 2003 \& 2004). The purpose of this study is to investigate potential differences in student academic standing between those with Internet access at home and those without Internet access at home, and to take into consideration the potential confounding factors of family affluence. Family affluence, specifically, will be defined as household income, and the highest education level of an immediate relative (mother or father or guardian). These factors of family affluence are selected because a large body of research from the National Center for Educational Statistics Scholastic Assessment indicates an association of difference in standardized test scores and these factors.

\section{Statement of the Problem}

As previously established, research indicates that technology access contributes to differences in student academic standing. However, other research attributes differences to family affluence. Is just Internet access at home related to academic standing, or is academic standing more closely related to other factors of family affluence?

The essence of this study is to determine if students with Internet access at home have an academic standing different than those without Internet access and if the potential academic standing differences are dependent or independent of family affluence. Findings of this research could help in understanding the value of Internet 
access at home. Findings could support policies to promote home Internet access in the interest of promoting student performance.

\section{Research Question}

What are the differences among the standardized test scores of students due to factors of Internet access at home, household income, and the highest level of education attained by mother, father, or guardian?

Procedures of the Study

1. Identify, refine and develop the problem for the focus of the research;

2. Review the literature of computer and Internet use at home, family affluence as it relates to students academic standing, research methods, and statistical methods;

3. Identify the methods to determine if any significant differences exist among the factors;

4. Query the San Miguel GEARUP Partnership database for the data to perform the tests;

5. Conduct analysis of measured results and;

6. Draw conclusions from analysis;

7. Present findings, conclusions and recommendations.

\section{Assumptions}

The following assumptions are made in this study:

1. Assumes the self-reported data on the San Miguel GEARUP Partnership applications are accurate; 
2. The data input process was accurate and the data in the database are accurate;

3. Assumes the CTB/McGraw-Hill -TerraNova was provided an accurate and valid test score.

4. Other factors not considered apply equally to all of the students in the study.

$$
\text { Definition of Terms }
$$

Internet:

Global networks connecting millions of computers. More than 100 countries are linked into exchanges of data, news and opinions (Webopedia, 2004, ๆ 1).

Globally Unique Identifier (GUID): a unique 128-bit number that is produced by the Windows OS or by some Windows applications to identify a particular component, application, file, database entry, and/or user (Webopedia, 2004, ๆ 1).

Normal Curve Equivalent (NCE) Score:

The NCE was developed to allow mathematical manipulation of NP scores — especially for program evaluation and research requiring the comparison of scores across groups or across time. The NCE scores can be thought of as NP scores rescaled on an equal interval scale (which allows them to be used in mathematical calculations such as deriving a mean score) (Indiana Department of Education, 2005, Normal Curve Equivalent (NCE) Score section, ๆ 1). 
CTB/McGraw-Hill -TerraNova:

The TerraNova is the standardized test adopted by the State of New Mexico for use in all schools. This is a norm-referenced test (McGrawHill, 2004, ๆ 2).

San Miguel GEARUP Partnership: Located in rural Northeastern New Mexico the NMHU/San Miguel GEAR UP Project is a U.S. Department of Education five-year grant designed to increase the number of low-income students who will be prepared to enter and succeed in college. GEAR UP serves an entire cohort of students beginning in the sixth grade and following them as a cohort through the completion of high school (U.S. Department of Education, 2004).

San Miguel GEARUP Partnership database:

The San Miguel GEARUP Partnership has developed a database containing the program information necessary to conduct the initiatives set forth by the funding agency. The Database has evolved from a series of spreadsheets to a Microsoft Access relational database and the current state as a fully normalized MS-SQL 2000 database. The primary sources of data in the database are demographics collected from participant parents and academic and behavioral data entered by teachers. Imported data sources include results of standardized tests, state content standards and benchmarks, and educational objectives. 


\section{CHAPTER 2 - REVIEW OF LITERATURE}

\section{Background}

"One of the most common activities that youth perform online is schoolwork", specifically, $94 \%$ of 12 to 17 year olds who use the Internet, report that they the have used it for schoolwork (Levin \& Arafeh, p. 1, 2002). This widespread use of the Internet likely impacts student learning. The resource of the Internet is fundamentally different from other educational resources because it does not require physical access to the school (e.g., independent of space and time). Internet savvy students can perform their schoolwork independent of time restrictions because they can access school resources for their homework independent of the hours of operation for the school. Internet savvy students can access resources independent of physical space. They can access school resources for their homework independent of the physical location of the school.

Breaking the barriers of space and time is a part of the value the Internet delivers to all of its users. This potentially meaningful access to the Internet is however dependent upon the access existing for the students when they are not in school but presumably at home.

Almost every public school student in the United States has access to the Internet (U.S. Department of Commerce, 2004). However, Internet access at home is not as universal. It is assumed those who have Internet access at home are at an advantage versus those who do not have Internet access; this has been coined as the Digital Divide. The concept of a Digital Divide was a guiding principle for policy development and enactment in the late 1990s.

Following the Digital Divide educational policy focused on the No Child Left Behind Act, which holds that all students should perform at a common standard, and 
provides resources to achieve that goal. In regards to Internet access for students, providing Internet access within schools typically is considered the enactment of this policy. An exception is the Evaluation of Student \& Parent Access through Recycled Computers (eSPARC) program funded by the U.S. Department of Education in 2004 and conducted by the Pennsylvania State Department of Education. This three-year program is designed to study the "impact of computer technology and its benefits to students and families” (Pennsylvania State Department of Education, ๆ 2, 2004). This research identifies qualified participants, provides them training, gathers baseline data, and provides refurbished computers to high-need families. Initial results of this research are expected in June of 2006.

In the late 1990s, most schools had some sort of limited Internet access, and consequentially, so did most students. In schools deployment of the Internet occurred where it could be afforded in the early years of the introduction of the Internet in schools; in more affluent communities. The same is true of the training required for teachers to make "good" use of the resource and available technical support to maintain the systems.

From 2000 to 2005 there has been an impressive adoption of networks within schools. Net-days, E-rate, and other such programs have assisted in the creation of a network infrastructure that span nearly every American school. In addition to the existence of the physical infrastructure, a knowledge base to maintain these systems is becoming more common within schools. There had been several iterations of Internet based software and it has transformed the nature of interacting with information. Distributed network applications had become commonplace from 2000 to 2004. All of these factors have contributed to the creation of an environment that is compelling 
students to interact. “A July 2002 survey by the Pew Internet \& American Life Project shows that three in five children under the age of 18 -and more than $78 \%$ of children between the ages of 12 and 17—go online” (Levin \& Arafeh, p. ii, 2002).

In the last decade, the federal, state, and local governments have invested over $\$ 40$ billion to put computers in schools and connect classrooms to the Internet. Results are positive related to hardware and connectivity. The percentage of schools connected to the Internet rose from 35\% in 1994 to $99 \%$ in 2001 . The student to Internet connected computer ratio has improved dramatically in an even shorter time frame, going from 12 students per computer in 1998 to five to one in 2001. Many students who do not have computer and Internet access at home at least have some access at school. (Dickard, p. 7, 2003)

Magnitude of Student Use of the Internet

As stated in the U.S. Department of Education (2005) national technology plan Toward A New Golden Age in American Education: How the Internet, the Law and Today’s Students Are Revolutionizing Expectations, “94 percent of online teens use the Internet for school-related research” (p. 17). However, the scope of the growth of the Internet seems to break traditionally established lines.

Internet use is increasing for people regardless of income, education, age, races, ethnicity, or gender. Between December 1998 and September 2001, Internet use by individuals in the lowest income households (those earning less than $\$ 15,000$ per year) increased at a 25 percent annual growth rate. Internet use among individuals in the highest-income households (those earning $\$ 75,000$ per year or 
more) increased from a higher base but at a much slower 11 percent annual growth rate. (U.S. Department of Commerce, p. 1, 2002)

The growth of Internet usage is likely to continue until nearly every American is online. According to the U.S. Department of Commerce (2002) "children and teenagers use computers and the Internet more than any other age group” (p. 1). They state that "Ninety percent of children between the ages of 5 and 17 (or 48 million) now use computers" (p. 1), "Seventy-five percent of 14-17 year olds and 65 percent of 10-13 year olds use the Internet" (p. 1), and "Family households with children under the age of 18 are more likely to access the Internet” (p. 1).

A survey of 754 students who were 12-17 year olds, performed by Lenhart et al in 2001 for The Pew Internet \& American Life Project, reports that 94\% of the students who have Internet access say they have used it for school research and 78\% say they believe the Internet helps them with schoolwork. Most students (71\%) report that they have used the Internet as a "major source for their most recent major school project or report" (p. 2). About half (41\%) use email for school purposes, and about one third (34\%) have downloaded a study guide. Roughly, three in five (58\%) have used web sites made for one of their classes. About one in five (17\%) have created web pages for school projects, and about one in five (18\%) know of someone who has "used the Internet to cheat on a paper or test” (p. 2).

Further research by Rathbun et al, for the National Center for Education Statistics, Institute of Education Sciences, U.S. Department of Education indicates that "Public school children who had access to home computers used them an average of 3 to 4 days a 
week. Over 85 percent of young children with home computers used them for educational purposes” (p. 12, 2003).

Assumption that Technology in the Home has an Effect on Academic Standing While access to the technology is available, and studies indicate students are making use of both computers and Internet for schoolwork, what exactly does that mean? The factors and results of research on this issue, what is known about student use of the Internet for schoolwork, are presented in this section of the Literature review. Research on technology used by students does not include the effect that home Internet access may have on academic standing. In fact "large-scale research on school-related uses of the Internet-as distinguished from research on the use of computers and other technologies_-has focused on access” (Levin \& Arafeh, p. 2, 2002) and then not the assumed effect on academic performance.

Some data are available on how students use the Internet access at home. The section Student Behaviors when the Internet is available at Home offers the findings of research that support the notion of a Digital Divide, and other findings that explain in detail how students make use of the Internet at home to improve their academic performance.

\section{Digital Divide and Policy Issues}

The essence of the Digital Divide is based upon an assumption that the differential access to communications technology exacerbates social differences between haves and have-nots (Becker, 2000). In the late 1990s, this perceived difference became the impetus for a socially sensitive communications policy. In hope of bridging the access gap, many programs were created and supported by both government agencies and 
private entities. Most of the efforts, such as E-Rate, and Net-Day, were focused on providing assistance with physical facilities and equipment or the expenses associated with initiation of networks services (Becker, 2000, \& U.S. Department of Education, 2005). Stated in A Retrospective on Twenty Years of Education Technology Policy, by 1997, “As the Internet began to emerge, recommendations regarding access addressed the need for Internet connections in addition to the hardware and software” (McMillan-Culp, Honey \& Mandinach, p. 11, 2003). These efforts were for the most part successful, as of now nearly every student in the United States has access to the Internet at school.

By 2005, access to the Internet has become assumed for all students. The U.S. Department of Education cites priorities in the national technology plan, Toward A New Golden Age in American Education: How the Internet, the Law and Today's Students Are Revolutionizing Expectations, released on January 7, 2005. The only recommended technical initiatives stated as priorities in the national technology plan were to encourage broadband access, promote technical teacher training, and integrate data systems.

The expectation of universal access is expressed in the actions of the U.S. Department of Education. The registration document for the June 2003 event, Education Technology: Preparing Students and Parents for the Digital Age, states “Technology has tremendous potential to inspire students, improve academic performance, and close the achievement gap for children who historically have been left behind” (U.S. Department of Education, ๆ 1, 2003). The web-based workshop, which was only available to those who have Internet access, clearly draws the connection between the potential of a parent to participate in their child's education and the availability of technology. 
This registration document for the June 2003 event also illustrates another important aspect that may be potentially exacerbated, parent access to the students’ education process. The parents' role in the notion of the digital divide is important in two ways, providing access for themselves (the parent) to participate in the education process, and providing the technology in the home for their child to use as a learning tool. Most parents believe in providing Internet access, as indicated by the findings of The Pew Internet \& American Life Project.

Parents agree with their online children that Internet helps with learning. Fully 93\% believe that the Internet helps children learn new things. Eighty-seven percent of these parents say the Internet helps children with their schoolwork. And 95\% of these parents say it is important for children to learn about the Internet in order to be a success later in life; 55\% say it is essential. (Lenhart et al, p. 4, 2001)

The use of the Internet is not only in support of the students' activities; it also helps the parents as directors of their children's learning. Those without access to these technology resources will be at a disadvantage compared to the Internet equipped homes that do have access.

Technology has also become a powerful tool to help parents stay involved in their child's education. School Web sites, message boards and the like now provide mothers and fathers with access to everything from assignments and lunch menus to specific information on their children's academic performance and offer an almost infinite number of learning resources. (U.S. Department of Education, ๆ 2, 2003) 
Those parents who have access can be active participants in their students' academic life beyond attending parent teacher conferences. Those parents who have access can communicate with their child's teachers and may take part in the curriculum and do a better job of helping their children with homework, because they can go on line and see the homework. Likewise, information can flow from the school to home, from the teachers, and other practitioners to the parents concerning their children's needs. Internet access can enable and help spawn a conversation that does not have to wait for a semi-annual parent teacher meeting.

\section{Student Behavior Using the Internet}

The ways students use the Internet within the home can be observed and has been the topic of several studies. The behaviors students exhibit when making use of the Internet at home are an important aspect of study because they are in part the behaviors that are suspected to lead to a different academic standing. Sources reviewed in this study indicate students use the Internet to perform schoolwork, (Becker, 2000, Lenhart et al, 2001, Levin \& Arafeh, 2002, U.S. Department of Commerce 2002, U.S. Department of Education 2002 \& 2003) however the qualities of the use are described differently. The literature also typically agreed with the notion that teachers felt reserved to assign homework that would require home Internet use. Teachers underestimate how many students have access at home, and as a consequence lower their expectations of all students in an attempt to be fair to those without Internet access at home (Lenhart et al, 2001, Levin \& Arafeh, 2002).

The Pew Internet \& American Life Project has published the results of their research efforts regarding what students are doing with Internet access. Two studies of 
interest in this review of literature are The Internet \& Education Lenhart, A., Simon, M., \& Graziano, M., (2001) and The Digital Disconnect: The Widening Gap between Internet-Savvy Students and Their Schools by Levin, D.\& Arafeh, S. (2002). The research methods for both of these publications involved survey research. The Internet \& Education (2001) was based upon a survey of 754 teenagers (ages 12-17) who used the Internet including a parent or guardian and was "conducted by Princeton Survey Research Associates between November 2, 2000 and December 15, 2000” (p. 9) with a margin of error of plus or minus $4 \%$.

Notable among the 2002 study is the finding that "Internet-savvy students rely on the Internet to help them do their schoolwork” (Levin \& Arafeh, p. 26, 2002). This notion is central to the assumption that students with Internet access at home have the potential to perform better than those without Internet access. Levin and Arafeh go on to state:

Students told us they complete their schoolwork more quickly; they are less likely to get stymied by material they don’t understand; their papers and projects are more likely to draw upon up-to-date sources and state-of-the-art knowledge; and, they are better at juggling their school assignments and extracurricular activities when they use the Internet. In essence, they told us that the Internet helps them navigate their way through school and spend more time learning in depth about what is most important to them personally. (Levin \& Arafeh, p. ii, 2002) These findings reinforce the assumption that there is an advantage for students with access to the Internet and qualify the adeptness of the students by referring to them as Internet-savvy. This is another important factor in the argument that the students with 
Internet at home will perform differently because their additional exposure to the Internet will lead to greater skills in making use of the resource.

Levin \& Arafeh (2002) classified the students in this study as having five different metaphors for describing their use of the Internet in regards to schoolwork: as virtual textbook and reference library, as virtual tutor and study shortcut, as virtual study group, as virtual guidance counselor, and as virtual locker, backpack, and notebook. The great promise of improved communications technologies is that these improvements will eliminate the barriers of time and space. This appears to be embodied in how these students currently use the Internet. However, that would be dependent upon their access, in other words, where can they connect to the Internet.

\section{Internet Access at Home and Student Use}

Because there is no direct research on the Internet at home and the effect on academic standings, this section will present findings of research on students making use of Internet access, and how they are using it. The next three figures presented, Figure 1 Internet Use Among Children at Home / Any Location, 2001 as a Percent of U.S. Population, Figure 2 Internet Use by Age and Location, 2001, and Figure 3 Internet Use Among 10 to 17 Year-Olds By Income and Location, 2001 are reproduced from the U.S. Department of Commerce. All three of these figures were constructed with data from the National Telecommunications and Information Administration (NTIA) and U.S. Department of Labor Employment Standards Administration (ESA), U.S. Department of Commerce, using U.S. Census Bureau Current Population Survey Supplements. 
Figure 1. Internet Use Among Children at Home / Any Location, 2001 as a Percent of

\section{U.S. Population}

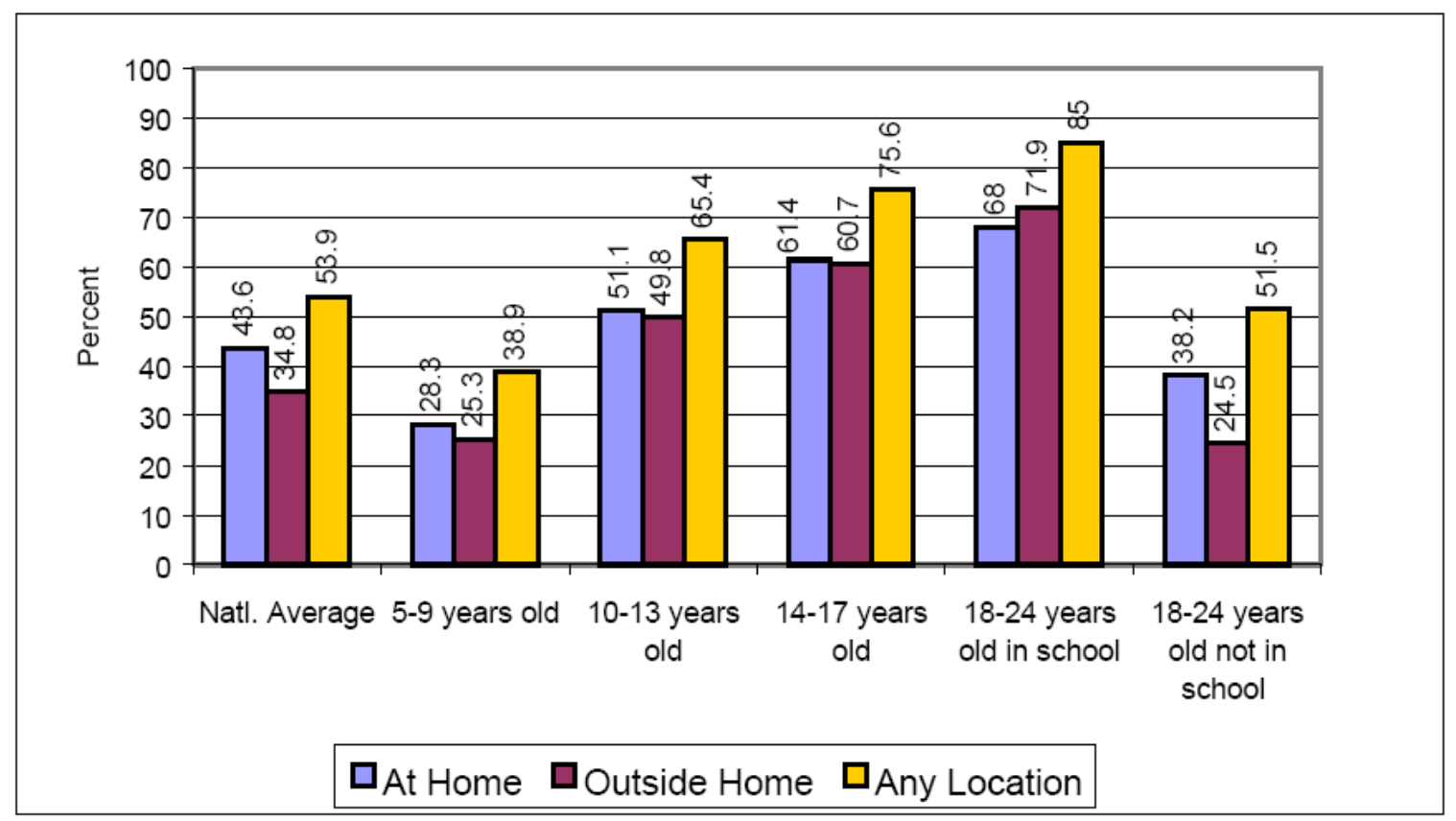

(U.S. Department of Commerce, p. 44, 2002)

The data in Figure 1 indicate the younger generations are by far the generation most likely to be using the Internet. The national average for all Internet use has exceeded half of all Americans. The highest use group was the 18 to 24 year olds, just beyond the scope of this study. The 10-13 year old group and the 14 - 17 year old group are the students of concern in this study. Their use of the Internet at home was $55.1 \%$ and $61.4 \%$ respectively in 2001.

Further analysis of the location where the Internet is being used is provided in Figure 2. For the 14-17 year olds, most students are using the Internet both at home and at school, $42.8 \%$ of the total. This does not hold true to the $10-13$ year olds of whom only 32.9\% use the Internet both at home and at school. It should be reasonable to question if that has changed since the 2001 publication of this research. Those who used 
the Internet only in school, $12.8 \%$, and $12.6 \%$ respectively are both smaller groups than those who use the Internet only at home, $18.7 \%$ and $18.6 \%$. These two groups, School only and Home only, combined were smaller than the group of those who were using the Internet both at home and at school already in 2001. Since the publication of the U.S. Department of Commerce report on how Americans made use of the Internet, The Pew Internet \& American Life Project published results indicating that more, 94\%, students are using the Internet (Levin \& Arafeh, 2002).

Figure 2. Internet Use by Age and Location, 2001

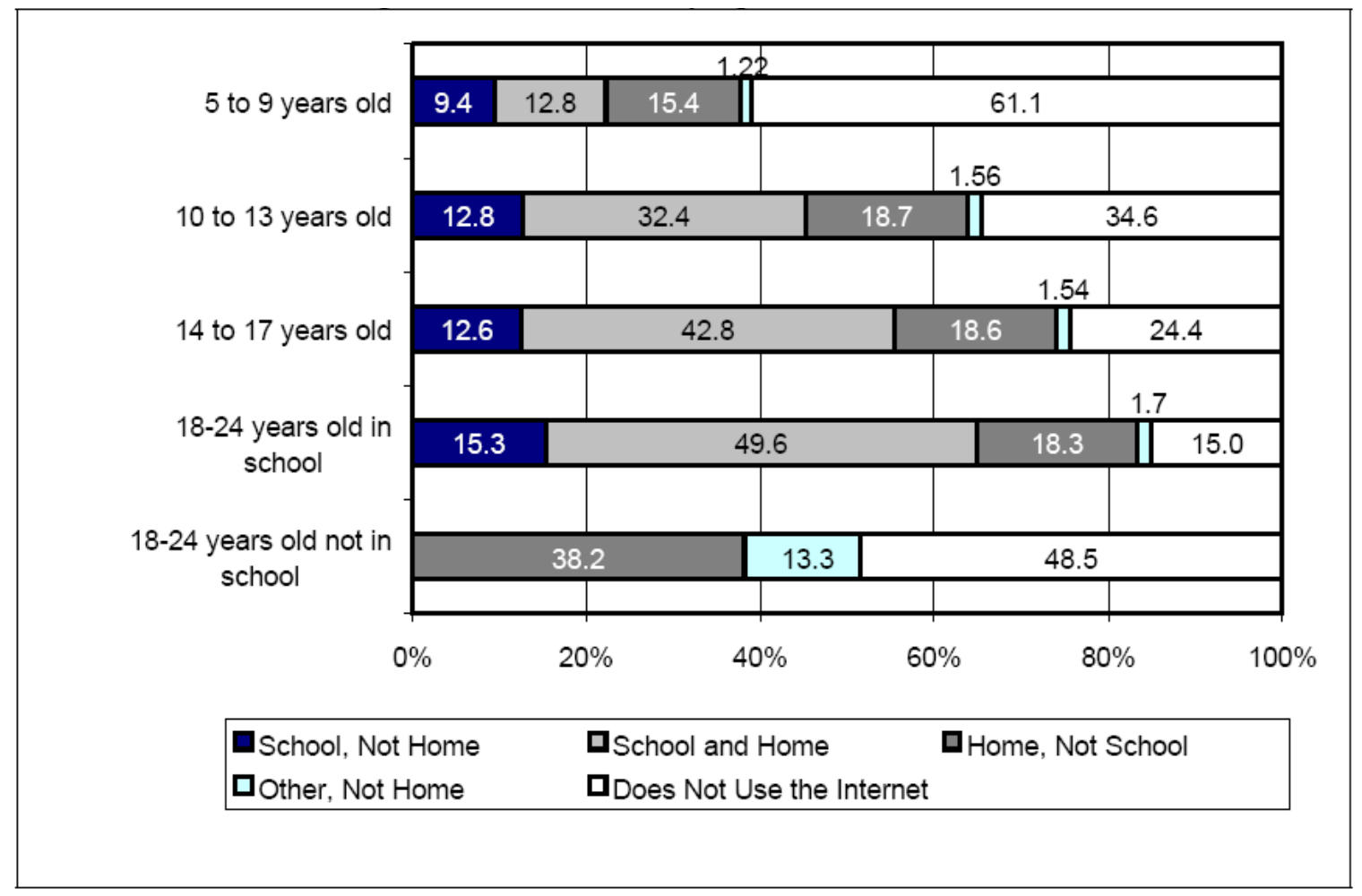

(U.S. Department of Commerce, p. 46, 2002)

\section{Personal Empowerment In The Study Of Home Internet Use By Low-Income}

Families, conducted by Bier et al (1997), was structured as an ethnographic study. One of the conclusions in this study was the most disadvantaged participants would become 
the most enthusiastic users; e.g., those who would benefit the most from access to the Internet. In this study, participants who were classified as information have-nots were given free Internet access in their homes from December of 1994 until January of 1996. The one-year of Internet access was evaluated and Bier concluded, “The data collected during this study provide strong evidence for the Internet's potential to empower and enrich the lives if those with access” (Conclusion section, ๆ 1). Further, “Having determined that ideal Internet access can indeed be an effective mechanism through which families from underserved communities may be empowered, we must identify technological and organizational strategies, tools, and models of access that are both effective and practical” (Bier et al, Discussion section, ๆ 3, 1997). “The ethnographically informed results of this study indicate that home Internet access enabled the research participants to experience powerful emotional and psychological transformations” (Bier et al, Discussion section, 9 3, 1997). These sorts of transformations would support the idea that Internet at home would contribute to a difference in student performance independent of family affluence.

\section{Affluence Effect on Student Performance}

This section of the literature review examines the inference of the haves and havenots. A quick glance at data such as that from the U.S. Department of Commerce (Figure 1, and Figure 2) may lead to an inference that there is an economic difference among those who have and do not have Internet access. This is notion is summarized, Surveys for commercial purposes indicate that parents are purchasing computers, software, and Internet connections to provide their children with an "advantage." Consequently, the children from more-advantaged circumstances gain even more 
access at home than in school. Those from less-advantaged homes are becoming a technological underclass ... (Kafai et al, p. 64, 2002).

Household Income and Internet Access

In support of the assertion Kafai et al put forth, less-advantaged homes are becoming a technological underclass, the U.S. Department of Commerce published the data in Figure 3 in 2002. The data suggests there is a relationship among the factors of income and Internet access at home.

A passing examination of Figure 3 reveals a pattern of descending use of the Internet according to the category of income. The group not using the Internet steadily grows with the descending income categories, from $12.14 \%$ for those whom earned more than $\$ 75,000,19.6 \%$ for those who earned $\$ 50,000-\$ 74,999,24.53 \%$ for those who earned $\$ 35,000-\$ 49,999,37.9 \%$ for those who earned $\$ 25,000$ - $\$ 34,999,45.12 \%$ for those who earned $\$ 15,000$ - $\$ 24,999$, and $54.3 \%$ for those who earned less than $\$ 15,000$ a year. The pattern is inverted when looking at those who use the Internet both at home at school with $57.71 \%$ for those who earned $\$ 75,000,46.89 \%$ for those who earned $\$ 50,000-\$ 74,999,38.6 \%$ for those who earned $\$ 35,000-\$ 49,999,25.63 \%$ for those who earned $\$ 25,000$ - \$34,999, 20.17\% for those who earned \$15,000 - \$24,999, and 13.54\% for those who earned less than $\$ 15,000$ a year. 
Figure 3. Internet Use Among 10 to 17 Year-Olds By Income and Location, 2001

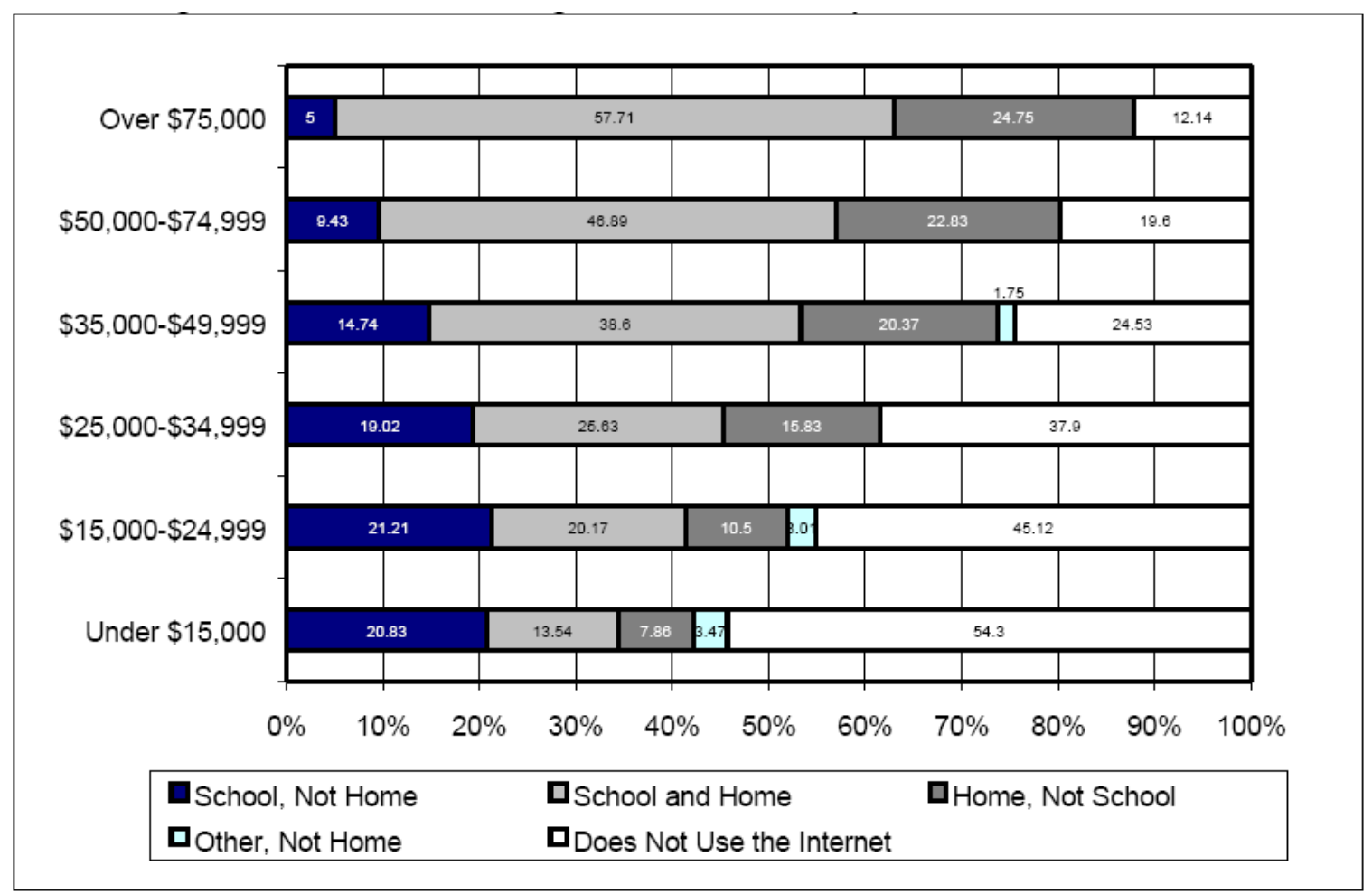

(U.S. Department of Commerce, p. 50, 2002)

Aside from the question of access, there is also an issue of how the resources are used. This question is partially addressed from the results of a data-mining study, Young Children's Access to Computers in the Home and at School in 1999 and 2000, performed by Rathbun et al, published in Education Statistics Quarterly. The data was mined from the U.S. Department of Education's National Center for Education Statistics (NCES) from a study performed in 1998 involving more than 22,000 students. Rathbun et al, offers from the analysis of the data, “... the purposes for which young children used computers at home varied by children's sex, race/ethnicity, and SES [socio-economicstatus]. For example, family SES was positively related to children's use of home computers for educational purposes overall” (p. 12, 2003). If these results are valid, they 
may set up a doubling effect of the digital divide. Those who did not have Internet access may not be as likely to have contributed to the advancement of their children's education. “Who’s Wired and Who’s Not: Children’s Access to and Use of Computer” was published in the The Future of Children and submitted by Becker (2000). Much of the data he puts forth is from 1998. Although the quantity of access may have changed in the years following this study, the activities that students pursue may have followed a trend being indicated from the results of other studies. Becker's study, states the “data suggest that lower-income students use computers more often for repetitive practice, whereas higher-income students use computers more often for more sophisticated, intellectually complex applications” (Becker, p. 44, 2000). This research indicated that these differences in use were school based. It is unknown if the same results hold true for home based technology use.

More than half of all American households are now on the Internet (U.S. Department of Commerce, 2002). Most students have Internet access at school, and for those who do not have Internet access at home, “About $11 \%$ of these wired teenagers say their primary access to the Internet is at school. Our survey suggests that school is often the place where those who are less privileged have their primary access to the Internet” (Lenhart et al, p. 3, 2001).

Embedded in the income question is the understanding of parental vocation. As it relates to this research, there is evidence that links parent's computer usage at work to usage at home. "The data show that when parents use computers at work, however, they are much more likely to provide their children with access to computers at home, especially those in low-income families” (Becker, p. 66, 2000). This notion is further 
reinforced: “The presence of someone who uses a computer or the Internet at work in a household is associated with substantially higher computer ownership or Internet use for that household, by a margin of about 77\% to 35\%” (U.S. Department of Commerce, p. 2, 2002).

\section{Household Income and Academic Standing}

It is common to find a statement like research has shown that test scores closely correlated with a parent's income and educational level; however it is not common to find supporting data. The assumption being that greater resources within a given students home will avail a greater variety of experiences. Table 1, Scholastic Assessment Test score averages by Family Income, 1995-96, 1997-98, and 1999-2000, reveals the differences in scaled scores. The extreme spread ranges over one hundred points in between the highest and lowest income groups in all categories and years.

Figure 4 Scholastic Assessment Test Score Averages by Family Income, 1995-96, 1997-98, and 1999-2000 illustrates the data from Table 1. The trend for those with greater income to have children whom score higher is quite apparent. 
Table 1.

Scholastic Assessment Test Score Averages by Family Income, 1995-96, 1997-98, and 1999-2000

\begin{tabular}{|c|c|c|c|c|c|c|c|c|c|}
\hline Selected characteristics & $\begin{array}{l}\text { Verbal } \\
\text { Score }\end{array}$ & $\begin{array}{l}\text { Math- } \\
\text { Score }\end{array}$ & $\%$ & $\begin{array}{l}\text { Verbal } \\
\text { Score }\end{array}$ & $\begin{array}{l}\text { Math- } \\
\text { Score }\end{array}$ & $\%$ & $\begin{array}{l}\text { Verbal } \\
\text { Score }\end{array}$ & $\begin{array}{l}\text { Math- } \\
\text { Score }\end{array}$ & $\%$ \\
\hline All students & 505 & 508 & 100 & 505 & 512 & 100 & 505 & 514 & 100 \\
\hline \multicolumn{10}{|l|}{ Family income } \\
\hline$\$ 10,001$ to $\$ 20,000$ & 456 & 464 & 8 & 451 & 463 & 9 & 447 & 460 & 8 \\
\hline$\$ 20,001$ to $\$ 30,000$ & 482 & 482 & 10 & 477 & 482 & 11 & 471 & 478 & 10 \\
\hline$\$ 30,001$ to $\$ 40,000$ & 497 & 495 & 12 & 495 & 497 & 13 & 490 & 493 & 12 \\
\hline$\$ 40,001$ to $\$ 50,000$ & 509 & 507 & 10 & 506 & 509 & 11 & 503 & 505 & 10 \\
\hline$\$ 80,001$ to $\$ 100,000$ & 541 & 544 & 7 & 539 & 546 & 9 & 536 & 543 & 10 \\
\hline More than $\$ 100,001$ & 560 & 569 & 9 & 559 & 572 & 13 & 558 & 571 & 16 \\
\hline
\end{tabular}

Source: National Center for Educational Statistics (2004). Digest of Statistical Tables and Figures - 2003. Table 135. Scholastic

Assessment Test score averages, by selected student characteristics: 1995-96, 1997-98, and 1999-2000 
Figure 4. Scholastic Assessment Test Score Averages by Family Income, 1995-96, 199798, and 1999-2000

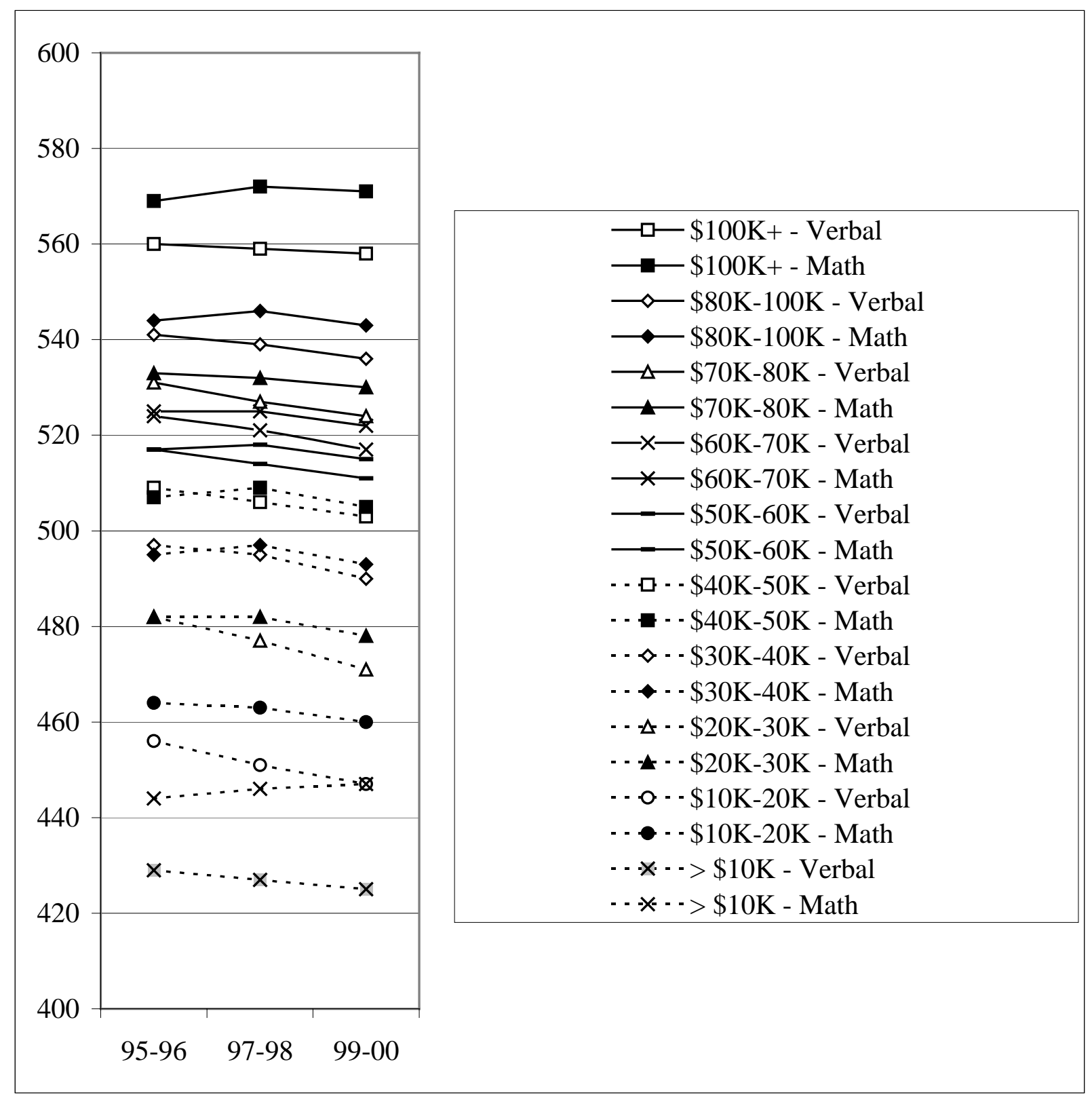

Source: National Center for Educational Statistics (2004). Digest of Statistical Tables and Figures - 2003. Table 135.--Scholastic Assessment Test score averages, by selected student characteristics: 1995-96, 1997-98, and 1999-2000. 


\section{Parent Education Level and Academic Standing}

Parent's education has also proven to be a factor that appears to be related to academic standing. Figure 5, Average Student Scale Score in Reading, Age 9: Selected Years, 1971 to 1999, contains nearly 30 years worth of data. The tendency that stands out is that those parents with higher levels of education have children who have achieved higher scores on standardized tests. Those children who were raised in households with a parent having post high school education appear to have higher average test scores over the two other categories.

Figure 5. Average Student Scale Score in Reading, age 9: Selected Years, 1971 to 1999

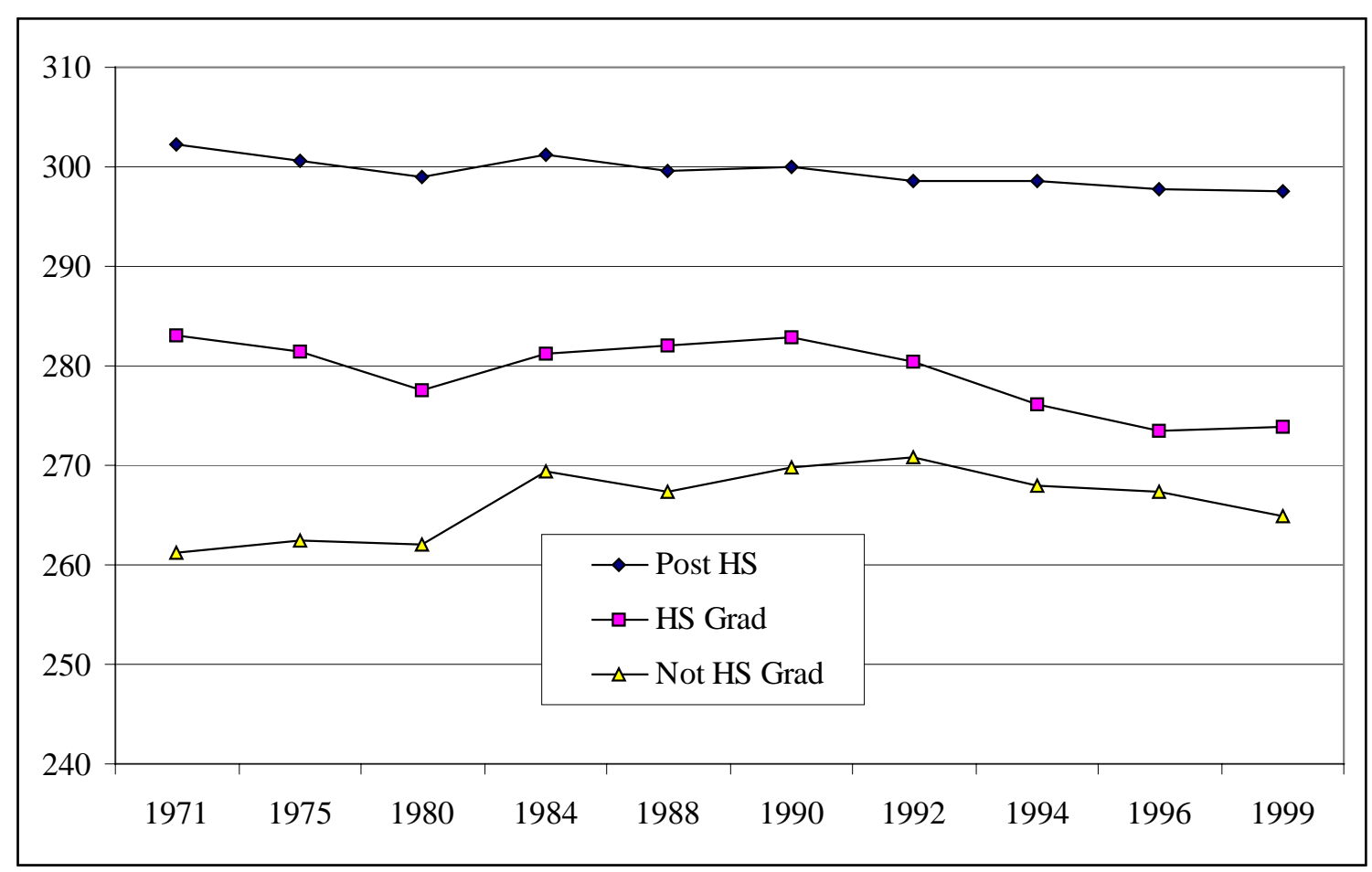

Source: National Center for Educational Statistics (2004). Digest of Statistical Tables and Figures - 2003. Table 110. Average Student Scale Score in Reading, by Age and Selected Student and School Characteristics: Selected Years, 1971 to 1999 
Table 2.

Scholastic Assessment Test Score Averages by Parent Education, 1995-96, 1997-98, and 1999-2000

\begin{tabular}{|c|c|c|c|c|c|c|c|c|c|}
\hline & \multicolumn{3}{|c|}{$1995-96$} & \multicolumn{3}{|c|}{ 1997-98 } & \multicolumn{3}{|c|}{$1999-2000$} \\
\hline & Verbal & Math - & & Verbal & Math - & & Verbal & Math - & \\
\hline & Score & Score & $\%$ & Score & Score & $\%$ & Score & Score & $\%$ \\
\hline All students & 505 & 508 & 100 & 505 & 512 & 100 & 505 & 514 & 100 \\
\hline \multicolumn{10}{|c|}{ Highest level of parental education } \\
\hline No high school diploma & 414 & 439 & 4 & 411 & 441 & 4 & 413 & 442 & 4 \\
\hline High school diploma & 475 & 474 & 31 & 473 & 477 & 34 & 472 & 477 & 33 \\
\hline Associate degree & 489 & 487 & 7 & 489 & 491 & 8 & 488 & 491 & 9 \\
\hline Bachelor's degree & 525 & 529 & 25 & 525 & 532 & 28 & 525 & 533 & 29 \\
\hline Graduate degree & 556 & 558 & 23 & 556 & 563 & 25 & 558 & 566 & 25 \\
\hline
\end{tabular}

(Note: Because of survey item non-response, percentage distributions may not add to 100 percent.)

Source: National Center for Educational Statistics (2004). Digest of Statistical Tables and Figures - 2003. Table 135. Scholastic Assessment Test score averages, by selected student characteristics: 1995-96, 1997-98, and 1999-2000. 
Table 2 Scholastic Assessment Test score averages by Parent Education, 1995-96, 1997-98, and 1999-2000 is the data used to generate Figure 6. The tendency illustrated in the figure and supported by the data in the table supports the notion that greater parent education seems to be related to difference in student test scores.

Figure 6. Scholastic Assessment Test Score Averages by Parent Education, 1995-96, 1997-98, and 1999-2000

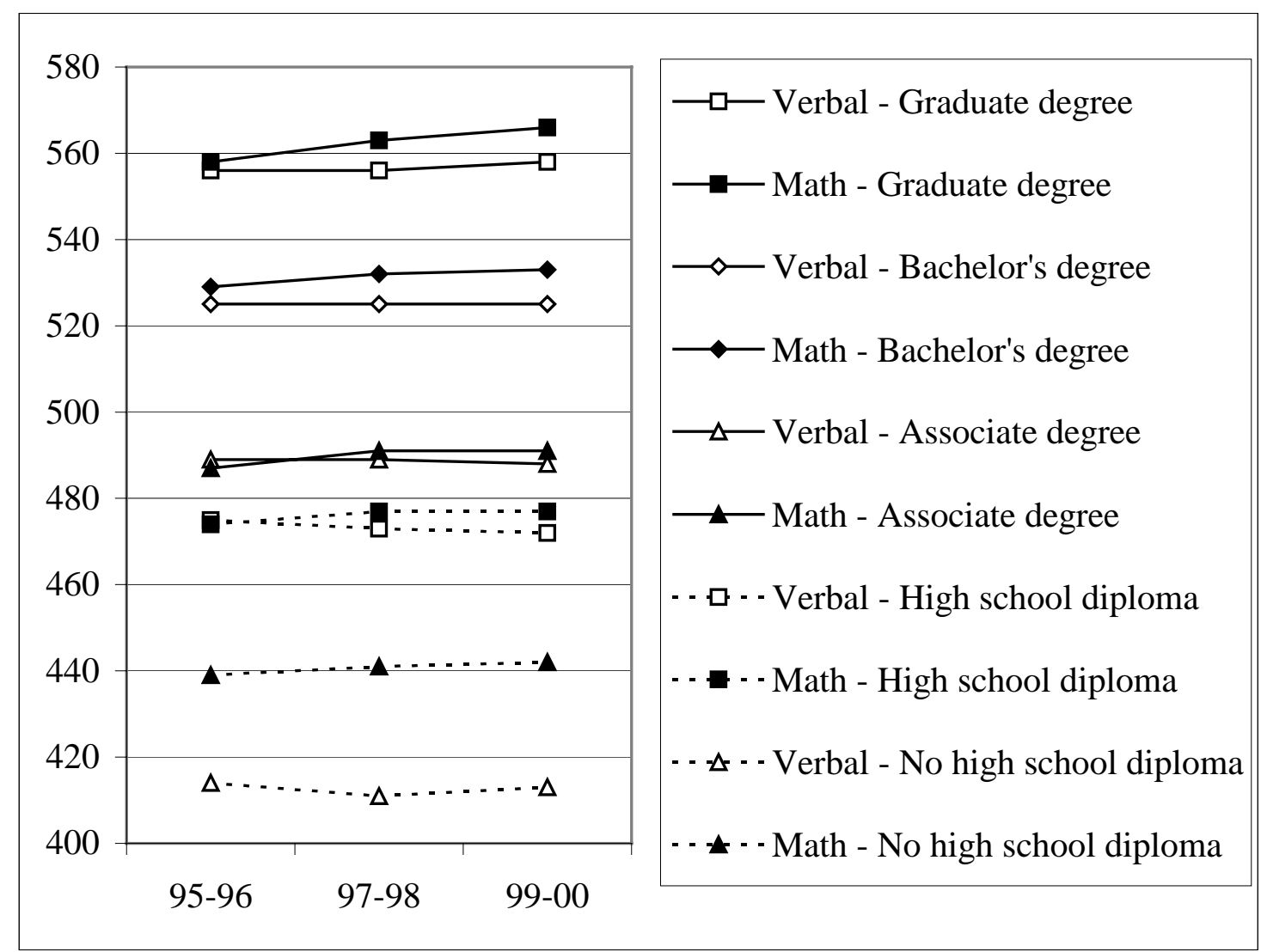

Source: National Center for Educational Statistics (2004). Digest of Statistical Tables and Figures - 2003. Table 135. Scholastic Assessment Test score averages, by selected student characteristics: 1995-96, 1997-98, and 1999-2000. 
There appears to be evidenced support that parent education and student performances are related. Both the effect of the parents education and household income need to considered in an investigation of the contribution of Internet access to student academic standing. As summarized:

Of course, student use of the Internet for school does not occur in a vacuum. Students' experiences, and those of their states, districts, schools, teachers, and parents, strongly affect how the Internet is adopted in schools. Nonetheless, large numbers of students say they are changing because of their out-of-school use of the Internet—and their reliance on it. Internet-savvy students are coming to school with different expectations, different skills, and access to different resources. (Levin \& Arafeh, p. v, 2002)

These statements by Levin \& Arafeh (2002) support the relevance of this research approach to determine if the effect of Internet access at home really does operate independent of other established factors.

\section{Measures}

The measures for this study are survey and standardized test data. The San Miguel GEARUP Partnership requires that parents of participants to complete a survey in the form of an annual application. The standardized test used in New Mexico in 2004 was the CTB/McGraw-Hill -TerraNova. The particular data set to be used from the battery of data available are the NCE total score. This section describes the survey (application form), the standardized test, and the NCE total score. 


\section{San Miguel GEARUP Partnership Application Form}

The San Miguel GEARUP Partnership is described in detail in a later section of this chapter. Parents of participants complete an application form annually. The Appendix NMHU/San Miguel GEAR-UP Student Application, 2003-2004 School Year, contains a reproduction of the survey form. The data collected from this instrument are used to conduct the GEARUP program and complete the Annual Performance Review (APR). There are a high rate of return on the applications because completed applications are required before any students can obtain their earned reward. The participant's application form contains questions that are within the scope of the objectives of GEARUP. e.g., Do you plan to go on to college? What college? What major?

For the purposes of this study, three of the San Miguel / New Mexico Highlands University GEARUP Partnership application (survey) questions are relevant: 1) Do you have Internet access? Yes No

, 2) Range of Family Income: $\$ 0-10,000$

$\$ 10,000-20,000$ $\$ 20,000-30,000$ $\$ 30,000-40,000$ $\$ 40,000-50,000$ $\$ 50,000-60,000$ Above $\$ 60,000$, and; 3) What is the highest level of education that was received by each family member?

\section{NCE Score}

Forms of measurement are an important aspect of research. There are many types of results available from standardized tests. National Percentile (NP) are perhaps the most common result published in the general media. The National Percentile scale represents a means of arranging the results in order of 1 to 100 , without any reference to the difference among those rated on the scale. The Normal-Curve Equivalents (NCE) 
appears to be similar to the National Percentile score commonly used to describe student performance on standardized test scores because the scores range from 1 to 99. The differences are that the scores are fit to a normal distribution, with a mean of 50 , and a standard deviation of 21.06 (Gottfredson, 2004 \& Gregg, 2004).

The NCE was developed to allow mathematical manipulation of NP scoresespecially for program evaluation and research requiring the comparison of scores across groups or across time. The NCE scores can be thought of as NP scores rescaled on an equal interval scale (which allows them to be used in mathematical calculations such as deriving a mean score). (Indiana Department of Education, Normal Curve Equivalent Score section, ๆ 1, 2005).

Because the NCE score has an equal interval scale, it has been selected as the score that will be used in the analysis of this study. The NCE is a continuous numeric scale which is the "highest level of measurement" as defined by Weardon \& Dowdy (p. 28, 1991). The attributes of the NCE score qualify it as a good selection from the battery of scores produced by standardized tests. The NCE scores will also meet the data distribution assumptions of many statistical analysis methods.

The use of the NCE score will permit students from different grades to be grouped into a single dataset. This is possible because the score is a number ranging in the same domain for each grade. The score reports the academic standing of students relative to their grade level.

The particular score to be used in this research is the NCE total, because the concern is with overall academic standing, not any particular subject. The NCE Total score is a is a composite score of Reading, Reading Vocabulary, Language, Language 
Mechanics, Math, Math Computation, Science, Social Studies, Spelling, and Word Analysis scores.

CTB/McGraw-Hill -TerraNova

CTB/McGraw-Hill has seventy years experience in producing tests and working with local and state agencies. During the 2003-2004 school year “ ... education in New Mexico was guided by the State Board's strategic plan, 'Charting Student Success in the New Millennium,' a quality, comprehensive, system-based approach to bring about needed educational reform” (New Mexico Public Education Department, p. 5, 2004). As a consequence, a standardized measure was selected to be used statewide. The selection was for a standardized test; the CTB/McGraw-Hill -TerraNova. (CTB/McGraw-Hill, 2004). "Due to concerns over test security, New Mexico for a second year used a new form of the TerraNova called The Second Edition, Complete Battery (CAT)" (New Mexico Public Education Department, p. 11, 2004). This is the exact form of data upon which this study will be based.

\section{Program Descriptions}

The research will use data from the specific population that participates in the NMHU San Miguel GEARUP Partnership. The first section describes the GEARUP program, as it is offered from the U.S. department of Education. The second section describes the San Miguel GEARUP Partnership. The final section describes the database the San Miguel GEARUP Partnership utilizes to conduct program activities.

\section{GEARUP}

Gaining Early Awareness and Readiness for Undergraduate Programs (GEARUP) is a federally funded program. The GEARUP Program is funded at over \$300 million 
annually and serves over 1.2 million students nationally. GEAR UP has received almost $\$ 1.2$ billion since its creation and has 280 partnership grants and 36 state grants (NCCEP, 2005).

The GEAR UP program is a discretionary grant program designed to increase the number of low-income students who are prepared to enter and succeed in postsecondary education. GEAR UP provides five-year grants to states and partnerships to provide services at high-poverty middle and high schools. GEAR UP grantees serve an entire cohort of students beginning no later than the seventh grade and follow the cohort through high school. GEAR UP funds are also used to provide college scholarships to low-income students. (U.S. Department of Education, Purpose section, $\mathbb{\uparrow} 1$, 2005).

\section{San Miguel GEARUP Partnership}

The San Miguel GEARUP Partnership is conducted in Las Vegas, New Mexico, at New Mexico Highlands University. There are two school districts, a community college and a university participating in the partnership. The participants are: Las Vegas City Schools, West Las Vegas Schools, Luna Community College, and New Mexico Highlands University. This partnership was funded by the U.S. Department of Education for five years, from 2000 to 2005.

The partnership objectives are to improve academic performance of the participating students in two major ways: first, by enabling individualized curriculum for students in reading comprehension and math, and second, a student incentive system. Individualized curriculums are supported such as SRA reading kits, along with Renaissance Learning products, such as Accelerated Math and Accelerated Reading. In 
the students incentive system, students "earn points for completing their educational tasks, for participating in the management of the system, and for demonstrating positive social behavior. Points are used for rewards such as monthly field trips” (U.S. Department of Education, p. 91, 2004). Over 3,500 students have interacted with this GEARUP program since 2000.

\section{NMHU/GEARUP Database}

The San Miguel GEARUP Partnership has developed a database containing the program information necessary to conduct the initiatives set forth by the U.S. Department of Education and the program goals of the San Miguel GEARUP Partnership. The database has evolved from a series of spreadsheets, to a Microsoft Access relational database and its current state as a fully normalized MS-SQL 2000 database. The primary sources of data in the database are demographics collected from participant parents (Appendix), academic and behavioral data entered by teachers, and imported data. Imported data sources include results of standardized tests, state content standards and benchmarks, and educational objectives.

The system maintains internal integrity by the use of a Globally Unique Identifier (GUID). A GUID is a unique 128-bit number that is produced by the Windows OS or by some Windows applications to identify a particular component, application, file, database entry, and/or user (Webopedia, 2004). These unique identifiers meet all the criteria for a relational database to have integrity at a table level, database level and entire systems level (Hernandez, p. 261-265, 2003). The Globally Unique Identifier is designed to be unique across all systems and lends a high degree of certainty that a record referred to in any data set is indeed the record called or requested. 


\section{Prior and Related Research}

There has been research that are related to the purpose of this study, and the results help justify this research. Most research on Internet and public education has been a count of network connections, machines and an accounting of the bandwidth available to how count of how many students. The next form of research counts how may students have access within the schools.

... the major emphasis of educational technology researchers has been the development and use of educational technologies within school settings. Noticeably absent has been research and considerations that focus on the home as a computer-based learning environment and potential connections between school and home learning. (Kafai et al, p. 52, 2002)

Furthermore the research focusing on computers within the home is becoming quickly dated, because the issues cited in the conclusions of research from ten and more years ago has questionable validity considering current computer and Internet technologies. In 1995, Internet connections were rare and had very limited value. Research from five years ago may be questioned as the nature of distributed applications has undergone several technical evolutions.

\section{Prior Research}

The findings of research performed by Attewell and Battle (1999) support the premises of this research. Their findings indicate there were relationships between the factors of home computer access and higher test scores in the National Educational Longitudinal Study of 1988. 
We find that having a home computer is associated with higher test scores in mathematics and reading, even after controlling for family income, and for cultural and social capital. However, children from high socio-economic status homes achieve larger educational gains from home computers than lower SES children. Boys' performance advantage is larger than girls'. Ethnic minorities gain far less of a performance boost than whites. Home computing may generate another "Sesame Street Effect" whereby an innovation which held great promise for poorer children to catch up educationally with more affluent children, in practice is increasing the educational gap between affluent and poor, between boys and girls, between ethnic minorities and whites, even among those with access to the technology. (Attewell \& Battle, p. 1, 1999)

There are two notable issues of the data analyzed in this study. First, there was some degree of effect from the socio-economic-status. Second, the data from 1988 which were analyzed eleven years later in 1999 may not be valid. Even by Attewell \& Battle’s assessment, the nature of the technology - home computers for their study, had changed, and may have an impact on the results of a similar study. The research is of interest because the design is comprehensive in treatment of other factors that may contribute to differences in student performance. This approach supports the rationale of the design of this study by giving consideration to confounding factors.

It would be simple to test whether the existence of home computing, by itself, was associated with higher test scores, but that could be misleading. Many factors, from family income to state of residence, are also related to children's academic performance, and some of these are correlated with ownership of a home 
computer as well. One therefore needs to separate out the effects of these multiple determinants of educational performance, and assess the contribution (if any) of home computers net of these other variables. (Attewell \& Battle, p. 3, 1999) A September 2004 publication, Technology and Equity in Schooling:

Deconstructing the Digital Divide, questions the contribution of technology access in the home, “Although home access to computers has long been regarded as important for supporting students’ academic achievement, research suggests that home ownership of computers alone does not level out inequalities in terms of technology's contributions to student learning” (Warschauer \& Knobel, p. 563, 2004). What is suggested is that there are other factors beyond ownership, such as the parent setting an example of what function, or role, the technology fills. In some cases where a parent is an Internet user at work, the observing child interprets the technology as a tool of work. While in the other extreme, the child observes only entertainment uses of the technologies, so they also interpret the technology as such. This trend extends in a way that seems to follow along income categories.

Just as children in families with lower income and less-educated parents were much less likely to have a computer in their home-or, if they had a computer, to have one with many features—-such children were also less likely to use their family’s computer in various ways. (Becker, p. 63, 2000)

In reference to various ways Becker (2000) wrote contextually about the use of six applications such as word processors and other productivity technologies typically used outside the educational environment. If one, or both parents use these technologies 
in the workplace, their children were more likely to use these technologies to support learning and completing schoolwork.

\section{Related Dissertation Research}

Queries of the West Virginia University Dissertation Database (Dissertation Abstracts Online - OCLC) produced a number of related dissertations. Some of the results, especially those more than five years old, may no longer reflect the state of Internet usage within the home. However, others reveal results relevant to the aims of this dissertation.

Dissertation research performed by Nonnamaker (2000), Pre-college Internet use and freshman year academic achievement in a private college: The effect of sociodemographic characteristics, family socioeconomic status, academic ability and high school experiences, at Fordham University, focused on the assumption that Internet technology will enhance academic achievement in college during the freshman year. Data were collected from the 1998 Student Information Form and included linked grades data from the institution. Findings indicated that "For freshmen grades in the top third of their class, however, both school based and home based pre-college Internet use directly affected academic achievement with home based use enhancing academic achievement, while school based use was, unexpectedly, negative” (Nonnamaker, ๆ 3, 2000). These findings support this research because Nonnamaker found that "Internet use directly affected academic achievement” (\$ 3, 2000).

Dissertation research performed by Davis (2003), An investigation of parental perceptions of and attitudes toward computer use in two predominantly Hispanic communities in the southwestern border region, at New Mexico State University, focused 
on parental perceptions of and attitudes toward their children's computer use. Data were collected from discussions with 26 participants in five parent focus groups. "Qualitative research analysis techniques were used to triangulate discussions” (Davis, ๆ 2, 2003). Four themes emerged in this research: “(a) digital divide issues, (b) the desires of respondents from all socioeconomic groups for technology training, (c) respondents' fears to use the Internet, and (d) respondents' concerns about children spending too much time on computers” (Davis, ๆ 3, 2003). Additional results included concerns about poverty stricken parents not being able to afford computers and that parents lacked experience to understand what their children are learning. "Parents from all ethnic backgrounds and income levels expressed the desire to have free computer training” (Davis, ๆ 4, 2003). Finally, the "digital divide problem was not an ethnic issue; rather, it was a socioeconomic status issue” (Davis, ๆ 4, 2003). These findings support this research because Davis states that "it was a socioeconomic status issue” (Davis, ๆ 4, 2003), supporting the importance of the confounding factors of this study.

Dissertation research performed by Toriskie (1999), the Effects of Internet Usage on Student Achievement and Student Attitudes (Fourth-Grade, Social Studies), at Loyola University of Chicago, focused on whether or not the use of the Internet would affect student achievement in social studies or students' attitudes toward school. Data were collected from using the Social Studies Battery of the California Achievement Test and a Student Attitude Survey. The variables in this study were gender, ethnicity, socioeconomic status, and home use of the Internet. "Internet usage was found to have a positive impact on both student achievement in social studies and on student attitudes” 
(Toriskie, ๆ 3, 1999). These findings support this research, because differences in academic standing were attributed to Internet usage.

\section{Research Method}

Interpreting statistics is an art - an art of making judgments under uncertainty. But as it becomes easier to obtain statistics on much larger samples, and as the providers of statistics become more professional, the problem of error is reduced and the problem of spurious associations remains. As the quality and quantity of data obtained in an observational study increases, the problem of confounding becomes the central problem. (Schield, p. 5, 1999)

To dismiss confounding factors can cause a spurious association. "What we take into account (or fail to take into account) strongly influences the conclusions we reach” (Schield, p. 5, 1999). According to Schield the three means of avoiding a spurious association are to 1) Increase the sample size, 2) Eliminate the problem of bias, and; 3) Eliminate the influence of confounding factors. To determine if there is a difference in academic standing for those whom have Internet access at home, consideration of other factors need to be included in the research design. The research design should determine differences, and potential interactions among factors such as Internet access at home, family affluence, and academic achievement.

The 3 way factorial Analysis of Variance (ANOVA) can be used when an "investigator is interested in the combined effect” (Wearden, p. 397, 1991) of the factors. "Factorial arrangements allow us to study the interaction between two or more factors" (Horsley, p.1, 2004). The results of this method produce main effects and interaction 
effects. In essence, this method of analysis can be used to test for differences among the means of the factors and the means of the various combinations interactions. 


\section{CHAPTER 3 - METHOD \\ Design}

The purpose of this study was to investigate differences in academic standing among those with Internet access at home and those without Internet access, and if the potential academic standing differences are dependent or independent of family affluence. A quasi-experimental research design was employed to determine if there were differences due to these factors. The statistical method of 3-way factorial ANOVA (A x B x C Factorial Design) was used for analysis.

This was a post hoc quasi-experimental design because the independent variables were not randomly assigned to the participants and the data were based upon what has already occurred (survey results from the 2003-04 school year, and test scores from the Spring 2004). The selection of a 3-way factorial ANOVA was supported because it would indicate if interactions among the factors existed. Post hoc comparisons and/or post hoc analyses were conducted if significant differences were determined to exist.

\section{Research Question}

What are the differences among the standardized test scores of students due to factors of Internet access at home, household income, and the highest level of education attained by mother, father, or guardian?

\section{Independent Variables}

The independent variables in this study were 1) Internet access at home, 2) family income, and; 3) highest level of education attained by mother or father or guardian. The independent variables were gathered from responses on the San Miguel GEARUP Partnership application. On the application, parents indicate whether or not the students 
have Internet access at home. Parents of participants also mark the form to indicate their household income and the level of education attained by mother, father and/or guardian. The highest level of education achieved was selected. To summarize, the independent variables were:

- Internet access at home, that were grouped: (yes versus no)

- Family income, that may have been grouped in an arrangement such as: (\$1-\$20,000, \$20,001-\$30,000, \$30,001-\$50,000, and \$50,001+)

- Highest level of education attained by mother or father or guardian, that may have been grouped in an arrangement such as: (elementary school high school, some college - 2 year degree, 4 year degree, and graduate degree)

The definitions of categories were dependent upon the data. The particular groupings of both family income and highest level of education attained by mother or father or guardian were determined by analyzing the to data.

\section{Dependent Variable}

In this study the dependent variable was the Normal-Curve Equivalents (NCE) total test score as calculated by the CTB/McGraw-Hill -TerraNova. The NCE Total score is a composite score of Reading, Reading Vocabulary, Language, Language Mechanics, Math, Math Computation, Science, Social Studies, Spelling, and Word Analysis scores. The NCE score is fit to a normally distributed curve, and these data should meet the assumptions for the method of analysis. To summarize, the dependent variable is: 
- NCE Total score from the CTB/McGraw-Hill -TerraNova NCE

\section{Factorial ANOVA}

For the research question a three-way factorial ANOVA was chosen to determine which factor had the most effect on the dependent variable, the NCE test scores, and to examine the degree of interaction among the independent variables (Wearden \& Dowdy, p. 409, 1991). Table 3 Quasi-Experimental Research Design: 3 Way ANOVA - 2 x 4 x 4 Factorial ANOVA illustrates how the independent variables, and the dependent variable, represented by the $x x$, may have been structured.

The exact form ( $\mathrm{x}$ x b x c) of the factorial ANOVA was determined by the data. It would likely be smaller than the example provided, and the category groupings were different. Certain categories were collapsed together to ensure adequate data in each cell of the table. For instance, if inadequate data were available for households led by highschool graduates whom are earning $\$ 50,001+$, that column would be combined with the next lower category to obtain an adequate number of data sets. Likewise, highest level of education within the household would also require the collapsing of rows to ensure adequate data in each cell. 
Table 3.

Quasi-Experimental Research Design: 3 Way ANOVA - $2 \times 4 \times 4$ Factorial ANOVA

\begin{tabular}{|c|c|c|c|c|c|c|c|c|c|}
\hline & & \multicolumn{8}{|c|}{ FACTOR A: Internet Access at Home } \\
\hline & $\begin{array}{l}\text { FACTOR B: } \\
\text { Household Income }\end{array}$ & $\begin{array}{c}\$ 0- \\
\$ 20 \mathrm{~K}\end{array}$ & $\begin{array}{l}\$ 20 \mathrm{~K}- \\
\$ 30 \mathrm{~K}\end{array}$ & $\begin{array}{l}\$ 30 \mathrm{~K}- \\
\$ 50 \mathrm{~K}\end{array}$ & $\$ 50 \mathrm{~K}+$ & $\begin{array}{l}\$ 0- \\
\$ 20 \mathrm{~K}\end{array}$ & $\begin{array}{l}\$ 20 \mathrm{~K}- \\
\$ 30 \mathrm{~K}\end{array}$ & $\begin{array}{l}\$ 30 \mathrm{~K}- \\
\$ 50 \mathrm{~K}\end{array}$ & $\$ 50 \mathrm{~K}+$ \\
\hline$\frac{\text { FACTOR C }}{\text { Highest }}$ & $\begin{array}{c}\text { Elementary School - } \\
\text { High School }\end{array}$ & $\mathrm{xx}$ & $\mathrm{XX}$ & $\mathrm{xx}$ & $\mathrm{XX}$ & $\mathrm{xx}$ & $\mathrm{xx}$ & $\mathrm{XX}$ & $\mathrm{xx}$ \\
\hline $\begin{array}{l}\text { Level of } \\
\text { Education }\end{array}$ & $\begin{array}{l}\text { Some College- } \\
2 \text { year degree }\end{array}$ & $\mathrm{xx}$ & $\mathrm{Xx}$ & $\mathrm{xx}$ & $\mathrm{xx}$ & $\mathrm{xx}$ & $\mathrm{xx}$ & $\mathrm{xx}$ & $\mathrm{xx}$ \\
\hline $\begin{array}{l}\text { Attained by } \\
\text { Mother, }\end{array}$ & 4 year degree & $\mathrm{xx}$ & $\mathrm{xx}$ & $\mathrm{xx}$ & $\mathrm{xx}$ & $\mathrm{xx}$ & $\mathrm{xx}$ & $\mathrm{xx}$ & $\mathrm{xx}$ \\
\hline $\begin{array}{l}\text { Father or } \\
\text { Guardian }\end{array}$ & Graduate degree & $\mathrm{xx}$ & $\mathrm{xx}$ & $\mathrm{xx}$ & $\mathrm{xx}$ & $\mathrm{xx}$ & $\mathrm{xx}$ & $\mathrm{Xx}$ & $\mathrm{xx}$ \\
\hline
\end{tabular}

Dependent Variable: Spring 2004 CTB/McGraw-Hill -TerraNova NCE Total Test score 


\section{Hypothesis Statement}

\section{Null Hypothesis}

Because neither the size (number of rows and columns) or particular groupings of the three-way ANOVA can be known until the data are analyzed, the precise form of the null hypothesis was speculation. Assuming the grouping would take the form illustrated in Table 3 Quasi-Experimental Research Design: 3 Way ANOVA - 2 × 4 × 4 Factorial ANOVA, the null hypothesis would be:

There is no significant difference, at the alpha $=0.05$ level, for the effects of the Independent Variables of (A) Internet access at home (yes versus no) by (B) family income (\$1-\$20,000, \$20, 001-\$30,000, \$30,001-\$50,000, \$50,001+) by (C) highest level of education attained by mother or father or guardian (elementary school - high school, some college - 2 year degree, 4 year degree, and graduate degree) on the dependent variable (NCE Total score).

The null hypothesis states the means of all groups would be equal. Expressed mathematically in simplest form:

$$
\mu_{\mathrm{oA}}=\mu_{\mathrm{oB}}=\mu_{\mathrm{oC}}=\mu_{\mathrm{oAB}}=\mu_{\mathrm{OAC}}=\mu_{\mathrm{oBC}}=\mu_{\mathrm{oABC}}
$$

The full expression of null hypothesis states that all means within groups as well as among groups will be equal. Using Table 3 Quasi-Experimental Research Design: 3 Way ANOVA - $2 \times 4 \times 4$ Factorial ANOVA as a reference, all means within and among combinations of cells will be equal. Expressed mathematically:

Main effect A: $\mu_{\text {Internet (yes) }}=\mu_{\text {Internet (no) }}$

Main effect B: $\mu_{\text {income }(\$ 1-\$ 20,000)}=\mu_{\text {income }(\$ 20,001-\$ 30,000)}=\mu_{\text {income }(\$ 30,001-\$ 50,000)}=\mu$ 
Main effect C: $\mu$ education (elementary school - high school) $=\mu_{\text {education (some college }-2 \text { year degree) }}=$

$\mu_{\text {education (4 year degree) }}=\mu_{\text {education (graduate degree) }}$

Interaction AB: $\mu_{\text {Internet (yes) income }(\$ 1-\$ 20,000)}=\mu_{\text {Internet (yes) income }(\$ 20,001-\$ 30,000)}=\mu$

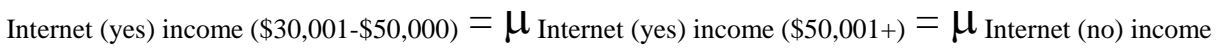

$(\$ 1-\$ 20,000)=\mu_{\text {Internet (no) income }(\$ 20,001-\$ 30,000)}=\mu_{\text {Internet (no) income }(\$ 30,001-\$ 50,000)}=$

$\mu_{\text {Internet (no) income }(\$ 50,001+)}$

Interaction AC: $\mu_{\text {Internet (yes) education (elementary school - high school) }}=\mu_{\text {Internet (yes) education }}$

(some college - 2 year degree) $=\ldots=\mu_{\text {Internet (no) education (some college }-2 \text { year degree) }}=\mu$

Internet (no) education (4 year degree) $=\mu_{\text {Internet (no) education (graduate degree) }}$

Interaction BC: $\mu_{\text {income }(\$ 1-\$ 20,000) \text { education (elementary school - high school) }}=\mu_{\text {income }(\$ 1-\$ 20,000)}$

education (some college - 2 year degree) $=\ldots=\mu_{\text {income }(\$ 50,001+\text { ) education (some college }-2 \text { year }}$

degree) $=\mu_{\text {income }(\$ 50,001+) \text { education (4 year degree) }}=\mu_{\text {income }(\$ 50,001+\text { ) education (graduate }}$

degree)

Interaction ABC: $\mu_{\text {Internet (yes) income (\$1-\$20,000) education (elementary school - high school) }}=\mu$

Internet (yes) income $(\$ 1-\$ 20,000)$ education (some college - 2 year degree) $=\ldots=\mu_{\text {Internet (no) income }}$

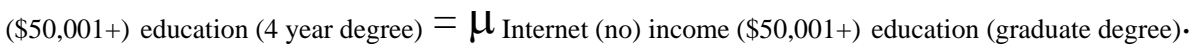

The means (yes versus no) of the main effect A (Internet access at home) will be equal. The means (\$1-\$20,000, $\$ 20,001-\$ 30,000, \$ 30,001-\$ 50,000$, and $\$ 50,001+)$ of the main effect B (income) will be equal. The means (elementary school - high school, some college - 2 year degree, 4 year degree, and graduate degree) of the main effect C 
(highest level of attained education) will be equal. The means of the 8 combinations of the interaction effect $\mathrm{AB}$ (Internet and income) will be equal. The means of the 8 combinations of the interaction effect AC (Internet and Education) will be equal. The means of the 16 combinations of the interaction effect BC (income and education) will be equal. Finally, the means of all 32 combinations of Internet, income and education of the interaction effect $\mathrm{ABC}$ will be equal.

\section{Instruments}

Data for this study are from two sources:

1. Survey: NMHU/GEARUP program application, and

2. Test score: NCE total score from the CTB/McGraw-Hill -TerraNova standardized test.

The NMHU/GEARUP program application was adapted from an application used by the Yakima, WA GEARUP program and developed with assistance from the University of Washington. The San Miguel GEARUP Partnership maintains a large database of participant demographics and student performance data. This database contains the data required to perform a statistical analysis of the proposed relationship of Internet access at home and academic standing. The NMHU/GEARUP database was queried for necessary data:

- Internet at home

- Household income

- Highest level of education attained by mother or father or guardian

- $\quad$ Spring 2004 standardized test scores (NCE Total score) 
The determination of Internet access at home, income, and education level of parents or guardians was self-reported on the annual NMHU/GEARUP application. These responses were coded into the NMHU/GEARUP database.

The standardized test scores were from the CTB/McGraw-Hill -TerraNova, Second Edition, Complete Battery (CAT). The score used in this research was the NCE total which was a composite score of Reading, Reading Vocabulary, Language, Language Mechanics, Math, Math Computation, Science, Social Studies, Spelling, and Word Analysis scores. The NCE score is similar to the National Percentile (NP), however the NCE scores are equal interval and fit to a normal distribution.

\section{Matrix of Analysis}

Table 4 Matrix of Analysis was a depiction of the data sources and analysis required for answering the research question. The first column illustrates the independent variables and dependent variable of the study. The independent variables were Internet access at home, household income, and the highest level of education attained by mother, father or guardian. The dependent variable was the NCE total score. The Data Sources Column illustrates the two sources of data for this research, survey data and the results of the standardized test scores. The Proposed Analysis indicates the method of a three-way ANOVA. 
Table 4.

Matrix of Analysis

\begin{tabular}{llc}
\hline \multicolumn{1}{c}{ Independent Variables } & \multicolumn{1}{c}{ Data Source } & Proposed Analysis \\
\hline Internet at home by & Survey & A x B x C ANOVA \\
Household income by & (NMHU/GEARUP & \\
Highest level of education & applications), and & \\
attained by mother or & & \\
father or guardian & & Proposed Analysis \\
\hline Dependent Variable & Data Source & A x B x C ANOVA \\
\hline NCE Total test Score & Standardized test scores & \\
& (CTB/McGraw-Hill -Terra & \\
& Nova) & \\
\hline
\end{tabular}

Population and Sample

The population of this study was from two school districts within San Miguel County in northern New Mexico. This population was comprised of households with students who were in grades six to ten in the 2003-04 school years. These two school districts were primarily Hispanic (85\%), and more than $80 \%$ of the student population was receiving free/reduced in school lunch.

Parents of students participating in the San Miguel GEARUP Partnership were required to submit an annual application for their children to participate in the GEARUP program. In excess of $95 \%$ of the households in these two school districts completed the application. A great number of complete datasets existed within the 1,963 applications received in the 2003-2004 school year. A complete dataset was a result of a union of all 
the variables in the study: Internet access at home (yes versus no), family income (\$1$\$ 20,000, \$ 21,000-\$ 30,000, \$ 30,001-\$ 50,001, \$ 50,001+)$ at least one education level of the mother or father or guardian (single highest will be selected), and the standardized test score (NCE Total of the CTB/McGraw-Hill -TerraNova). Only complete datasets were used.

Although the investigator has particular categories he wished to utilize for the independent variables, the availability of data in particular categorical levels may necessitate modifying the categories. The distribution was shaped by the requirements to provide enough data to place all the cells the A x B x C ANOVA. Certain cells, such as the income of $\$ 50,001+$ lead by a high-school education head of household would be difficult to populate with an adequate amount of data. The exact shape (number of rows and columns) of the three-way ANOVA would be determined by the distribution of the data.

\section{Human Subjects Clearance}

Data queried from the NMHU/GEARUP database did not contain information that could link any particular data set to an individual. Anonymity of participants was guarded and respected. Additionally, permission to use data provided on the NMHU/GEARUP application was provided and released by a guardian signature on the application. The two school districts included in this study had provided permission to use data on the standardized tests. Anonymity was further guaranteed by queries of the NMHU/GEARUP database were based upon the use of Globally Unique Identifiers (GUID) as the primary keys. The GUIDs will be replaced with a sequence of unrelated 
numbers (e.g. 1,, 2, 3) to further ensure no particular dataset could be related to any particular participant.

\section{Procedure of Analysis}

1. Identified the test for this study as a 3-way ANOVA;

2. Designed the A x B x C Factorial ANOVA and set significance levels;

3. Queried the San Miguel GEARUP Partnership database for the data to perform the tests;

4. Formatted and entered data into SPSS in the following form as shown in Table 5;

\section{Table 5.}

Sample of Data for Entry into SPSS

\begin{tabular}{ccccc}
\hline ID & $\begin{array}{c}\text { Internet Access } \\
\text { at home }\end{array}$ & $\begin{array}{c}\text { Household } \\
\text { Income }\end{array}$ & $\begin{array}{c}\text { Highest Attained } \\
\text { Education in family }\end{array}$ & NCE Total Score \\
\hline$\# \# \#$ & $(0$ or 1$)$ & $(1,2,3$, or 4$)$ & $(1,2,3$, or 4$)$ & $(1-99)$ \\
1 & 1 & 4 & 3 & 55 \\
2 & 0 & 1 & 2 & 47 \\
3 & 1 & 3 & 2 & 61 \\
\hline $\mathrm{n}$ & A & B & C & \\
\hline
\end{tabular}

5. Conducted ANOVA with SPSS;

6. Tested to ensure assumptions of ANOVA are met;

7. On significant F-test results, performed Scheffé's post hoc analysis; 
8. Specified which main effects and/or interaction(s) were significant by reporting multiple comparisons;

9. Presented conclusions from analysis;

10. Presented findings, conclusions, and recommendations. 


\section{CHAPTER 4 - FINDINGS}

This chapter presents findings from the analysis of data to address the research question: What are the differences among the standardized test scores of students related to factors of Internet access at home, household income, and the highest level of education attained by mother, father or guardian? The first section is a brief discussion of the use of the General Linear Model. This is followed by an explanation of the data used in the analysis. Details will examine the distribution of the data, and the arrangement established for the factorial analyses. The assumptions for an ANOVA are tested. Results of analysis are presented in the order of the portions of the null hypothesis; e.g. main effects and interaction effects. Measures of association are presented. Other analyses are presented because these results present interesting implications on findings; which will be addressed in chapter five. Four analyses, other than the primary analysis on the full dataset, were performed on trimmed datasets: 1) an unbalanced factorial ANOVA, 2) one-way ANOVA performed on main effects, 3) a completely crossed and balanced factorial ANOVA on a severely reduced data set, and; 4) one-way ANOVA on main effects performed with the fully crossed and balanced reduced data set. Finally, this chapter closes with a summary of analyses.

\section{Use the of General Linear Model}

The ANOVA, both factorial and one-way, used the General Linear Model (GLM). The GLM is selected because the data are arranged in categories. The method is essentially a form of regression, evaluating the distance from an "expected mean", however the expected mean is not based upon the slope of a " $y=m x+b$ " sort of line. Instead of determining the "expected value" of y from the x-position, the expected value 
of $y$ is determined by the mean of the category to which the value is assigned. If it were displayed on a Cartesian coordinate system, the $y$-axis is a continuous variable, however the $\mathrm{x}$-axis of data is on a non-continuous scale - due to the data being based upon categorical groupings - as opposed to a continuous scale.

\section{Data Explanation}

The San Miguel GEARUP Database was queried, and produced 572 complete sets of data. The number of complete sets was lower than expected because the selection of a dataset is based upon the highest attained education per household, prior estimates included all education values (up to three per student). The next sections detail how the data distribution was examined to determine the best arrangement for the method of analysis.

\section{Data Queries}

The queries were performed in several steps. First, each factor (Internet, income and education) was queried. These queries used data from the demographics cluster (a set of related vertically integrated tables) and the students table. The results of these three queries were imported into MS Access as separate tables; the native format for the GEARUP archives of standardized test scores. The imported tables were related to the standardized test data and queried for final set results used in the analysis.

The first query was performed to obtain data on Internet access at home. The Structured Query Language (SQL) statement used is shown in APPENDIX B - Internet Access Query. The second query was performed to obtain data on income levels. The SQL statement used is shown in APPENDIX C - Income Query. The third query was performed to obtain data on parent/guardian education levels. The SQL statement used is 
shown in APPENDIX D - Education Query. The results of these three queries were imported into MS Access. The standardized test data were related to the three imported tables. APPENDIX E - NCE Test Scores reveals the SQL statement used to generate a result with data in four fields: Internet, income, education, and NCE score. The final steps to transform the data format for import to SPSS were performed in MS Excel.

\section{Implications of Data Distribution}

The method designated for analysis of data was a factorial ANOVA. The challenge inherent in using the factorial was to arrange for a "completely crossed" design (Hays, 1988, p. 430) where every cell in the matrix contains values. A balanced design also contains an equal n, or number of datasets in each cell. Hays stated a strong preference for arranging data in a completely crossed and balanced arrangement.

The results of the queries distribution are shown in Table 6. Distribution of data Internet access at home, and Table 7. Distribution of data - No Internet access at home. Many of the possible combinations were eliminated because of cells that contain no data. This required combing rows and columns of data to obtain an adequate number of test scores for each cell of the factorial ANOVA. 
Table 6.

Distribution of data - Internet access at home

Total of those with Internet access at home 276

0-10K 10K-20K 20K-30K 30K-40K 40K-50K 50K-60K 60k+

Finished Elementary School

Graduated From High School

Attended College or training after High School

Completed a 2-year college or training program

Completed a 4-year college or University degree

Attended / completed College Graduate Program

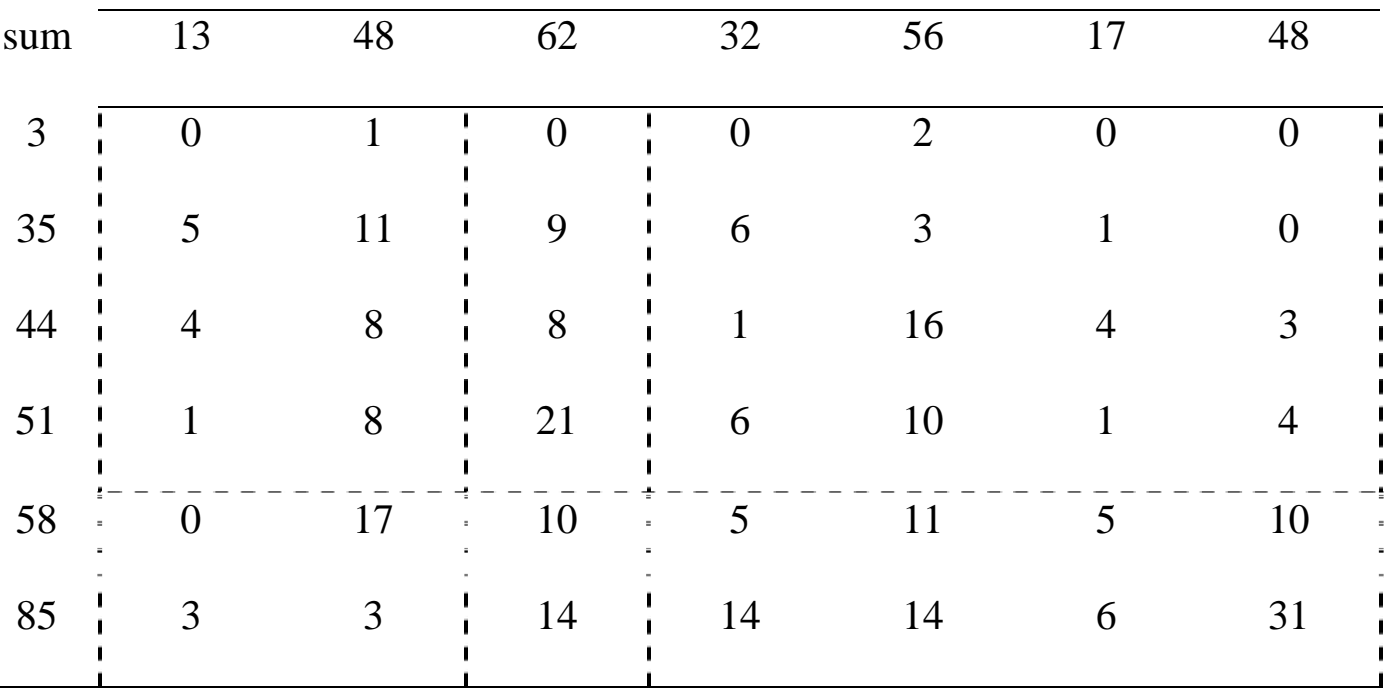

The dashed lines are placed in the table to illustrate the grouping of data. 
Table 7.

Distribution of data - No Internet access at home

Total of those with No Internet access at home

296

0-10K 10K-20K 20K-30K 30K-40K 40K-50K 50K-60K 60k+

\begin{tabular}{llllllll}
\cline { 2 - 7 } & 75 & 74 & 70 & 22 & 18 & 17 & 20
\end{tabular}

Finished Elementary School

Graduated From High School

Attended College or training after High School

Completed a 2-year college or training program

Completed a 4-year college or University degree

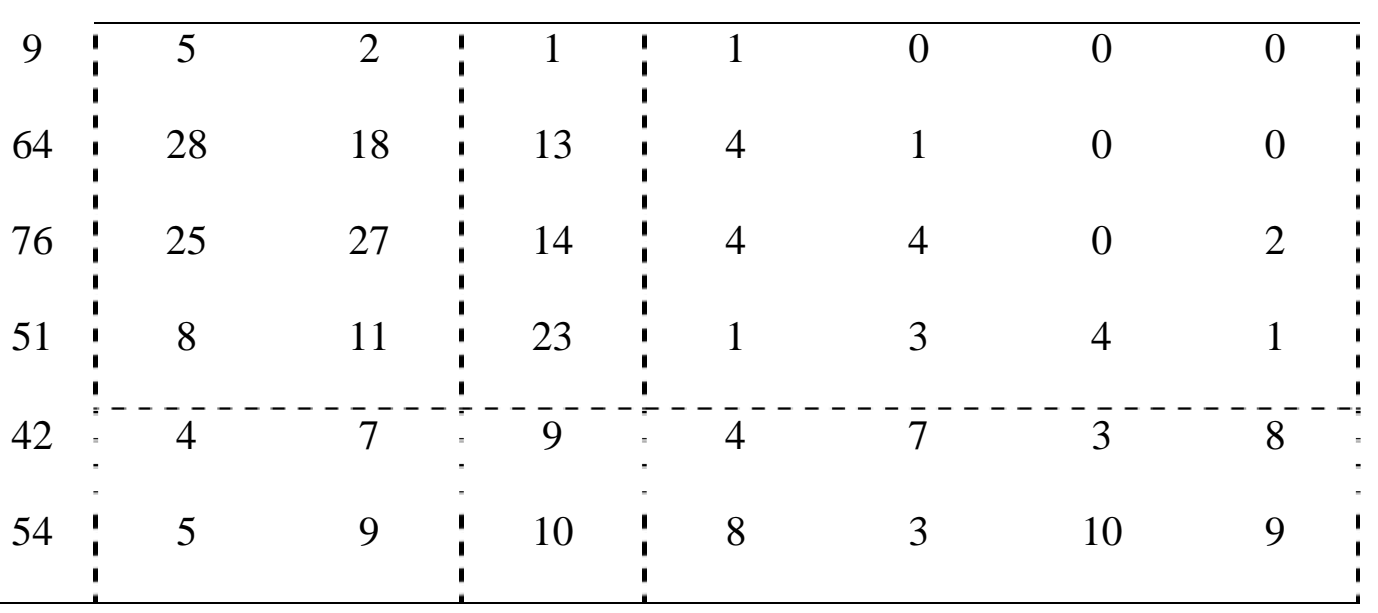

The dashed lines are placed in the table to illustrate the grouping of data. 
Examination of the data in Table 6 and Table 7 revealed certain categories lacked data, most notably on the extremes. For instance, the combination of high income, low education and those without Internet is particularly vacuous. The other area of Table 6 and Table 7 that lacked data were the combination those with higher education and lower incomes. Other distribution issues are split among those with and without Internet access. Such is the case of lowest income category with Internet (13) versus the lowest income category without Internet access (75). The lack of data in these cells necessitated the combining of cells for analyses.

\section{Forming Data for Analysis}

With 13 of the cells in Table 6 and Table 7 containing zeros, i.e. no data, collapsing categories became necessary to form a “completely crossed” design (Hays, 1988, p. 430) where every cell contains values. Given that each cell does not have an equal number of observations, the design is not balanced. Therefore, the design was completely crossed, and unbalanced. Table 8. Distribution of data - Count of data in each cell, illustrates the number of datasets in each cell of the factorial ANOVA arrangement used to analyze that data. The Group without Internet access and with the lowest income and education is the largest cell with 124 datasets. In an attempt to maintain at least 20 observations per cell, the following grouping was derived.

Table 8.

Distribution of data - Count of data in each cell

\begin{tabular}{|c|c|c|c|c|c|c|}
\hline \multirow{4}{*}{$\begin{array}{l}\text { elementary school - high school } \\
\text { some college - } 2 \text { year degree } \\
4 \text { year degree - }\end{array}$} & \multicolumn{3}{|c|}{ Internet access } & \multicolumn{3}{|c|}{ No Internet access } \\
\hline & $\$ 0-20 \mathrm{~K}$ & $\$ 20 \mathrm{~K}-30 \mathrm{~K}$ & $\$ 30 k^{+}$ & $\$ 0-20 K$ & $\$ 20 \mathrm{~K}-30 \mathrm{~K}$ & $\$ 30 k^{+}$ \\
\hline & 38 & 38 & 57 & 124 & 51 & 25 \\
\hline & 23 & 24 & 96 & 25 & 19 & 52 \\
\hline
\end{tabular}


The distribution was arranged according to the dashed rectangles that group cells in Tables 6 and Table 7. The $\mathrm{n}$ for each cell is shown in Table 9. Distribution of Data for Main Effects. The categories for Effect A (Internet access) were Yes versus No. Effect A has a distribution of 276 for those with Internet versus 296 for those without Internet access. The three categories for Effect B (Income) were: 1) \$0-\$20K, 2) \$20K-\$30K, and; 3) \$30k+. Effect B has a distribution of 210 for those in the lowest income, 132 for those in the second category, and 230 for the third category. The two categories for Effect C (education) essentially were divided by those with/without a 4-year degree. The specific categories for Effect C were: 1) elementary school - high school some college 2-year degree, and; 2) 4 year degree -graduate program) Effect $C$ has a distribution of 333 for those with lowest education level and 239 for those with highest education level. Table 9.

Distribution of Data for Main Effects

\begin{tabular}{lcc}
\hline Effect & Category & $\mathrm{n}$ \\
\hline Effect A - Internet access at home & 1 & 276 \\
Effect A - No Internet access at home & 0 & 296 \\
Effect B - \$0-\$20,000 & 1 & 210 \\
Effect B - \$20,001-\$30,000 & 2 & 132 \\
Effect B - \$30,001+ & 3 & 230 \\
Effect C - 2 year degree or less & 1 & 333 \\
Effect C - Bachelor's or greater & 2 & 239 \\
\hline
\end{tabular}




\section{Testing the Assumptions for ANOVA}

Having obtained results, tests were performed to ensure the data met the assumptions for ANOVA. The next three sections address the testing of these assumptions in detail. There are three assumptions for an ANOVA (Wearden, 1991, p. 347). These assumptions are:

1. Normality

2. Homoscedasticity (groups have equal variance)

3. Random assignment.

\section{Assumption of Normality}

The initial step in this process was to generate a histogram on the data. Figure 7, Histogram of NCE scores illustrates a distribution that is generally unimodal, symmetrical, asymptotic to the y-axis, and bell shaped (Wearden, 1991, p. 163).

Wearden (1991) states that more than 99\% of the distribution should dwell between $+/-3$ standard deviations of the mean were calculated (p. 163). The Mean for the NCE on the entire distribution is 46.52 and the standard deviation is 16.02 . The range established with $+/-3$ standard deviations is -3.13 to 94.58 . The number of observations within the range of -3.13 and 94.58 is 569 of the 572 total observations. The result of 569/572 indicates that $99.48 \%$ of the observations are within three standard deviations of the mean. Given the results of this test and the histogram, it was concluded that the distribution is relatively normal. 
Figure 7. Histogram of NCE scores

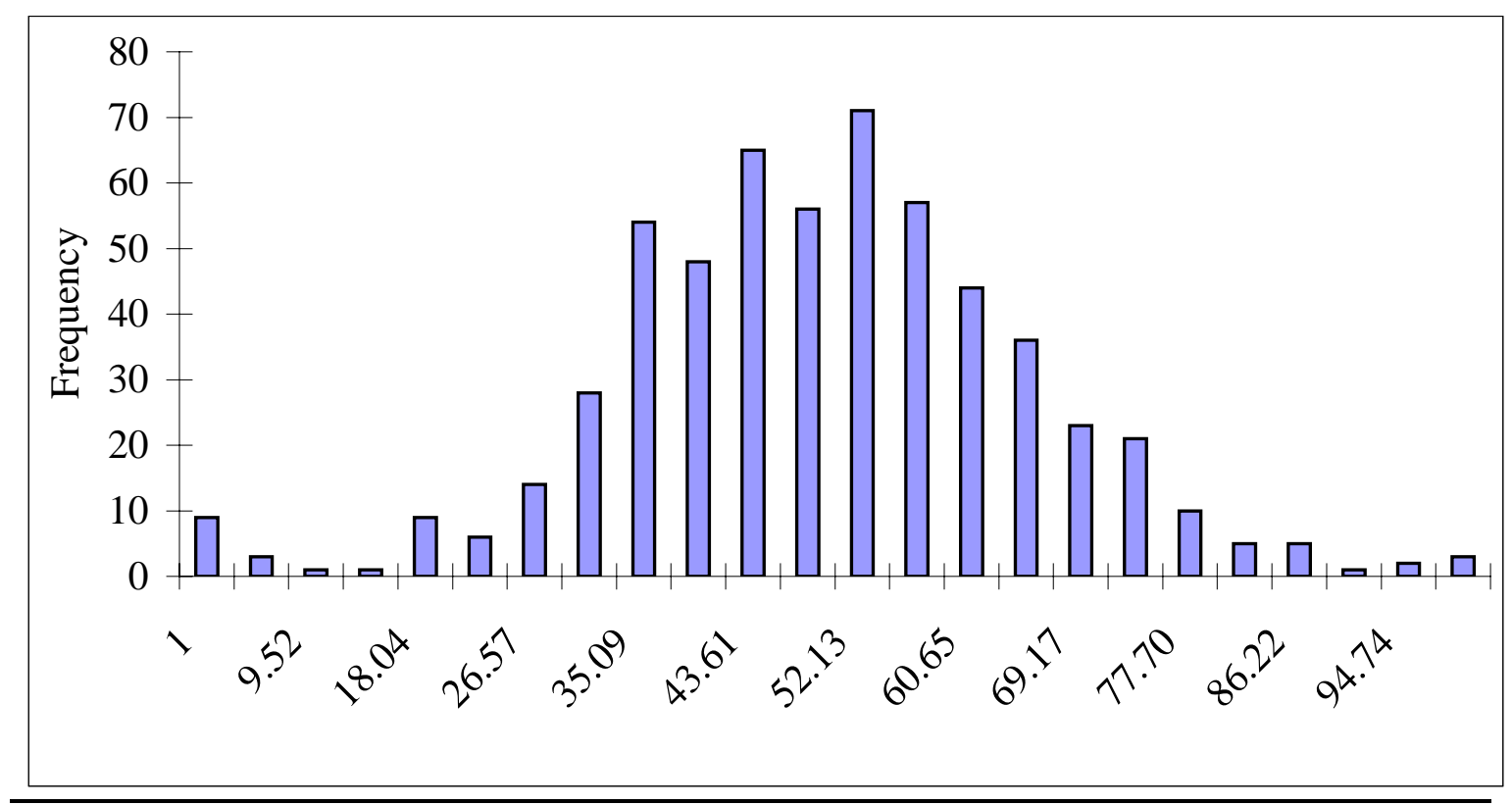

Assumption of Homoscedasticity

Homoscedasticity, equal variance among the groups, can be tested in various ways. A suitable test is Levene's test of homogeneity of variance, which is ... computed by SPSS to test the ANOVA assumption that each group (category) of the independent)(s) has the same variance ... Note, however, that failure to meet the assumption of homogeneity of variances is not fatal to ANOVA, which is relatively robust, particularly when groups are of equal sample size (Garson, 2005, Assumptions section, ๆ 3).

"When the results of this test are significant, that is, the "2-tail Sig." is less than .05 , the assumption has been violated” (Wielkiewicz, 2005, Analysis of Variance with SPSS section, ף 4). This test produced a significance result of $p=0.063$. This was greater than the required 0.05 , therefore the assumption of homogeneity was valid $\left(\mathrm{F}_{11,560}\right.$ 
= 1.732). Full results of this analysis are available in APPENDIX F - Primary Factorial ANOVA.

\section{Assumption of Random Assignment}

This was a post hoc quasi-experimental design because the independent variables were not being randomly assigned to the participants and the data were based upon what has already occurred (survey results from the 2003-04 school year, and test scores from the Spring 2004). This assumption was violated by the nature of the method.

\section{Results of Analysis}

The Null Hypothesis states the means of each row, column and interaction (combination of cells) will be equal. Expressed mathematically:

$$
\mu_{\mathrm{OA}}=\mu_{\mathrm{oB}}=\mu_{\mathrm{oC}}=\mu_{\mathrm{oAB}}=\mu_{\mathrm{oAC}}=\mu_{\mathrm{oBC}}=\mu_{\mathrm{oABC}}
$$

Although a single statement, it essentially was arranged into two broad categories, main effects and interaction effects. Within the main effects, there were three basic statements, and four combinations of interaction effects.

Main effects null hypotheses for the distribution expressed mathematically:

Main effect A: $\mu_{\text {Internet (yes) }}=\mu_{\text {Internet (no) }}$

Main effect B: $\mu_{\text {income }(\$ 1-\$ 20,000)}=\mu_{\text {income }(\$ 20,001-\$ 30,000)}=\mu_{\text {income }(\$ 30,001-+)}$

Main effect C: $\mu_{\text {education (elementary school - high school-some college }-2 \text { year degree) }}=\mu_{\text {education (4 }}$ 
Interaction effects null hypotheses for the distribution expressed mathematically:

Interaction AB: $\mu_{\text {Internet (yes) income }(\$ 1-\$ 20,000)}=\mu_{\text {Internet (yes) income }(\$ 20,001-\$ 30,000)}=\mu$

Internet (yes) income $(\$ 30,001+)=\ldots=\mu_{\text {Internet (no) income }(\$ 20,001-\$ 30,000)}=\mu_{\text {Internet (no) }}$

income $(\$ 30,001+)$

Interaction AC: $\mu_{\text {Internet (yes) education (elementary school - high school-some college }-2 \text { year degree) }}=$

$\ldots=\mu_{\text {Internet (no) education (4 year degree-graduate degree) }}$

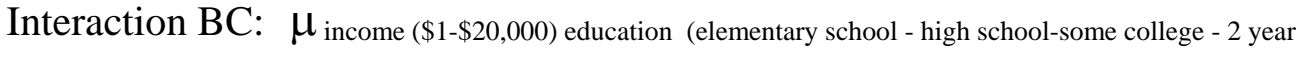

degree) $=\ldots=\mu_{\text {income }(\$ 30,001+) \text { education (4 year degree-graduate degree) }}$

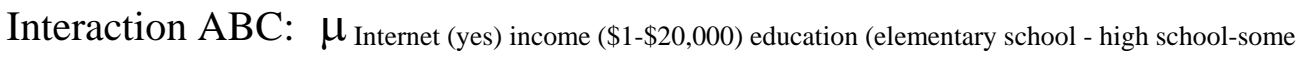

college -2 year degree) $=\ldots=\mu_{\text {Internet }(\text { no) income }(\$ 30,001+) \text { education (4 year degree-graduate }}$

degree)

\section{Main Effects}

The results of each of the three main effects are briefly presented. Results

presented on each main effect are: means, levels of significance and post hoc

comparisons if the results proved to be significant.

Main Effect A (Internet access at home: yes versus no)

The main effect means were very close for those with Internet versus for those without Internet: 47.88 versus 47.74 . These means were not significantly different, $F(1$, $560)=0.008, p=0.931$. The null hypothesis for main effect A failed to reject; therefore the effect of Internet access was not a determinant factor for student NCE test performance. Details are in APPENDIX F - Primary Factorial ANOVA. 
Main Effect B (Income of household: three categories)

The main effect means for the three income categories $\$ 0-\$ 20,000, \$ 20,001$ $\$ 30,000$, and $\$ 30,001+$ were $46.36,47.56$, and 49.52 respectively. These means were not significantly different, $F(2,560)=1.729, p=0.178$. The null hypothesis for main effect B failed to reject; therefore the effect of household income was not a determinant factor for student NCE test performance. Post hoc comparisons were not discussed due to the non-significant result, however such comparisons were performed. Details are in APPENDIX F - Primary Factorial ANOVA.

Main Effect C (Highest level of education attained: two categories)

The main effect means for the two education categories were 44.60 for those with a 2 year post secondary degree or less, and 51.02 for those with a bachelor's degree or greater. These means were significantly different, $F(1,560)=18.250, p<0.001$. The null Hypothesis for the main effect $C$ was rejected; therefore the effect of education level of parent/guardian was a factor related to student NCE test performance. Further details are in APPENDIX F - Primary Factorial ANOVA.

\section{Interaction Effects}

The following results for each interaction effect include the means, and levels of significance. Post hoc comparisons were presented if the results were proven to be significant.

\section{AB Interaction (Internet \& Income)}

The AB Interaction means ranged from a low of 45.15 for those with Internet and the lowest income to a high of 50.63 for those with Internet and the highest income. These means were not significantly different, $F(2,560)=0.901, p=0.407$. The null 
hypothesis for the interaction effect failed to reject; therefore the interaction effect of Internet access and household income was not a determinant factor for student NCE test performance. Graphing the means indicated potential interactions; details are available in APPENDIX G - Primary Interaction Graphs for Factors A\&B. Post hoc comparisons were not discussed due to the non-significant result, however such comparisons were performed. Details are in APPENDIX F - Primary Factorial ANOVA.

\section{AC Interaction (Internet \& Education)}

The AC Interaction means ranged from a low of 43.26 for those without Internet and the lowest education level to a high of 51.54 for those without Internet and the highest education level. These means were not significantly different, $F(1,560)=0.614, p$ $=0.434$. The null hypothesis for the interaction effect failed to reject; therefore the interaction effect of Internet access and the highest attained level education in the household was not a determinant factor for student NCE test performance. Graphing the means indicated a potential interactions; details are available in APPENDIX H - Primary Interaction Graphs for Factors A\&C. Analysis details are in APPENDIX F - Primary Factorial ANOVA.

BC Interaction (Income \& Education)

The BC Interaction means ranged from a low of 42.10 for those with the lowest income and lowest education level to a high of 52.79 for those with the highest income and the highest education level. These means were not significantly different, $F(2,560)$ $=0.612, p=0.542$. The null hypothesis for the interaction effect failed to reject; therefore the interaction effect of household income and the highest attained level education in the household was not a determinant factor for student NCE test 
performance. Graphing the means indicated a potential interactions however the results were not significant; details are available in APPENDIX I - Primary Interaction Graphs for Factors B\&C. Post hoc comparisons were not discussed due to the non-significant result, however such comparisons were performed. Further details are in APPENDIX F Primary Factorial ANOVA.

\section{ABC Interaction (Internet \& Income \& Education)}

The ABC Interaction means ranged from a low of 40.78 for those without Internet, lowest income and lowest education level to a high of 55.67 for those with Internet, the highest income and the highest education level. These means were significantly different, $F(2,560)=3.234, p=0.040$. The null hypothesis for the interaction effect was rejected; therefore the interaction effect of Internet access, household income, and the highest attained level education in the household was a factor related to student NCE test performance. Graphing the means indicated the potential of interactions, and post hoc comparisons evidenced 3 interactions. Details are available in APPENDIX J - Primary Interaction Graphs for Factors A\&B\&C.

Scheffé's Post hoc comparison was too conservative to be of use because the critical difference was larger than most groups; e.g., 53.87. The Scheffé’s Post hoc critical difference was so large due to the large n (572), and the disparate differences among group sizes (ranging from 19 to 124). The critical difference for Tukey’s Post hoc comparison was 12.02. Tukey's test yielded results that indicated 3 differences among the 12 means: 1) those without Internet, lowest income, and lowest education were different from those without Internet, lowest income, and highest education, 2) those without Internet, lowest income, and lowest education were different from those with 
Internet, highest income, and highest education, and; 3) those with Internet, lowest income, and lowest education were different from those with Internet, highest income, and highest education. Details are available in APPENDIX K - Tukey’s Post Hoc Comparison on Primary ABC Interaction.

Measures of Association

The Partial Eta Squared score estimates the portion of the variance due to the factors in the analysis. The Partial Eta Squared scores were all very small. The largest was 0.032 for the main effect on Education - saying that 3.2\% of the variability can be attributed to education differences. The other significant finding, the ABC interaction, was 0.011. All other Partial Eta Squared scores were $>0.006$. By this estimation, only $5.5 \%$ of the variability is explained by the factors of the analysis. Further details are in APPENDIX F - Primary Factorial ANOVA.

\section{Summary of Primary Factorial ANOVA}

There were two significant differences in students NCE total scores: 1) the main effect for the education level of the parent and/or guardian, $F(1,544)=20.412$, $p<$ 0.001, and; 2) the three way interaction of the factors of Internet access at home, household income and highest level of parent education, $F(2,560)=3.234, p=0.040$. The education level of the parent and/or guardian proved to far exceed the level of rejection in this study. It is also worth noting that only $5.5 \%$ of the variability is explained by the factors of the analysis.

One-way ANOVAs on Uncategorized and Categorized Data

The data were collapsed in to coarse categories to meet the requirement of being fully crossed. Revealing results were found in performing one-way ANOVAs on all 
three factors in the raw categorical form. Further, the factorial ANOVA results are based upon the means of each cell, and the n of the cells were different, one-way ANOVAs performed on each of the factors will yield different results than that of the main effects in the factorial ANOVA. 2 sets of one-way ANOVAs are presented to address these issues: 1) 3 one-way ANOVAs on the uncategorized full set data for all three factors, and; 2) 2 one-way ANOVAs on categorized full set data of the factors of income and education.

One-Way ANOVA on Uncategorized Full Set Data

The data were grouped according to the requirements of the factorial ANOVA method in the previous analysis. The groupings were 3 income categories, and 2 education categories. However, there were 7 categories of household income, and 6 categories of highest level of education in the raw data. Internet access had only 2 categories: 1) Yes, and; 2) No. The raw data income categories were: 1) \$0-10,000, 2) $\$ 10,000-20,000,3) \$ 20,000-30,000,4) \$ 30,000-40,000,5) \$ 40,000-50,000,6) \$ 50,000$ 60,000 , and; 7) Above $\$ 60,000$. The raw data highest level of education categories were: 1) Finished Elementary School, 2) Graduated From High School, 3) Attended College or training after High School, 4) Completed a 2-year college or training program, 5) Completed a 4-year degree at a college or University, and; 6) Attended or completed a College Graduate Program.

The next sections present 3 one-way ANOVAs on Internet, Income, and Education with the full dataset, and all the categories of each factor. Post hoc test were performed to determine which categories were different. 


\section{One-Way ANOVA of Uncategorized Internet Access on Full Data Set}

The one-way ANOVA for Internet access at home contained 296 without Internet and 276 with Internet. The means were 45.25 and 49.36 respectively. These means were significantly different, $F(1,570)=9.535, p=0.002$. Levene's test of equality of error variances produced a significance result of $F(1,570=6.836), p=0.009$. This was less than alpha 0.05 , therefore the assumption of homogeneity is invalid and results should be treated with extreme caution. Full results of this analysis are available in APPENDIX L One-way ANOVA on Uncategorized Full Set Data.

\section{One-Way ANOVA of Uncategorized Income on Full Data Set}

The one-way ANOVA for household income contained 7 categories: 1) \$0$10,000,2) \$ 10,000-20,000,3) \$ 20,000-30,000,4) \$ 30,000-40,000,5) \$ 40,000-50,000,6)$ $\$ 50,000-60,000$, and; 7) Above $\$ 60,000$. The $n$ and mean of these categories were: 1 ) $n$ $=88, \mu=40.83,2) \mathrm{n}=122, \mu=45.50,3) \mathrm{n}=132, \mu=46.67,4) \mathrm{n}=54, \mu=51.28,5) \mathrm{n}$ $=74, \mu=43.70,6) \mathrm{n}=34, \mu=51.03$, and; 7) $\mathrm{n}=68, \mu=58.43$. These means were significantly different, $F(6,565)=10.589, p<0.001$. Levene's test of equality of error variances produced a significance result of $F(6,565=2.318), p=0.032$. This was less than alpha 0.05 , therefore the assumption of homogeneity is invalid and results should be treated with caution. Full results of this analysis are available in APPENDIX L - Oneway ANOVA on Uncategorized Full Set Data.

Post hoc comparisons were performed to determine which of the income means were different; there were 7 categories of income. The results of Scheffé's method indicate that the lowest 3 and the5th income categories were different, $p<0.001$, from 
the highest category $(\$ 60,000+)$. Full results of this analysis are available in APPENDIX L - One-way ANOVA on Uncategorized Full Set Data.

\section{One-Way ANOVA of Uncategorized Education Access on Full Data Set}

The one-way ANOVA for education of parent/guardian, contained 6 categories:

1) Finished Elementary School, 2) Graduated From High School, 3) Attended College or training after High School, 4) Completed a 2-year college or training program, 5) Completed a 4-year degree at a college or University, and; 6) Attended or completed a College Graduate Program. The $n$ and mean of these categories were: 1) $n=12, \mu=$ 46.00, 2) $n=99, \mu=41.48,3) n=120, \mu=42.214) n=102, \mu=46.90,5) n=100, \mu$ $=50.66$, and; 6$) \mathrm{n}=139, \mu=53.54$. These means were significantly different, $F(5,566)$ $=11.035, p<0.001$. Levene's test of equality of error variances produced a significance result of $F(5,566=0.707), p=0.618$. This was more than alpha 0.05 , therefore the assumption of homogeneity is valid. Full results of this analysis are available in APPENDIX L - One-way ANOVA on Uncategorized Full Set Data.

Post hoc comparisons were performed to determine which of the parent/guardian education means were different; there were 6 categories of education. The results of Scheffé's method indicate that the 2nd and 3rd education category was different from the top two categories 5 and 6, $p=0.004$ and $p<001, p=0.006$, and $p<001$, respectively. Full results of this analysis are available in APPENDIX L - One-way ANOVA on Uncategorized Full Set Data. Therefore, the parent/guardian education categories were differences centered about the bachelors' level of education. The exception was the lowest group, which had a relatively small $n$. 


\section{One-Way ANOVA on Categorized Full Set Data}

The factorial ANOVA results are based upon the means of each cell. Because the n of the cells were different, one-way ANOVAs performed on the factors of income and education will yield different results than that of the main effects in the factorial ANOVA. Because the factor of Internet access was not collapsed (data was yes versus no) it would yield the same result as the previous section and is not presented here. .

\section{One-Way ANOVA of Categorized Income on Full Data Set}

The one-way ANOVA for household income contained 210 in the lowest income category, 132 in the middle-income category, and 230 in the highest income category. The means were 43.54, 46.67, and 50.93 respectively. These means were significantly different, $F(2,569)=12.178, p<0.001$. Levene's test of equality of error variances produced a significance result of $F(2,569=6.663), p=0.001$. This was less than alpha 0.05, therefore the assumption of homogeneity is invalid and results should be treated with caution. Full results of this analysis are available in APPENDIX M - One-way ANOVA on categorized full set data.

Post hoc comparisons were performed to determine which of the income means were different; there were three categories of income. The results of Scheffé's method indicate that the lowest income and middle-income categories were not different, $p=$ 0.201. The comparisons of the lowest income category and the highest income category were different, $p<0.001$. Comparisons of the middle-income income category and the highest income category were also different, $p=0.048$. Full results of this analysis are available in APPENDIX M - One-way ANOVA on categorized full set data. Therefore, low-income category and the middle-income category were not significantly different. 
However, the low-income category and the high-income category were significantly different, and the middle-income category and the high-income category were significantly different.

One-Way ANOVA of Categorized Education Access on Full Data Set

The one-way ANOVA for the factor C, Education of Parent/Guardian, contained 333 in the category with a 2-year degree or less and 239 in the category with a bachelor's or greater. The means were 43.57 and 52.33 respectively. These means were significantly different, $F(1,570)=44.812, p<0.001$. Levene's test of equality of error variances produced a significance result of $F(1,570=0.789), p=0.375$. This was greater than alpha 0.05 , therefore the assumption of homogeneity is valid. Full results of this analysis are available in APPENDIX M - One-way ANOVA on categorized full set data.

Summary of One-way ANOVAs on Uncategorized and Categorized Data

The results from all these analyses were very significant; $p<0.001$. However, Internet and income, both uncategorized and categorized, broke the assumption of homogeneity. These findings support the literature presented in chapter 2.

Results of Further Analysis with Outliers Removed

Two troubling features existed in the data from the primary analysis: 1) an excess number of outlying data points, and the assumption of homoscedasticity could be challenged by other methods. The following sections and analyses present findings that are a result of trimming questionable data. Other analyses presented address issues with the design of the factorial model; namely the design being unbalanced. 


\section{Assumption of Homoscedasticity Part 2}

An additional test to prove that groups have equal variance is Hartley's Test for Homogeneity of Variance as specified by Wearden (1991, p. 350-351) \& Winer (1971, p. 206-208) to prove homoscedasticity. The null hypothesis for Hartley’s Test is that the variances of the groups are equal as illustrated in Equation 1.

$$
H o: \sigma_{1}^{2}=\sigma_{2}^{2}=\sigma_{3}^{2}=\sigma_{n}^{2}
$$

The critical $\mathrm{F}_{\max }$ Statistics illustrated in Equation 2 show the range of rejection. Commonly published tables (Wearden, 1991, p. 591, Winer, 1971, p. 875), contain distribution tables for the $F_{\max }$ Statistic in a range up to 12 groups and 60 observations. 46.3 was the average number of observations in the cells of the distribution. Tables display a critical statistic for 30 and then 60 degrees of freedom. Given that the number of degrees of freedom for this distribution fell between the available critical statistics, both are displayed. If the distribution meets the more rigorous number, then homoscedasticity is proven.

$$
F_{\text {max }_{01,12,60}}=2.7 \text { to } F_{\text {max }_{.01,12,30}}=4.2
$$

The average degrees of freedom were greater than 30. Equation 3 details results that indicate that the critical statistic for 30 degrees of freedom was not met. Therefore, the second assumption for ANOVA, homoscedasticity, was not met.

$$
F_{\max }=\frac{\text { LargestVariance }}{\text { SmallestVariance }}=\frac{371.49}{78.48}=4.73<F_{\text {max }_{.01,12,30}}=4.2
$$

To meet the homoscedasticity requirement, data from both ends were removed, such that the distribution would be of equal variance. A quick glance at the histogram 
indicates an abundance of data on the extremes. Precisely, 9 values of “ 1 ”, and 3 values of “99” were removed. Additionally, these values did not seem to be valid -- perhaps these students did not understand the directions to the test, or purposefully answered incorrectly. For these reasons, homoscedasticity and validity, these data were removed or trimmed from both ends as specified by Winer (1971, p. 51). The calculated result of Equation 4 indicated the critical value might have been in the proper range. The value is valid for 30 degrees of freedom, but not 60 degrees of freedom. Because the average degrees of freedom were near 45 , the value may or may not have met the requirement.

$$
F_{\max }=\frac{\text { LargestVariance }}{\text { SmallestVariance }}=\frac{291.15}{73.61}=3.95<F_{\text {max }_{.01,12,30}}=4.2
$$

Levene's test of equality of error variances was performed on the first data trim set, which had the 9 values of 1 , and 3 values of 99 removed. Levene's test of homogeneity of variance produced a significance result of $p=0.026$. This was less than the required 0.05, therefore the assumption of homogeneity was invalid $\left(F_{11,548}=2.009\right)$. Full results of this analysis are available in APPENDIX N - Analysis: First Trimmed Dataset.

Because the homoscedasticity requirement was still not yet met, the data were trimmed again to $+/-3$ standard deviations of the mean. This resulted in removing two scores of “3”, and two scores of "92”. The second factorial ANOVA produced an acceptable result of Levene's test of equality of error variances, $p=0.052$. That result was greater than alpha 0.05 ; therefore the assumption of homogeneity is valid $\left(\mathrm{F}_{11,544}=\right.$ 1.794). Full results of this analysis are available in APPENDIX O - Unbalanced Factorial ANOVA. With the improved trim homoscedasticity is met. The results from this 
improved set (second trim) were used for analysis of data. As for the concerns of normality, with this data set, $100 \%$ of the distribution is $+/-3$ standard deviations. Figure 8. Histogram of NCE scores after second trim illustrates the new distribution.

Figure 8. Histogram of NCE scores after second trim

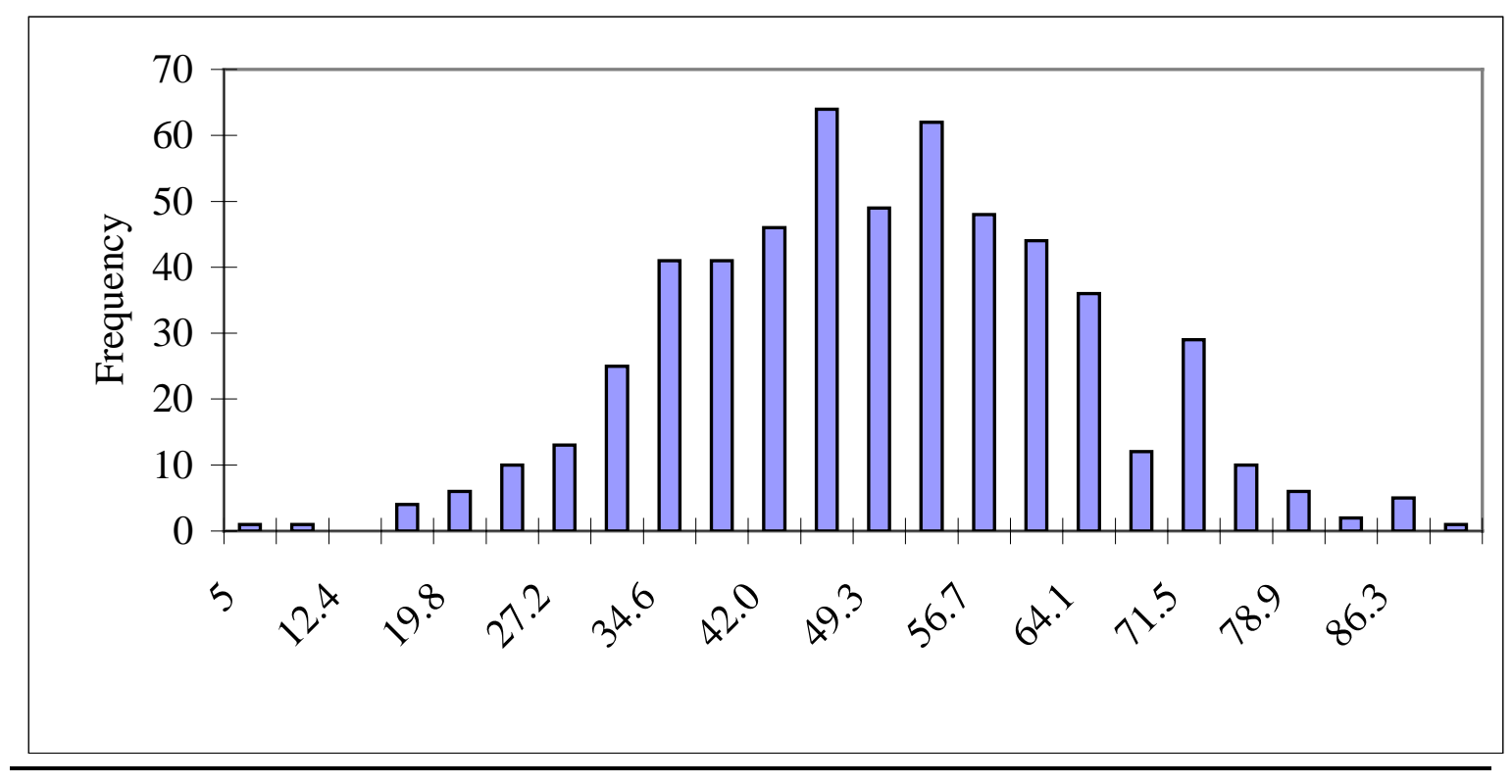

\section{Data for Further Analyses}

The distribution was arranged according to the dashed rectangles that group cells in table 6 and table 7. The results of the data trimming process are show in Table 10. Distribution of Data for Main Effects $2^{\text {nd }}$ Trim. The data removed was nearly even (9 and 7) for Effect A. Effect A had a distribution of 267 for those with Internet versus 289 for those without Internet access. The data removed for Effect B was 4 in the first category, 1 in the second category, and 11 in the third category. Effect B has a distribution of 206 for those in the lowest income, 131 for those in the second category, and 219 for the third category. The data removed for Effect $\mathrm{C}$ was 12 in the first category, and 4 in the second category. Effect C has a distribution of 321 for those with lowest education level and 235 for those with highest education level. 
Table 10.

Distribution of Data for Main Effects 2nd Trim

\begin{tabular}{lcccc}
\hline Effect & Category & Full Set & $2^{\text {nd }}$ Trim & Change \\
\hline Effect A - Internet access at home & 1 & 276 & 267 & 9 \\
Effect A - No Internet access at home & 0 & 296 & 289 & 7 \\
Effect B - \$0-\$20,000 & 1 & 210 & 206 & 4 \\
Effect B - \$20,001-\$30,000 & 2 & 132 & 131 & 1 \\
Effect B - \$30,001+ & 3 & 230 & 219 & 11 \\
Effect C - 2 year degree or less & 1 & 333 & 321 & 12 \\
Effect C - Bachelor’s or greater & 2 & 239 & 235 & 4 \\
\hline
\end{tabular}

Table 11. Distribution of data - Count in each cell illustrates the $\mathrm{n}$ of each cell to be used in the analysis of data. Originally, each cell was targeted to have at least 20 observations. This was nearly achieved; only one cell contained less than 20. Those without Internet, in the \$20,001-\$30,000 income category and with a bachelor’s degree or greater comprise a group of 19. Four other groups were near the requirement of 20 that contained between 23 and 25 observations. Two groups had a much larger number of observations. Those without Internet, $\$ 0-\$ 20,000$ income and a 2 year degree or less comprise a group of 121 . Also worth noting is the group with Internet, $\$ 30,001+$ income, and bachelor's or greater whom comprise a group of 94. Comparison of cells such as those with/without Internet and low income and low education reveals a difference of 84 (37 versus 121). Because the factorial ANOVA compares the means of the cells, the effect of different numbers of observations with cells will only affect the degrees of freedom. 
Table 11.

Distribution of data - Count in each cell

\begin{tabular}{|c|c|c|c|c|c|c|}
\hline \multirow[b]{3}{*}{$\begin{array}{l}\text { elementary school - high school } \\
\text { some college - } 2 \text { year degree }\end{array}$} & \multicolumn{3}{|c|}{ Internet access } & \multicolumn{3}{|c|}{ No Internet access } \\
\hline & $\$ 0-20 \mathrm{~K}$ & $\$ 20 \mathrm{~K}-30 \mathrm{~K}$ & $\$ 30 \mathrm{k}^{+}$ & $\$ 0-20 \mathrm{~K}$ & $\begin{array}{l}\$ 20 \mathrm{~K}- \\
30 \mathrm{~K}\end{array}$ & $\$ 30 \mathrm{k}^{+}$ \\
\hline & 37 & 38 & 51 & 121 & 50 & 24 \\
\hline $\begin{array}{l}4 \text { year degree - } \\
\text { graduate program }\end{array}$ & 23 & 24 & 94 & 25 & 19 & 50 \\
\hline
\end{tabular}

\section{Unbalanced Main Effects}

The results of each of the three main effects are briefly presented. Results presented on each main effect are: means, levels of significance and post hoc comparisons if the results proved to be significant.

Unbalanced Main Effect A (Internet access at home: yes versus no)

The main effect means were very close for those with Internet versus for those without Internet: 48.37 versus 47.69 . These means were not significantly different, $F(1$, $544)=0.261, p=0.610$. The null hypothesis for the main effect A failed to reject; therefore the effect of Internet access was not a determinant factor for student NCE test performance. Details are in APPENDIX O - Unbalanced Factorial ANOVA.

Unbalanced Main Effect B (Income of household: three categories)

The main effect means for the three income categories $\$ 0-\$ 20,000, \$ 20,001$ $\$ 30,000$, and $\$ 30,001+$ were $46.89,47.78$, and 49.41 respectively. These means were not significantly different, $F(2,544)=1.389, p=0.248$. The null hypothesis for the main effect B failed to reject; therefore the effect of household income was not a determinant factor for student NCE test performance. Post hoc comparisons were not discussed due 
to the non-significant result, however such comparisons were performed. Details are in APPENDIX O - Unbalanced Factorial ANOVA.

Unbalanced Main Effect C (Highest level of education attained: two categories)

The main effect means for the two education categories were 45.02 for those with a 2 year post secondary degree or less, and 51.03 for those with a bachelor's degree or greater. These means were significantly different, $F(1,544)=20.412, p<0.001$. The null hypothesis for the main effect $\mathrm{C}$ was rejected; therefore the effect of education level of parent/guardian was a factor related to student NCE test performance. Further details are in APPENDIX O - Unbalanced Factorial ANOVA.

\section{Unbalanced Interaction Effects}

The following results for each interaction effect include the means, and levels of significance. Post hoc comparisons were presented if the results were proven to be significant.

\section{Unbalanced AB Interaction (Internet \& Income)}

The AB Interaction means ranged from a low of 45.72 for those with Internet and the lowest income to a high of 51.52 for those with Internet and the highest income. These means were not significantly different, $F(2,544)=2.337, p=0.098$. The null hypothesis for the interaction effect failed to reject; therefore the interaction effect of Internet access and household income was not a determinant factor for student NCE test

performance. Graphing the means indicated potential interactions; details are available in APPENDIX P - Unbalanced Interaction Graphs for Factors A\&B. Post hoc comparisons were not discussed due to the non-significant result, however such comparisons were performed. Details are in APPENDIX O - Unbalanced Factorial ANOVA. 


\section{Unbalanced AC Interaction (Internet \& Education)}

The AC Interaction means ranged from a low of 43.85 for those without Internet and the lowest education level to a high of 51.53 for those without Internet and the highest education level. These means were not significantly different, $F(1,544)=1.591$, $p=0.208$. The null hypothesis for the interaction effect failed to reject; therefore the interaction effect of Internet access and the highest attained level education in the household was not a determinant factor for student NCE test performance. Graphing the means indicated a potential interactions; details are available in APPENDIX Q Unbalanced Interaction Graphs for Factors A\&C. Analysis details are in APPENDIX O Unbalanced Factorial ANOVA.

\section{Unbalanced BC Interaction (Income \& Education)}

The BC Interaction means ranged from a low of 43.17 for those with the lowest income and lowest education level to a high of 52.81 for those with the highest income and the highest education level. These means were not significantly different, $F(2,544)$ $=0.651, p=0.522$. The null hypothesis for the interaction effect failed to reject; therefore the interaction effect of household income and the highest attained level education in the household was not a determinant factor for student NCE test performance. Graphing the means indicated a potential interactions however the results were not significant; details are available in APPENDIX R - Unbalanced Interaction Graphs for Factors B\&C. Post hoc comparisons were not discussed due to the nonsignificant result, however such comparisons were performed. Further details are in APPENDIX O - Unbalanced Factorial ANOVA. 


\section{Unbalanced ABC Interaction (Internet \& Income \& Education)}

The ABC Interaction means ranged from a low of 41.77 for those without Internet, lowest income and lowest education level to a high of 55.67 for those with Internet, the highest income and the highest education level. These means were not significantly different, $F(2,544)=2.453, p=0.087$. The null hypothesis for the interaction effect failed to reject; therefore the interaction effect of Internet access, household income, and the highest attained level education in the household was not a determinant factor for student NCE test performance. Graphing the means indicated the potential of interactions, however, the results were not significant. Details are available in APPENDIX S - Unbalanced Interaction Graphs for Factors A\&B\&C. Post hoc comparisons were not discussed due to the non-significant result, however such comparisons were performed. Further details are in APPENDIX O - Unbalanced

\section{Factorial ANOVA.}

\section{Unbalanced Measures of Association}

The Partial Eta Squared scores were all very small. The largest was 0.036 for the main effect on Education - saying that 3.6\% of the variability can be attributed to education differences. Both the Internet-income interaction and the Internet-incomeeducation interaction have a Partial Eta Squared value of 0.009 - almost $1 \%$ of the variability can be attributed to each of these interactions. By this estimation, only $6.4 \%$ of the variability is explained by the factors of the analysis. Further details are in APPENDIX O - Unbalanced Factorial ANOVA. 


\section{Summary of Unbalance Factorial ANOVA}

The only significant difference in students’ NCE total score was the main effect for the education level of the parent and/or guardian. It proved to far exceed the level of rejection in this study, $F(1,544)=20.412, p<0.001$. The other result that proved close was the three-way interaction of all independent variables, $F(2,544)=2.453, p=0.087$. Although the result was not significant, it is of interest because it indicates a weak link to support the notion that an interaction of all the factors contributes to student NCE test performance.

\section{Other Analysis}

The unbalanced factorial ANOVA compares the means of the cells, and it will yield a different main effect result than a one-way ANOVA performed upon the same data. Essentially factorial ANOVA does not perform a weighting for of the distribution of groups. Because of this difference, results from one-way ANOVA on the data of main effects are presented.

An additional ABC factorial ANOVA was conducted. In this factorial ANOVA the cells were balanced. Hays (1988, p. 430) \& Winer (1971, p. 314) expressed an extreme preference for a factorial ANOVA design that is both fully crossed and balanced. Thus, the results of a fully crossed and balanced factorial ANOVA can be contrasted with the crossed-unbalanced factorial ANOVA. Table 12. Differences in $n$ of cells shows the difference in the number of observations between the unbalanced and the fully crossed and balanced factorial ANOVA. The extreme differences are exemplified in the cell for those without Internet access and the lowest income and education, containing 102 more data points than the extreme least populated cell. 
Table 12.

Differences in $n$ of cells

\begin{tabular}{|c|c|c|c|c|c|c|}
\hline & \multicolumn{3}{|c|}{ Internet access } & \multicolumn{3}{|c|}{ No Internet access } \\
\hline & $\$ 0-20 K$ & $\$ 20 K-30 K$ & $\$ 30 \mathrm{k}+$ & $\$ 0-20 K$ & $\$ 20 K-30 K$ & $\$ 30 \mathrm{k}+$ \\
\hline $\begin{array}{l}\text { elementary school - high school } \\
\text { some college - } 2 \text { year degree }\end{array}$ & 18 & 19 & 32 & 102 & 31 & 5 \\
\hline $\begin{array}{l}4 \text { year degree - } \\
\text { graduate program }\end{array}$ & 4 & 5 & 75 & 6 & - & 31 \\
\hline
\end{tabular}

Finally, another set of one-way ANOVAs was performed with the data used from the fully crossed and balanced factorial ANOVA. The differences of $n$ in certain categories could have "pulled" the results to favor a category with a greater $n$ than other categories, and the lack equality of variance was also a concern with the results of the first set of one-way ANOVAs. The results of these one-way ANOVA analyses of the fully crossed and balanced data set were compared to the results of the both fully crossedunbalanced and fully crossed-balanced factorial ANOVA.

\section{One-way ANOVA on Main effects}

One-way ANOVA analyses were conducted on each of the factors with the same data used to calculate the main effects in the Factorial ANOVA. Specifically, the second trimmed set that met the requirements for ANOVA. Each one-way ANOVA produced results significant beyond 0.001. Details of this analysis are in APPENDIX T - One-Way ANOVA for Factors A, B, \& C.

One-Way ANOVA for Internet Access

The one-way ANOVA for the factor A, Internet access at home, contained 289 without Internet and 267 with Internet. The means were 45.63 and 49.93 respectively. 
These means were significantly different, $F(1,544)=13.057, p<0.001$. Levene's test of equality of error variances produced a significance result of $F(1,554=7.389), p=$ 0.007. This was less than alpha 0.05 , therefore the assumption of homogeneity is invalid and results should be treated with extreme caution. Full results of this analysis are available in APPENDIX T - One-Way ANOVA for Factors A, B, \& C.

One-Way ANOVA for Income

The one-way ANOVA for the factor B, household income, contained 206 in the lowest income category, 131 in the middle-income category, and 219 in the highest income category. The means were 44.37, 47.02, and 51.23 respectively. These means were significantly different, $F(2,554)=13.208, p<0.001$. Levene's test of equality of error variances produced a significance result of $F(2,553=3.375), p=0.035$. This was less than alpha 0.05 , therefore the assumption of homogeneity is invalid and results should be treated with caution. Full results of this analysis are available in APPENDIX T - One-Way ANOVA for Factors A, B, \& C.

Post hoc comparisons were performed to determine which of the income means were different; there were three categories of income. The post hoc comparison will determine which categories are significantly different. Scheffé's method for comparing means was selected because it is regarded as conservative method (Hays, 1988, p. 415418, Wearden, 1991, p. 308-309). Scheffé’s method for comparing means uses a null hypothesis stating two other means combined and divided by two equal the mean being examined for difference. Stated mathematically in illustrated in Equation 5:

$$
H_{o}: \mu_{1}-\frac{\mu_{2}}{2}-\frac{\mu_{3}}{2}=0
$$


The results of Scheffé's method indicate that the lowest income and middleincome categories were not different, $p=0.232$. The comparisons of the lowest income category and the highest income category were different, $p<0.001$. Comparisons of the middle-income category and the highest income category were also different, $p=0.023$. Full results of this analysis are available in APPENDIX T - One-Way ANOVA for Factors A, B, \& C. Therefore, low-income category and the middle-income category were not significantly different. However, the low-income category and the high-income category were significantly different, and the middle-income category and the highincome category were significantly different. One-Way ANOVA for Education of Parent/Guardian

The one-way ANOVA for the factor C, Education of Parent/Guardian, contained 321 in the category with a 2-year degree or less and 235 in the category with a bachelor's or greater. The means were 44.29 and 52.36 respectively. These means were significantly different, $F(1,254)=47.733, p<0.001$. Levene's test of equality of error variances produced a significance result of $F(1,554=3.983), p=0.046$. This was less than alpha 0.05 , therefore the assumption of homogeneity is invalid however, it is within the range of rounding error. Full results of this analysis are available in APPENDIX T One-Way ANOVA for Factors A, B, \& C. Summary of One-way ANOVA

The results from all three analyses were significant, though two broke the assumption of homogeneity. Levene's test of equality of error variances was very close for education, $p=0.046$ within rounding error for the expected 0.050 . Income was also 
close, $p=0.035$, however Internet was not close, $p=0.007$. These results support the results of the unbalance factorial ANOVA.

\section{Results of the Fully Crossed and Balanced Factorial AVOVA}

To balance a factorial ANOVA each cell must have an equal n; contain the same number of data sets. In this case, the n of each cell as set to the smallest complete data set of 19; the group without Internet, income of $\$ 20,001-\$ 30,000$, and an education level of bachelor's or greater. The other cells were populated with pseudo-random selections from their complete datasets containing similar means and variances. The selection was based upon the mean and standard deviation being within a range of 1.00 of the original values for the entire dataset.

For this fully crossed and balanced distribution, Levene's test of equality of error variances produced a result of $F(11,216=1.248), p=0.257$. This was greater than

alpha 0.05 , therefore the assumption of homogeneity is valid. Full results of this analysis are available in APPENDIX U - Fully Crossed and Balanced A\&B\&C Factorial ANOVA.

Main Effects of the Fully Crossed and Balanced Factorial AVOVA

The results of each of the three main effects of the fully crossed and balanced factorial AVOVA are briefly presented. Results on each main effect included the means, levels of significance and post hoc comparisons if the results proved to be significant. Fully Crossed and Balanced Main Effect A (Internet)

The main effect means were very close for those without Internet versus for those with Internet: 47.79 versus 48.83 . These means were not significantly different, $F(1$, 216) $=0.331, p=0.566$. The null hypothesis for the main effect A failed to reject; 
therefore the effect of Internet access was not a determinant factor for student NCE test performance. Details are in APPENDIX U - Fully Crossed and Balanced A\&B\&C Factorial ANOVA.

\section{Fully Crossed and Balanced Main Effect B (Income)}

The main effect means for the three income categories $\$ 0$-\$20,000, \$20,001$\$ 30,000$, and $\$ 30,001+$ were $46.79,48.03$, and 50.11 respectively. These means were not significantly different, $F(2,216)=1.155, p=0.317$. The null hypothesis for the main effect B failed to reject; therefore the effect of household income was not a determinant factor for student NCE test performance. Post hoc comparisons were not discussed due to the non-significant result, however such comparisons were performed. Details are in APPENDIX U - Fully Crossed and Balanced A\&B\&C Factorial ANOVA. Fully Crossed and Balanced Main Effect C (Education)

The main effect means for the two education categories were 45.49 for those with a 2 year post secondary degree or less, and 51.12 for those with a bachelor's degree or greater. These means were significantly different, $F(1,216)=9.787, p=0.002$. The null hypothesis for the main effect $\mathrm{C}$ was rejected; therefore the effect of education level of parent/guardian was a factor related to student NCE test performance. Further details are in APPENDIX U - Fully Crossed and Balanced A\&B\&C Factorial ANOVA. Interaction Effects of the Fully Crossed and Balanced Factorial AVOVA

The results of each of the fully crossed and balanced factorial AVOVA interaction effects will be briefly presented. Results on each interaction effect included the means, levels of significance and post hoc comparisons if the results proved to be significant. 


\section{Fully Crossed and Balanced AB Interaction (Internet \& Income)}

The AB Interaction means ranged from a low of 45.95 for those with Internet and the lowest income to a high of 52.32 for those with Internet and the highest income. These means were not significantly different, $F(2,216)=0.993, p=0.372$. The null hypothesis for the interaction effect $A B$ failed to reject; therefore the interaction effect of Internet access and household income was not a determinant factor for student NCE test performance. Post hoc comparisons were not discussed due to the non-significant result, however such comparisons were performed. Details are in APPENDIX U - Fully Crossed and Balanced A\&B\&C Factorial ANOVA. Fully Crossed and Balanced AC Interaction (Internet \& Education)

The AC Interaction means ranged from a low of 44.04 for those without Internet and the lowest education level to a high of 51.54 for those without Internet and the highest education level. These means were not significantly different, $F(1,216)=1.087$, $p=0.298$. The null hypothesis for the interaction effect AC failed to reject; therefore the interaction effect of Internet access and the highest attained level education in the household was not a determinant factor for student NCE test performance. Further details are in APPENDIX U - Fully Crossed and Balanced A\&B\&C Factorial ANOVA. Fully Crossed and Balanced BC Interaction (Income \& Education)

The BC Interaction means ranged from a low of 43.21 for those lowest income and lowest education level to a high of 53.29 for those with the highest income and the highest education level. These means were not significantly different, $F(2,216)=0.411$, $p=0.663$. The null hypothesis for the interaction effect BC failed to reject; therefore the interaction effect of household income and the highest attained level education in the 
household was not a determinant factor for student NCE test performance. Post hoc comparisons were not discussed due to the non-significant result, however such comparisons were performed. Further details are in APPENDIX U - Fully Crossed and Balanced A\&B\&C Factorial ANOVA. Fully Crossed and Balanced ABC Interaction (Internet \& Income \& Education)

The ABC Interaction means were ranged from a low of 40.84 for those without Internet, lowest income and lowest education level to a high of 56.74 for those with Internet, the highest income and the highest education level. These means were not significantly different, $F(2,216)=2.037, p=0.133$. The null hypothesis for the interaction effect failed to reject; therefore the interaction effect of Internet access, household income, and the highest attained level education in the household was not a determinant factor for student NCE test performance. Post hoc comparisons were not discussed due to the non-significant result, however such comparisons were performed. Further details are in APPENDIX U - Fully Crossed and Balanced A\&B\&C Factorial ANOVA.

\section{Fully Crossed and Balanced Measures of Association}

The Partial Eta Squared scores were all very small. The largest was 0.043 for the main effect on education, indicating that $4.3 \%$ of the variability can be attributed to education differences. Internet-income-education interaction had a Partial Eta Squared value of 0.019 - almost $2 \%$ of the variability can be attributed to this interaction. Internet-income interaction had a Partial Eta Squared value of 0.011 - about $1 \%$ of the variability can be attributed to this interaction. By this estimation, only $9.3 \%$ of the variability was explained by the factors of the analysis. Conversely, $90 \%$ of the 
variability in the NCE total score is apparently due to factors not considered in this research. Further details are in APPENDIX U - Fully Crossed and Balanced A\&B\&C Factorial ANOVA.

Summary of the Fully Crossed and Balanced Factorial AVOVA

Although the dataset was severely trimmed the results were essentially the same as the first unbalanced factorial ANOVA. Levene's test of equality of error variances produced a far better result, $F(1,216)=1.248, p=0.257$, which was much greater than the required 0.05 . The only independent variable which had a significant effect on the dependent variable was education, $F(1,216)=9.787, p=0.002$. This value far exceeded the established alpha of 0.05 . No other result was close to the required alpha. While these results were essentially the same findings as the unbalanced factorial ANOVA, however in this analysis the homoscedasticity assumption was clearly met.

\section{One-Way ANOVA Results with Fully Crossed and Balanced Data}

Because two of the three of the first three one-way ANOVA analyses did not meet the requirement of homoscedasticity, it is prudent to calculate results based upon the fully crossed and balanced data set. This dataset possessed means and variances similar to the original set, and contained only 19 samples per cell. In the prior analysis, Fully Crossed and Balanced Factorial AVOVA, the findings were similar to the unbalanced factorial ANOVA, however the homoscedasticity assumption was improved. The prior one-way ANOVA produced lower $\mathrm{p}$ values, however the homoscedasticity requirement was broken for two of the factors. The next three sections present the results of those analyses. 
One-way ANOVA for Internet Access With Fully Crossed and Balanced Data

The one-way ANOVA for the factor A, Internet access at home, contained 114 without Internet and 114 with Internet. The means were 47.79 and 48.82 respectively. These means were not significantly different, $F(1,226)=0.317, p=0.574$. Levene's test of equality of error variances produced a significance result of $F(1,226=1.684), p=$ 0.196. This was grater than 0.05 , therefore the assumption of homogeneity is valid. Full results of this analysis are available in APPENDIX V - One-Way ANOVA - Balanced Data.

One-way ANOVA for Income With Fully Crossed and Balanced Data

The one-way ANOVA for the factor B, household income, contained 76 in the lowest income category, 76 in the middle-income category, and 76 in the highest income category. The means were $46.79,48.03$, and 50.11 respectively. These means were not significantly different, $F(2,225)=1.110, p=0.311$. Levene's test of equality of error variances produced a significance result of $F(2,225=2.097), p=0.125$. This was greater than 0.05 , therefore the assumption of homogeneity is valid. A post hoc comparison was not performed because the result was not significant. Full results of this analysis are available in APPENDIX V - One-Way ANOVA - Balanced Data. One-way ANOVA for Education of Parent/Guardian With Fully Crossed and Balanced Data

The one-way ANOVA for the factor C, Education of Parent/Guardian, contained 114 in the category with a 2-year degree or less and 114 in the category with a bachelor's or greater. The means were 45.49 and51.12 respectively. These means were significantly different, $F(1,226)=9.760, p=0.002$. Levene's test of equality of error 
variances produced a significance result of $F(1,226=0.005), p=0.942$. This was greater than 0.05 , therefore the assumption of homogeneity is valid. Full results of this analysis are available in APPENDIX V - One-Way ANOVA - Balanced Data. Summary of One-way ANOVA Results with Fully Crossed and Balanced Data

Education of Parent/Guardian proved to be a significant factor $(F(1,226)=9.760$, $p=0.002)$ in the analysis of the data, even when the data had been severely trimmed. The assumption of homogeneity was valid; $p=0.942$. While the other two factors, Internet access and household income were not significant; the assumption of homogeneity was valid for both.

\section{Summary of Analyses}

Many analyses were presented in this chapter. Table 13. Summary of Analyses is provided to briefly summarize these findings. Results that were valid and significant are indicated with an X. The cells indicated with “*” did calculate significant results, however, they did not meet the assumption of Homoscedasticity (groups have equal variance); therefore those results should be treated cautiously. It is worth noting that the One-way ANOVA on Unbalanced Factorial data for education was rounded up to meet the assumption of Homoscedasticity; the calculated value was $p=0.047$ and needed to meet or exceed 0.050 .

The significant $\mathrm{ABC}$ interaction, $F(2,560)=3.234, p=0.040$, in the primary analysis included outliers. After the outliers were removed, the other two three-way interactions were not significant; $p=0.087$ in the unbalanced factorial ANOVA, and $p=$ 0.113 in the fully crossed and balanced factorial ANOVA. The outliers were perhaps the 
result of students did not understand the directions to the test, or purposefully answered incorrectly.

The general trend revealed in Table 13 from the analyses of data was that Factor C, highest attained education in household, was significant in all analyses. Students from homes where the parent /guardian had completed at least a bachelors degree scored significantly higher NCE total test scores than students from homes where the highest level of education was less than a bachelors degree.

Table 13.

Summary of Analyses

Factors

Primary Factorial ANOVA

Uncategorized one-way ANOVA

Categorized one-way ANOVA

Unbalanced Factorial ANOVA

One-way ANOVA on Unbalanced

Factorial data

Fully crossed \& balanced Factorial

ANOVA

One-way ANOVA on Fully

crossed \& balanced data

\begin{tabular}{|c|c|c|c|c|c|c|}
\hline A & B & $\mathrm{C}$ & $A B$ & $A C$ & BC & $\mathrm{ABC}$ \\
\hline & & $\mathrm{X}$ & & & & $X$ \\
\hline
\end{tabular}

* $\quad * \quad \mathrm{X}$

* X

$\mathrm{X}$

* $\quad * \quad \mathrm{X}$


For this study Factor A was Internet access at home, Factor B was household income, and Factor $\mathrm{C}$ was highest education attained within the household. $\mathrm{AB}$ was the results of the combined interaction of $\mathrm{A}$ and $\mathrm{B}, \mathrm{AC}$, was the results of the combined interaction of $\mathrm{A}$ and $\mathrm{B}, \mathrm{BC}$, was the results of the combined interaction of $\mathrm{B}$ and $\mathrm{B}$, and $\mathrm{ABC}$, was the results of the combined interaction of A, B and C.

Findings Related to Hypotheses \& Research Question

The research question of this study was: What are the differences among the standardized test scores of students due to factors of Internet access at home, household income, and the highest level of education attained by mother, father or guardian? Results were mostly consistent among all the various analysis performed. The significant difference in student standardized test performance was the attained education level of their parent/guardian. This finding was consistent in all five analyses presented.

The other significant difference was the three-way interaction of Internet access at home, household income and the highest level of education in the student home. However, other analyses performed after outlying data were removed did not reveal significant differences. Because this result was apparently the result of the outliers, the validity was suspect.

The primary analysis accounted for only 5.5\% of the observed variability. In the best-case scenario, the fully crossed and balanced analysis, $90 \%$ of the effects observed were attributed to something other than the factors of this study. This begs the question what accounts for all this other variance? 


\section{Contrast of Findings from Analyses}

Table 14. Detailed Summary of Findings, Main Effects and One-Way ANOVAs, Table 15. Detailed Summary of Findings, Interactions in Primary Factorial ANOVAs, and Table 16. Detailed Summary of Findings, Interactions in Unbalanced and Fully Crossed \& Balanced Factorial ANOVAs show for each factor and combination of factors in all the analyses: 1) mean, 2) n, 3) Levene's test of homogeneity of variance, and; 4) the significance.

As the various challenges to validity (outliers and unbalanced factorial ANOVA) were addressed in the various analyses, one finding clearly distilled out: the level of the parents' education was the significant factor in determining a students NCE test performance. 
Table 14.

Detailed Summary of Findings, Main Effects and One-Way ANOVAs

\begin{tabular}{|c|c|c|c|}
\hline & \multicolumn{3}{|c|}{ Factors } \\
\hline & A (Internet) & B (Income) & $\mathrm{C}$ (Education) \\
\hline $\begin{array}{l}\text { Primary factorial ANOVA } \\
\text { main effects }\end{array}$ & $\begin{array}{l}\mu_{\text {yes }}=47.88, \mu_{\text {no }}=47.75 \\
\mathrm{n}_{\text {yes }}=296, \mathrm{n}_{\text {no }}=276 \\
\mathrm{~L}=0.063 \\
p=0.931\end{array}$ & $\begin{array}{l}\mu_{1}=46.36, \mu_{2}=47.56, \mu_{3}=49.52 \\
\mathrm{n}_{1}=210, \mathrm{n}_{2}=132, \mathrm{n}_{3}=230 \\
\mathrm{~L}=0.063 \\
p=0.178\end{array}$ & $\begin{array}{l}\mu_{1}=44.60, \mu_{2}=51.02 \\
\mathrm{n}_{1}=333, \mathrm{n}_{2}=239 \\
\mathrm{~L}=0.063 \\
p<0.001\end{array}$ \\
\hline Unbalanced factorial & $\begin{array}{l}\mu_{\mathrm{yes}}=48.37, \mu_{\mathrm{no}}=47.69 \\
\mathrm{n}_{\mathrm{yes}}=289, \mathrm{n}_{\mathrm{no}}=267\end{array}$ & $\begin{array}{l}\mu_{1}=46.89, \mu_{2}=47.78, \mu_{3}=49.41 \\
n_{1}=206, n_{2}=131, n_{3}=219\end{array}$ & $\begin{array}{l}\mu_{1}=45.02, \mu_{2}=51.03 \\
n_{1}=321, n_{2}=235\end{array}$ \\
\hline ANOVA main effects & $\begin{array}{l}\mathrm{L}=0.052 \\
p=0.610\end{array}$ & $\begin{array}{l}\mathrm{L}=0.052 \\
p=0.248\end{array}$ & $\begin{array}{l}\mathrm{L}=0.052 \\
p<0.001\end{array}$ \\
\hline One-way ANOVA on & $\begin{array}{l}\mu_{\mathrm{yes}}=49.93, \mu_{\mathrm{no}}=45.63 \\
\mathrm{n}_{\mathrm{yes}}=267, \mathrm{n}_{\mathrm{no}}=289\end{array}$ & $\begin{array}{l}\mu_{1}=44.37, \mu_{2}=47.02, \mu_{3}=51.23 \\
n_{1}=206, n_{2}=131, n_{3}=219\end{array}$ & $\begin{array}{l}\mu_{1}=44.29, \mu_{2}=52.36 \\
n_{1}=321, n_{2}=235\end{array}$ \\
\hline unbalanced factorial data & $\begin{array}{l}\mathrm{L}=0.007 \\
p<0.001\end{array}$ & $\begin{array}{l}\mathrm{L}=0.035 \\
p<0.001\end{array}$ & $\begin{array}{l}\mathrm{L}=0.046 \\
p<0.001\end{array}$ \\
\hline $\begin{array}{l}\text { Fully crossed \& balanced } \\
\text { factorial ANOVA main } \\
\text { effects }\end{array}$ & $\begin{array}{l}\mu_{\text {yes }}=47.79, \mu_{\text {no }}=48.82 \\
\mathrm{n}_{\text {yes }}=114, \mathrm{n}_{\text {no }}=114 \\
\mathrm{~L}=0.257 \\
p=0.566\end{array}$ & $\begin{array}{l}\mu_{1}=46.79, \mu_{2}=48.03, \mu_{3}=50.10 \\
\mathrm{n}_{1}=76, \mathrm{n}_{2}=76, \mathrm{n}_{3}=76 \\
\mathrm{~L}=0.257 \\
p=0.317\end{array}$ & $\begin{array}{l}\mu_{1}=45.49, \mu_{2}=51.12 \\
\mathrm{n}_{1}=114, \mathrm{n}_{2}=114 \\
\mathrm{~L}=0.257 \\
p=0.002\end{array}$ \\
\hline $\begin{array}{l}\text { One-way ANOVA on fully } \\
\text { crossed \& balanced data }\end{array}$ & $\begin{array}{l}\mu_{\text {yes }}=48.82, \mu_{\text {no }}=47.79 \\
\mathrm{n}_{\text {yes }}=114, \mathrm{n}_{\mathrm{no}}=114 \\
\mathrm{~L}=0.196 \\
p=0.574\end{array}$ & $\begin{array}{l}\mu_{1}=46.79, \mu_{2}=48.03, \mu_{3}=50.11 \\
\mathrm{n}_{1}=76, \mathrm{n}_{2}=76, \mathrm{n}_{3}=76 \\
\mathrm{~L}=0.125 \\
p=0.125\end{array}$ & $\begin{array}{l}\mu_{1}=45.49, \mu_{2}=51.12 \\
\mathrm{n}_{1}=114, \mathrm{n}_{2}=114 \\
\mathrm{~L}=0.942 \\
p=0.002\end{array}$ \\
\hline
\end{tabular}

Key: $\mu$ is the mean, $\mathrm{n}$ is the number of datasets per analysis, $\mathrm{L}$ is the results Levene's test of homogeneity of variance ( 0.050 or better is required), and $\mathrm{p}$ is the significance result ( 0.050 of less is required). 
Table 15.

Detailed Summary of Findings, Interactions in Primary Factorial ANOVAs

\begin{tabular}{|c|c|c|c|c|}
\hline & $\begin{array}{c}\mathrm{AB} \\
\text { (Internet \& Income) }\end{array}$ & $\begin{array}{c}\mathrm{AC} \\
\text { (Internet \& Education) }\end{array}$ & $\begin{array}{c}\text { BC } \\
\text { (Income \& Education) }\end{array}$ & $\begin{array}{c}\mathrm{ABC} \\
\text { (Internet, Income \& Education) }\end{array}$ \\
\hline $\begin{array}{l}\text { Primary } \\
\text { factorial } \\
\text { ANOVA }\end{array}$ & $\begin{array}{l}\mu_{\mathrm{AyB} 1}=45.15, \mu_{\mathrm{AyB} 2}=47.86, \\
\mu_{\mathrm{AyB} 3}=50.68 \\
\mu_{\mathrm{AnB} 1}=47.57, \mu_{\mathrm{AnB} 2}=47.27, \\
\mu_{\mathrm{AyB} 3}=48.41 \\
\mathrm{n}_{\mathrm{AyB} 1}=61, \mathrm{n}_{\mathrm{AyB} 2}=62, \\
\mathrm{n}_{\mathrm{AyB} 3}=153 \\
\mathrm{n}_{\mathrm{AnB} 1}=149, \mathrm{n}_{\mathrm{AnB} 2}=70 \\
\mathrm{n}_{\mathrm{AnB} 3}=77 \\
\mathrm{~L}=0.063 \\
p=0.931\end{array}$ & $\begin{array}{l}\mu_{\mathrm{AyC1} 1}=45.26, \mu_{\mathrm{AyC} 2}=50.53, \\
\mu_{\mathrm{AnC1}}=43.95, \mu_{\mathrm{AnC} 2}=51.54 \\
\mathrm{n}_{\mathrm{AyC} 1}=133, \mathrm{n}_{\mathrm{AyC} 2}=143, \\
\mathrm{n}_{\mathrm{AnC1}}=200, \mathrm{n}_{\mathrm{AnC2}}=96 \\
\mathrm{~L}=0.063 \\
p=0.614\end{array}$ & $\begin{array}{l}\mu_{\mathrm{B} 1 \mathrm{C} 1}=42.10, \mu_{\mathrm{B} 1 \mathrm{C} 2}=50.62, \\
\mu_{\mathrm{B} 2 \mathrm{C} 1}=45.46, \mu_{\mathrm{B} 2 \mathrm{C} 2}=49.66 \\
\mu_{\mathrm{B} 3 \mathrm{C} 1}=46.26, \mu_{\mathrm{B} 3 \mathrm{C} 2}=52.83 \\
\mathrm{n}_{\mathrm{B} 1 \mathrm{C} 1}=162, \mathrm{n}_{\mathrm{B} 1 \mathrm{C} 2}=48, \\
\mathrm{n}_{\mathrm{B} 2 \mathrm{C} 1}=89 \mathrm{n}_{\mathrm{B} 2 \mathrm{C} 2}=43, \\
\mathrm{n}_{\mathrm{B} 3 \mathrm{C} 1}=82, \mathrm{n}_{\mathrm{B} 3 \mathrm{C} 2}=148 \\
\mathrm{~L}=0.063 \\
p=0.612\end{array}$ & 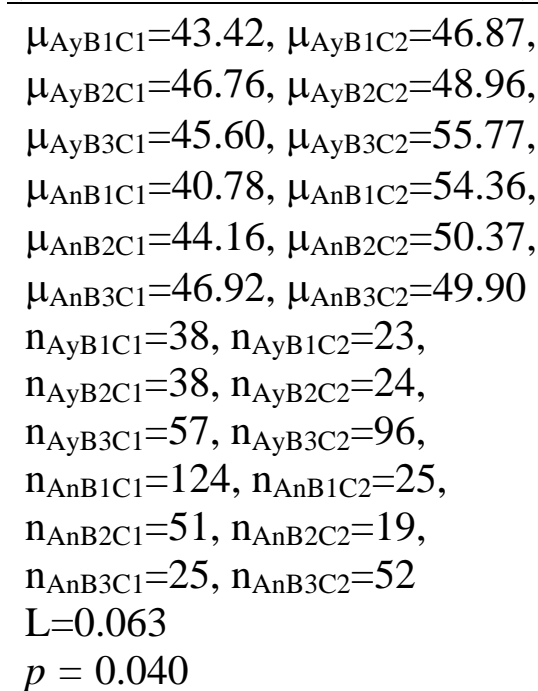 \\
\hline
\end{tabular}

Key: $\mu$ is the mean, $n$ is the number of datasets per analysis, $L$ is the results Levene's test of homogeneity of variance $(0.050$ or better is required), and $\mathrm{p}$ is the significance result ( 0.050 of less is required). 
Table 16.

Detailed Summary of Findings, Interactions in Unbalanced and Fully Crossed \& Balanced Factorial ANOVAs

\begin{tabular}{|c|c|c|c|c|}
\hline & $\begin{array}{c}\mathrm{AB} \\
\text { (Internet \& Income) }\end{array}$ & $\begin{array}{c}\mathrm{AC} \\
\text { (Internet \& Education) }\end{array}$ & $\begin{array}{c}\mathrm{BC} \\
\text { (Income \& Education) }\end{array}$ & $\begin{array}{c}\mathrm{ABC} \\
\text { (Internet, Income \& Education) }\end{array}$ \\
\hline $\begin{array}{l}\text { Unbalanced } \\
\text { factorial }\end{array}$ & $\begin{array}{l}\mu_{\mathrm{AyB} 1}=48.06, \mu_{\mathrm{AyB} 2}=47.69, \\
\mu_{\mathrm{AyB} 3}=47.03 \\
\mu_{\mathrm{AnB} 1}=45.72, \mu_{\mathrm{AnB} 2}=47.86, \\
\mu_{\mathrm{AyB} 3}=51.52 \\
\mathrm{n}_{\mathrm{AyB} 1}=60, \mathrm{n}_{\mathrm{AyB} 2}=62, \\
\mathrm{n}_{\mathrm{AyB} 3}=148 \\
\mathrm{n}_{\mathrm{AnB} 1}=146, \mathrm{n}_{\mathrm{AnB} 2}=69 \\
\mathrm{n}_{\mathrm{AnB} 3}=75 \\
\mathrm{~L}=0.052 \\
p=0.098\end{array}$ & $\begin{array}{l}\mu_{\mathrm{AyC} 1}=51.53, \mu_{\mathrm{AyC} 2}=50.53, \\
\mu_{\mathrm{AnC} 1}=43.85, \mu_{\mathrm{AnC} 2}=46.20 \\
\mathrm{n}_{\mathrm{AyC} 1}=126, \mathrm{n}_{\mathrm{AyC} 2}=141, \\
\mathrm{n}_{\mathrm{AnC} 1}=195, \mathrm{n}_{\mathrm{AnC} 2}=94 \\
\mathrm{~L}=0.052 \\
p=0.208\end{array}$ & $\begin{array}{l}\mu_{\mathrm{B} 1 \mathrm{C} 1}=43.17, \mu_{\mathrm{B} 1 \mathrm{C} 2}=45.89, \\
\mu_{\mathrm{B} 2 \mathrm{C} 1}=50.61, \mu_{\mathrm{B} 2 \mathrm{C} 2}=49.66 \\
\mu_{\mathrm{B} 3 \mathrm{C} 1}=46.01, \mu_{\mathrm{B} 3 \mathrm{C} 2}=52.81 \\
\mathrm{n}_{\mathrm{B} 1 \mathrm{C} 1}=158, \mathrm{n}_{\mathrm{B} 1 \mathrm{C} 2}=48, \\
\mathrm{n}_{\mathrm{B} 2 \mathrm{C} 1}=88 \mathrm{n}_{\mathrm{B} 2 \mathrm{C} 2}=43, \\
\mathrm{n}_{\mathrm{B} 3 \mathrm{C} 1}=75, \mathrm{n}_{\mathrm{B} 3 \mathrm{C} 2}=144 \\
\mathrm{~L}=0.052 \\
p=0.522\end{array}$ & 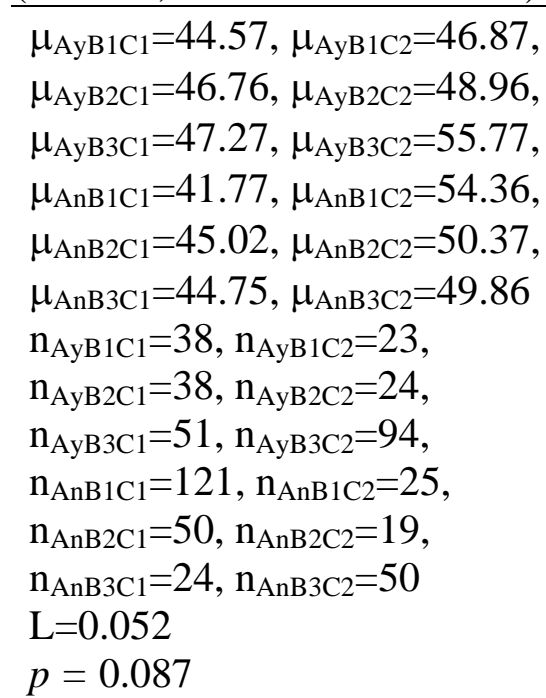 \\
\hline $\begin{array}{l}\text { Fully } \\
\text { crossed \& } \\
\text { balanced } \\
\text { factorial } \\
\text { ANOVA }\end{array}$ & $\begin{array}{l}\mu_{\mathrm{AyB} 1}=45.95, \mu_{\mathrm{AyB} 2}=48.21, \\
\mu_{\mathrm{AyB} 3}=52.31 \\
\mu_{\mathrm{AnB} 1}=47.84, \mu_{\mathrm{AnB} 2}=47.84, \\
\mu_{\mathrm{AyB} 3}=47.89 \\
\mathrm{n}_{\mathrm{AyB} 1}=38, \mathrm{n}_{\mathrm{AyB} 2}=38, \\
\mathrm{n}_{\mathrm{AyB} 3}=38 \\
\mathrm{n}_{\mathrm{AnB} 1}=38, \mathrm{n}_{\mathrm{AnB} 2}=38 \\
\mathrm{n}_{\mathrm{AnB} 3}=38 \\
\mathrm{~L}=0.257 \\
p=0.372\end{array}$ & $\begin{array}{l}\mu_{\mathrm{AyC} 1}=46.95, \mu_{\mathrm{AyC} 2}=50.70, \\
\mu_{\mathrm{AnC} 1}=44.03, \mu_{\mathrm{AnC} 2}=51.54 \\
\mathrm{n}_{\mathrm{AyC} 1}=57, \mathrm{n}_{\mathrm{AyC} 2}=57, \\
\mathrm{n}_{\mathrm{AnC} 1}=57, \mathrm{n}_{\mathrm{AnC2}}=57 \\
\mathrm{~L}=0.257 \\
p=0.298\end{array}$ & $\begin{array}{l}\mu_{\mathrm{B} 1 \mathrm{C} 1}=43.21, \mu_{\mathrm{B} 1 \mathrm{C} 2}=50.37, \\
\mu_{\mathrm{B} 2 \mathrm{C} 1}=46.34, \mu_{\mathrm{B} 2 \mathrm{C} 2}=49.71, \\
\mu_{\mathrm{B} 3 \mathrm{C} 1}=46.92, \mu_{\mathrm{B} 3 \mathrm{C} 2}=53.29 \\
\mathrm{n}_{\mathrm{B} 1 \mathrm{C} 1}=38, \mathrm{n}_{\mathrm{B} 1 \mathrm{C} 2}=38, \\
\mathrm{n}_{\mathrm{B} 2 \mathrm{C} 1}=38, \mathrm{n}_{\mathrm{B} 2 \mathrm{C} 2}=38, \\
\mathrm{n}_{\mathrm{B} 3 \mathrm{C} 1}=38, \mathrm{n}_{\mathrm{B} 3 \mathrm{C} 2}=38 \\
\mathrm{~L}=0.257 \\
p=0.663\end{array}$ & 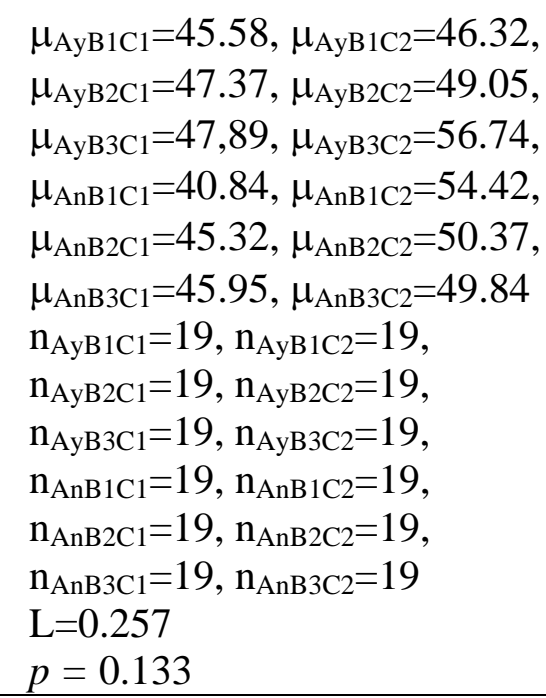 \\
\hline
\end{tabular}


The Factorial ANOVA compared the means of each cell within the matrix, whereas the one-way ANOVA does not weight the factors in accordance to categories set in the factorial analyses. An instance of this effect of the different methods is shown in Table 12, by comparing the means for Internet access at home. In the unbalanced factorial ANOVA, the means for Internet access at home were calculated as a mean of the cells (yes versus no), and the one-way ANOVA on unbalanced factorial data calculates the mean based on all the individual data points. The means for the unbalanced factorial ANOVA were $\mu_{\text {yes }}=48.37, \mu_{\mathrm{no}}=47.69$, and for the one-way ANOVA $\mu_{\mathrm{yes}}=49.93, \mu_{\mathrm{no}}$ $=45.63$. The differences between these means were 0.68 for the factorial ANOVA versus 4.3 for the one-way ANOVA.

\section{Other Findings}

The analyses conducted beyond those originally planned for this study were revealing. Although the balanced factorial ANOVA analyses yielded essentially the same result, it seems to have only lost power for having a smaller $\mathrm{n}$. The balanced factorial ANOVA reinforced the results of the unbalanced. The results of the one-way ANOVA analyses raise interesting issues, especially because they were all significant and only parent/guardian education was significantly different in the factorial analyses.

\section{Discussion of the One-Way ANOVA Findings}

The results of one-way ANOVA on the unbalanced data were all significant, but when all is taken into account, two (Internet \& income) of the three one-way ANOVAs performed on the unbalanced data set were invalid due to unequal variance. The difference in the method of the factorial ANOVA yields a better comparison of the real nature of the data. That was because the factorial ANOVA compared the cell means and 
it accounted for differences in the group sizes. For instance, the $\mathrm{n}$ for the one-way AONVA reports $n_{\text {yes }}=267, n_{n o}=289$ and this appears to be equal. However, the factorial ANOVA used the mean of the means of the cells, and the $n$ for the cells ranged from $n_{\mathrm{AnB2C} 2}=19$ to the other extreme of $\mathrm{n}_{\mathrm{AnB1C1}}=124$. The method of the factorial ANOVA caused the mean of the cell with an $\mathrm{n}$ of 19 to have the same bearing on the outcome as the cell with an $n$ of 124 . Essentially the factorial method caused an equal effect for each group, and showed a more comprehensive view of the data in regards to the research question.

The three one-way ANOVAs conducted on the fully crossed and balanced data yielded a similar result; two of the three were not significant. The main differences from fully crossed and balanced one-way ANOVA being: 1) the weighting effect different cell sizes were not a factor, and; 2) that the data did meet the assumption of homoscedasticity. However, just like the factorial results, only the highest attained education of the parent/guardian was significant.

\section{Other Findings Issues}

The GEARUP Program has demonstrated it has a measured effect on the NCE scores of the participants. All student data sets were complete, and therefore received the same treatment. It is assumed that this effect was equally distributed among the participants. 


\section{CHAPTER 5 - CONCLUSIONS, IMPLICATIONS AND RECOMMENDATIONS}

This chapter presents the conclusions, implications and recommendations of this

study. The conclusions are those directly related to the hypothesis and other conclusions derived from the findings. The implications are insights based upon the data as they relate to the larger world. Recommendations are a combination of the implications and conclusions - rational directions to proceed with the results of this research.

\section{Review of Chapters I - IV}

The purpose of this study was to examine differences among the standardized test scores of students due to factors of Internet access at home, household income, and the highest level of education attained by mother, father or guardian. Nearly every student has Internet access at school, and over half of the nation has an Internet connection at home. If students with Internet access at home have a different academic standing, is it influenced by the Internet connection or family affluence? There are established bodies of evidence that link academic standing with factors of family affluence, i.e., parental education and household income.

The population consisted of the participants of the San Miguel GEAR UP program at New Mexico Highlands University, located in northern New Mexico. The independent variables were: A) Internet access grouped as yes versus no, B) highest level of education within the household grouped as those with or without a bachelor's degree and C) household income in three categories $(\$ 0-\$ 20,000, \$ 20,001-\$ 30,000$, and $\$ 30,001+$ ) of annual income. The dependent variable was the NCE total score from Spring 2004 CTB/McGraw-Hill-TerraNova. 
There were two significant differences in students NCE total scores: 1) the main effect for the education level of the parent and/or guardian, $F(1,544)=20.412$, $p<$ 0.001, and; 2) the three way interaction of the factors of Internet access at home, household income and highest level of parent education, $F(2,560)=3.234, p=0.040$. Only the education level of the parent and/or guardian proved to far exceed the level of rejection in this study. The three-way interaction was suspect because further analyses performed after removing obvious outliers produced no other significant findings. It is also worth noting that only $5.5 \%$ of the variability is explained by the factors of the analysis.

Additional analyses were based upon removing outliers which appeared to be of suspect validity; i.e., 9 values of “ 1 ” on the NCE scale. The other analyses performed were another unbalanced factorial ANOVA, a fully crossed and balanced factorial ANOVA and two sets of one-way ANOVAs. The fully crossed and balanced factorial ANOVA required removing a great deal of data. Findings were consistent among all the various analyses performed. The highest level of education within the household was the only determinant factor of student NCE total score performance in the unbalanced factorial ANOVA, $F(1,544)=20.412, p<0.001$. The dataset was reduced to create a fully crossed and balance factorial ANOVA. In this analysis the education of the parent/guardian was significant, $F(1,216)=9.787, p=0.002$. One-way ANOVAs were performed on both sets of data, the unbalanced data set and the fully crossed and balanced data set. Both sets yielded a significant result only for the education of the parent/guardian, $F(1,254)=47.733, p<0.001$ and $F(1,226)=9.760, p=0.002$, respectively. 


\section{Conclusions Related to Hypothesis \& Research Questions}

The null hypothesis states that the means of all groups (main effects and interactions) would be equal. Expressed mathematically:

$$
\mu_{\mathrm{OA}}=\mu_{\mathrm{oB}}=\mu_{\mathrm{oC}}=\mu_{\mathrm{oAB}}=\mu_{\mathrm{OAC}}=\mu_{\mathrm{oBC}}=\mu_{\mathrm{oABC}}
$$

There were seven parts to the null hypothesis. The two general portions were main effects and interactions: 1) three main effects (A, B, \& C), and; 2) four interaction effects (AB, AC, BC, \& ABC). The three main effects were: A) Internet access at home, B) household income, and C) highest level of education within the household. The interaction effects were: $\mathrm{AB}$ ) Internet and income, $\mathrm{AC}$ ) Internet and education, $\mathrm{BC}$ ) income \& education, and $\mathrm{ABC}$ ) Internet, income and education. Of the seven parts of the null hypothesis, the one significant finding was main effect $C$, highest level of education within the household.

The Research Question was: What are the differences among the standardized test scores of students due to factors of Internet access at home, household income, and the highest level of education attained by mother, father or guardian? The one significant difference was main effect $\mathrm{C}$, highest level of education within the household.

\section{Highest Level of Education Within the Household}

There were six levels of education within the raw data. However, to arrange the data for the design, a completely crossed (enough data in every cell) factorial ANOVA, the six levels were collapsed into two categories. The categorical break was coarse; the categories of education for the parent/guardian were either with or without a bachelor's degree. 
Highest level of education within the household proved to be of significance in every form of analysis performed. In the primary analysis the main effect for the education level of the parent and/or guardian was significant, $F(1,544)=20.412$, $p<$ 0.001. In the unbalanced factorial ANOVA, with the outliers removed, the finding was significant, $F(1,544)=20.412, p<0.001$. With a severely reduced dataset in a fully crossed and balanced factorial ANOVA the result was also significant, $F(1,216)=9.787$, $p=0.002$. Two one-way ANOVAs were also performed, one on each of the two sets of data (unbalanced and fully crossed and balanced). Both were significant for education of the parent/guardian, $F(1,254)=47.733, p<0.001$, and $F(1,226)=9.760, p=0.002$, respectively. These findings support more than 30 years worth of data presented in the Literature Review. Therefore, based upon the data, the education of the parent/guardian will have a far greater impact upon a student's likely test performance than Internet access in the home.

\section{Interaction of Internet, Income and Education}

The three way interaction of the factors of Internet access at home, household income and highest level of parent education were significant, $F(2,560)=3.234, p=$ 0.040. However, this result is suspect because after removing obvious outliers the result was no longer significant, $p=0.087$. When the design became fully crossed and balanced the result was further from significant, $p=0.113$. Had the result emerged in the other analyses it would not be suspect. There may be an interaction due to the combination of these factors - supporting the notion of a digital divide. However the parent/guardians education, based upon the data, is a far greater factor. 


\section{Other Conclusions}

In addition to the hypothesis and research question, there are additional conclusions that can be drawn from the data. These other conclusions relate to the population of the study, cell sizes in the factorial ANOVA, distribution of groups, education stratification, and unaccounted variability.

\section{Population}

It is likely the population of this study is not representative of the general population. If there had been more data in the extreme categories, the design of the factorial ANOVA could have contained more categories. The effect of more categories may have yielded more effects not observed in this study. With enough data to breakout more categories, particular groupings may have proven significant.

\section{Cell Sizes}

The extreme differences are exemplified in the cell for those without Internet access and the lowest income and education, containing 102 more data points than the extreme least-populated cell. The fully crossed and balanced factorial controlled for this and yielded similar results. The fully crossed and balanced design with random assignment produced the results that accounted for the most variability.

\section{Distribution of Groups}

The collapsing of categories may have been too extreme to detect differences. In the realm of economic groups, three categories may represent a low, middle and highincome category. However, within the population studied, the category definitions do not appear to match the national profile. It would be difficult to argue that $\$ 30,000$ annual income is the threshold for a high income. The grouping of education category was 
separated on those with or without a bachelor's degree. Potential effects were not observed because of the collapsed of the data.

\section{Education Stratification}

Although the highest attained education within the household proved to be a factor of significance, the groupings were coarse. Other results may surface with more data because the categories of education could be expanded. Such results could reveal more precisely what level of education makes a difference. The raw data contained six different levels of education: 1) finished elementary school, 2) graduated from high school, 3) attended college or training after high school, 4) completed a 2-year college or training program, 5) completed a 4-year degree at a college or university, and; 6) attended or completed a college graduate program. With enough data to create more categories, the precise levels of education that differ could be identified. The categories were too coarse to observe potential effects due to various levels of parent/guardian education.

\section{Unaccounted Variability}

The Partial Eta Squared scores were all very small. The largest was 0.032 for the main effect on Education - saying that 3.2\% of the variability can be attributed to education differences. The other significant finding, the ABC interaction, was 0.011. All other Partial Eta Squared scores were $>0.006$. By this estimation, only $5.5 \%$ of the variability is explained by the factors of the analysis. Conversely, more than $94 \%$ of the variability was due to factors not included in this study.

Removing outliers improved the estimation to $6.4 \%$ in the unbalance factorial ANOVA. In the fully crossed and balanced ANOVA the estimate was that $9.3 \%$ of the 
variability is explained by the factors of the analysis. The trend of improvement supports better validity in the trimmed data.

\section{Implications}

The implications of this research are drawn from the findings and conclusions. There are five implications presented: 1) highest education within the household matters, 2) confounding factors reveal better results, 3) population size, 4) unaccounted variability, and; 5) gifting Internet access would be imprudent. A sub-section of the last implication titled The Killer App is an explanation of a concept introduced within that implication.

\section{Highest Education Within the Household Matters}

The clear conclusion of this research is that the highest education within the household was the significant finding. The findings on the interactions of Internet access at home and parent/guardian education were far from significant in all analyses. Likewise, the findings on the interaction of income and education were not significant. The three-way interaction of all factors was significant in the primary analysis, but it was not significant in any other analyses. This indicates that parent/guardian education truly stands as the one significant factor in the study.

\section{Confounding Factors Reveal Better Results}

The arguments presented by Schield (1999) regarding spurious association appear to be a valid explanation of the results of this study. If factors are viewed in singularity and assumptions are ignored, each factor appears to be significant. In a vacuum, each factor is significant. However, in a more comprehensive analysis, only one factor proves 
to be determinant. Although the three-way interaction of Internet, income and education produced a significant result in one of the five analyses, it is suspect.

The base question of this study was to investigate the contribution of Internet access to a students academic standing. However, it was the confounding factor of parent/guardian education that proved to be significant.

\section{Larger Population Would Improve Quality}

If the size of the study were increased, perhaps the "tails" would prove to be significant. Filling the cells in the extremes proved to be difficult, e.g., there was a lack of data for 1) low income and higher education levels of the parents, and; 2) high income and low education. There was also an abundance of data in the category of those without Internet but with low income and low education. In order to conduct an analysis that would contain many categories there would need to be enough data to fill the unlikely extremes. This would also overfill the expected categories and likely require a random assignment process to create the preferred fully crossed and balanced factorial ANOVA.

There are two implications: 1) the population would need to be much larger, and; 2) a random selection process would be required to balance the data. As a rough estimate from the distribution observed in this study, it may require 20-30 times as much data to fill the extremes and provide for the random selection process. Because the data gathered will likely be representative of the general population, there would need to be a random selection process to arrange the data into a fully crossed and balanced ANOVA.

\section{Unaccounted Variability}

The accounted variability increased with the data trim and the fully crossed and balanced design. Perhaps a larger population in a fully crossed and balanced design 
could lead to further improvement. The introduction of other factors, or more categories may also improve the results.

\section{Gifting Internet Access Would Be Imprudent}

The San Miguel GEARUP program has considered gifting Internet access to parents/guardians who currently do not have Internet access. The distribution of this population reveals large portions that were low income and without Internet access; 146 of the 267 without Internet reported an annual household income of less than $\$ 20,000$. It was believed such households would not likely obtain Internet access for economic reasons. The distribution of Internet access to that population would probably not improve academic standing of the students. However, an effort to raise the education level of their parents may raise the academic standing of their children.

Unless some other factor(s) was/were associated with the act of providing Internet access, there appear to be no solid grounds to expect improvement in student performance. However, if other associated activities or different technologies were present, there may be grounds to expect a difference in student performance. If a new education killer app for monitoring student performance and facilitating parent involvement were to accompany the gift, it may be reasonable to expect a difference in student performance. It is also possible that providing education to the parents in concert with a gift of Internet access could facilitate a difference in student performance.

\section{The killer App}

In the development of the personal computer revolution, there have been foundational technical developments often referred to as a "killer app". Spreadsheets (Excel and Lotus 123) are thought to be the killer-apps that brought PCs into the business 
world. Word processors (WordPerfect and MS Word) are thought to be the killer apps that brought PCs onto nearly every desktop, replacing the now outdated typewriters. Email editors (Eudora and Outlook) are the killer apps that brought the Internet and networks to prominence, although both had existed for decades. Web browsers (Netscape and MS Internet Explorer) are thought to be the killer apps that brought the World Wide Web (WWW) to prominence, although the Internet had existed for decades.

Perhaps a killer app for education has yet to emerge. If a new education killer app were to be Internet based it would change the horizon for this study. As in the other realms of PC and Internet use, when the killer app was diffused, the rules changed.

\section{Recommendations}

The recommendations presented are based upon the findings and conclusions. There are three recommendations: 1) confounding factors, 2) replication, and; 3) gifting Internet access must be accompanied.

\section{Confounding Factors}

In this study, 94\% of the variance was not accounted for by the factors analyzed. Consideration of a design that takes other factors of affluence into account may complicate the design, however it may improve the applicability to other populations and provide better insight.

The recommendation is to grant further consideration of other factors that may have a greater bearing than reckoned. Some confounding factors may be obvious, and if so, they would be included in quality research. If the confounding factors are not obvious, they should be sought out; i.e., student health, curriculum, et. 


\section{Replication With a Larger $N$}

It would seem prudent to replicate this study with a broader population. The essential goal is to create more categories and perhaps reveal trends and interactions. Because the distributions will likely be uneven in categories, as they were in this study, a random selection of categorical data into the cells may be necessary. A 2x4x4 factorial ANOVA was cited in Chapter 3. The dataset used in this study could not support a design with that many categories. More categories should be used in a replication study to reveal trends not evident in the 2x3x2 factorial ANOVA used in this study.

The recommendation is to perform the factorial analysis on a larger data set to enable the establishment of more categories. With a factorial design containing more categories, interaction effect(s) may become more evident. Also, the categorical definitions could become more representative of a broader audience.

\section{Replication With a Randomly Assigned Fully Crossed and Balanced Design}

Replication with a fully crossed and balanced design is based partially improved Partial Eta Squared scores observed. It is also not likely to gather data in a fashion that would lead to the exact $n$ required for each cell. It would be reasonable to expect that the popular data categories would load up with extra data quickly, and need to be randomly chosen to maintain a balanced design. This supports the prior recommendation of a much larger $\mathrm{N}$.

The recommendation is to design the study as a quasi-experimental design, which would gather enough data to allow for the random selection of data into a fully crossed and balanced factorial ANOVA. 


\section{Gifting Internet Access Must be Accompanied}

The natural diffusion of Internet access into the various categories established in this research indicated that no measurable contribution was made by internet access at home to student academic standing. That is to say, if Internet access is gifted with no additional services, training, programs or other accompaniments, there is no reason to expect students in the homes receiving the gift to perform differently.

The recommendation is that if Internet access is gifted, it must have some accompaniment. This accompaniment may be parent training/education, some sort of new education killer app, or a combination of such. To form a rational argument for gifting Internet access, which would lead to the expectation of a result different from the conclusions this research, new factors need to be introduced. 


\section{REFERENCES}

Attewell, P., \& Battle, J. (1999). Home Computers and School Performance. The Information Society, 15(1), 1-10. Retrieved October 13, 2004, from http://www.ingentaconnect.com/content/tandf/utis/1999/00000015/00000001/art0 0002;jsessionid=3ojfjvmaa8doo.victoria.

Becker, H. J. (2000). Who’s Wired and Who’s Not: Children’s Access to and Use of Computer: Technology Children and Computer Technology. The Future of Children, 10(2), 44-75.

Bier, M. C. (1997). Assessing the Effect of Unrestricted Home Internet Access on the Underserved Community: A Case Study of Four East Central Florida Families. (Doctoral dissertation, Florida Institute of Technology, 1997). Retrieved October 12, 2004, from Dissertation Abstracts Online.

Bruning, J. L., \& Kintz, B. L. (1997). Computational Handbook of Statistics. Reading, MA: Addison-Wesley.

CTB/McGraw-Hill. (2004). A Guide for Effective Assessment. Retrieved January 25, 2005, from http://www.ctb.com/articles/article_information.jsp?CONTENT\%3C\%3Ecnt_id= 10134198673254779\&FOLDER\%3C\%3Efolder_id=1408474395222381\&bmUI $\mathrm{D}=1106714628755$. 
Davis, S. (2003). An investigation of parental perceptions of and attitudes toward computer use in two predominantly Hispanic communities in the southwestern border region. (Doctoral dissertation, New Mexico State University, 2003). Retrieved October 12, 2004, from Dissertation Abstracts Online.

Dickard, N. (Ed.) (2003). The sustainability challenge: Taking ed-tech to the next level. The Benton Foundation Communications Policy Program \& EDC Center for Children and Technology. Retrieved January 3, 2005, from http://www.benton.org/publibrary/sustainability/sus_challenge.pdf.

Fairlie, R. (2003, May). The Effects of Home computers on School Enrollment. JCPR Working Paper. (Report No JCPR-WP-337). University of Chicago. Joint Center for Poverty Research.

Garson, G. D. (2005). ANOVA. Retrieved May 22, 2005, from http://www2.chass.ncsu.edu/garson/pa765/anova.htm\#levene

Gottfredson, L. (2004). Interpreting Standardized Test Scores. Retrieved January 25, 2005, from http://www.udel.edu/educ/gottfredson/451/unit10-chap19.htm.

Gregg. (2004). Dr. Gregg's Testing \& Measurement Corner, Tucson Unified School District. Retrieved January 25, 2005, from http://tusdstats.tusd.k12.az.us/planning/resources/dr_gregg/dr.html\#nce.

Hays, W. (1988). Statistics (4th ed.). New York: Holt, Rinehart and Winston, Inc. Hernandez, M. (2003). Database Design for Mere Mortals (2nd Ed). Boston, MA: Pearson Education, Inc. 
Horsley, R. (2004). Factorial Arrangements. Retrieved February 8, 2005, from http://www.ndsu.nodak.edu/ndsu/horsley/fact.pdf.

Indiana Department of Education. (2005). Definition of Terms - NCE. Retrieved January 25, 2005, from http://www.doe.state.in.us/asap/definitions.html.

Kafai, Y. B., Fishman, B. J., Bruckman, A. S., Rockman, S. (2002). Models of Educational Computing @ Home: New Frontiers for Research on Technology in Learning. Educational Technology Review, 10 (2), 52-68. Retrieved February 19, 2005, from http://www.aace.org/pubs/etr/issue3/Kafai.pdf.

Lenhart, A., Simon, M., \& Graziano, M. (2001). The Internet \& Education: Findings of the Pew Internet \& American Life Project. Retrieved January 12, 2005, from http://www.pewinternet.org/reports/toc.asp?Report=39.

Levin, D., Arafeh, S. (2002). The Digital Disconnect: The Widening Gap between Internet-Savvy Students and Their Schools. The Pew Internet \& American Life Project. Retrieved January 12, 2005, from http://www.pewinternet.org/pdfs/PIP_Schools_Internet_Report.pdf.

McGraw-Hill. (2004). CTB/McGraw-Hill -TerraNova, The Second Edition. Retrieved August 17, 2004, from http://www.ctb.com/netcaster/state_home.jsp?NC_ DIRECTORY\%3C\%3Edirectory_id=131\&FOLDER\%3C\%3Efolder_id=1408474 $395214059 \& b m U I D=1092808835513$. 
McMillan-Culp, K., Honey, M. \& Mandinach E. (2003). A Retrospective on Twenty Years of Education Technology Policy. U.S. Department of Education, Office of Educational Technology. Retrieved October 13, 2004, from http://www.ed.gov/rschstat/eval/tech/20years.pdf.

National Center for Educational Statistics. (2003). Computer and Internet used by Children and Adolescents in 2001 Statistical Analysis Report. The U.S. Department of Education, Institute of Educational Sciences and NCES 2004-014. Retrieved October 12, 2004, from http://nces.ed.gov/pubs2004/2004014.pdf.

National Center for Educational Statistics. (2004). Digest of Statistical Tables and Figures - 2003. Retrieved February 11, 2005, from: http://nces.ed.gov/programs/digest/d03_tf.asp.

New Mexico Public Education Department. (2004). Focusing On Becoming Stronger: The State Of Public Education In New Mexico-2003. Retrieved January 25, 2005, from http://www.ped.state.nm.us/resources/downloads/2003.annual.report.pdf.

Nonnamaker, J. (2000). Pre-college Internet use and freshman year academic achievement in a private college: The effect of sociodemographic characteristics, family socioeconomic status, academic ability and high school experiences. (Doctoral dissertation, Fordham University, 2000). Retrieved October 12, 2004, from: Dissertation Abstracts Online. 
Pennsylvania Department of Education. (2004). Evaluation of Student \& Parent Access through Recycled Computers. Retrieved January 6, 2005, from http://www.pde.state.pa.us/ed_tech/cwp/view.asp?A=169\&Q=100397.

Rathbun, A., West, J., \& Hausken, E. (2003). Young Children’s Access to Computers in the Home and at School in 1999 and 2000. Education Statistics Quarterly, 5(1), 25-30. National Center for Education Statistics, Institute of Education Sciences, U.S. Department of Education. Retrieved October 12, 2004, from http://nces.ed.gov/pubsearch/pubsinfo.asp?pubid=2003036.

San Miguel / New Mexico Highlands University GEARUP Partnership. (2004). NMHU/San Miguel GEAR-UP Student Application, 2003-2004 School Year. Retrieved February 05, 2005, from http://gearup.nmhu.edu/par_stud/Student_Application_2003_2004.pdf.

Schield, M. (1999). Statistical literacy: Thinking critically about statistics. Of Significance published by The Association of Public Data Users, 1(1), 1-7. Retrieved October 12, 2004 from http://web.augsburg.edu/ schield/MiloPapers/984StatisticalLiteracy6.pdf.

Toriskie, J. (1999). The Effects Of Internet Usage on Student Achievement and Student Attitudes (Fourth-Grade, Social Studies). (Doctoral dissertation, Loyola University of Chicago, 1999). Retrieved October 12, 2004, from Dissertation Abstracts Online. 
U.S. Department of Commerce. (2002). A Nation Online: How Americans Are Expanding Their Use of the Internet. Pew Internet Project Also, Economics and Statistics Administration, National Telecommunications and Information Administration. Retrieved January 12, 2005, from http://www.ntia.doc.gov/ntiahome/dn/nationonline_020502.htm.

U.S. Department of Education. (2004). Partnership Grants. Retrieved January 26, 2005, from http://www.ed.gov/programs/gearup/partnerships-GA-NM.pdf.

U.S. Department of Education. (2003). Education Technology: Preparing Students and Parents for the Digital Age. Retrieved October 12, 2004, from http://registerevent.ed.gov/downlink/event-flyer.asp?intEventID=168 , 10,13,04.

U.S. Department of Education. (2005). Toward A New Golden Age in American Education: How the Internet, the Law and Today's Students Are Revolutionizing Expectations. Office of Educational Technology. Retrieved January 7, 2005, from http://www.nationaledtechplan.org/theplan/NETP_Final.pdf.

U.S. Department of Education. (2001). Archived Information: Gaining Early Awareness And Readiness For Undergraduate Programs (GEAR UP). Retrieved January 12, 2005, from http://www.ed.gov/pubs/AnnualPlan2002/rV185-GEARUP-0412.pdf.

U.S. Department of Education. (2005). Gaining Early Awareness and Readiness for Undergraduate Programs (GEAR UP), Washington, D.C. Retrieved January 25, 2005, from http://www.ed.gov/programs/gearup.

Warschauer, M., \& Knobel, M. (2004). Technology and Equity in Schooling: Deconstructing the Digital Divide. Educational Policy, 18, 562-588. 
Wearden, S. \& Dowdy, S. (1991). Statistics for Research (2nd Ed.). New York: John Wiley \& Sons.

Webopedia. (2004). Definition of GUID. Retrieved October 12, 2004, from http://www.webopedia.com/TERM/G/GUID.html.

Webopedia. (2004). Definition of the Internet. Retrieved October 12, 2004, from http://www.webopedia.com/TERM/I/Internet.html.

Wielkiewicz, R. (2005). Using SPSS for Windows. Retrieved May 22, 2005, from http://employees.csbsju.edu/rwielk/psy347/spssinst.htm

Winer, B. J. (1971). Statistical Principles in Experimental Design (2nd Ed.). New York: McGraw Hill. 


\section{APPENDIXES}




\section{APPENDIX A - Student Application}

\section{NMHU/San Miguel GEAR-UP \\ STUDENT APPLICATION \\ 2003-2004 School Year}

CIRCLE SCHOOL: MMS RHS WLVHS WLVMS WLV Valley FP

\begin{tabular}{l}
\hline Grade \\
\hline
\end{tabular}

With which ethnic group do you identify yourself? (Choose only one)

African American_Asian/Pacific Islander Anglo_ Hispanic

Native American - Tribe

Other

Please check if the following is true: Do you participate in a Free/Reduced Lunch Program?

Do you have a disability?

Are you planning on attending a College/University or Tech School after graduation?

If yes, what school are you planning to attend?

\begin{tabular}{|l|r|r|r|}
\cline { 2 - 4 } \multicolumn{1}{c|}{} & Name of Institution & State & Intended Major \\
\hline $1^{\text {st }}$ Choice & & & \\
\hline $2^{\text {nd }}$ Choice & & & \\
\hline
\end{tabular}

If No, please state why.

\section{Parent/Guardian Information}

Name of First
Guardian:
Work Place:
Work Number:
Would you like for your child to attend a post
secondary institute (college or technical school)
Yes_ No _ _
If No, why not?
student has a lack of interest
_ school is too far away
_ costs too much
_ will be starting or taking care of a family
student wants to work
additional education is not necessary
O Other (please complete)

Name of Second

Guardian:

Work Place:

Work Number:

Would you like for your child to attend a post secondary institute (college or technical school)?

Yes No

If No, why not?

student has a lack of interest

- school is too far away

_ costs too much

will be starting or taking care of a family

student wants to work

_ additional education is not necessary

Other (please complete)
Do you have a computer at home? Yes_ No Range of Family Income: $\$ 0-10,000$ $\$ 40,000-50,000$
Do you have Internet access? Yes No 


\section{APPENDIX A - Student Application (cont.)}

\section{Family Educational Information}

What is the highest level of education that was received by each family member?

\begin{tabular}{|l|l|l|l|l|l|l|}
\hline & $\begin{array}{l}\text { Finished } \\
\text { Elementary } \\
\text { School }\end{array}$ & $\begin{array}{l}\text { Graduated } \\
\text { from High } \\
\text { School }\end{array}$ & $\begin{array}{l}\text { Attended } \\
\text { College or } \\
\text { training after } \\
\text { High School }\end{array}$ & $\begin{array}{l}\text { Completed a 2- } \\
\text { year college or } \\
\text { training program }\end{array}$ & $\begin{array}{l}\text { Completed a 4- } \\
\text { year degree at a } \\
\text { college or } \\
\text { University }\end{array}$ & $\begin{array}{l}\text { Attended or } \\
\text { completed a } \\
\text { College Graduate } \\
\text { Program }\end{array}$ \\
\hline $\begin{array}{l}\text { Mother or } \\
\text { Guardian }\end{array}$ & & & & & & \\
\hline $\begin{array}{l}\text { Father or } \\
\text { Guardian }\end{array}$ & & & & & & \\
\hline Grandparents & & & & & & \\
\hline $\begin{array}{l}\text { Older Brother(s) } \\
\text { or Sister(s) }\end{array}$ & & & & & & \\
\hline $\begin{array}{l}\text { Other Family } \\
\text { Members }\end{array}$ & & & & & & \\
\hline
\end{tabular}

\section{Medical Information}

Does the participant have any medical or learning conditions that we should know about in order to ensure that the NMHU/San Miguel GEAR-UP experience is the best we can provide?

Name of Physician: Phone:

Is the participant taking any medication? If yes, explain:

Emergency Contact:

Phone:

Relationship to participant:

Consent/Release

Medical Consent

Liability Release

Photo/Video Release

Trip Release

School Release
I authorize all medical, surgical, diagnostic and hospital procedures including ambulance transportation that may be performed or prescribed by a treating physician for the youth listed herein if I cannot be reached in an emergency.

I waive all rights and release all claims that might be held against the school district and the NMHU/San Miguel GEAR-UP Project Partnership, its hired or contracted instructors, staff, volunteers, agencies and their employees and agents, for any and all injuries or losses which may be suffered because of my child's participation in the above activity.

I authorize NMHU/San Miguel GEAR-UP to use my child's photo and/or name for promotional reasons.

I give permission for my child to go on scheduled field trips.

I authorize my child's school district to release information about my child's grades and progress in school to NMHU/San Miguel GEAR-UP for the purpose of evaluating the student's progress. This information will remain confidential and will be used only for program evaluation.

We certify that the above is true to the best of our knowledge, as well as give permission to NMHU/San Miguel GEAR-UP and it's funding agencies to acquire information about the above's academic performance from middle school and testing agencies for the purpose of evaluating programs sponsored by NMHU/San Miguel GEAR-UP. 
APPENDIX B - Internet Access Query

SELECT tDemographicQuery.QueryShortDescription, tStudents.

tDemographicResults.Result

FROM tDemographicResults INNER JOIN

tDemographicQuery ON tDemographicResults.QueryID =

tDemographicQuery.QueryID INNER JOIN

tStudents ON tDemographicResults.surStudentID = tStudents.surStudentID

INNER JOIN

tPeople ON tStudents.PersonID = tPeople.PersonID

WHERE (tDemographicQuery.QueryShortDescription = 'InternetAccess') 


\section{APPENDIX C - Income Query}

SELECT tStudents.surStudentID, tDemographicLookups.LookUpValue FROM tDemographicResults INNER JOIN

tDemographicQuery ON tDemographicResults.QueryID = tDemographicQuery.QueryID INNER JOIN

tDemographicLookups ON tDemographicResults. Result = tDemographicLookups.LookUpValueID INNER JOIN

tStudents ON tDemographicResults.surStudentID = tStudents.surStudentID INNER JOIN

tPeople ON tStudents.PersonID = tPeople.PersonID

WHERE (tDemographicQuery.QueryShortDescription = 'IncomeRange') AND (tDemographicResults.Result = 'c26899aa-0e2c-4e36-8f28-edc0b329bffa') OR (tDemographicResults. Result = '5c1d6402-08ff-4227-9111-095b74801c8c') OR (tDemographicResults.Result = '7e61806d-9937-4f22-ad55-0ab6479a7131') OR (tDemographicResults.Result = '85aabf35-9fca-45cd-aa2c-4a3a52be3c2d') OR (tDemographicResults.Result = '3CC17E06-FCF7-4FBF-866C-50269E204A87') OR (tDemographicResults.Result = 'c949c67e-be7d-4f80-9a87-61bcdf78defa') OR (tDemographicResults.Result = 'fefedb51-ef4a-482a-b341-6ad4d776b1c0') ORDER BY tStudents.StudentID 


\section{APPENDIX D - Education Query}

SELECT tStudents.surStudentID, tDemographicLookups.Description, tDemographicLookups.ListOrder, tDemographicQuery.QueryShortDescription FROM tDemographicResults INNER JOIN tDemographicQuery ON tDemographicResults.QueryID = tDemographicQuery.QueryID INNER JOIN tDemographicLookups ON tDemographicResults. Result = tDemographicLookups.LookUpValueID INNER JOIN tStudents ON tDemographicResults.surStudentID = tStudents.surStudentID INNER JOIN

tPeople ON tStudents.PersonID = tPeople.PersonID

WHERE (tDemographicResults.Result = '99057a14-4d0d-4752-81ec464224414a1e') OR (tDemographicResults.Result = 'a9721ca3-ad06-4c92-ba26-4e0d07c3267c') OR (tDemographicResults.Result = 'a247ff4c-e2c7-4e2f-adef-5c37c5ab9df6') OR (tDemographicResults.Result = 'd4788e1a-7d99-41b8-8be9-691abc6586de') OR (tDemographicResults.Result = 'be51792e-b240-4520-b716-bc9b761cf0ae') OR (tDemographicResults.Result = '4dbb122d-1630-4672-b92e-e1688215ed92') 


\section{APPENDIX E - NCE Test Scores Query}

Part 1

SELECT [2004_GRT_Master_Fixed_ID].[NCE Total Score], Internet.[Got-it], income.income, [Parent education].[Edu-descrpt], Internet.[Student ID]

FROM ((Internet INNER JOIN 2004_GRT_Master_Fixed_ID ON

Internet.[Student ID] = [2004_GRT_Master_Fixed_ID].[Student ID]) INNER

JOIN income ON Internet.[Student ID] = income.[Student ID]) INNER JOIN

[Parent education] ON income.[Student ID] = [Parent education].[Student ID];

Part 2

SELECT [full distd].Internet, [full distd].income, [full distd].education, Count([full distd].education) AS CountOfeducation

FROM [full distd]

GROUP BY [full distd].Internet, [full distd].income, [full distd].education

ORDER BY [full distd].Internet, [full distd].income, [full distd].education; 


\section{APPENDIX F - Primary Factorial ANOVA}

Univariate Analysis of Variance

Between-Subjects Factors

\begin{tabular}{|ll|l|}
\hline & & $\mathrm{N}$ \\
\hline Internet @ & 0 & 296 \\
home & 1 & 276 \\
income & 1 & 210 \\
& 2 & 132 \\
& 3 & 230 \\
education & 1 & 333 \\
& 2 & 239 \\
\hline
\end{tabular}

\section{Levene's Test of Equality of Error Variances}

Dependent Variable: NCE total

\begin{tabular}{|c|r|r|r|}
\hline $\mathrm{F}$ & $\mathrm{df} 1$ & $\mathrm{df} 2$ & Sig. \\
\hline 1.732 & 11 & 560 & .063 \\
\hline
\end{tabular}

Tests the null hypothesis that the error variance of the dependent variable is equal across groups.

a. Design:

Intercept+Internet@home+income+education+ Internet@home * income+Internet@home * education+income * education+Internet@home * income * education 


\section{APPENDIX F - Primary Factorial ANOVA (cont.)}

\section{Descriptive Statistics}

Dependent Variable: NCE total

\begin{tabular}{|c|c|c|c|c|c|}
\hline Internet @ home & income & education & Mean & Std. Deviation & $\mathrm{N}$ \\
\hline \multirow[t]{12}{*}{0} & \multirow[t]{3}{*}{$\overline{1}$} & 1 & 40.78 & 13.594 & 124 \\
\hline & & 2 & 54.36 & 14.688 & 25 \\
\hline & & Total & 43.06 & 14.645 & 149 \\
\hline & \multirow[t]{3}{*}{2} & 1 & 44.16 & 13.646 & 51 \\
\hline & & 2 & 50.37 & 8.858 & 19 \\
\hline & & Total & 45.84 & 12.773 & 70 \\
\hline & \multirow[t]{3}{*}{3} & 1 & 46.92 & 16.060 & 25 \\
\hline & & 2 & 49.90 & 16.161 & 52 \\
\hline & & Total & 48.94 & 16.084 & 77 \\
\hline & \multirow[t]{3}{*}{ Total } & 1 & 42.41 & 14.039 & 200 \\
\hline & & 2 & 51.16 & 14.604 & 96 \\
\hline & & Total & 45.25 & 14.780 & 296 \\
\hline \multirow[t]{12}{*}{1} & \multirow[t]{3}{*}{1} & 1 & 43.42 & 15.848 & 38 \\
\hline & & 2 & 46.87 & 11.760 & 23 \\
\hline & & Total & 44.72 & 14.437 & 61 \\
\hline & \multirow[t]{3}{*}{2} & 1 & 46.76 & 14.325 & 38 \\
\hline & & 2 & 48.96 & 12.338 & 24 \\
\hline & & Total & 47.61 & 13.529 & 62 \\
\hline & \multirow[t]{3}{*}{3} & 1 & 45.60 & 19.274 & 57 \\
\hline & & 2 & 55.67 & 17.552 & 96 \\
\hline & & Total & 51.92 & 18.795 & 153 \\
\hline & \multirow[t]{3}{*}{ Total } & 1 & 45.31 & 16.947 & 133 \\
\hline & & 2 & 53.13 & 16.304 & 143 \\
\hline & & Total & 49.36 & 17.042 & 276 \\
\hline \multirow[t]{12}{*}{ Total } & \multirow[t]{3}{*}{1} & 1 & 41.40 & 14.148 & 162 \\
\hline & & 2 & 50.77 & 13.755 & 48 \\
\hline & & Total & 43.54 & 14.570 & 210 \\
\hline & \multirow[t]{3}{*}{2} & 1 & 45.27 & 13.920 & 89 \\
\hline & & 2 & 49.58 & 10.839 & 43 \\
\hline & & Total & 46.67 & 13.113 & 132 \\
\hline & \multirow[t]{3}{*}{3} & 1 & 46.00 & 18.266 & 82 \\
\hline & & 2 & 53.64 & 17.243 & 148 \\
\hline & & Total & 50.92 & 17.953 & 230 \\
\hline & \multirow[t]{3}{*}{ Total } & 1 & 43.57 & 15.308 & 333 \\
\hline & & 2 & 52.33 & 15.642 & 239 \\
\hline & & Total & 47.23 & 16.030 & 572 \\
\hline
\end{tabular}




\section{APPENDIX F - Primary Factorial ANOVA (cont.)}

Tests of Between-Subjects Effects

Dependent Variable: NCE total

\begin{tabular}{|c|c|c|c|c|c|c|c|c|}
\hline Source & $\begin{array}{l}\text { Type III Sum } \\
\text { of Squares }\end{array}$ & df & Mean Square & $\mathrm{F}$ & Sig. & $\begin{array}{l}\text { Partial Eta } \\
\text { Squared }\end{array}$ & $\begin{array}{l}\text { Noncent. } \\
\text { Parameter }\end{array}$ & $\begin{array}{l}\text { Observed } \\
\text { Power }^{\mathrm{a}}\end{array}$ \\
\hline Corrected Model & $15088.381^{b}$ & 11 & 1371.671 & 5.835 & .000 & .103 & 64.187 & 1.000 \\
\hline Intercept & 953475.585 & 1 & 953475.585 & 4056.136 & .000 & .879 & 4056.136 & 1.000 \\
\hline Internet@home & 1.780 & 1 & 1.780 & .008 & .931 & .000 & .008 & .051 \\
\hline income & 812.697 & 2 & 406.348 & 1.729 & .178 & .006 & 3.457 & .363 \\
\hline education & 4290.099 & 1 & 4290.099 & 18.250 & .000 & .032 & 18.250 & .989 \\
\hline Internet@home * income & 423.610 & 2 & 211.805 & .901 & .407 & .003 & 1.802 & .206 \\
\hline $\begin{array}{l}\text { Internet@home * } \\
\text { education }\end{array}$ & 144.331 & 1 & 144.331 & .614 & .434 & .001 & .614 & .123 \\
\hline income * education & 287.888 & 2 & 143.944 & .612 & .542 & .002 & 1.225 & .152 \\
\hline $\begin{array}{l}\text { Internet@home * income } \\
\text { * education }\end{array}$ & 1520.543 & 2 & 760.271 & 3.234 & .040 & .011 & 6.468 & .616 \\
\hline Error & 131639.158 & 560 & 235.070 & & & & & \\
\hline Total & 1422714.000 & 572 & & & & & & \\
\hline Corrected Total & 146727.538 & 571 & & & & & & \\
\hline
\end{tabular}

a. Computed using alpha $=.05$

b. R Squared $=.103$ (Adjusted R Squared $=.085$ ) 
APPENDIX F - Primary Factorial ANOVA (cont.)

\section{Estimated Marginal Means}

\section{Grand Mean}

Dependent Variable: NCE total

\begin{tabular}{|c|r|r|r|}
\hline & & \multicolumn{2}{|c|}{$95 \%$ Confidence Interval } \\
\cline { 3 - 4 } Mean & Std. Error & Lower Bound & Upper Bound \\
\hline 47.814 & .751 & 46.339 & 49.289 \\
\hline
\end{tabular}

\section{Internet @ home}

Dependent Variable: NCE total

\begin{tabular}{|l|r|r|r|r|}
\hline & & & \multicolumn{2}{|c|}{ 95\% Confidence Interval } \\
\cline { 4 - 5 } Internet @ home & Mean & Std. Error & Lower Bound & Upper Bound \\
\hline 0 & 47.749 & 1.083 & 45.622 & 49.875 \\
1 & 47.879 & 1.040 & 45.836 & 49.923 \\
\hline
\end{tabular}

\section{3. income}

Dependent Variable: NCE total

\begin{tabular}{|l|c|r|r|r|}
\hline & & & \multicolumn{2}{|c|}{$95 \%$ Confidence Interval } \\
\cline { 4 - 5 } income & Mean & Std. Error & Lower Bound & Upper Bound \\
\hline 1 & 46.358 & 1.316 & 43.774 & 48.943 \\
2 & 47.562 & 1.435 & 44.742 & 50.381 \\
3 & 49.522 & 1.132 & 47.299 & 51.745 \\
\hline
\end{tabular}

\section{4. education}

Dependent Variable: NCE total

\begin{tabular}{|l|c|r|r|r|}
\hline & & & \multicolumn{2}{|c|}{ 95\% Confidence Interval } \\
\cline { 4 - 5 } education & Mean & Std. Error & Lower Bound & Upper Bound \\
\hline 1 & 44.607 & .949 & 42.743 & 46.470 \\
2 & 51.021 & 1.164 & 48.735 & 53.307 \\
\hline
\end{tabular}

\section{Internet @ home * income}

Dependent Variable: NCE total

\begin{tabular}{|ll|r|r|r|r|}
\hline \multirow{2}{*}{ Internet @ home } & & & & \multicolumn{2}{|c|}{$95 \%$ Confidence Interval } \\
\cline { 5 - 6 } & & & & & \\
& & & & & \\
& 1 & 47.571 & 1.681 & 44.270 & 50.872 \\
& 2 & 47.263 & 2.060 & 43.216 & 51.310 \\
& 3 & 48.412 & 1.866 & 44.747 & 52.077 \\
\hline 1 & 1 & 45.145 & 2.025 & 41.167 & 49.123 \\
& 2 & 47.861 & 1.999 & 43.935 & 51.787 \\
& 3 & 50.632 & 1.282 & 48.114 & 53.149 \\
\hline
\end{tabular}




\section{APPENDIX F - Primary Factorial ANOVA (cont.)}

\section{Internet @ home * education}

Dependent Variable: NCE total

\begin{tabular}{|ll|c|r|r|r|}
\hline & & & & \multicolumn{2}{|c|}{$95 \%$ Confidence Interval } \\
\cline { 5 - 6 } Internet @ home & education & Mean & Std. Error & Lower Bound & Upper Bound \\
\hline 0 & 1 & 43.953 & 1.329 & 41.342 & 46.564 \\
& 2 & 51.544 & 1.709 & 48.187 & 54.902 \\
\hline 1 & 1 & 45.260 & 1.354 & 42.601 & 47.919 \\
& 2 & 50.498 & 1.580 & 47.395 & 53.601 \\
\hline
\end{tabular}

\section{7. income * education}

Dependent Variable: NCE total

\begin{tabular}{|ll|r|r|r|r|}
\hline & & & & \multicolumn{2}{|c|}{$95 \%$ Confidence Interval } \\
\cline { 5 - 6 } income & education & Mean & Std. Error & Lower Bound & Upper Bound \\
\hline 1 & 1 & 42.102 & 1.421 & 39.310 & 44.894 \\
& 2 & 50.615 & 2.215 & 46.264 & 54.965 \\
\hline 2 & 1 & 45.460 & 1.643 & 42.233 & 48.687 \\
& 2 & 49.663 & 2.354 & 45.039 & 54.287 \\
\hline 3 & 1 & 46.258 & 1.839 & 42.646 & 49.870 \\
& 2 & 52.785 & 1.320 & 50.193 & 55.378 \\
\hline
\end{tabular}

\section{Internet @ home * income * education}

Dependent Variable: NCE total

\begin{tabular}{|lll|r|r|r|r|}
\hline & & & & & \multicolumn{2}{|c|}{ 95\% Confidence Interval } \\
\cline { 6 - 7 } Internet @ home & income & education & Mean & Std. Error & Lower Bound & Upper Bound \\
\hline 0 & 1 & 1 & 40.782 & 1.377 & 38.078 & 43.487 \\
& 2 & 54.360 & 3.066 & 48.337 & 60.383 \\
\cline { 6 - 7 } & 2 & 1 & 44.157 & 2.147 & 39.940 & 48.374 \\
& 2 & 50.368 & 3.517 & 43.460 & 57.277 \\
\hline & 3 & 1 & 46.920 & 3.066 & 40.897 & 52.943 \\
& 2 & 49.904 & 2.126 & 45.728 & 54.080 \\
\hline 1 & 1 & 1 & 43.421 & 2.487 & 38.536 & 48.306 \\
& 2 & 46.870 & 3.197 & 40.590 & 53.149 \\
\hline & 2 & 1 & 46.763 & 2.487 & 41.878 & 51.648 \\
& & 2 & 48.958 & 3.130 & 42.811 & 55.106 \\
\hline & 3 & 1 & 45.596 & 2.031 & 41.608 & 49.585 \\
& 2 & 55.667 & 1.565 & 52.593 & 58.740 \\
\hline
\end{tabular}


APPENDIX F - Primary Factorial ANOVA (cont.)

Post Hoc Tests

INCOME

\section{Multiple Comparisons}

\begin{tabular}{|c|c|c|c|c|c|c|c|}
\hline & \multirow[b]{2}{*}{ (I) income } & \multirow[b]{2}{*}{ (J) income } & \multirow{2}{*}{$\begin{array}{c}\text { Mean } \\
\text { Difference } \\
(\mathrm{I}-\mathrm{J})\end{array}$} & \multirow[b]{2}{*}{ Std. Error } & \multirow[b]{2}{*}{ Sig. } & \multicolumn{2}{|c|}{ 95\% Confidence Interval } \\
\hline & & & & & & Lower Bound & Upper Bound \\
\hline \multirow{6}{*}{ Tukey HSD } & 1 & 2 & -3.13 & 1.703 & .158 & -7.13 & .87 \\
\hline & & 3 & $-7.37^{*}$ & 1.463 & .000 & -10.81 & -3.94 \\
\hline & 2 & 1 & 3.13 & 1.703 & .158 & -.87 & 7.13 \\
\hline & & 3 & $-4.24 *$ & 1.674 & .031 & -8.18 & -.31 \\
\hline & 3 & 1 & $7.37^{\star}$ & 1.463 & .000 & 3.94 & 10.81 \\
\hline & & 2 & $4.24^{*}$ & 1.674 & .031 & .31 & 8.18 \\
\hline \multirow[t]{6}{*}{ Scheffe } & 1 & 2 & -3.13 & 1.703 & .185 & -7.31 & 1.05 \\
\hline & & 3 & $-7.37^{*}$ & 1.463 & .000 & -10.97 & -3.78 \\
\hline & 2 & 1 & 3.13 & 1.703 & .185 & -1.05 & 7.31 \\
\hline & & 3 & $-4.24^{*}$ & 1.674 & 041 & -8.35 & -.13 \\
\hline & 3 & 1 & $7.37^{*}$ & 1.463 & .000 & 3.78 & 10.97 \\
\hline & & 2 & $4.24^{*}$ & 1.674 & .041 & .13 & 8.35 \\
\hline
\end{tabular}

Based on observed means.

*. The mean difference is significant at the .05 level. 
APPENDIX F - Primary Factorial ANOVA (cont.)

Homogeneous Subsets

\begin{tabular}{|c|c|c|c|c|}
\hline \multicolumn{5}{|c|}{ NCE total } \\
\hline & \multirow[b]{2}{*}{ income } & \multirow[b]{2}{*}{$\mathrm{N}$} & \multicolumn{2}{|c|}{ Subset } \\
\hline & & & 1 & 2 \\
\hline \multirow{4}{*}{$\begin{array}{l}\text { Student-Newman- } \\
\text { Keuls, }\end{array}$} & 1 & 210 & 43.54 & \\
\hline & 2 & 132 & 46.67 & \\
\hline & 3 & 230 & & 50.92 \\
\hline & Sig. & & .053 & 1.000 \\
\hline \multirow[t]{4}{*}{ Tukey HSDa,b,c } & 1 & 210 & 43.54 & \\
\hline & 2 & 132 & 46.67 & \\
\hline & 3 & 230 & & 50.92 \\
\hline & Sig. & & .129 & 1.000 \\
\hline \multirow[t]{4}{*}{ Scheffe ${ }^{a, b, c}$} & 1 & 210 & 43.54 & \\
\hline & 2 & 132 & 46.67 & \\
\hline & 3 & 230 & & 50.92 \\
\hline & Sig. & & .154 & 1.000 \\
\hline
\end{tabular}

Means for groups in homogeneous subsets are displayed.

Based on Type III Sum of Squares

The error term is Mean Square (Error) $=235.070$.

a. Uses Harmonic Mean Sample Size $=179.797$.

b. The group sizes are unequal. The harmonic mean of the group sizes is used. Type I error levels are not guaranteed.

c. Alpha $=.05$. 
APPENDIX G - Primary Interaction Graphs for Factors A\&B

Primary AB Interaction Data: Internet \& Income, on NCE Total Scale

\begin{tabular}{|c|c|c|c|c|c|c|}
\hline Internet & No & Yes & No & Yes & No & Yes \\
\hline Income Category & 1 & 1 & 2 & 2 & 3 & 3 \\
\hline Mean & 47.57 & 45.15 & 47.27 & 47.86 & 48.41 & 50.68 \\
\hline $\mathrm{n}$ & 149 & 61 & 70 & 62 & 77 & 153 \\
\hline
\end{tabular}

Primary Interaction Chart: Internet \& Income, on NCE Total Scale

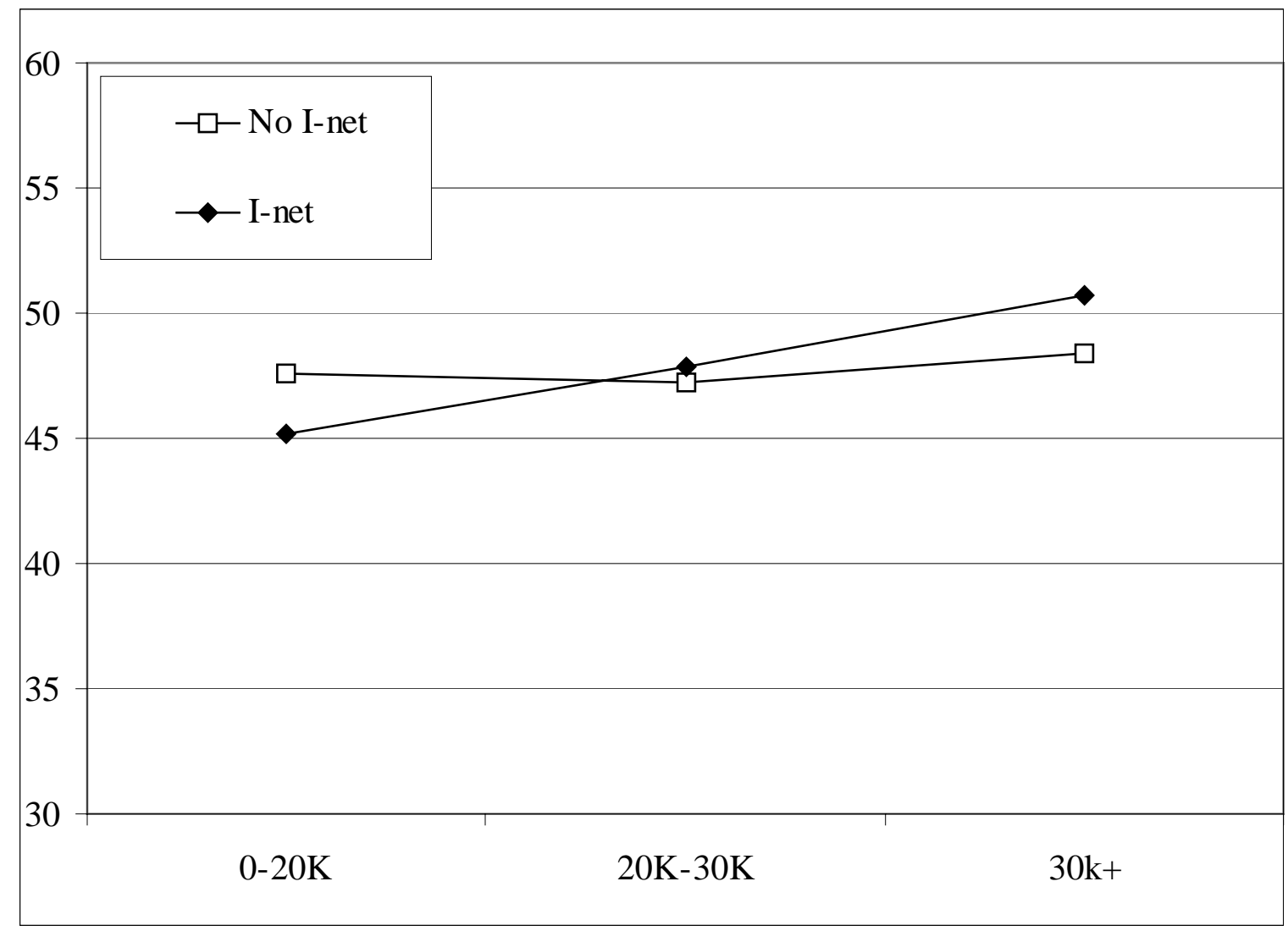

Primary Interaction Chart Data: Internet \& Income, on NCE Total Scale

\begin{tabular}{lccc}
\hline & $0-20 \mathrm{~K}$ & $20 \mathrm{~K}-30 \mathrm{~K}$ & $30 \mathrm{k}^{+}$ \\
\cline { 2 - 4 } No I-net & 47.57 & 47.27 & 48.41 \\
I-net & 45.15 & 47.86 & 50.68 \\
\hline
\end{tabular}


Primary Interaction Chart: Income\& Internet, on NCE Total Scale

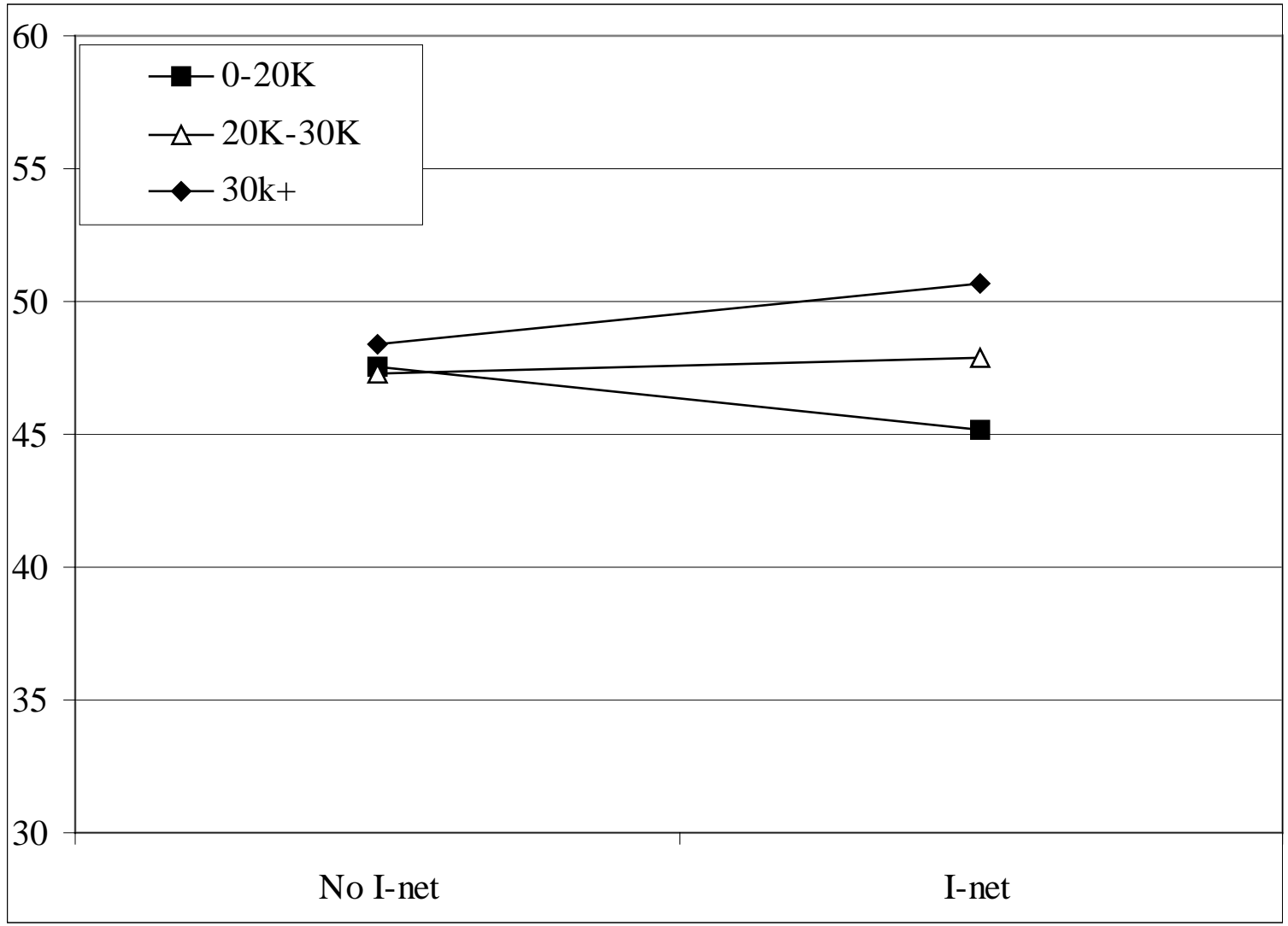

Primary Interaction Chart Data: Income \& Internet, on NCE Total Scale

\begin{tabular}{lcc}
\hline & No I-net & I-net \\
\cline { 2 - 3 } $0-20 \mathrm{~K}$ & 47.57 & 45.15 \\
$20 \mathrm{~K}-30 \mathrm{~K}$ & 47.27 & 47.86 \\
$30 \mathrm{k}^{+}$ & 48.41 & 50.68 \\
\hline
\end{tabular}


APPENDIX H - Primary Interaction Graphs for Factors A\&C

Primary AC Interaction Data: Internet \& Education, on NCE Total Scale

\begin{tabular}{lllllc}
\hline & Internet & No & Yes & No & Yes \\
\cline { 3 - 6 } & Education Category & 1 & 1 & 2 & 2 \\
\cline { 3 - 6 } & & & & & \\
\cline { 3 - 6 } & Mean & 43.95 & 45.26 & 51.54 & 50.53 \\
& & 200 & 133 & 96 & 143 \\
\hline
\end{tabular}

Primary Interaction Chart: Internet \& Education, on NCE Total Scale

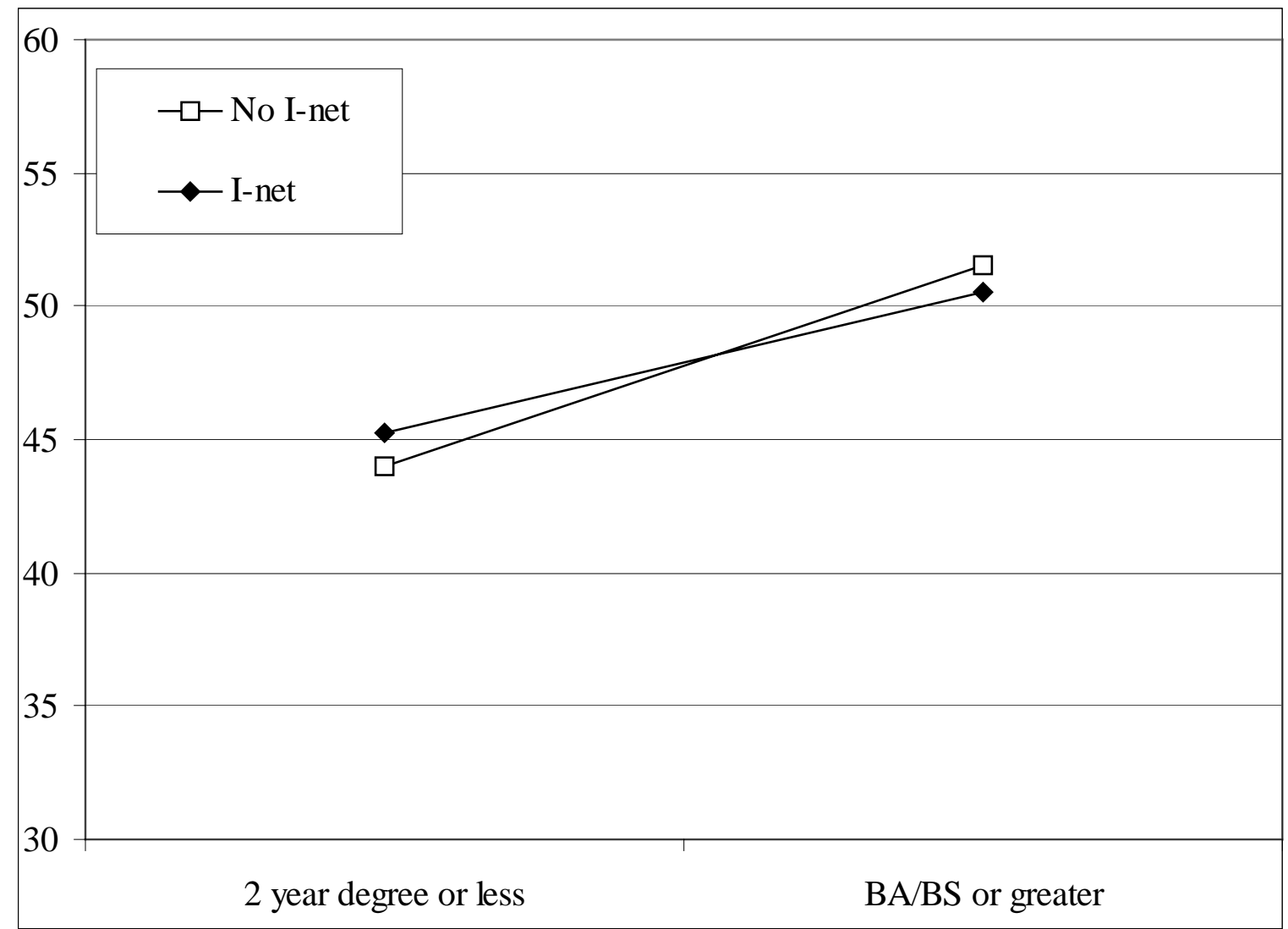

Primary Interaction Chart Data: Internet \& Education, on NCE Total Scale

\begin{tabular}{lcc}
\hline & 2 year degree or less & BA/BS or greater \\
\cline { 2 - 3 } No I-net & 43.95 & 51.54 \\
I-net & 45.26 & 50.53 \\
\hline
\end{tabular}


APPENDIX H - Primary Interaction Graphs for Factors A\&C (cont)

Primary Interaction Chart: Education \& Internet, on NCE Total Scale

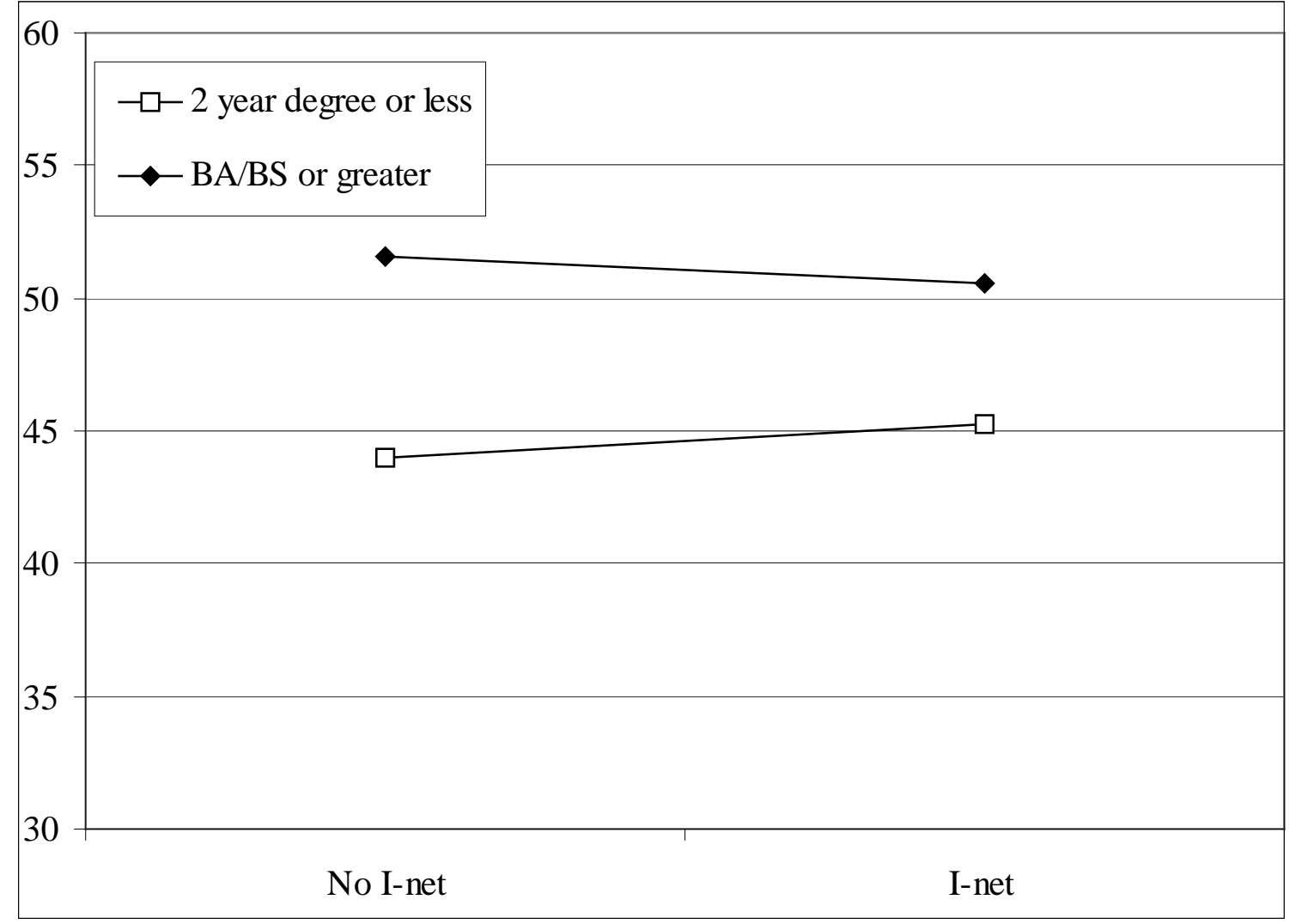

Primary Interaction Chart Data: Education \& Internet, on NCE Total Scale

No I-net I-net

2 year degree or less

43.95

45.26

$\mathrm{BA} / \mathrm{BS}$ or greater

51.54

50.53 
APPENDIX I - Primary Interaction Graphs for Factors B\&C

Primary BC Interaction Data: Income \& Education, on NCE Total Scale

\begin{tabular}{lcccccc}
\hline Income Category & 1 & 1 & 2 & 2 & 3 & 3 \\
\cline { 2 - 7 } Education Category & 1 & 2 & 1 & 2 & 1 & 2 \\
\cline { 2 - 7 } Mean & 42.10 & 50.62 & 45.46 & 49.66 & 46.26 & 52.83 \\
$\mathrm{n}$ & 162 & 48 & 89 & 43 & 82 & 148 \\
\hline
\end{tabular}

Primary Interaction Chart: Income \& Education, on NCE Total Scale

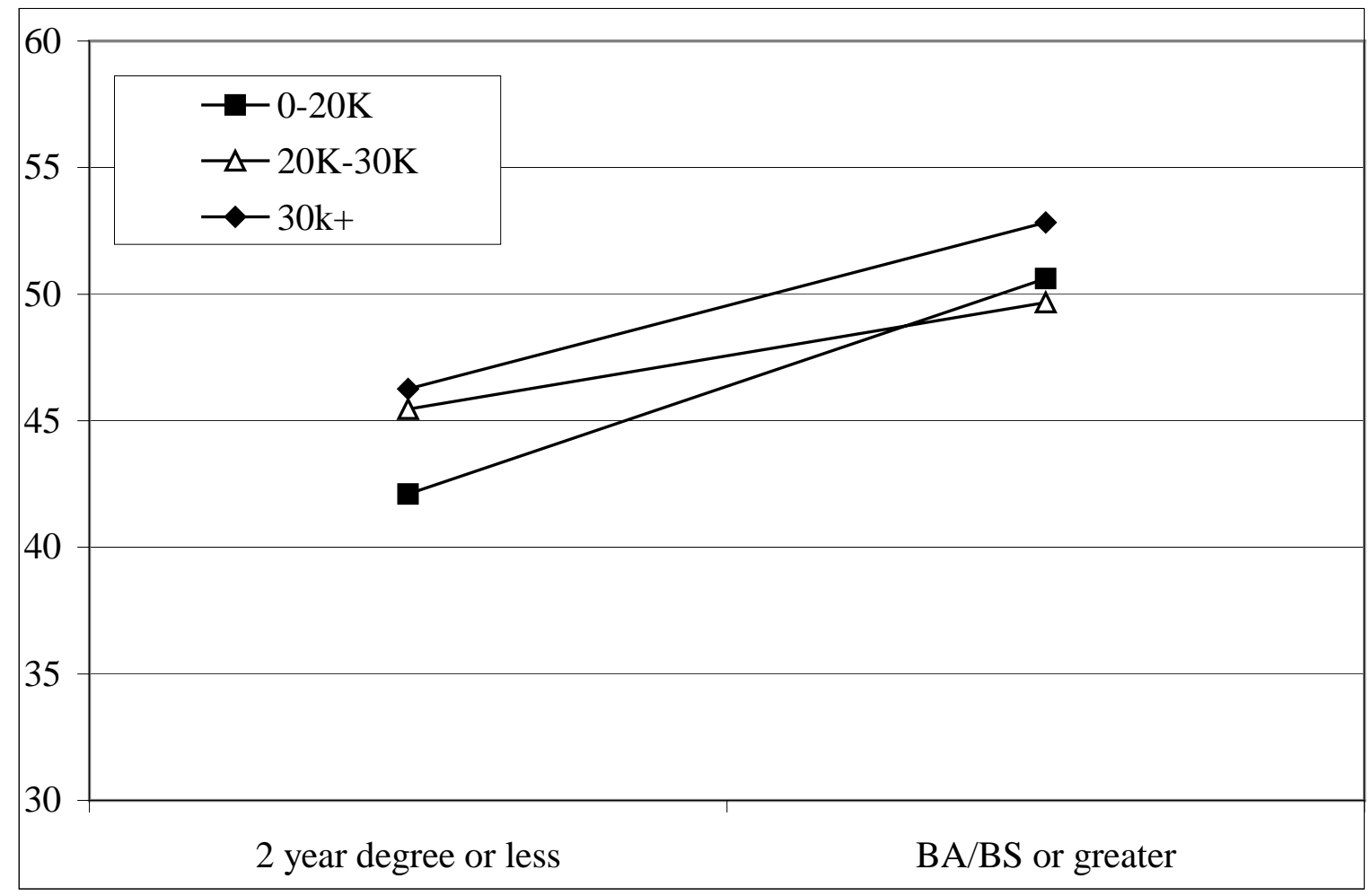

Primary Interaction Chart Data: Income \& Education, on NCE Total Scale

\begin{tabular}{lcc}
\hline & 2 year degree or less & BA/BS or greater \\
\cline { 2 - 3 } $20-20 \mathrm{~K}$ & 42.10 & 50.62 \\
$20 \mathrm{~K}-30 \mathrm{~K}$ & 45.46 & 49.66 \\
$30 \mathrm{k}+$ & 46.26 & 52.83 \\
\hline
\end{tabular}


APPENDIX I - Primary Interaction Graphs for Factors B\&C (cont.)

Primary Interaction Chart: Education \& Income, on NCE Total Scale

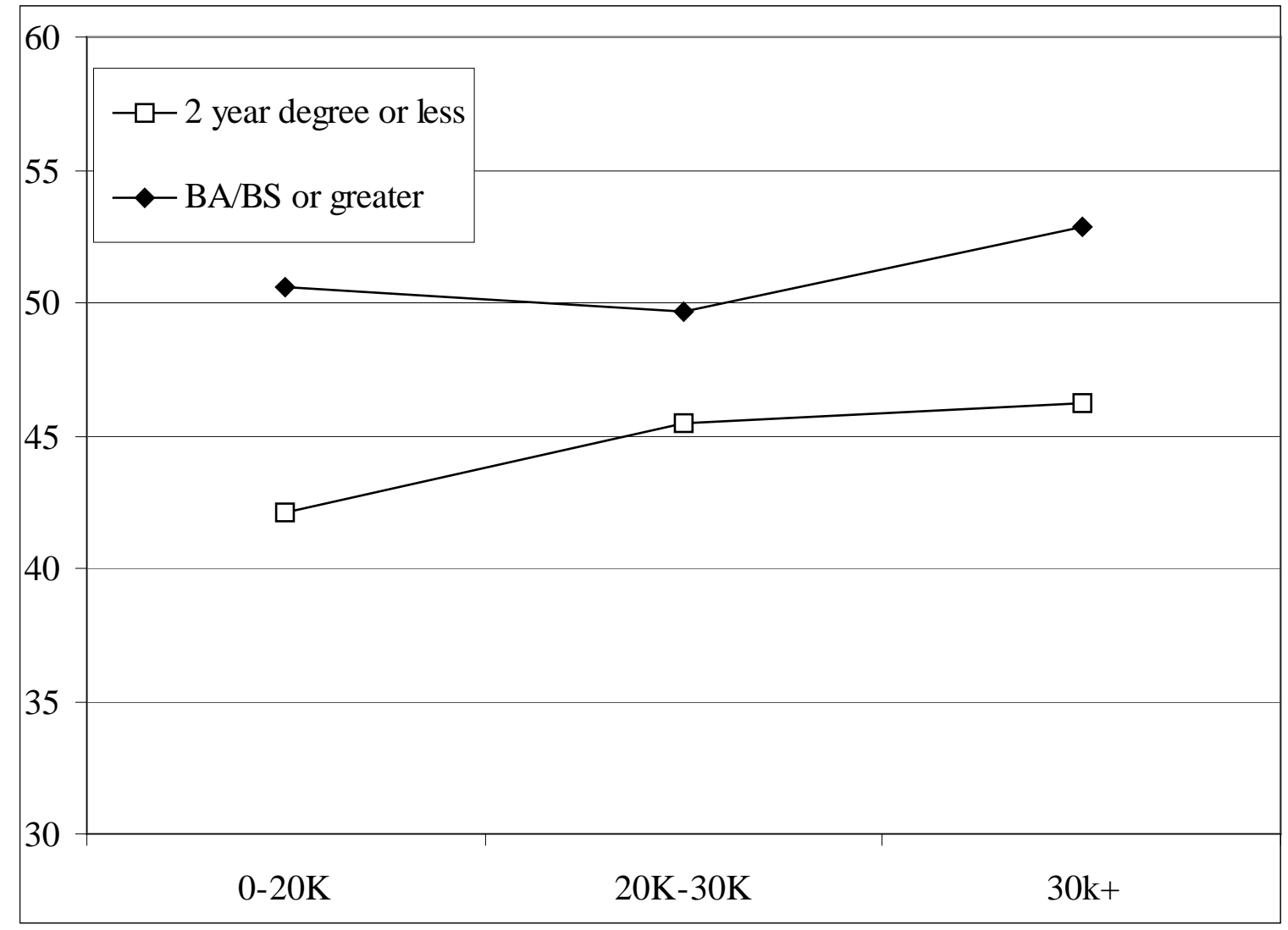

Primary Interaction Chart Data: Education \& Income, on NCE Total Scale

\begin{tabular}{lccc}
\hline & $0-20 \mathrm{~K}$ & $20 \mathrm{~K}-30 \mathrm{~K}$ & $30 \mathrm{k}^{+}$ \\
\cline { 2 - 4 } 2 year degree or less & 42.10 & 45.46 & 46.26 \\
BA/BS or greater & 50.62 & 49.66 & 52.83 \\
\hline
\end{tabular}


APPENDIX J - Primary Interaction Graphs for Factors A\&B\&C

Primary ABC Interaction Data: Internet, Income \& Education, on NCE Total Scale

Elementary School -

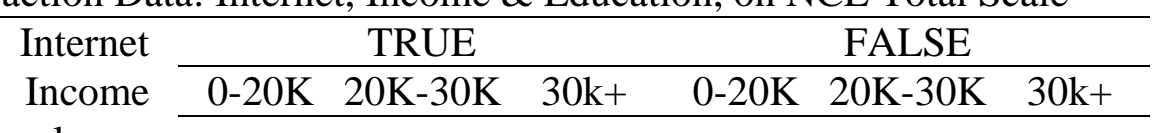

High School - Some

College - 2 year degree

$\begin{array}{llllll}43.42 & 46.76 & 45.60 & 40.78 & 44.16 & 46.92\end{array}$

4 year degree - -

Graduate Program

$\begin{array}{llllll}46.87 & 48.96 & 55.77 & 54.36 & 50.37 & 49.90\end{array}$

Primary Interaction Chart: Internet, Income \& Education, on NCE Total Scale

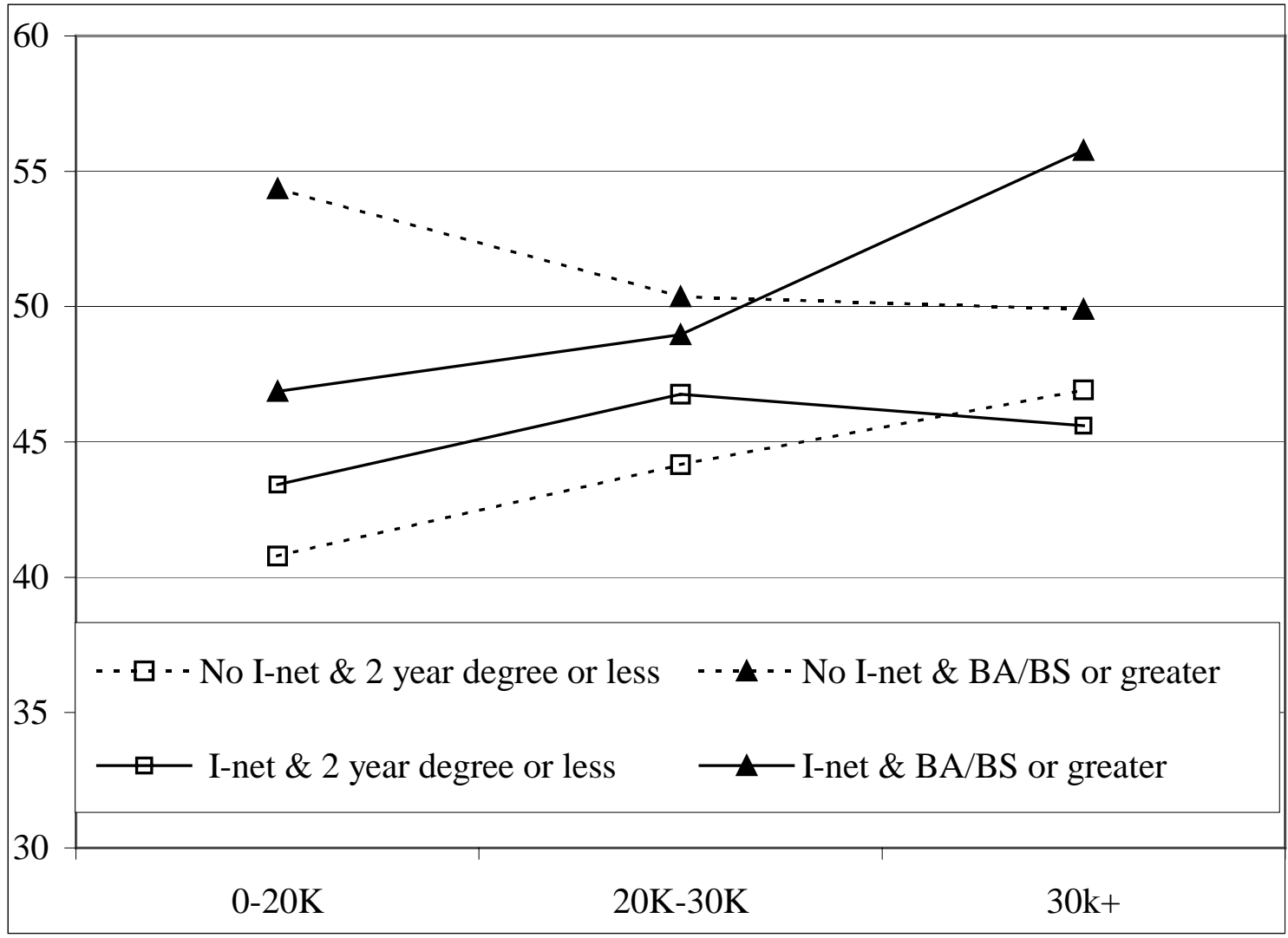

Primary Interaction Chart Data: Internet, Income \& Education, on NCE Total Scale

\begin{tabular}{lccc}
\hline & $0-20 \mathrm{~K}$ & $20 \mathrm{~K}-30 \mathrm{~K}$ & $30 \mathrm{k}^{+}$ \\
\cline { 2 - 4 } No I-net \& 2 year degree or less & 40.78 & 44.16 & 46.92 \\
No I-net \& BA/BS or greater & 54.36 & 50.37 & 49.90 \\
I-net \& 2 year degree or less & 43.42 & 46.76 & 45.60 \\
I-net \& BA/BS or greater & 46.87 & 48.96 & 55.77 \\
\hline
\end{tabular}


APPENDIX J - Primary Interaction Graphs for Factors A\&B\&C (cont.)

Primary Interaction Chart: Internet, Income \& Education, on NCE Total Scale

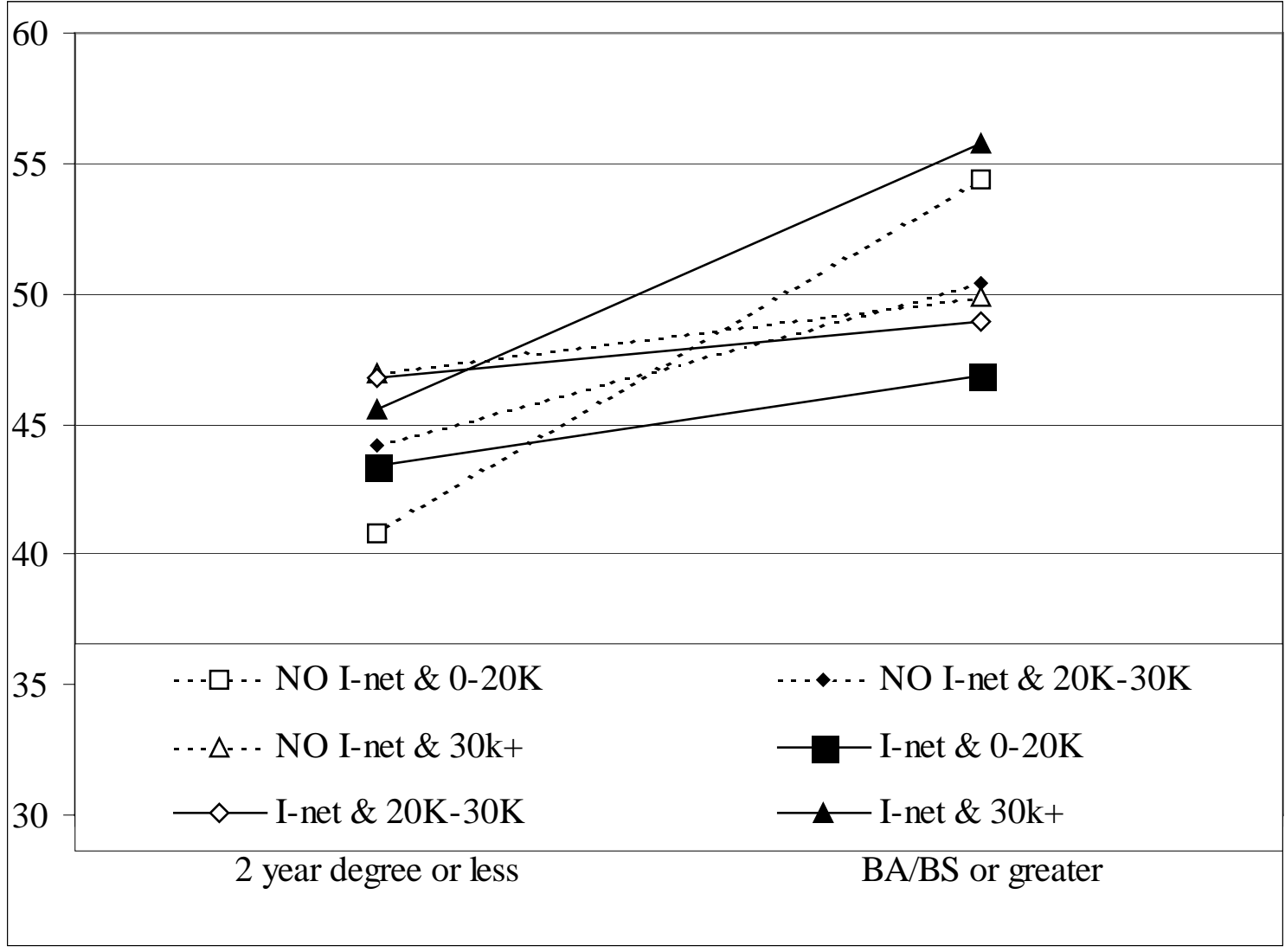

Primary Interaction Chart Data: Internet, Income \& Education, on NCE Total Scale 2 year degree or less $\quad \mathrm{BA} / \mathrm{BS}$ or greater

NO I-net \& 0-20K

NO I-net \& 20K-30K

NO I-net \& 30k+

I-net \& 0-20K

I-net \& 20K-30K

I-net \& $30 \mathrm{k}^{+}$
40.78

44.16

46.92

43.42

46.76

45.60
54.36

50.37

49.90

46.87

48.96

55.77 
APPENDIX J - Primary Interaction Graphs for Factors A\&B\&C (cont.)

Primary Interaction Chart: Internet, Income \& Education, on NCE Total Scale

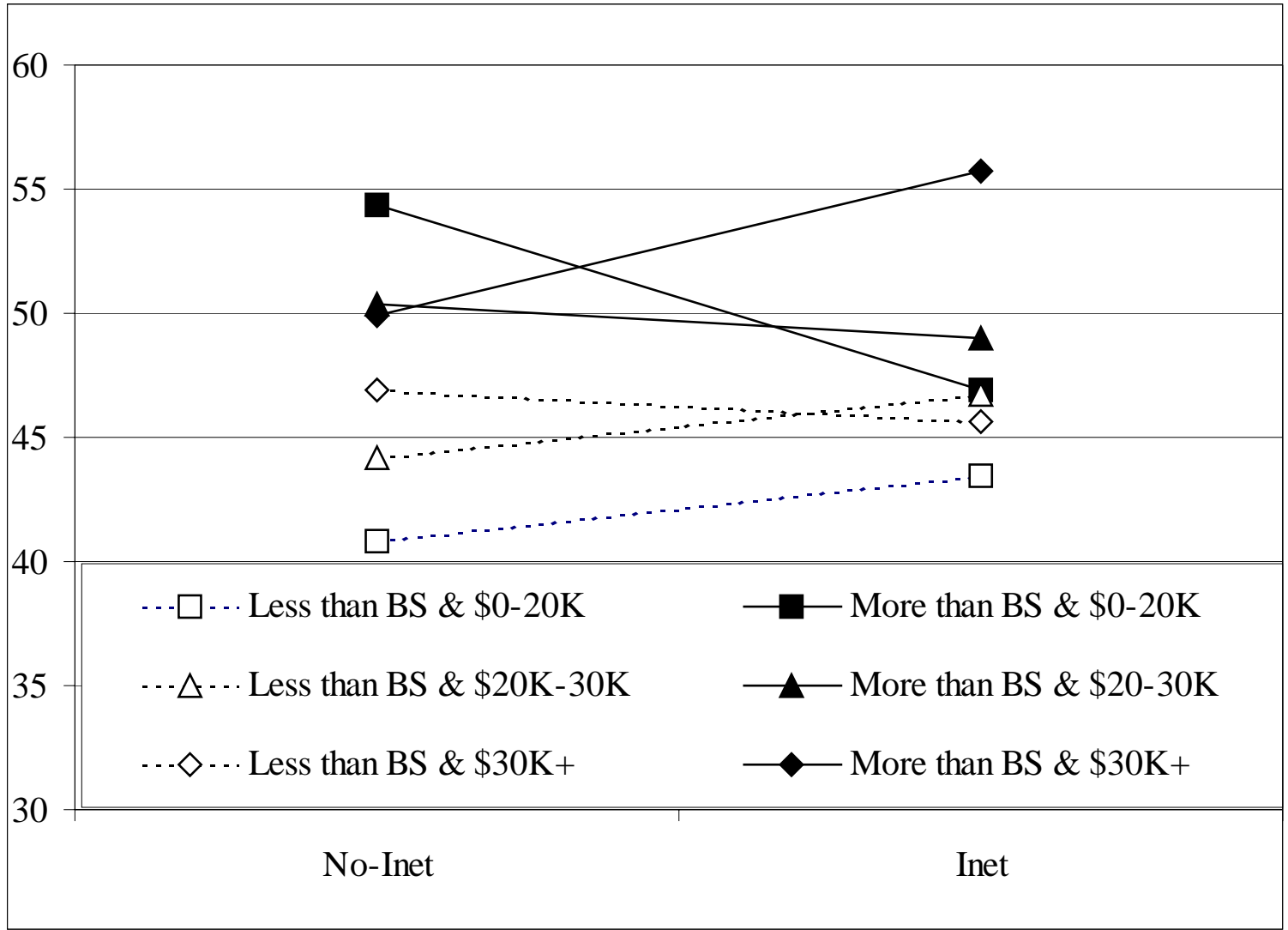

Primary Interaction Chart Data: Internet, Income \& Education, on NCE Total Scale No-Internet at home Internet at home

Less than BS \& \$0-20K

More than BS \& \$0-20K

Less than BS \& \$20K-30K

More than BS \& \$20-30K

Less than BS \& \$30K+

More than BS \& \$30K+
40.78

54.36

44.16

50.37

46.92

49.90
43.42

46.87

46.76

48.96

45.60

55.77 
APPENDIX K - Tukey’s Post Hoc Comparison on Primary ABC Interaction

SPSS did not calculate the post on the 3-way interaction. Therefore, the comparison was performed on Microsoft Excel. Critical difference was calculated as follows:

Critical difference $=\mathrm{q}_{\mathrm{r}} \sqrt{\frac{M S_{\text {within_group_error }}}{n_{(\text {per_group })}}}$

Where:

$q_{r}$ - Significant Studentized Ranges for Tukey Multiple-Comparison Tests

$\mathrm{MS}_{\text {within group error }}$ - taken from the SPSS output

$\mathrm{n}=$ the groups have different $\mathrm{n}$, therefore a harmonic mean was calculated.

$q_{r}$ was found to be 4.62 , where $r=12$ (number of groups that were compared) and $d f=\propto$. While the actual $d f=572$, the table for Significant Studentized Ranges for Tukey Multiple-Comparison Tests (Bruning, \& Kintz, 1997, p 344) listed $d f$ in the increment from 60,120 , and $\propto$.

$\mathrm{MS}_{\text {within group error }}$ was taken from the SPSS output on the Primary Factorial ANOVA.

The calculation for a harmonic mean was specified (Bruning, \& Kintz, 1997, p. 195) as follows:

harmonic mean $=\overline{\mathrm{n}}=\frac{\text { number of groups }}{\frac{1}{\mathrm{n}_{1}}+\frac{1}{\mathrm{n}_{2}}+\frac{1}{\mathrm{n}_{3}}+\frac{1}{\mathrm{n}_{4}}+\frac{1}{\mathrm{n}_{5}}+\ldots+\frac{1}{\mathrm{n}_{\mathrm{n}}}}$ 
APPENDIX K - Tukey’s Post Hoc Comparison on Primary ABC Interaction (cont.)

Therefore the harmonic mean for this study would be

$$
\begin{aligned}
& \overline{\mathrm{n}}=\frac{1}{\frac{1}{124}+\frac{1}{25}+\frac{1}{51}+\frac{1}{19}+\frac{1}{25}+\frac{1}{52}+\frac{1}{38}+\frac{1}{23}+\frac{1}{38}+\frac{1}{24}+\frac{1}{57}+\frac{1}{96}} \\
& \overline{\mathrm{n}}=\frac{12}{0.3453} \\
& \overline{\mathrm{n}}=34.76
\end{aligned}
$$

The critical difference can now be calculated based upon:

$$
\begin{aligned}
& q_{r}=4.62 \\
& \mathrm{MS}_{\text {within group error }}=235.07 \\
& \mathrm{n}=34.76
\end{aligned}
$$

Again, the equation for Tukey's test is:

Critical difference $=\mathrm{q}_{\mathrm{r}} \sqrt{\frac{M S_{\text {within_group_error }_{\text {f }}}}{n_{(\text {per_group })}}}$

Critical difference $=4.62 \sqrt{\frac{235.07}{34.76}}$

Critical difference $=4.62 \times 2.60$

Critical difference $=12.015$ 
APPENDIX K - Tukey’s Post Hoc Comparison on Primary ABC Interaction (cont.)

\begin{tabular}{|c|c|c|c|c|c|c|c|c|c|c|c|c|c|}
\hline \multicolumn{14}{|c|}{ Difference among the 12 means in interaction ABC } \\
\hline \multirow[t]{2}{*}{ GROUP } & & $0-1-1$ & $0-1-2$ & $0-2-1$ & $0-2-2$ & $0-3-1$ & $0-3-2$ & $1-1-1$ & $1-1-2$ & $1-2-1$ & $1-2-2$ & $1-3-1$ & $1-3-2$ \\
\hline & Mean & 40.78 & 54.36 & 44.16 & 50.37 & 46.92 & 49.9 & 43.42 & 46.87 & 46.76 & 48.96 & 45.6 & 55.67 \\
\hline $0-1-1$ & 40.78 & - & -13.58 & -3.38 & -9.59 & -6.14 & -9.12 & -2.64 & -6.09 & -5.98 & -8.18 & -4.82 & -14.89 \\
\hline $0-1-2$ & 54.36 & 13.58 & - & 10.2 & 3.99 & 7.44 & 4.46 & 10.94 & 7.49 & 7.6 & 5.4 & 8.76 & -1.31 \\
\hline $0-2-1$ & 44.16 & 3.38 & -10.2 & - & -6.21 & -2.76 & -5.74 & 0.74 & -2.71 & -2.6 & -4.8 & -1.44 & -11.51 \\
\hline $0-2-2$ & 50.37 & 9.59 & -3.99 & 6.21 & - & 3.45 & 0.47 & 6.95 & 3.5 & 3.61 & 1.41 & 4.77 & -5.3 \\
\hline $0-3-1$ & 46.92 & 6.14 & -7.44 & 2.76 & -3.45 & - & -2.98 & 3.5 & 0.05 & 0.16 & -2.04 & 1.32 & -8.75 \\
\hline $0-3-2$ & 49.9 & 9.12 & -4.46 & 5.74 & -0.47 & 2.98 & - & 6.48 & 3.03 & 3.14 & 0.94 & 4.3 & -5.77 \\
\hline $1-1-1$ & 43.42 & 2.64 & -10.94 & -0.74 & -6.95 & -3.5 & -6.48 & - & -3.45 & -3.34 & -5.54 & -2.18 & -12.25 \\
\hline $1-1-2$ & 46.87 & 6.09 & -7.49 & 2.71 & -3.5 & -0.05 & -3.03 & 3.45 & - & 0.11 & -2.09 & 1.27 & -8.8 \\
\hline $1-2-1$ & 46.76 & 5.98 & -7.6 & 2.6 & -3.61 & -0.16 & -3.14 & 3.34 & -0.11 & - & -2.2 & 1.16 & -8.91 \\
\hline $1-2-2$ & 48.96 & 8.18 & -5.4 & 4.8 & -1.41 & 2.04 & -0.94 & 5.54 & 2.09 & 2.2 & - & 3.36 & -6.71 \\
\hline $1-3-1$ & 45.6 & 4.82 & -8.76 & 1.44 & -4.77 & -1.32 & -4.3 & 2.18 & -1.27 & -1.16 & -3.36 & - & -10.07 \\
\hline $1-3-2$ & 55.67 & 14.89 & 1.31 & 11.51 & 5.3 & 8.75 & 5.77 & 12.25 & 8.8 & 8.91 & 6.71 & 10.07 & - \\
\hline
\end{tabular}

The group code: Internet (1=yes, or $0=$ no), income (category 1,2 , or 3 ), and education (category 1 or 2 ) 
APPENDIX K - Tukey’s Post Hoc Comparison on Primary ABC Interaction (cont.)

\begin{tabular}{|c|c|c|c|c|c|c|c|c|c|c|c|c|c|}
\hline GROUP & & $0-1-1$ & $0-1-2$ & $0-2-1$ & $0-2-2$ & $0-3-1$ & $0-3-2$ & $1-1-1$ & $1-1-2$ & $1-2-1$ & $1-2-2$ & $1-3-1$ & $1-3-2$ \\
\hline & Mean & 40.78 & 54.36 & 44.16 & 50.37 & 46.92 & 49.9 & 43.42 & 46.87 & 46.76 & 48.96 & 45.6 & 55.67 \\
\hline $0-1-1$ & 40.78 & - & -13.58 & - & - & - & - & - & - & - & - & - & -14.89 \\
\hline $0-1-2$ & 54.36 & 13.58 & - & - & - & - & - & - & - & - & - & - & - \\
\hline $0-2-1$ & 44.16 & - & - & - & - & - & - & - & - & - & - & - & - \\
\hline $0-2-2$ & 50.37 & - & - & - & - & - & - & - & - & - & - & - & - \\
\hline $0-3-1$ & 46.92 & - & - & - & - & - & - & - & - & - & - & - & - \\
\hline $0-3-2$ & 49.9 & - & - & - & - & - & - & - & - & - & - & - & - \\
\hline $1-1-1$ & 43.42 & - & - & - & - & - & - & - & - & - & - & - & -12.25 \\
\hline $1-1-2$ & 46.87 & - & - & - & - & - & - & - & - & - & - & - & - \\
\hline $1-2-1$ & 46.76 & - & - & - & - & - & - & - & - & - & - & - & - \\
\hline $1-2-2$ & 48.96 & - & - & - & - & - & - & - & - & - & - & - & - \\
\hline $1-3-1$ & 45.6 & - & - & - & - & - & - & - & - & - & - & - & - \\
\hline $1-3-2$ & 55.67 & 14.89 & - & - & - & - & - & 12.25 & - & - & - & - & - \\
\hline
\end{tabular}

The group code: Internet (1=yes, or $0=$ no), income (category 1,2 , or 3 ), and education (category 1 or 2 ) 
APPENDIX L - One-way ANOVA on Uncategorized Full Set Data

One-way (Internet access)

\section{Descriptives}

\begin{tabular}{|c|c|c|c|c|c|c|c|c|}
\hline & \multirow[b]{2}{*}{$\mathrm{N}$} & \multirow[b]{2}{*}{ Mean } & \multirow[b]{2}{*}{ Std. Deviation } & \multirow[b]{2}{*}{ Std. Error } & \multicolumn{2}{|c|}{$\begin{array}{l}\text { 95\% Confidence Interval for } \\
\text { Mean }\end{array}$} & \multirow[b]{2}{*}{ Minimum } & \multirow[b]{2}{*}{ Maximum } \\
\hline & & & & & Lower Bound & Upper Bound & & \\
\hline 0 & 296 & 45.25 & 14.780 & .859 & 43.56 & 46.94 & 1 & 99 \\
\hline 1 & 276 & 49.36 & 17.042 & 1.026 & 47.34 & 51.38 & 1 & 99 \\
\hline Total & 572 & 47.23 & 16.030 & 670 & 45.91 & 48.55 & 1 & 99 \\
\hline
\end{tabular}

Test of Homogeneity of Variances

NCE total
\begin{tabular}{|r|r|r|r|}
\hline $\begin{array}{c}\text { Levene } \\
\text { Statistic }\end{array}$ & df1 & df2 & Sig. \\
\hline 6.836 & 1 & 570 & .009 \\
\hline
\end{tabular}

ANOVA

NCE total
\begin{tabular}{|l|l|r|r|l|l|}
\hline & $\begin{array}{c}\text { Sum of } \\
\text { Squares }\end{array}$ & df & Mean Square & \multicolumn{1}{c|}{ F } & Sig. \\
\hline Between Groups & 2415.053 & 1 & 2415.053 & 9.539 & .002 \\
Within Groups & 144312.5 & 570 & 253.180 & & \\
Total & 146727.5 & 571 & & & \\
\hline
\end{tabular}


APPENDIX L - One-way ANOVA on Uncategorized Full Set Data (cont.)

One-way ANOVA -

income in 7 categories

Category Description

$1 \quad 0-10 \mathrm{~K}$

2 10K-20K

$3 \quad 20 K-30 K$

$4 \quad 30 \mathrm{~K}-40 \mathrm{~K}$

$5 \quad 40 \mathrm{~K}-50 \mathrm{~K}$

$6 \quad 50 \mathrm{~K}-60 \mathrm{~K}$

$7 \quad 60 \mathrm{k}^{+}$
Descriptives

NCE Total Score

\begin{tabular}{|c|c|c|c|c|c|c|c|c|}
\hline & \multirow[b]{2}{*}{$\mathrm{N}$} & \multirow[b]{2}{*}{ Mean } & \multirow[b]{2}{*}{ Std. Deviation } & \multirow[b]{2}{*}{ Std. Error } & \multicolumn{2}{|c|}{$\begin{array}{c}\text { 95\% Confidence Interval for } \\
\text { Mean }\end{array}$} & \multirow[b]{2}{*}{ Minimum } & \multirow[b]{2}{*}{ Maximum } \\
\hline & & & & & Lower Bound & Upper Bound & & \\
\hline 1 & 88 & 40.83 & 14.770 & 1.575 & 37.70 & 43.96 & 1 & 74 \\
\hline 2 & 122 & 45.50 & 14.163 & 1.282 & 42.96 & 48.04 & 1 & 85 \\
\hline 3 & 132 & 46.67 & 13.113 & 1.141 & 44.42 & 48.93 & 1 & 76 \\
\hline 4 & 54 & 51.28 & 19.579 & 2.664 & 45.93 & 56.62 & 1 & 99 \\
\hline 5 & 74 & 43.70 & 18.447 & 2.144 & 39.43 & 47.98 & 1 & 83 \\
\hline 6 & 34 & 51.03 & 14.246 & 2.443 & 46.06 & 56.00 & 27 & 99 \\
\hline 7 & 68 & 58.43 & 14.590 & 1.769 & 54.89 & 61.96 & 14 & 90 \\
\hline Total & 572 & 47.23 & 16.030 & .670 & 45.91 & 48.55 & 1 & 99 \\
\hline
\end{tabular}

Test of Homogeneity of Variances

\begin{tabular}{|c|c|c|c|}
\hline $\begin{array}{l}\text { Levene } \\
\text { Statistic }\end{array}$ & df1 & $\mathrm{df} 2$ & Sig. \\
\hline 2.318 & 6 & 565 & .032 \\
\hline
\end{tabular}

ANOVA

NCE Total Score
\begin{tabular}{|l|r|r|r|r|r|}
\hline & \multicolumn{1}{|c|}{ Sum of } & df & Mean Square & \multicolumn{1}{c|}{ F } & Sig. \\
\hline Squares & df & 6 & 2471.951 & 10.589 & .000 \\
Within Groups & 131895.8 & 565 & 233.444 & & \\
Total & 146727.5 & 571 & & & \\
\hline
\end{tabular}




\section{APPENDIX L - One-way ANOVA on Uncategorized Full Set Data (cont.)}

Post Hoc Tests - income in 7 categories

\section{Multiple Comparisons}

Dependent Variable: NCE Total Score

Scheffe

\begin{tabular}{|c|c|c|c|c|c|c|}
\hline \multirow[b]{2}{*}{ (I) Income } & \multirow[b]{2}{*}{ (J) Income } & \multirow{2}{*}{$\begin{array}{c}\text { Mean } \\
\text { Difference } \\
(\mathrm{I}-\mathrm{J})\end{array}$} & \multirow[b]{2}{*}{ Std. Error } & \multirow[b]{2}{*}{ Sig. } & \multicolumn{2}{|c|}{ 95\% Confidence Interval } \\
\hline & & & & & Lower Bound & Upper Bound \\
\hline \multirow[t]{6}{*}{1} & 2 & -4.670 & 2.137 & .573 & -12.28 & 2.94 \\
\hline & 3 & -5.845 & 2.103 & .261 & -13.33 & 1.65 \\
\hline & 4 & $-10.448^{*}$ & 2.641 & .017 & -19.86 & -1.04 \\
\hline & 5 & -2.873 & 2.410 & .964 & -11.46 & 5.71 \\
\hline & 6 & -10.200 & 3.085 & .093 & -21.19 & .79 \\
\hline & 7 & $-17.597^{*}$ & 2.467 & .000 & -26.38 & -8.81 \\
\hline \multirow[t]{6}{*}{2} & 1 & 4.670 & 2.137 & .573 & -2.94 & 12.28 \\
\hline & 3 & -1.174 & 1.919 & .999 & -8.01 & 5.66 \\
\hline & 4 & -5.778 & 2.497 & .500 & -14.67 & 3.12 \\
\hline & 5 & 1.797 & 2.251 & 996 & -6.22 & 9.82 \\
\hline & 6 & -5.529 & 2.963 & .746 & -16.08 & 5.02 \\
\hline & 7 & $-12.926^{*}$ & 2.312 & .000 & -21.16 & -4.69 \\
\hline \multirow[t]{6}{*}{3} & 1 & 5.845 & 2.103 & .261 & -1.65 & 13.33 \\
\hline & 2 & 1.174 & 1.919 & .999 & -5.66 & 8.01 \\
\hline & 4 & -4.604 & 2.468 & .747 & -13.39 & 4.19 \\
\hline & 5 & 2.972 & 2.219 & .937 & -4.93 & 10.87 \\
\hline & 6 & -4.355 & 2.938 & .900 & -14.82 & 6.11 \\
\hline & 7 & $-11.752^{*}$ & 2.281 & .000 & -19.88 & -3.63 \\
\hline \multirow[t]{6}{*}{4} & 1 & $10.448^{*}$ & 2.641 & .017 & 1.04 & 19.86 \\
\hline & 2 & 5.778 & 2.497 & .500 & -3.12 & 14.67 \\
\hline & 3 & 4.604 & 2.468 & .747 & -4.19 & 13.39 \\
\hline & 5 & 7.575 & 2.735 & .265 & -2.17 & 17.32 \\
\hline & 6 & .248 & 3.345 & 1.000 & -11.67 & 12.16 \\
\hline & 7 & -7.149 & 2.785 & .362 & -17.07 & 2.77 \\
\hline \multirow[t]{6}{*}{5} & 1 & 2.873 & 2.410 & .964 & -5.71 & 11.46 \\
\hline & 2 & -1.797 & 2.251 & .996 & -9.82 & 6.22 \\
\hline & 3 & -2.972 & 2.219 & .937 & -10.87 & 4.93 \\
\hline & 4 & -7.575 & 2.735 & .265 & -17.32 & 2.17 \\
\hline & 6 & -7.327 & 3.166 & .500 & -18.60 & 3.95 \\
\hline & 7 & $-14.724^{*}$ & 2.567 & .000 & -23.87 & -5.58 \\
\hline \multirow[t]{6}{*}{6} & 1 & 10.200 & 3.085 & .093 & -.79 & 21.19 \\
\hline & 2 & 5.529 & 2.963 & .746 & -5.02 & 16.08 \\
\hline & 3 & 4.355 & 2.938 & .900 & -6.11 & 14.82 \\
\hline & 4 & -.248 & 3.345 & 1.000 & -12.16 & 11.67 \\
\hline & 5 & 7.327 & 3.166 & .500 & -3.95 & 18.60 \\
\hline & 7 & -7.397 & 3.209 & .505 & -18.83 & 4.03 \\
\hline \multirow[t]{6}{*}{7} & 1 & $17.597^{\star}$ & 2.467 & .000 & 8.81 & 26.38 \\
\hline & 2 & $12.926^{*}$ & 2.312 & .000 & 4.69 & 21.16 \\
\hline & 3 & $11.752^{*}$ & 2.281 & .000 & 3.63 & 19.88 \\
\hline & 4 & 7.149 & 2.785 & .362 & -2.77 & 17.07 \\
\hline & 5 & $14.724^{*}$ & 2.567 & .000 & 5.58 & 23.87 \\
\hline & 6 & 7.397 & 3.209 & .505 & -4.03 & 18.83 \\
\hline
\end{tabular}

*. The mean difference is significant at the .05 level. 


\section{APPENDIX L - One-way ANOVA on Uncategorized Full Set Data (cont.)}

One-way ANOVA education in 6 categories

\begin{tabular}{|c|c|}
\hline Category & Description \\
\hline 1 & Finished Elementary School \\
2 & Graduated From High School \\
\hline 3 & Attended College or training after High School \\
4 & Completed a 2-year college or training program \\
\hline 5 & Completed a 4-year degree at a college or University \\
\hline 6 & Attended or completed a College Graduate Program \\
\hline
\end{tabular}

\section{Descriptives}

\begin{tabular}{|c|c|c|c|c|c|c|c|c|}
\hline & \multirow[b]{2}{*}{$\mathrm{N}$} & \multirow[b]{2}{*}{ Mean } & \multirow[b]{2}{*}{ Std. Deviation } & \multirow[b]{2}{*}{ Std. Error } & \multicolumn{2}{|c|}{$\begin{array}{l}\text { 95\% Confidence Interval for } \\
\text { Mean }\end{array}$} & \multirow[b]{2}{*}{ Minimum } & \multirow[b]{2}{*}{ Maximum } \\
\hline & & & & & Lower Bound & Upper Bound & & \\
\hline$\overline{1}$ & 12 & 46.00 & 15.556 & 4.491 & 36.12 & 55.88 & 1 & 63 \\
\hline 2 & 99 & 41.48 & 16.151 & 1.623 & 38.26 & 44.71 & 1 & 92 \\
\hline 3 & 120 & 42.21 & 15.092 & 1.378 & 39.48 & 44.94 & 1 & 76 \\
\hline 4 & 102 & 46.90 & 14.288 & 1.415 & 44.10 & 49.71 & 1 & 99 \\
\hline 5 & 100 & 50.66 & 15.542 & 1.554 & 47.58 & 53.74 & 3 & 85 \\
\hline 6 & 139 & 53.54 & 15.658 & 1.328 & 50.91 & 56.17 & 14 & 99 \\
\hline Total & 572 & 47.23 & 16.030 & .670 & 45.91 & 48.55 & 1 & 99 \\
\hline
\end{tabular}




\section{APPENDIX L - One-way ANOVA on Uncategorized Full Set Data (cont.)}

Test of Homogeneity of Variances

NCE Total Score

\begin{tabular}{|r|r|r|r|}
\hline $\begin{array}{l}\text { Levene } \\
\text { Statistic }\end{array}$ & df1 & df2 & Sig. \\
\hline .707 & 5 & 566 & .618 \\
\hline
\end{tabular}

ANOVA

NCE Total Score

\begin{tabular}{|l|r|r|r|r|r|}
\hline & \multicolumn{1}{|c|}{$\begin{array}{c}\text { Sum of } \\
\text { Squares }\end{array}$} & df & Mean Square & F & Sig. \\
\hline Between Groups & 13033.028 & 5 & 2606.606 & 11.035 & .000 \\
Within Groups & 133694.5 & 566 & 236.209 & & \\
Total & 146727.5 & 571 & & & \\
\hline
\end{tabular}




\section{APPENDIX L - One-way ANOVA on Uncategorized Full Set Data (cont.)}

Post Hoc Tests - Education in 6 categories

\section{Multiple Comparisons}

Dependent Variable: NCE Total Score

Scheffe

\begin{tabular}{|c|c|c|c|c|c|c|}
\hline \multirow[b]{2}{*}{ (I) Education } & \multirow[b]{2}{*}{ (J) Education } & \multirow{2}{*}{$\begin{array}{c}\text { Mean } \\
\text { Difference } \\
(\mathrm{I}-\mathrm{J})\end{array}$} & \multirow[b]{2}{*}{ Std. Error } & \multirow[b]{2}{*}{ Sig. } & \multicolumn{2}{|c|}{ 95\% Confidence Interval } \\
\hline & & & & & Lower Bound & Upper Bound \\
\hline \multirow[t]{5}{*}{1} & 2 & 4.515 & 4.698 & .968 & -11.17 & 20.20 \\
\hline & 3 & 3.792 & 4.653 & .985 & -11.75 & 19.33 \\
\hline & 4 & -.902 & 4.690 & 1.000 & -16.56 & 14.76 \\
\hline & 5 & -4.660 & 4.695 & .964 & -20.34 & 11.02 \\
\hline & 6 & -7.540 & 4.624 & .752 & -22.98 & 7.90 \\
\hline \multirow[t]{5}{*}{2} & 1 & -4.515 & 4.698 & .968 & -20.20 & 11.17 \\
\hline & 3 & -.723 & 2.087 & 1.000 & -7.69 & 6.24 \\
\hline & 4 & -5.417 & 2.168 & .285 & -12.66 & 1.82 \\
\hline & 5 & $-9.175^{\star}$ & 2.179 & .004 & -16.45 & -1.90 \\
\hline & 6 & $-12.055^{\star}$ & 2.021 & .000 & -18.80 & -5.31 \\
\hline \multirow[t]{5}{*}{3} & 1 & -3.792 & 4.653 & .985 & -19.33 & 11.75 \\
\hline & 2 & .723 & 2.087 & 1.000 & -6.24 & 7.69 \\
\hline & 4 & -4.694 & 2.070 & .400 & -11.61 & 2.22 \\
\hline & 5 & $-8.452^{\star}$ & 2.081 & .006 & -15.40 & -1.50 \\
\hline & 6 & $-11.331^{*}$ & 1.915 & .000 & -17.73 & -4.94 \\
\hline \multirow[t]{5}{*}{4} & 1 & .902 & 4.690 & 1.000 & -14.76 & 16.56 \\
\hline & 2 & 5.417 & 2.168 & .285 & -1.82 & 12.66 \\
\hline & 3 & 4.694 & 2.070 & .400 & -2.22 & 11.61 \\
\hline & 5 & -3.758 & 2.163 & .697 & -10.98 & 3.46 \\
\hline & 6 & -6.638 & 2.004 & .053 & -13.33 & .05 \\
\hline \multirow[t]{5}{*}{5} & 1 & 4.660 & 4.695 & .964 & -11.02 & 20.34 \\
\hline & 2 & $9.175^{\star}$ & 2.179 & .004 & 1.90 & 16.45 \\
\hline & 3 & $8.452^{\star}$ & 2.081 & .006 & 1.50 & 15.40 \\
\hline & 4 & 3.758 & 2.163 & .697 & -3.46 & 10.98 \\
\hline & 6 & -2.880 & 2.015 & .843 & -9.61 & 3.85 \\
\hline \multirow[t]{5}{*}{6} & 1 & 7.540 & 4.624 & .752 & -7.90 & 22.98 \\
\hline & 2 & $12.055^{\star}$ & 2.021 & .000 & 5.31 & 18.80 \\
\hline & 3 & $11.331^{*}$ & 1.915 & .000 & 4.94 & 17.73 \\
\hline & 4 & 6.638 & 2.004 & .053 & -.05 & 13.33 \\
\hline & 5 & 2.880 & 2.015 & .843 & -3.85 & 9.61 \\
\hline
\end{tabular}

*. The mean difference is significant at the .05 level. 
APPENDIX M - One-way ANOVA on categorized full set data

One-way - Income in 3 categories

\section{Descriptives}

\begin{tabular}{|c|c|c|c|c|c|c|c|c|}
\hline & \multirow[b]{2}{*}{$\mathrm{N}$} & \multirow[b]{2}{*}{ Mean } & \multirow[b]{2}{*}{ Std. Deviation } & \multirow[b]{2}{*}{ Std. Error } & \multicolumn{2}{|c|}{$\begin{array}{l}\text { 95\% Confidence Interval for } \\
\text { Mean }\end{array}$} & \multirow[b]{2}{*}{ Minimum } & \multirow[b]{2}{*}{ Maximum } \\
\hline & & & & & Lower Bound & Upper Bound & & \\
\hline 1 & 210 & 43.54 & 14.570 & 1.005 & 41.56 & 45.52 & 1 & 85 \\
\hline 2 & 132 & 46.67 & 13.113 & 1.141 & 44.42 & 48.93 & 1 & 76 \\
\hline 3 & 230 & 50.92 & 17.953 & 1.184 & 48.58 & 53.25 & 1 & 99 \\
\hline Total & 572 & 47.23 & 16.030 & .670 & 45.91 & 48.55 & 1 & 99 \\
\hline
\end{tabular}

\section{Test of Homogeneity of Variances}

\begin{tabular}{|c|c|c|c|}
\hline \multicolumn{4}{|l|}{ NCE total } \\
\hline $\begin{array}{l}\text { Levene } \\
\text { Statistic }\end{array}$ & df1 & df2 & Siq. \\
\hline 6.663 & 2 & 569 & .001 \\
\hline
\end{tabular}

NCE total
\begin{tabular}{|l|l|r|r|r|c|}
\hline & $\begin{array}{l}\text { Sum of } \\
\text { Squares }\end{array}$ & \multicolumn{1}{c|}{ df } & Mean Square & F & Sig. \\
\hline Between Groups & 6023.001 & 2 & 3011.501 & 12.178 & .000 \\
Within Groups & 140704.5 & 569 & 247.284 & & \\
Total & 146727.5 & 571 & & & \\
\hline
\end{tabular}


APPENDIX M - One-way ANOVA on categorized full set data (cont.)

Post Hoc Tests - Income in 3 categories

\section{Multiple Comparisons}

\begin{tabular}{|c|c|c|c|c|c|c|c|}
\hline & \multirow[b]{2}{*}{ (I) INCOME } & \multirow[b]{2}{*}{ (J) INCOME } & \multirow{2}{*}{$\begin{array}{c}\text { Mean } \\
\text { Difference } \\
(\mathrm{I}-\mathrm{J})\end{array}$} & \multirow[b]{2}{*}{ Std. Error } & \multirow[b]{2}{*}{ Sig. } & \multicolumn{2}{|c|}{ 95\% Confidence Interval } \\
\hline & & & & & & Lower Bound & Upper Bound \\
\hline \multirow[t]{6}{*}{ Scheffe } & \multirow[t]{2}{*}{1} & 2 & -3.13 & 1.747 & .201 & -7.42 & 1.16 \\
\hline & & 3 & $-7.37^{*}$ & 1.501 & .000 & -11.06 & -3.69 \\
\hline & \multirow[t]{2}{*}{2} & 1 & 3.13 & 1.747 & .201 & -1.16 & 7.42 \\
\hline & & 3 & $-4.24^{*}$ & 1.717 & .048 & -8.46 & -.03 \\
\hline & \multirow[t]{2}{*}{3} & 1 & $7.37^{*}$ & 1.501 & .000 & 3.69 & 11.06 \\
\hline & & 2 & $4.24^{*}$ & 1.717 & .048 & .03 & 8.46 \\
\hline
\end{tabular}

*. The mean difference is significant at the .05 level. 
APPENDIX M - One-way ANOVA on categorized full set data (cont.)

One-way (Education)

\section{Descriptives}

\begin{tabular}{|c|c|c|c|c|c|c|c|c|}
\hline & \multirow[b]{2}{*}{$\mathrm{N}$} & \multirow[b]{2}{*}{ Mean } & \multirow[b]{2}{*}{ Std. Deviation } & \multirow[b]{2}{*}{ Std. Error } & \multicolumn{2}{|c|}{$\begin{array}{l}\text { 95\% Confidence Interval for } \\
\text { Mean }\end{array}$} & \multirow[b]{2}{*}{ Minimum } & \multirow[b]{2}{*}{ Maximum } \\
\hline & & & & & Lower Bound & Upper Bound & & \\
\hline 1 & 333 & 43.57 & 15.308 & .839 & 41.92 & 45.22 & 1 & $\overline{99}$ \\
\hline 2 & 239 & 52.33 & 15.642 & 1.012 & 50.34 & 54.33 & 3 & 99 \\
\hline Total & 572 & 47.23 & 16.030 & .670 & 45.91 & 48.55 & 1 & 99 \\
\hline
\end{tabular}

Test of Homogeneity of Variances

NCE total
\begin{tabular}{|r|r|r|c|}
\hline $\begin{array}{c}\text { Levene } \\
\text { Statistic }\end{array}$ & df1 & df2 & Sig. \\
\hline .789 & 1 & 570 & .375 \\
\hline
\end{tabular}

ANOVA

NCE total
\begin{tabular}{|l|r|r|r|r|r|}
\hline & \multicolumn{1}{|c|}{ Sum of } & df & Mean Square & \multicolumn{1}{c|}{ F } & Sig. \\
\hline Between Groups & 10694.587 & 1 & 10694.587 & 44.812 & .000 \\
Within Groups & 136033.0 & 570 & 238.654 & & \\
Total & 146727.5 & 571 & & & \\
\hline
\end{tabular}


APPENDIX N - Analysis: First Trimmed Dataset

Univariate Analysis of Variance

Between-Subjects Factors

\begin{tabular}{|ll|l|}
\hline & & N \\
\hline INTERNET & 0 & 290 \\
& 1 & 270 \\
INCOME & 1 & 206 \\
& 2 & 131 \\
& 3 & 223 \\
education & 1 & 323 \\
& 2 & 237 \\
\hline
\end{tabular}

Levene's Test of Equality of Error Variances

Dependent Variable: NCE total

\begin{tabular}{|c|r|r|r|}
\hline$F$ & df1 & df2 & Sig. \\
\hline 2.009 & 11 & 548 & .026 \\
\hline
\end{tabular}

Tests the null hypothesis that the error variance of the dependent variable is equal across groups.

a. Design:

Intercept+INTERNET+INCOME+EDUCATIO+INTERNET

* INCOME+INTERNET * EDUCATIO+INCOME *

EDUCATIO+INTERNET * INCOME * EDUCATIO 
APPENDIX N - Analysis: First Trimmed Dataset (cont.)

Descriptive Statistics

Dependent Variable: NCE total

\begin{tabular}{|c|c|c|c|c|c|}
\hline INTERNET & INCOME & education & Mean & Std. Deviation & $\mathrm{N}$ \\
\hline \multirow[t]{12}{*}{0} & \multirow[t]{3}{*}{1} & 1 & 41.77 & 12.201 & 121 \\
\hline & & 2 & 54.36 & 14.688 & 25 \\
\hline & & Total & 43.92 & 13.474 & 146 \\
\hline & \multirow[t]{3}{*}{2} & 1 & 45.02 & 12.298 & 50 \\
\hline & & 2 & 50.37 & 8.858 & 19 \\
\hline & & Total & 46.49 & 11.642 & 69 \\
\hline & \multirow[t]{3}{*}{3} & 1 & 44.75 & 12.095 & 24 \\
\hline & & 2 & 48.94 & 14.740 & 51 \\
\hline & & Total & 47.60 & 14.005 & 75 \\
\hline & \multirow[t]{3}{*}{ Total } & 1 & 42.97 & 12.247 & 195 \\
\hline & & 2 & 50.65 & 13.818 & 95 \\
\hline & & Total & 45.49 & 13.261 & 290 \\
\hline \multirow[t]{12}{*}{1} & \multirow[t]{3}{*}{1} & 1 & 44.57 & 14.381 & 37 \\
\hline & & 2 & 46.87 & 11.760 & 23 \\
\hline & & Total & 45.45 & 13.380 & 60 \\
\hline & \multirow[t]{3}{*}{2} & 1 & 46.76 & 14.325 & 38 \\
\hline & & 2 & 48.96 & 12.338 & 24 \\
\hline & & Total & 47.61 & 13.529 & 62 \\
\hline & \multirow[t]{3}{*}{3} & 1 & 48.96 & 15.347 & 53 \\
\hline & & 2 & 55.21 & 17.063 & 95 \\
\hline & & Total & 52.97 & 16.689 & 148 \\
\hline & \multirow[t]{3}{*}{ Total } & 1 & 47.04 & 14.771 & 128 \\
\hline & & 2 & 52.80 & 15.896 & 142 \\
\hline & & Total & 50.07 & 15.613 & 270 \\
\hline \multirow[t]{12}{*}{ Total } & \multirow[t]{3}{*}{1} & 1 & 42.42 & 12.752 & 158 \\
\hline & & 2 & 50.77 & 13.755 & 48 \\
\hline & & Total & 44.37 & 13.432 & 206 \\
\hline & \multirow[t]{3}{*}{2} & 1 & 45.77 & 13.161 & 88 \\
\hline & & 2 & 49.58 & 10.839 & 43 \\
\hline & & Total & 47.02 & 12.534 & 131 \\
\hline & \multirow[t]{3}{*}{3} & 1 & 47.65 & 14.467 & 77 \\
\hline & & 2 & 53.02 & 16.512 & 146 \\
\hline & & Total & 51.17 & 16.009 & 223 \\
\hline & \multirow[t]{3}{*}{ Total } & 1 & 44.58 & 13.432 & 323 \\
\hline & & 2 & 51.94 & 15.104 & 237 \\
\hline & & Total & 47.70 & 14.611 & 560 \\
\hline
\end{tabular}


APPENDIX N - Analysis: First Trimmed Dataset (cont.)

Tests of Between-Subjects Effects

\begin{tabular}{|c|c|c|c|c|c|c|c|c|}
\hline Source & $\begin{array}{l}\text { Type III Sum } \\
\text { of Squares }\end{array}$ & df & Mean Square & $\mathrm{F}$ & Sig. & $\begin{array}{l}\text { Partial Eta } \\
\text { Squared }\end{array}$ & $\begin{array}{l}\text { Noncent. } \\
\text { Parameter }\end{array}$ & $\begin{array}{c}\text { Observed } \\
\text { Power }^{\mathrm{a}} \\
\end{array}$ \\
\hline Corrected Model & $12041.157^{b}$ & 11 & 1094.651 & 5.591 & .000 & .101 & 61.502 & 1.000 \\
\hline Intercept & 949565.806 & 1 & 949565.806 & 4850.086 & .000 & .898 & 4850.086 & 1.000 \\
\hline INTERNET & 107.109 & 1 & 107.109 & .547 & .460 & .001 & .547 & .114 \\
\hline INCOME & 533.819 & 2 & 266.909 & 1.363 & .257 & .005 & 2.727 & .294 \\
\hline EDUCATIO & 3087.708 & 1 & 3087.708 & 15.771 & .000 & .028 & 15.771 & .977 \\
\hline INTERNET * INCOME & 1165.974 & 2 & 582.987 & 2.978 & .052 & .011 & 5.955 & .578 \\
\hline INTERNET * EDUCATIO & 370.319 & 1 & 370.319 & 1.891 & .170 & .003 & 1.891 & .279 \\
\hline INCOME * EDUCATIO & 215.904 & 2 & 107.952 & .551 & .576 & .002 & 1.103 & .141 \\
\hline $\begin{array}{l}\text { INTERNET * INCOME * } \\
\text { EDUCATIO }\end{array}$ & 727.926 & 2 & 363.963 & 1.859 & .157 & .007 & 3.718 & .388 \\
\hline Error & 107289.236 & 548 & 195.783 & & & & & \\
\hline Total & 1393302.000 & 560 & & & & & & \\
\hline Corrected Total & 119330.393 & 559 & & & & & & \\
\hline
\end{tabular}

a. Computed using alpha $=.05$

b. R Squared $=.101$ (Adjusted R Squared $=.083$ ) 
APPENDIX N - Analysis: First Trimmed Dataset (cont.)

\section{Estimated Marginal Means}

\section{Grand Mean}

Dependent Variable: NCE total

\begin{tabular}{|c|r|r|r|}
\hline & & \multicolumn{2}{|c|}{$95 \%$ Confidence Interval } \\
\cline { 3 - 4 } Mean & Std. Error & Lower Bound & Upper Bound \\
\hline 48.045 & .690 & 46.690 & 49.400 \\
\hline
\end{tabular}

\section{INTERNET}

Dependent Variable: NCE total

\begin{tabular}{|l|r|r|r|r|}
\hline & & & \multicolumn{2}{|c|}{ 95\% Confidence Interval } \\
\cline { 4 - 5 } INTERNET & Mean & Std. Error & Lower Bound & Upper Bound \\
\hline 0 & 47.535 & .995 & 45.580 & 49.490 \\
1 & 48.555 & .956 & 46.678 & 50.432 \\
\hline
\end{tabular}

\section{INCOME}

Dependent Variable: NCE total

\begin{tabular}{|l|c|r|r|r|}
\hline & & & \multicolumn{2}{|c|}{ 95\% Confidence Interval } \\
\cline { 4 - 5 } INCOME & Mean & Std. Error & Lower Bound & Upper Bound \\
\hline 1 & 46.891 & 1.206 & 44.523 & 49.259 \\
2 & 47.777 & 1.312 & 45.201 & 50.354 \\
3 & 49.466 & 1.053 & 47.397 & 51.535 \\
\hline
\end{tabular}

\section{4. education}

Dependent Variable: NCE total

\begin{tabular}{|l|c|r|r|r|}
\hline & & & \multicolumn{2}{|c|}{ 95\% Confidence Interval } \\
\cline { 4 - 5 } education & Mean & Std. Error & Lower Bound & Upper Bound \\
\hline 1 & 45.305 & .879 & 43.578 & 47.032 \\
2 & 50.785 & 1.063 & 48.696 & 52.873 \\
\hline
\end{tabular}

\section{INTERNET * INCOME}

Dependent Variable: NCE total

\begin{tabular}{|ll|r|r|r|r|}
\hline & & & & \multicolumn{2}{|c|}{ 95\% Confidence Interval } \\
\cline { 5 - 6 } INTERNET & INCOME & Mean & Std. Error & Lower Bound & Upper Bound \\
\hline 0 & 1 & 48.064 & 1.537 & 45.045 & 51.083 \\
& 2 & 47.694 & 1.885 & 43.991 & 51.398 \\
& 3 & 46.846 & 1.732 & 43.444 & 50.247 \\
\hline 1 & 1 & 45.719 & 1.858 & 42.070 & 49.368 \\
& 2 & 47.861 & 1.824 & 44.278 & 51.444 \\
& 3 & 52.086 & 1.199 & 49.730 & 54.443 \\
\hline
\end{tabular}


APPENDIX N - Analysis: First Trimmed Dataset (cont.)

\section{INTERNET * education}

Dependent Variable: NCE total

\begin{tabular}{|c|c|c|c|c|c|}
\hline \multirow[b]{2}{*}{ INTERNET } & \multirow[b]{2}{*}{ education } & \multirow[b]{2}{*}{ Mean } & \multirow[b]{2}{*}{ Std. Error } & \multicolumn{2}{|c|}{ 95\% Confidence Interval } \\
\hline & & & & Lower Bound & Upper Bound \\
\hline \multirow[t]{2}{*}{0} & 1 & 43.846 & 1.233 & 41.423 & 46.269 \\
\hline & 2 & 51.223 & 1.563 & 48.154 & 54.293 \\
\hline \multirow[t]{2}{*}{1} & 1 & 46.764 & 1.253 & 44.302 & 49.226 \\
\hline & 2 & 50.346 & 1.443 & 47.512 & 53.180 \\
\hline
\end{tabular}

\section{INCOME * education}

Dependent Variable: NCE total

\begin{tabular}{|ll|r|r|r|r|}
\hline & & & & \multicolumn{2}{|c|}{$95 \%$ Confidence Interval } \\
\cline { 5 - 6 } INCOME & education & Mean & Std. Error & Lower Bound & Upper Bound \\
\hline 1 & 1 & 43.168 & 1.314 & 40.586 & 45.750 \\
& 2 & 50.615 & 2.021 & 46.644 & 54.585 \\
\hline 2 & 1 & 45.892 & 1.506 & 42.934 & 48.849 \\
& 2 & 49.663 & 2.148 & 45.443 & 53.883 \\
\hline 3 & 1 & 46.856 & 1.721 & 43.475 & 50.237 \\
& 2 & 52.076 & 1.214 & 49.690 & 54.461 \\
\hline
\end{tabular}

\section{INTERNET * INCOME * education}

Dependent Variable: NCE total

\begin{tabular}{|c|c|c|c|c|c|c|}
\hline \multirow[b]{2}{*}{ INTERNET } & \multirow[b]{2}{*}{ INCOME } & \multirow[b]{2}{*}{ education } & \multirow[b]{2}{*}{ Mean } & \multirow[b]{2}{*}{ Std. Error } & \multicolumn{2}{|c|}{ 95\% Confidence Interval } \\
\hline & & & & & Lower Bound & Upper Bound \\
\hline \multirow[t]{6}{*}{0} & \multirow[t]{2}{*}{1} & 1 & 41.769 & 1.272 & 39.270 & 44.267 \\
\hline & & 2 & 54.360 & 2.798 & 48.863 & 59.857 \\
\hline & \multirow[t]{2}{*}{2} & 1 & 45.020 & 1.979 & 41.133 & 48.907 \\
\hline & & 2 & 50.368 & 3.210 & 44.063 & 56.674 \\
\hline & \multirow[t]{2}{*}{3} & 1 & 44.750 & 2.856 & 39.140 & 50.360 \\
\hline & & 2 & 48.941 & 1.959 & 45.093 & 52.790 \\
\hline \multirow[t]{6}{*}{1} & \multirow[t]{2}{*}{1} & 1 & 44.568 & 2.300 & 40.049 & 49.086 \\
\hline & & 2 & 46.870 & 2.918 & 41.139 & 52.601 \\
\hline & \multirow[t]{2}{*}{2} & 1 & 46.763 & 2.270 & 42.304 & 51.222 \\
\hline & & 2 & 48.958 & 2.856 & 43.348 & 54.569 \\
\hline & \multirow[t]{2}{*}{3} & 1 & 48.962 & 1.922 & 45.187 & 52.738 \\
\hline & & 2 & 55.211 & 1.436 & 52.391 & 58.030 \\
\hline
\end{tabular}


APPENDIX N - Analysis: First Trimmed Dataset (cont.)

Post Hoc Tests

INCOME

\section{Multiple Comparisons}

\begin{tabular}{|c|c|c|c|c|c|c|c|}
\hline & \multirow[b]{2}{*}{ (I) INCOME } & \multirow[b]{2}{*}{ (J) INCOME } & \multirow{2}{*}{$\begin{array}{c}\text { Mean } \\
\text { Difference } \\
(\mathrm{I}-\mathrm{J})\end{array}$} & \multirow[b]{2}{*}{ Std. Error } & \multirow[b]{2}{*}{ Sig. } & \multicolumn{2}{|c|}{ 95\% Confidence Interval } \\
\hline & & & & & & Lower Bound & Upper Bound \\
\hline \multirow[t]{6}{*}{ Scheffe } & \multirow[t]{2}{*}{1} & 2 & -2.65 & 1.564 & .238 & -6.49 & 1.18 \\
\hline & & 3 & $-6.80^{*}$ & 1.352 & .000 & -10.12 & -3.48 \\
\hline & \multirow[t]{2}{*}{2} & 1 & 2.65 & 1.564 & .238 & -1.18 & 6.49 \\
\hline & & 3 & $-4.14^{\star}$ & 1.540 & .027 & -7.92 & -.36 \\
\hline & \multirow[t]{2}{*}{3} & 1 & $6.80^{\star}$ & 1.352 & .000 & 3.48 & 10.12 \\
\hline & & 2 & $4.14^{\star}$ & 1.540 & .027 & .36 & 7.92 \\
\hline \multirow[t]{6}{*}{ LSD } & \multirow[t]{2}{*}{1} & 2 & -2.65 & 1.564 & .090 & -5.73 & .42 \\
\hline & & 3 & $-6.80^{*}$ & 1.352 & .000 & -9.45 & -4.14 \\
\hline & \multirow[t]{2}{*}{2} & 1 & 2.65 & 1.564 & .090 & -.42 & 5.73 \\
\hline & & 3 & $-4.14^{\star}$ & 1.540 & .007 & -7.17 & -1.12 \\
\hline & \multirow[t]{2}{*}{3} & 1 & $6.80^{\star}$ & 1.352 & .000 & 4.14 & 9.45 \\
\hline & & 2 & $4.14^{\star}$ & 1.540 & .007 & 1.12 & 7.17 \\
\hline \multirow[t]{6}{*}{ Dunnett T3 } & \multirow[t]{2}{*}{1} & 2 & -2.65 & 1.441 & 186 & -6.11 & .80 \\
\hline & & 3 & $-6.80^{*}$ & 1.423 & .000 & -10.21 & -3.39 \\
\hline & \multirow[t]{2}{*}{2} & 1 & 2.65 & 1.441 & .186 & -.80 & 6.11 \\
\hline & & 3 & $-4.14^{*}$ & 1.532 & .021 & -7.82 & -.47 \\
\hline & \multirow[t]{2}{*}{3} & 1 & $6.80^{*}$ & 1.423 & .000 & 3.39 & 10.21 \\
\hline & & 2 & $4.14^{\star}$ & 1.532 & .021 & .47 & 7.82 \\
\hline
\end{tabular}

Based on observed means.

*. The mean difference is significant at the .05 level. 
APPENDIX N - Analysis: First Trimmed Dataset (cont.)

\section{Homogeneous Subsets}

\begin{tabular}{|c|c|c|c|c|}
\hline \multicolumn{5}{|c|}{ NCE total } \\
\hline & \multirow[b]{2}{*}{ INCOME } & \multirow[b]{2}{*}{$\mathrm{N}$} & \multicolumn{2}{|c|}{ Subset } \\
\hline & & & 1 & 2 \\
\hline \multirow[t]{4}{*}{ Student-Newman-Keulsa, } & 1 & 206 & 44.37 & \\
\hline & 2 & 131 & 47.02 & \\
\hline & 3 & 223 & & 51.17 \\
\hline & Sig. & & .075 & 1.000 \\
\hline \multirow[t]{4}{*}{ Scheffe ${ }^{a, b, c}$} & 1 & 206 & 44.37 & \\
\hline & 2 & 131 & 47.02 & \\
\hline & 3 & 223 & & 51.17 \\
\hline & Sig. & & 205 & 1.000 \\
\hline
\end{tabular}

Means for groups in homogeneous subsets are displayed.

Based on Type III Sum of Squares

The error term is Mean Square(Error) $=195.783$.

a. Uses Harmonic Mean Sample Size = 176.759.

b. The group sizes are unequal. The harmonic mean of the group sizes is used. Type I error levels are not guaranteed.

c. Alpha $=.05$. 


\section{APPENDIX O - Unbalanced Factorial ANOVA}

Univariate Analysis of Variance

Between-Subjects Factors

\begin{tabular}{|ll|l|}
\hline & & N \\
\hline INTERNET & 0 & 289 \\
& 1 & 267 \\
INCOME & 1 & 206 \\
& 2 & 131 \\
& 3 & 219 \\
education & 1 & 321 \\
& 2 & 235 \\
\hline
\end{tabular}

Levene's Test of Equality of Error Variances

Dependent Variable: NCE total

\begin{tabular}{|l|r|r|r|}
\hline$F$ & df1 & df2 & Sig. \\
\hline 1.794 & 11 & 544 & .052 \\
\hline
\end{tabular}

Tests the null hypothesis that the error variance of the dependent variable is equal across groups.

a. Design:

Intercept+INTERNET+INCOME+EDUCATIO+INTERNET

* INCOME+INTERNET * EDUCATIO+INCOME *

EDUCATIO+INTERNET * INCOME * EDUCATIO 
APPENDIX O - Unbalanced Factorial ANOVA (cont.)

Descriptive Statistics

Dependent Variable: NCE total

\begin{tabular}{|c|c|c|c|c|c|}
\hline INTERNET & INCOME & education & Mean & Std. Deviation & $\mathrm{N}$ \\
\hline \multirow[t]{12}{*}{0} & \multirow[t]{3}{*}{1} & 1 & 41.77 & 12.201 & 121 \\
\hline & & 2 & 54.36 & 14.688 & 25 \\
\hline & & Total & 43.92 & 13.474 & 146 \\
\hline & \multirow[t]{3}{*}{2} & 1 & 45.02 & 12.298 & 50 \\
\hline & & 2 & 50.37 & 8.858 & 19 \\
\hline & & Total & 46.49 & 11.642 & 69 \\
\hline & \multirow[t]{3}{*}{3} & 1 & 44.75 & 12.095 & 24 \\
\hline & & 2 & 49.86 & 13.332 & 50 \\
\hline & & Total & 48.20 & 13.085 & 74 \\
\hline & \multirow[t]{3}{*}{ Total } & 1 & 42.97 & 12.247 & 195 \\
\hline & & 2 & 51.16 & 12.973 & 94 \\
\hline & & Total & 45.63 & 13.045 & 289 \\
\hline \multirow[t]{12}{*}{1} & \multirow[t]{3}{*}{1} & 1 & 44.57 & 14.381 & 37 \\
\hline & & 2 & 46.87 & 11.760 & 23 \\
\hline & & Total & 45.45 & 13.380 & 60 \\
\hline & \multirow[t]{3}{*}{2} & 1 & 46.76 & 14.325 & 38 \\
\hline & & 2 & 48.96 & 12.338 & 24 \\
\hline & & Total & 47.61 & 13.529 & 62 \\
\hline & \multirow[t]{3}{*}{3} & 1 & 47.27 & 12.960 & 51 \\
\hline & & 2 & 55.77 & 16.268 & 94 \\
\hline & & Total & 52.78 & 15.678 & 145 \\
\hline & \multirow[t]{3}{*}{ Total } & 1 & 46.33 & 13.742 & 126 \\
\hline & & 2 & 53.16 & 15.383 & 141 \\
\hline & & Total & 49.93 & 14.998 & 267 \\
\hline \multirow[t]{12}{*}{ Total } & \multirow[t]{3}{*}{1} & 1 & 42.42 & 12.752 & 158 \\
\hline & & 2 & 50.77 & 13.755 & 48 \\
\hline & & Total & 44.37 & 13.432 & 206 \\
\hline & \multirow[t]{3}{*}{2} & 1 & 45.77 & 13.161 & 88 \\
\hline & & 2 & 49.58 & 10.839 & 43 \\
\hline & & Total & 47.02 & 12.534 & 131 \\
\hline & \multirow[t]{3}{*}{3} & 1 & 46.47 & 12.663 & 75 \\
\hline & & 2 & 53.72 & 15.524 & 144 \\
\hline & & Total & 51.23 & 14.980 & 219 \\
\hline & \multirow[t]{3}{*}{ Total } & 1 & 44.29 & 12.938 & 321 \\
\hline & & 2 & 52.36 & 14.472 & 235 \\
\hline & & Total & 47.70 & 14.168 & 556 \\
\hline
\end{tabular}


APPENDIX O - Unbalanced Factorial ANOVA (cont.)

Tests of Between-Subjects Effects

Dependent Variable: NCE total

\begin{tabular}{|c|c|c|c|c|c|c|c|c|}
\hline Source & $\begin{array}{l}\text { Type III Sum } \\
\text { of Squares }\end{array}$ & df & Mean Square & $\mathrm{F}$ & Sig. & $\begin{array}{l}\text { Partial Eta } \\
\text { Squared }\end{array}$ & $\begin{array}{l}\text { Noncent. } \\
\text { Parameter }\end{array}$ & $\begin{array}{c}\text { Observed } \\
\text { Power }^{\mathrm{a}}\end{array}$ \\
\hline Corrected Model & $12877.511^{b}$ & 11 & 1170.683 & 6.463 & .000 & .116 & 71.098 & 1.000 \\
\hline Intercept & 945502.428 & 1 & 945502.428 & 5220.180 & .000 & .906 & 5220.180 & 1.000 \\
\hline INTERNET & 47.202 & 1 & 47.202 & .261 & .610 & .000 & .261 & .080 \\
\hline INCOME & 506.547 & 2 & 253.273 & 1.398 & .248 & .005 & 2.797 & .301 \\
\hline EDUCATIO & 3697.074 & 1 & 3697.074 & 20.412 & .000 & .036 & 20.412 & .995 \\
\hline INTERNET * INCOME & 846.531 & 2 & 423.265 & 2.337 & .098 & .009 & 4.674 & .473 \\
\hline INTERNET * EDUCATIO & 288.155 & 1 & 288.155 & 1.591 & .208 & .003 & 1.591 & .242 \\
\hline INCOME * EDUCATIO & 235.768 & 2 & 117.884 & .651 & .522 & .002 & 1.302 & .159 \\
\hline $\begin{array}{l}\text { INTERNET * INCOME * } \\
\text { EDUCATIO }\end{array}$ & 888.772 & 2 & 444.386 & 2.453 & .087 & .009 & 4.907 & .493 \\
\hline Error & 98531.726 & 544 & 181.124 & & & & & \\
\hline Total & 1376356.000 & 556 & & & & & & \\
\hline Corrected Total & 111409.237 & 555 & & & & & & \\
\hline
\end{tabular}

a. Computed using alpha $=.05$

b. $\mathrm{R}$ Squared $=.116$ (Adjusted R Squared $=.098$ ) 


\section{APPENDIX O - Unbalanced Factorial ANOVA (cont.)}

\section{Estimated Marginal Means}

\section{Grand Mean}

Dependent Variable: NCE total

\begin{tabular}{|c|r|r|r|}
\hline & & \multicolumn{2}{|c|}{$95 \%$ Confidence Interval } \\
\cline { 3 - 4 } Mean & Std. Error & Lower Bound & Upper Bound \\
\hline 48.027 & .665 & 46.721 & 49.333 \\
\hline
\end{tabular}

\section{INTERNET}

Dependent Variable: NCE total

\begin{tabular}{|l|r|r|r|r|}
\hline & & & \multicolumn{2}{|c|}{ 95\% Confidence Interval } \\
\cline { 4 - 5 } INTERNET & Mean & Std. Error & Lower Bound & Upper Bound \\
\hline 0 & 47.688 & .958 & 45.805 & 49.570 \\
1 & 48.367 & .921 & 46.557 & 50.176 \\
\hline
\end{tabular}

\section{INCOME}

Dependent Variable: NCE total

\begin{tabular}{|l|c|r|r|r|}
\hline & & & \multicolumn{2}{|c|}{$95 \%$ Confidence Interval } \\
\cline { 4 - 5 } INCOME & Mean & Std. Error & Lower Bound & Upper Bound \\
\hline 1 & 46.891 & 1.160 & 44.614 & 49.169 \\
2 & 47.777 & 1.262 & 45.299 & 50.256 \\
3 & 49.413 & 1.020 & 47.409 & 51.416 \\
\hline
\end{tabular}

\section{4. education}

Dependent Variable: NCE total

\begin{tabular}{|l|c|r|r|r|}
\hline \multirow{2}{*}{ education } & & & \multicolumn{2}{|c|}{ 95\% Confidence Interval } \\
\cline { 4 - 5 } & Mean & Std. Error & Lower Bound & Upper Bound \\
\hline 1 & 45.024 & .848 & 43.358 & 46.689 \\
2 & 51.030 & 1.024 & 49.019 & 53.042 \\
\hline
\end{tabular}

\section{INTERNET * INCOME}

Dependent Variable: NCE total

\begin{tabular}{|ll|r|r|r|r|}
\hline & & & & \multicolumn{2}{|c|}{ 95\% Confidence Interval } \\
\cline { 5 - 6 } INTERNET & INCOME & \multicolumn{1}{|c|}{ Mean } & Std. Error & Lower Bound & Upper Bound \\
\hline 0 & 1 & 48.064 & 1.478 & 45.160 & 50.968 \\
& 2 & 47.694 & 1.814 & 44.132 & 51.257 \\
& 3 & 47.305 & 1.671 & 44.023 & 50.587 \\
\hline 1 & 1 & 45.719 & 1.787 & 42.209 & 49.228 \\
& 2 & 47.861 & 1.755 & 44.414 & 51.307 \\
& 3 & 51.520 & 1.170 & 49.221 & 53.819 \\
\hline
\end{tabular}




\section{APPENDIX O - Unbalanced Factorial ANOVA (cont.)}

\section{INTERNET * education}

Dependent Variable: NCE total

\begin{tabular}{|ll|r|r|r|r|}
\hline & & & & \multicolumn{2}{|c|}{$95 \%$ Confidence Interval } \\
\cline { 5 - 6 } INTERNET & education & Mean & Std. Error & Lower Bound & Upper Bound \\
\hline 0 & 1 & 43.846 & 1.186 & 41.516 & 46.177 \\
& 2 & 51.529 & 1.506 & 48.572 & 54.487 \\
\hline 1 & 1 & 46.202 & 1.212 & 43.822 & 48.582 \\
& 2 & 50.531 & 1.388 & 47.804 & 53.259 \\
\hline
\end{tabular}

\section{INCOME * education}

Dependent Variable: NCE total

\begin{tabular}{|ll|r|r|r|r|}
\hline & & & & \multicolumn{2}{|c|}{ 95\% Confidence Interval } \\
\cline { 5 - 6 } INCOME & education & Mean & Std. Error & Lower Bound & Upper Bound \\
\hline 1 & 1 & 43.168 & 1.264 & 40.685 & 45.651 \\
& 2 & 50.615 & 1.944 & 46.796 & 54.434 \\
\hline 2 & 1 & 45.892 & 1.448 & 43.047 & 48.736 \\
& 2 & 49.663 & 2.066 & 45.604 & 53.722 \\
\hline 3 & 1 & 46.012 & 1.666 & 42.740 & 49.284 \\
& 2 & 52.813 & 1.178 & 50.499 & 55.127 \\
\hline
\end{tabular}

8. INTERNET * INCOME * education

Dependent Variable: NCE total

\begin{tabular}{|lll|r|r|r|r|}
\hline & & & & & \multicolumn{2}{|c|}{ 95\% Confidence Interval } \\
\cline { 6 - 7 } INTERNET & INCOME & education & Mean & Std. Error & Lower Bound & Upper Bound \\
\hline 0 & 1 & 1 & 41.769 & 1.223 & 39.365 & 44.172 \\
& 2 & 54.360 & 2.692 & 49.073 & 59.647 \\
\cline { 6 - 7 } & 2 & 1 & 45.020 & 1.903 & 41.281 & 48.759 \\
& 2 & 50.368 & 3.088 & 44.303 & 56.433 \\
\hline & 3 & 1 & 44.750 & 2.747 & 39.354 & 50.146 \\
& 2 & 49.860 & 1.903 & 46.121 & 53.599 \\
\hline 1 & 1 & 44.568 & 2.213 & 40.221 & 48.914 \\
& 2 & 46.870 & 2.806 & 41.357 & 52.382 \\
\hline & 2 & 1 & 46.763 & 2.183 & 42.475 & 51.052 \\
& 2 & 48.958 & 2.747 & 43.562 & 54.355 \\
\hline & 1 & 47.275 & 1.885 & 43.573 & 50.976 \\
& 3 & 2 & 55.766 & 1.388 & 53.039 & 58.493 \\
\hline
\end{tabular}


APPENDIX O - Unbalanced Factorial ANOVA (cont.)

Post Hoc Tests

INCOME

\section{Multiple Comparisons}

\begin{tabular}{|c|c|c|c|c|c|c|c|}
\hline & \multirow[b]{2}{*}{ (I) INCOME } & \multirow[b]{2}{*}{ (J) INCOME } & \multirow{2}{*}{$\begin{array}{c}\text { Mean } \\
\text { Difference } \\
(\mathrm{I}-\mathrm{J})\end{array}$} & \multirow[b]{2}{*}{ Std. Error } & \multirow[b]{2}{*}{ Sig. } & \multicolumn{2}{|c|}{ 95\% Confidence Interval } \\
\hline & & & & & & Lower Bound & Upper Bound \\
\hline \multirow[t]{6}{*}{ Scheffe } & \multirow[t]{2}{*}{1} & 2 & -2.65 & 1.504 & .212 & -6.35 & 1.04 \\
\hline & & 3 & $-6.86^{\star}$ & 1.306 & .000 & -10.07 & -3.66 \\
\hline & \multirow[t]{2}{*}{2} & 1 & 2.65 & 1.504 & .212 & -1.04 & 6.35 \\
\hline & & 3 & $-4.21^{\star}$ & 1.486 & .019 & -7.86 & -.56 \\
\hline & \multirow[t]{2}{*}{3} & 1 & $6.86^{\star}$ & 1.306 & .000 & 3.66 & 10.07 \\
\hline & & 2 & $4.21^{*}$ & 1.486 & .019 & .56 & 7.86 \\
\hline \multirow[t]{6}{*}{ LSD } & \multirow[t]{2}{*}{1} & 2 & -2.65 & 1.504 & .078 & -5.61 & .30 \\
\hline & & 3 & $-6.86^{*}$ & 1.306 & .000 & -9.43 & -4.30 \\
\hline & \multirow[t]{2}{*}{2} & 1 & 2.65 & 1.504 & .078 & -.30 & 5.61 \\
\hline & & 3 & $-4.21^{*}$ & 1.486 & .005 & -7.13 & -1.29 \\
\hline & \multirow[t]{2}{*}{3} & 1 & $6.86^{\star}$ & 1.306 & .000 & 4.30 & 9.43 \\
\hline & & 2 & $4.21^{*}$ & 1.486 & .005 & 1.29 & 7.13 \\
\hline \multirow[t]{6}{*}{ Dunnett T3 } & \multirow[t]{2}{*}{1} & 2 & -2.65 & 1.441 & .186 & -6.11 & .80 \\
\hline & & 3 & $-6.86^{\star}$ & 1.379 & .000 & -10.17 & -3.56 \\
\hline & \multirow[t]{2}{*}{2} & 1 & 2.65 & 1.441 & .186 & -.80 & 6.11 \\
\hline & & 3 & $-4.21^{\star}$ & 1.491 & .015 & -7.79 & -.63 \\
\hline & \multirow[t]{2}{*}{3} & 1 & $6.86^{*}$ & 1.379 & .000 & 3.56 & 10.17 \\
\hline & & 2 & $4.21^{*}$ & 1.491 & .015 & .63 & 7.79 \\
\hline
\end{tabular}

Based on observed means.

*. The mean difference is significant at the .05 level. 


\section{APPENDIX O - Unbalanced Factorial ANOVA (cont.)}

\section{Homogeneous Subsets}

\section{NCE total}

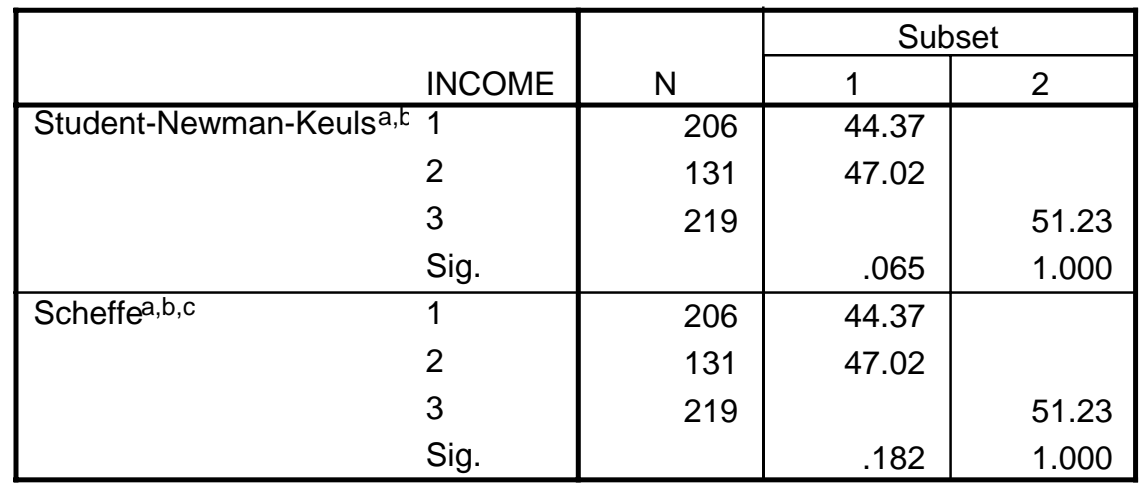

Means for groups in homogeneous subsets are displayed.

Based on Type III Sum of Squares

The error term is Mean Square(Error) $=181.124$.

a. Uses Harmonic Mean Sample Size $=175.910$.

b. The group sizes are unequal. The harmonic mean of the group sizes is used. Type I error levels are not guaranteed.

c. Alpha $=.05$. 
APPENDIX P - Unbalanced Interaction Graphs for Factors A\&B

Unbalanced AB Interaction Data: Internet \& Income, on NCE Total Scale

\begin{tabular}{|c|c|c|c|c|c|c|}
\hline Internet & No & Yes & No & Yes & No & Yes \\
\hline Income Category & 1 & 1 & 2 & 2 & 3 & 3 \\
\hline Mean & 48.06 & 45.72 & 47.69 & 47.86 & 47.31 & 51.52 \\
\hline $\mathrm{n}$ & 146 & 60 & 69 & 62 & 75 & 148 \\
\hline
\end{tabular}

Unbalanced Interaction Chart: Internet \& Income, on NCE Total Scale

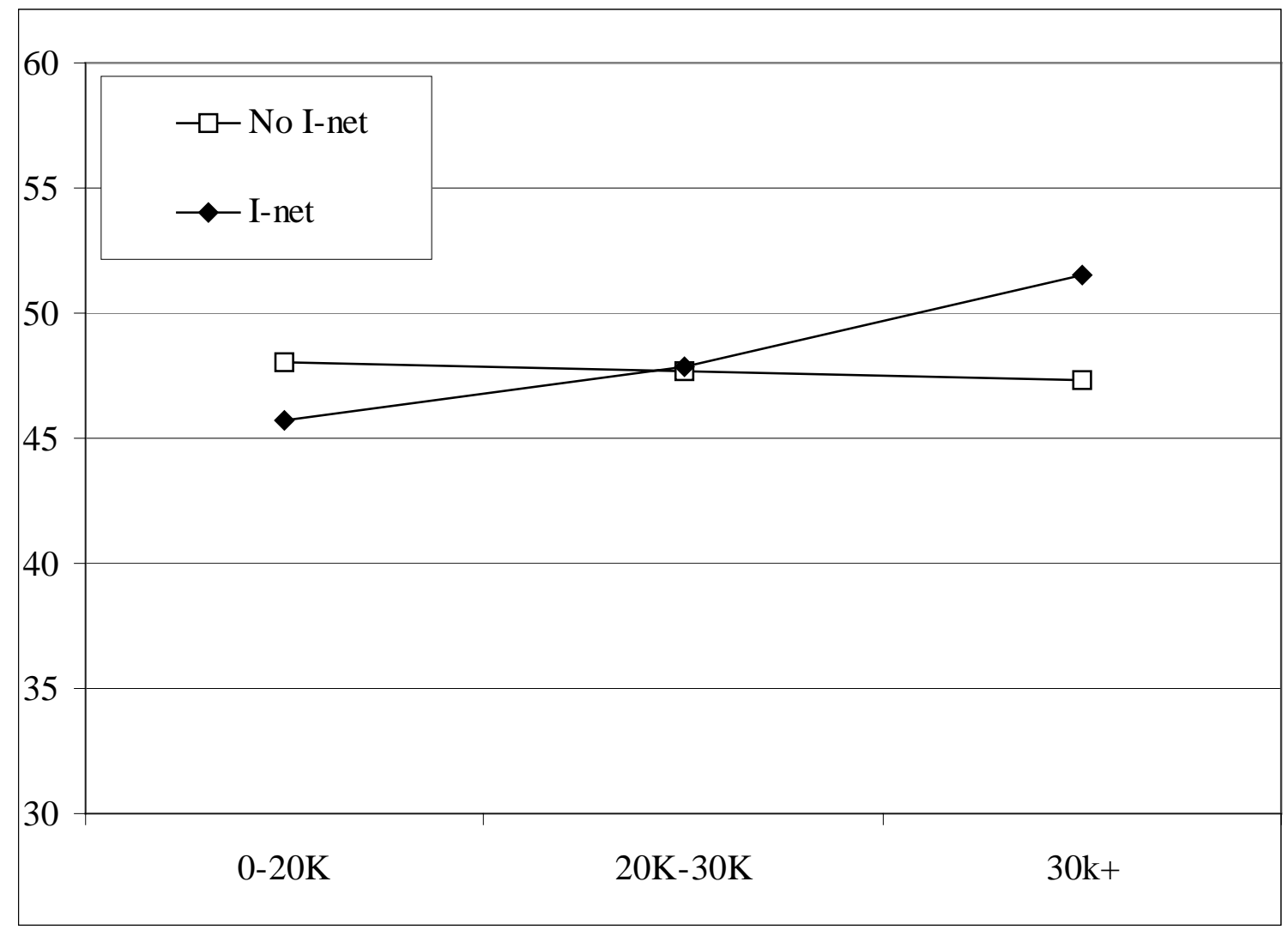

Unbalanced Interaction Chart Data: Internet \& Income, on NCE Total Scale

\begin{tabular}{lccc}
\hline & $0-20 \mathrm{~K}$ & $20 \mathrm{~K}-30 \mathrm{~K}$ & $30 \mathrm{k}+$ \\
\cline { 2 - 4 } No I-net & 48.06 & 47.69 & 47.31 \\
I-net & 45.72 & 47.86 & 51.52 \\
\hline
\end{tabular}


APPENDIX P - Unbalanced Interaction Graphs for Factors A\&B

Unbalanced Interaction Chart: Income\& Internet, on NCE Total Scale

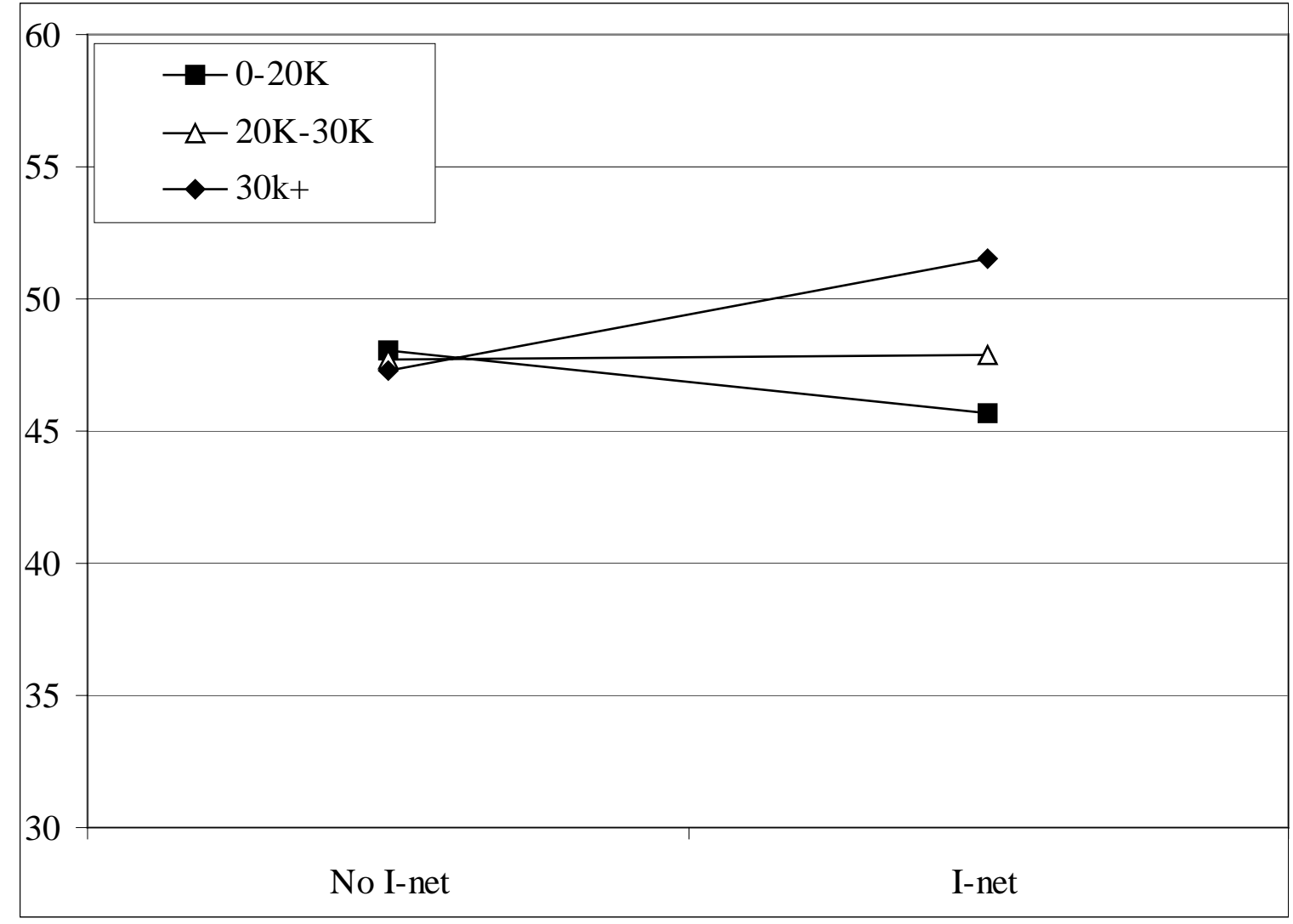

Unbalanced Interaction Chart Data: Income \& Internet, on NCE Total Scale

\begin{tabular}{lcc}
\hline & No I-net & I-net \\
\cline { 2 - 3 } $0-20 \mathrm{~K}$ & 48.06 & 45.72 \\
$20 \mathrm{~K}-30 \mathrm{~K}$ & 47.69 & 47.86 \\
$30 \mathrm{k}+$ & 47.31 & 51.52 \\
\hline
\end{tabular}


APPENDIX Q - Unbalanced Interaction Graphs for Factors A\&C

Unbalanced AC Interaction Data: Internet \& Education, on NCE Total Scale

\begin{tabular}{|c|c|c|c|c|c|}
\hline & Internet & No & Yes & No & Yes \\
\hline & Education Category & 1 & 1 & 2 & 2 \\
\hline Mean & & 43.85 & 46.20 & 51.53 & 50.53 \\
\hline $\mathrm{n}$ & & 195 & 126 & 94 & 141 \\
\hline
\end{tabular}

Unbalanced Interaction Chart: Internet \& Education, on NCE Total Scale

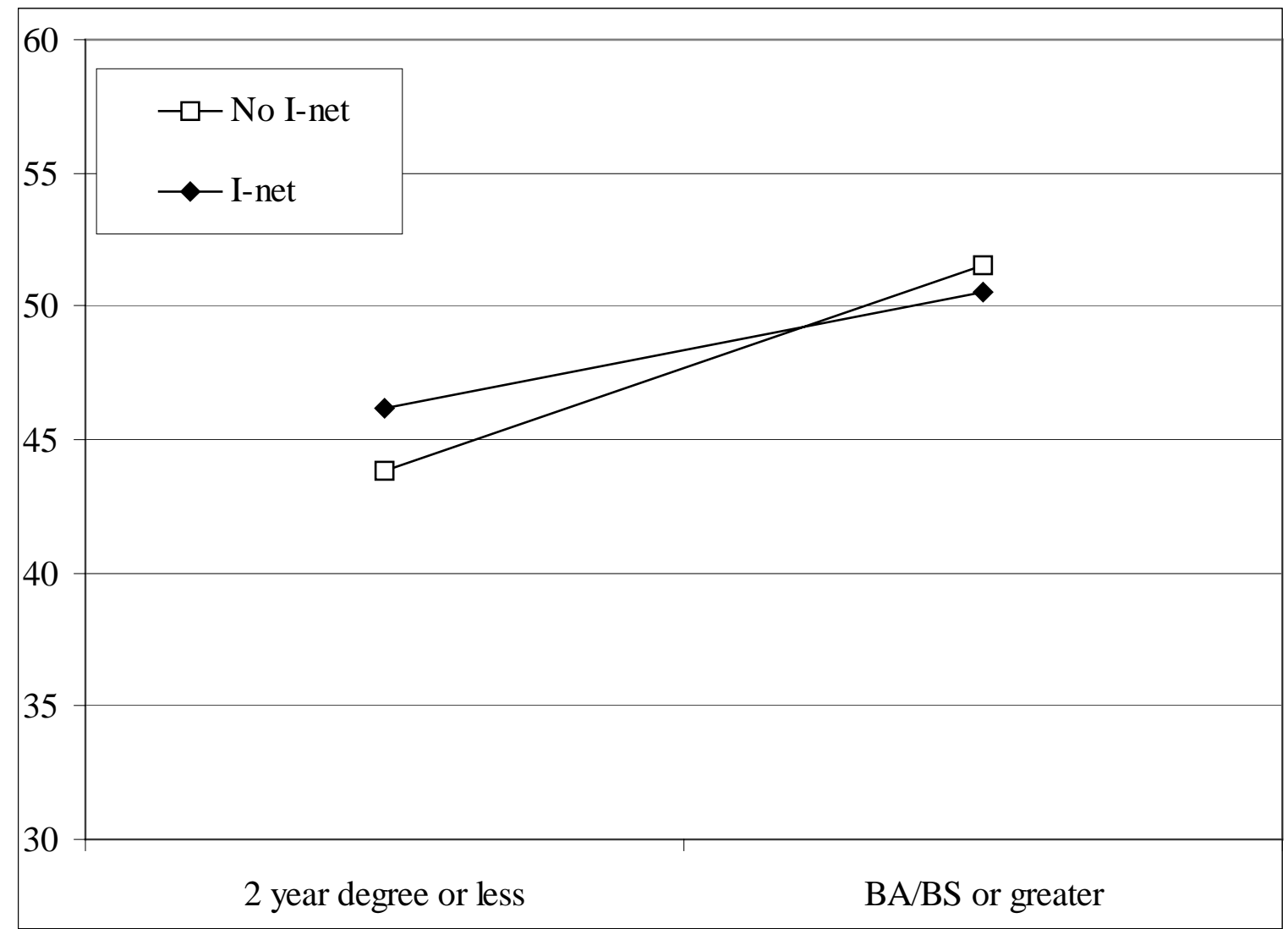

Unbalanced Interaction Chart Data: Internet \& Education, on NCE Total Scale

\begin{tabular}{lcc}
\hline & 2 year degree or less & BA/BS or greater \\
\cline { 2 - 3 } No I-net & 43.85 & 51.53 \\
I-net & 46.20 & 50.53 \\
\hline
\end{tabular}


APPENDIX Q - Unbalanced Interaction Graphs for Factors A\&C (cont)

Unbalanced Interaction Chart: Education \& Internet, on NCE Total Scale

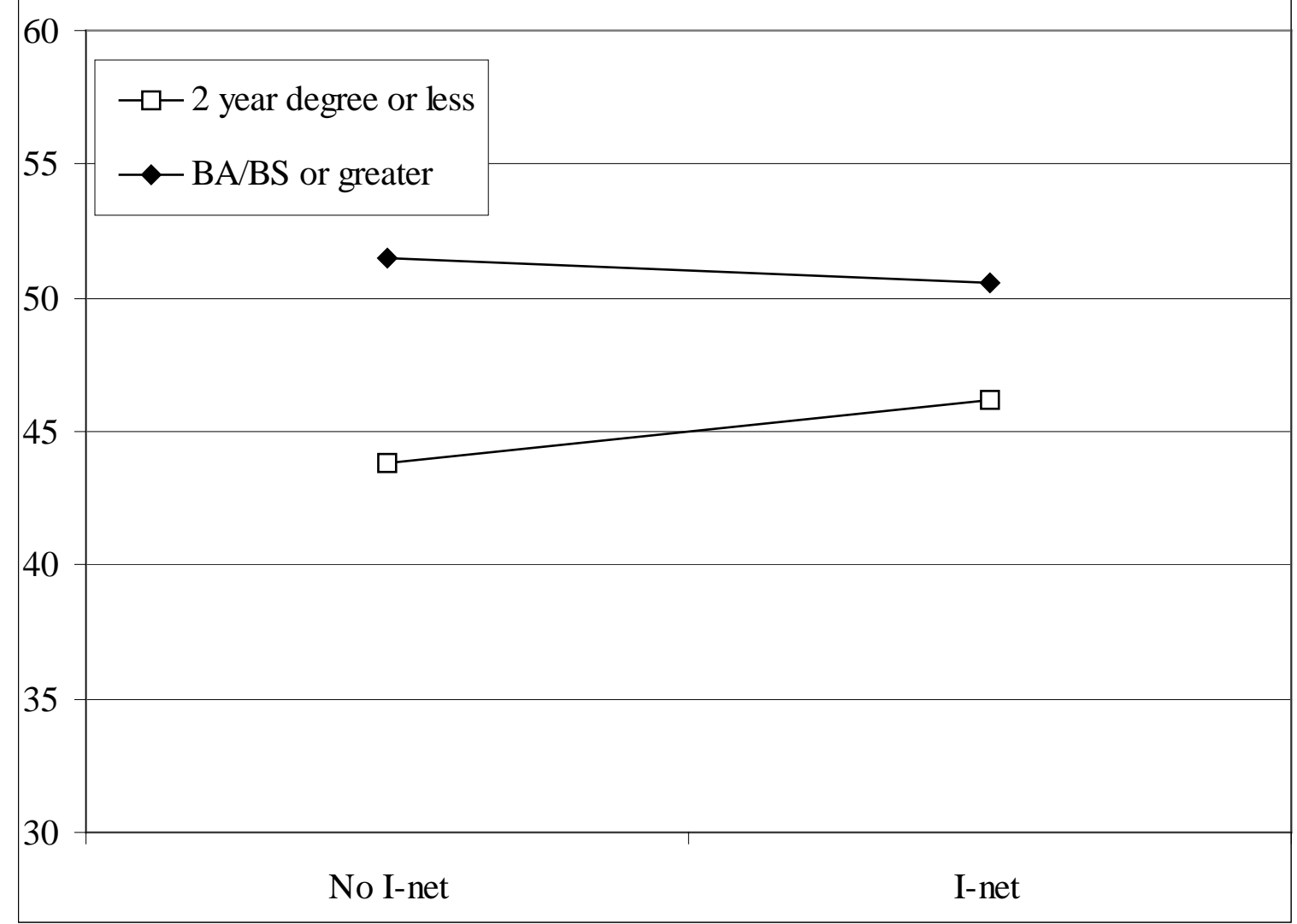

Unbalanced Interaction Chart Data: Education \& Internet, on NCE Total Scale No I-net I-net

2 year degree or less

BA/BS or greater

$43.85 \quad 46.20$

51.53 50.53 
APPENDIX R - Unbalanced Interaction Graphs for Factors B\&C

Unbalanced BC Interaction Data: Income \& Education, on NCE Total Scale

\begin{tabular}{lcccccc}
\hline Income Category & 1 & 1 & 2 & 2 & 3 & 3 \\
\cline { 2 - 7 } Education Category & 1 & 2 & 1 & 2 & 1 & 2 \\
\cline { 2 - 7 } Mean & & & & & & \\
$\mathrm{n}$ & 43.17 & 50.61 & 45.89 & 49.66 & 46.01 & 52.81 \\
158 & 48 & 88 & 43 & 75 & 144 \\
\hline
\end{tabular}

Unbalanced Interaction Chart: Income \& Education, on NCE Total Scale

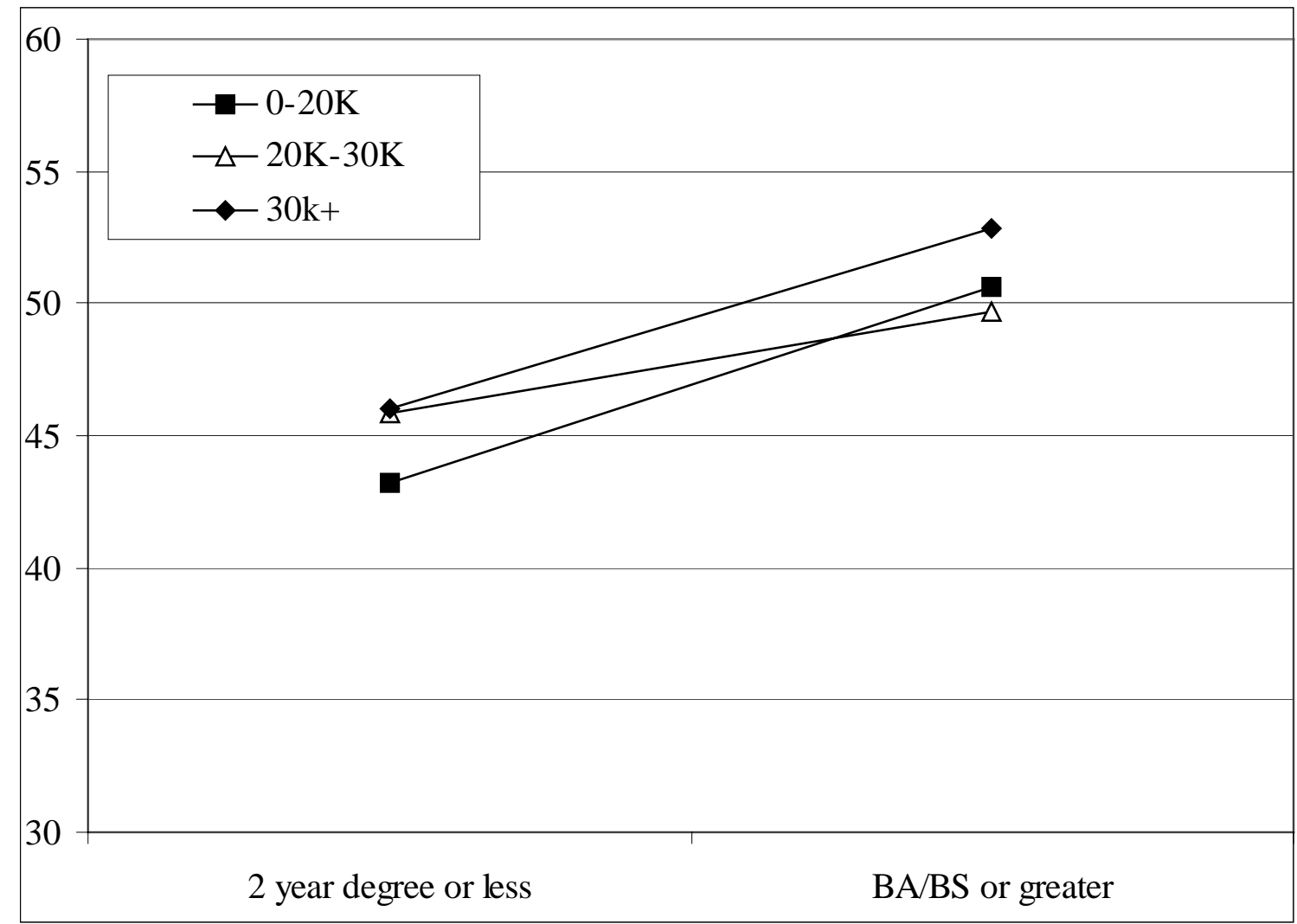

Unbalanced Interaction Chart Data: Income \& Education, on NCE Total Scale

2 year degree or less $\quad$ BA/BS or greater

\begin{tabular}{lrc}
\cline { 2 - 3 } $0-20 \mathrm{~K}$ & 43.17 & 50.61 \\
$20 \mathrm{~K}-30 \mathrm{~K}$ & 45.89 & 49.66 \\
$30 \mathrm{k}+$ & 46.01 & 52.81
\end{tabular}


APPENDIX R - Unbalanced Interaction Graphs for Factors B\&C (cont.)

Unbalanced Interaction Chart: Education \& Income, on NCE Total Scale

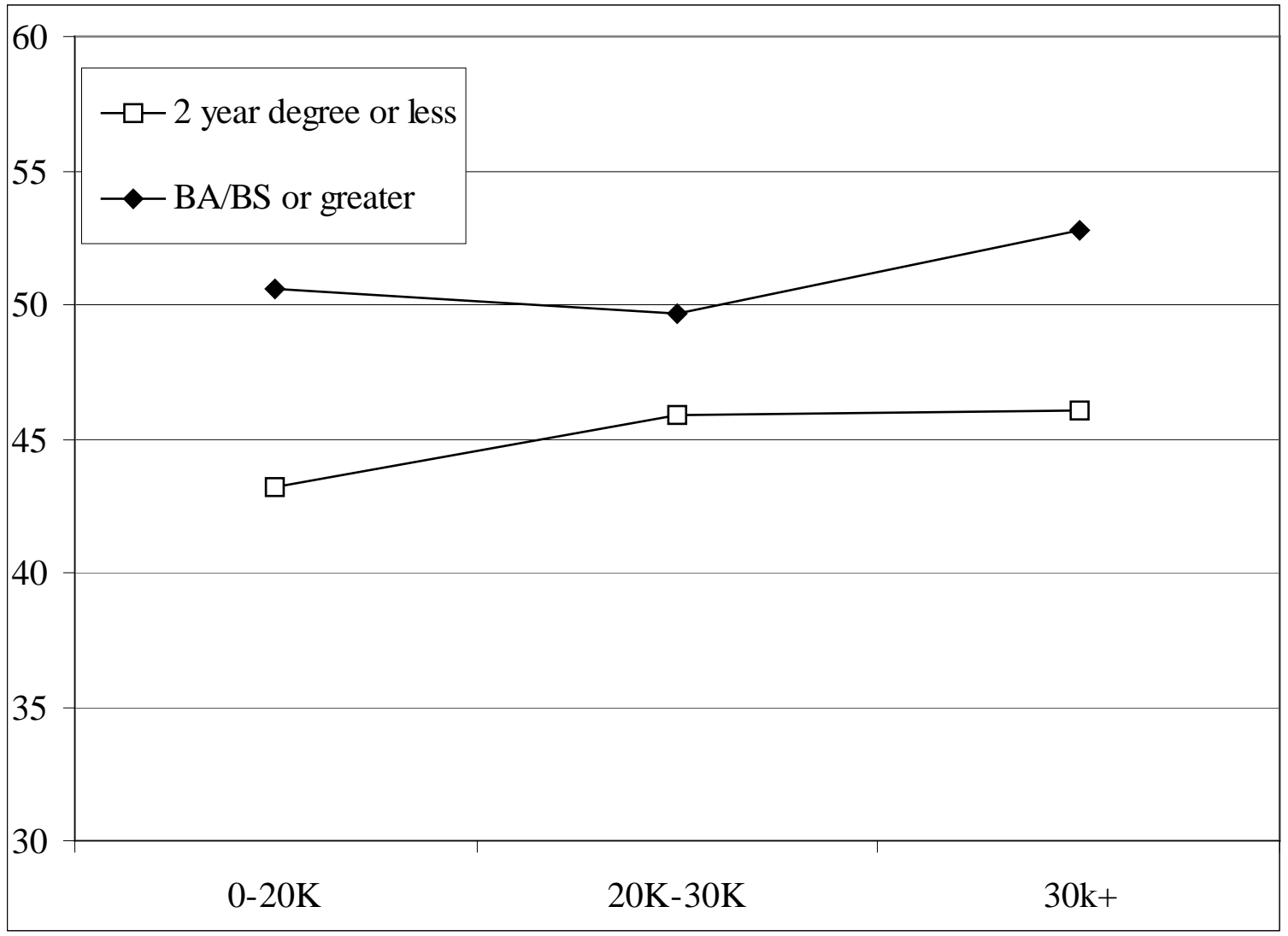

Interaction Chart Data: Education \& Income, on NCE Total Scale

\begin{tabular}{lccc}
\hline & $0-20 \mathrm{~K}$ & $20 \mathrm{~K}-30 \mathrm{~K}$ & $30 \mathrm{k}^{+}$ \\
\cline { 2 - 4 } 2 year degree or less & 43.17 & 45.89 & 46.01 \\
BA/BS or greater & 50.61 & 49.66 & 52.81 \\
\hline
\end{tabular}


APPENDIX S - Unbalanced Interaction Graphs for Factors A\&B\&C

Unbalanced ABC Interaction Data: Internet, Income \& Education, on NCE Total Scale Elementary School -

\begin{tabular}{|c|c|c|c|c|c|c|}
\hline \multirow{2}{*}{$\begin{array}{l}\text { Internet } \\
\text { Income } \\
\text { ool - }\end{array}$} & \multicolumn{3}{|c|}{ TRUE } & \multicolumn{3}{|c|}{ FALSE } \\
\hline & $0-20 \mathrm{~K}$ & $20 \mathrm{~K}-30 \mathrm{~K}$ & $30 \mathrm{k}+$ & $0-20 \mathrm{~K}$ & $20 \mathrm{~K}-30 \mathrm{~K}$ & $30 \mathrm{k}^{+}$ \\
\hline $\begin{array}{l}\text { ome } \\
\text { degree }\end{array}$ & 44.57 & 46.76 & 47.27 & 41.77 & 45.02 & 44.75 \\
\hline & 46.87 & 48.96 & 55.77 & 54.36 & 50.37 & 49.86 \\
\hline
\end{tabular}

Unbalanced Interaction Chart: Internet, Income \& Education, on NCE Total Scale

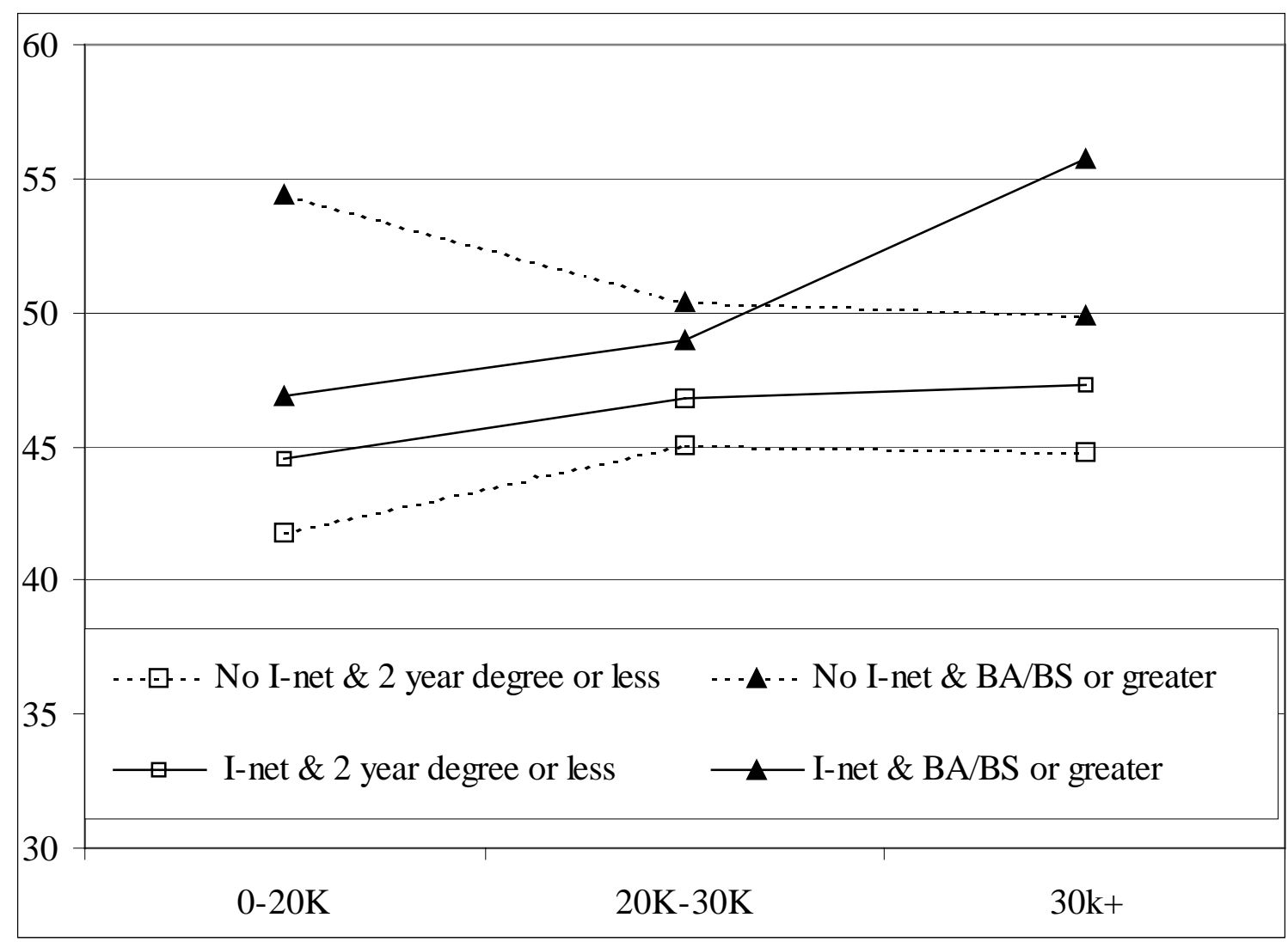

Unbalanced Interaction Chart Data: Internet, Income \& Education, on NCE Total Scale College - 2 year degree 4 year degree - Graduate Program 0-20K 20K-30K $30 \mathrm{k}+$

No I-net \& 2 year degree or less

\begin{tabular}{lll}
41.77 & 45.02 & 44.75 \\
54.36 & 50.37 & 49.86 \\
44.57 & 46.76 & 47.27 \\
46.87 & 48.96 & 55.77 \\
\hline
\end{tabular}


APPENDIX S - Unbalanced Interaction Graphs for Factors A\&B\&C (cont.)

Unbalanced Interaction Chart: Internet, Income \& Education, on NCE Total Scale

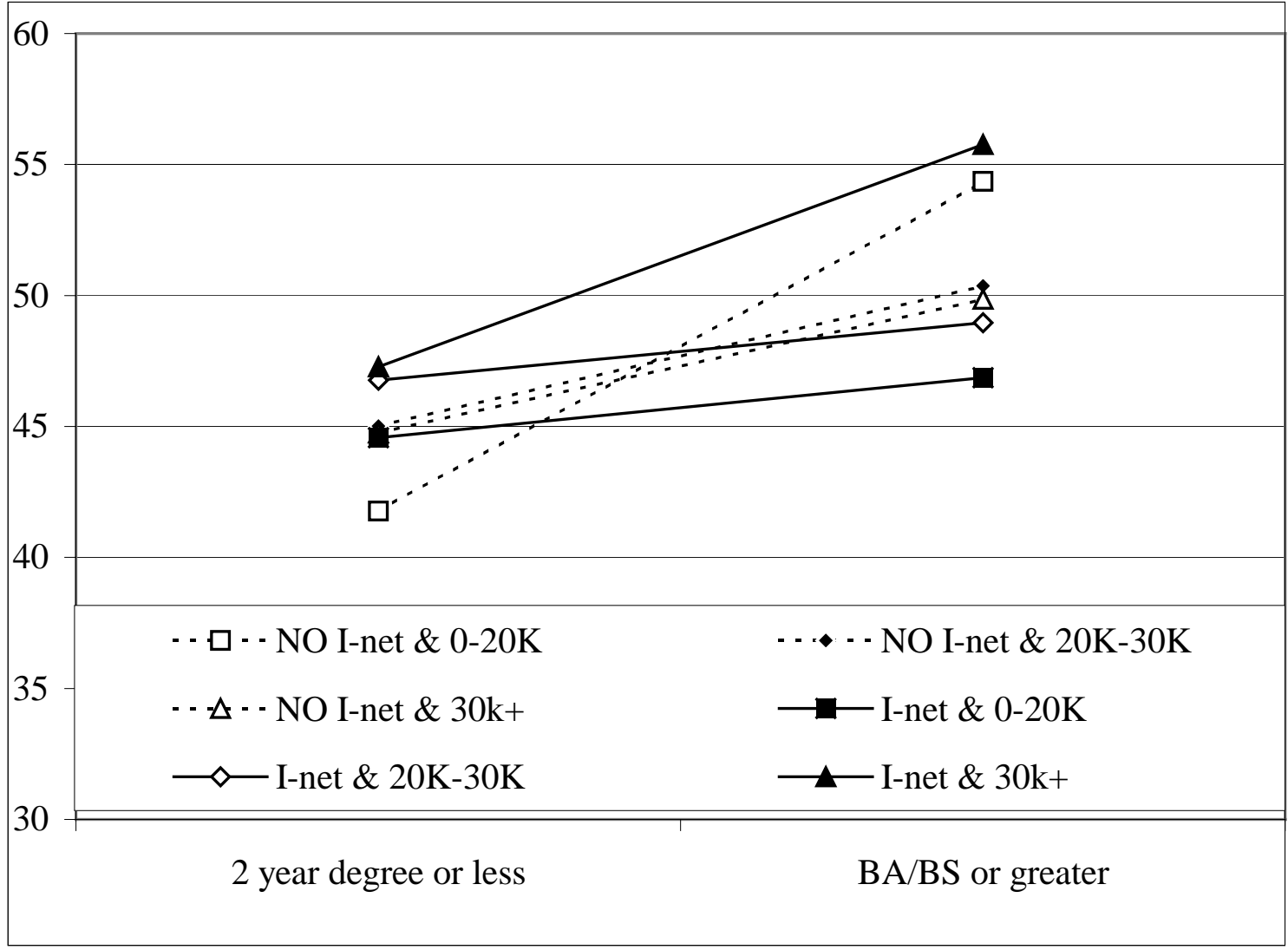

Unbalanced Interaction Chart Data: Internet, Income \& Education, on NCE Total Scale

2 year degree or less $\quad \mathrm{BA} / \mathrm{BS}$ or greater

NO I-net \& 0-20K

41.77

54.36

NO I-net \& 20K-30K

45.02

50.37

NO I-net \& $30 \mathrm{k}^{+}$

44.75

49.86

I-net \& 0-20K

44.57

46.87

I-net \& 20K-30K

46.76

48.96

I-net \& 30k+

47.27

55.77 
APPENDIX S - Unbalanced Interaction Graphs for Factors A\&B\&C (cont.)

Unbalanced Interaction Chart: Internet, Income \& Education, on NCE Total Scale

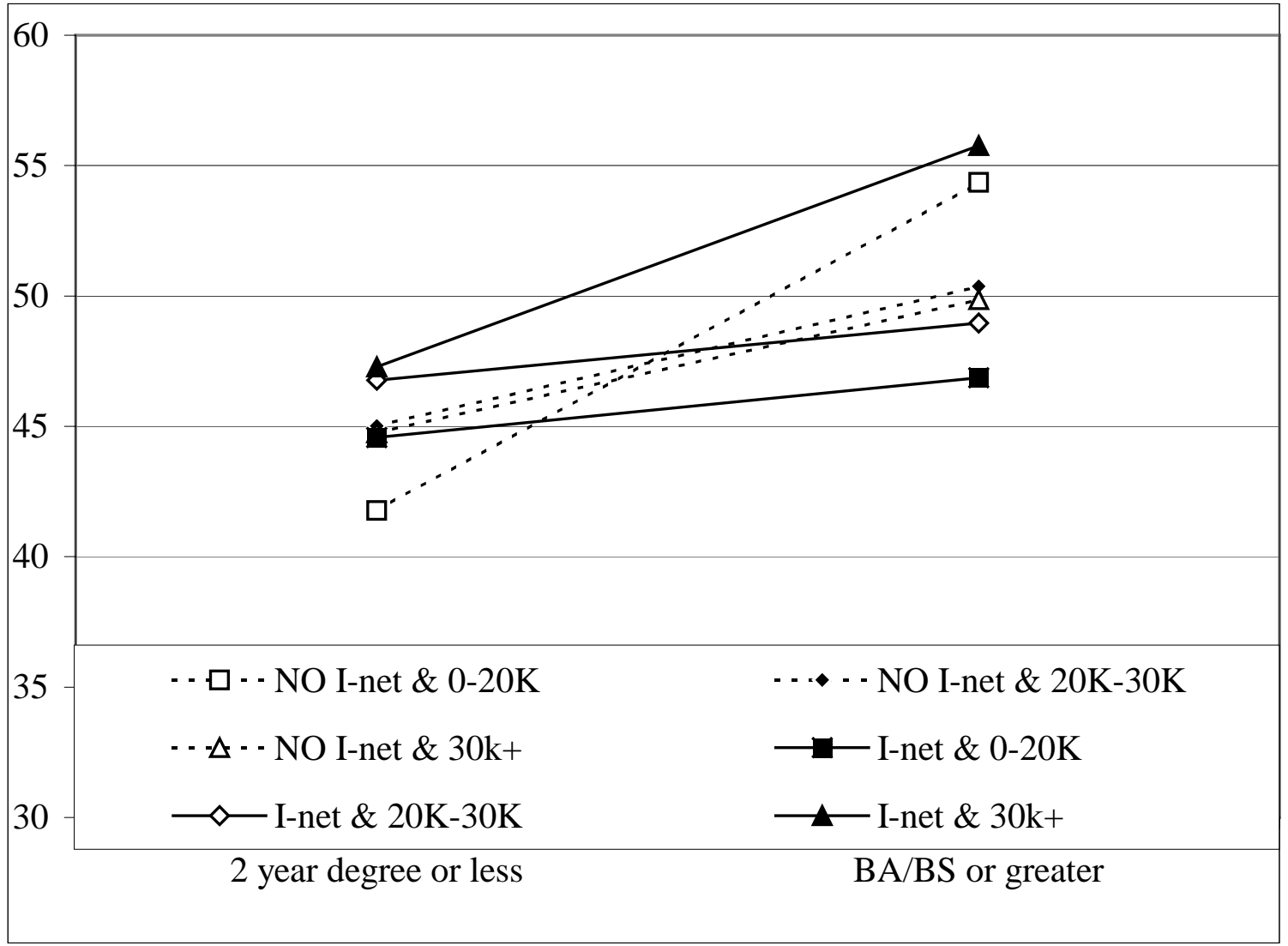

Interaction Chart Data: Internet, Income \& Education, on NCE Total Scale No-Internet at home Internet at home

Less than BS \& $\$ 0-20 \mathrm{~K}$

More than BS \& \$0-20K

Less than BS \& \$20K-30K

More than BS \& \$20-30K

Less than BS \& \$30K+

More than BS \& \$30K+

41.77

45.02

44.75

44.57

46.76

47.27
54.36

50.37

49.86

46.87

48.96

55.77 
APPENDIX T - One-Way ANOVA for Factors A, B, \& C

One-way ANOVA for Factor A (Internet)

\section{Descriptives}

\begin{tabular}{|c|c|c|c|c|c|c|c|c|}
\hline & \multirow[b]{2}{*}{$\mathrm{N}$} & \multirow[b]{2}{*}{ Mean } & \multirow[b]{2}{*}{ Std. Deviation } & \multirow[b]{2}{*}{ Std. Error } & \multicolumn{2}{|c|}{$\begin{array}{c}\text { 95\% Confidence Interval for } \\
\text { Mean }\end{array}$} & \multirow[b]{2}{*}{ Minimum } & \multirow[b]{2}{*}{ Maximum } \\
\hline & & & & & Lower Bound & Upper Bound & & \\
\hline 0 & 289 & 45.63 & 13.045 & .767 & 44.12 & 47.14 & 8 & 85 \\
\hline 1 & 267 & 49.93 & 14.998 & .918 & 48.13 & 51.74 & 5 & 90 \\
\hline Total & 556 & 47.70 & 14.168 & .601 & 46.52 & 48.88 & 5 & 90 \\
\hline
\end{tabular}

\section{Test of Homogeneity of Variances}

NCE total
\begin{tabular}{|r|r|r|r|}
\hline $\begin{array}{c}\text { Levene } \\
\text { Statistic }\end{array}$ & df1 & df2 & Sig. \\
\hline 7.389 & 1 & 554 & .007 \\
\hline
\end{tabular}

ANOVA

NCE total
\begin{tabular}{|l|l|r|r|r|r|}
\hline & \multicolumn{1}{|c|}{$\begin{array}{c}\text { Sum of } \\
\text { Squares }\end{array}$} & \multicolumn{1}{c|}{ df } & Mean Square & \multicolumn{1}{c|}{ F } & Sig. \\
\hline Between Groups & 2565.330 & 1 & 2565.330 & 13.057 & .000 \\
Within Groups & 108843.9 & 554 & 196.469 & & \\
Total & 111409.2 & 555 & & & \\
\hline
\end{tabular}


APPENDIX T - One-Way ANOVA for Factors A, B, \& C (cont.)

One-way ANOVA for Factor B (income)

\section{Descriptives}

\begin{tabular}{|c|c|c|c|c|c|c|c|c|}
\hline & \multirow[b]{2}{*}{$\mathrm{N}$} & \multirow[b]{2}{*}{ Mean } & \multirow[b]{2}{*}{ Std. Deviation } & \multirow[b]{2}{*}{ Std. Error } & \multicolumn{2}{|c|}{$\begin{array}{l}\text { 95\% Confidence Interval for } \\
\text { Mean }\end{array}$} & \multirow[b]{2}{*}{ Minimum } & \multirow[b]{2}{*}{ Maximum } \\
\hline & & & & & Lower Bound & Upper Bound & & \\
\hline 1 & 206 & 44.37 & 13.432 & .936 & 42.52 & 46.21 & 5 & 85 \\
\hline 2 & 131 & 47.02 & 12.534 & 1.095 & 44.86 & 49.19 & 16 & 76 \\
\hline 3 & 219 & 51.23 & 14.980 & 1.012 & 49.24 & 53.23 & 14 & 90 \\
\hline Total & 556 & 47.70 & 14.168 & .601 & 46.52 & 48.88 & 5 & 90 \\
\hline
\end{tabular}

Test of Homogeneity of Variances

NCE total
\begin{tabular}{|c|c|c|c|}
\hline $\begin{array}{c}\text { Levene } \\
\text { Statistic }\end{array}$ & df1 & df2 & Sig. \\
\hline 3.375 & 2 & 553 & .035 \\
\hline
\end{tabular}

ANOVA

NCE total
\begin{tabular}{|l|l|r|r|r|r|}
\hline & $\begin{array}{c}\text { Sum of } \\
\text { Squares }\end{array}$ & \multicolumn{1}{c|}{ df } & Mean Square & F & Sig. \\
\hline Between Groups & 5079.222 & 2 & 2539.611 & 13.208 & .000 \\
Within Groups & 106330.0 & 553 & 192.279 & & \\
Total & 111409.2 & 555 & & & \\
\hline
\end{tabular}


APPENDIX T - One-Way ANOVA for Factors A, B, \& C (cont.)

Post Hoc Tests

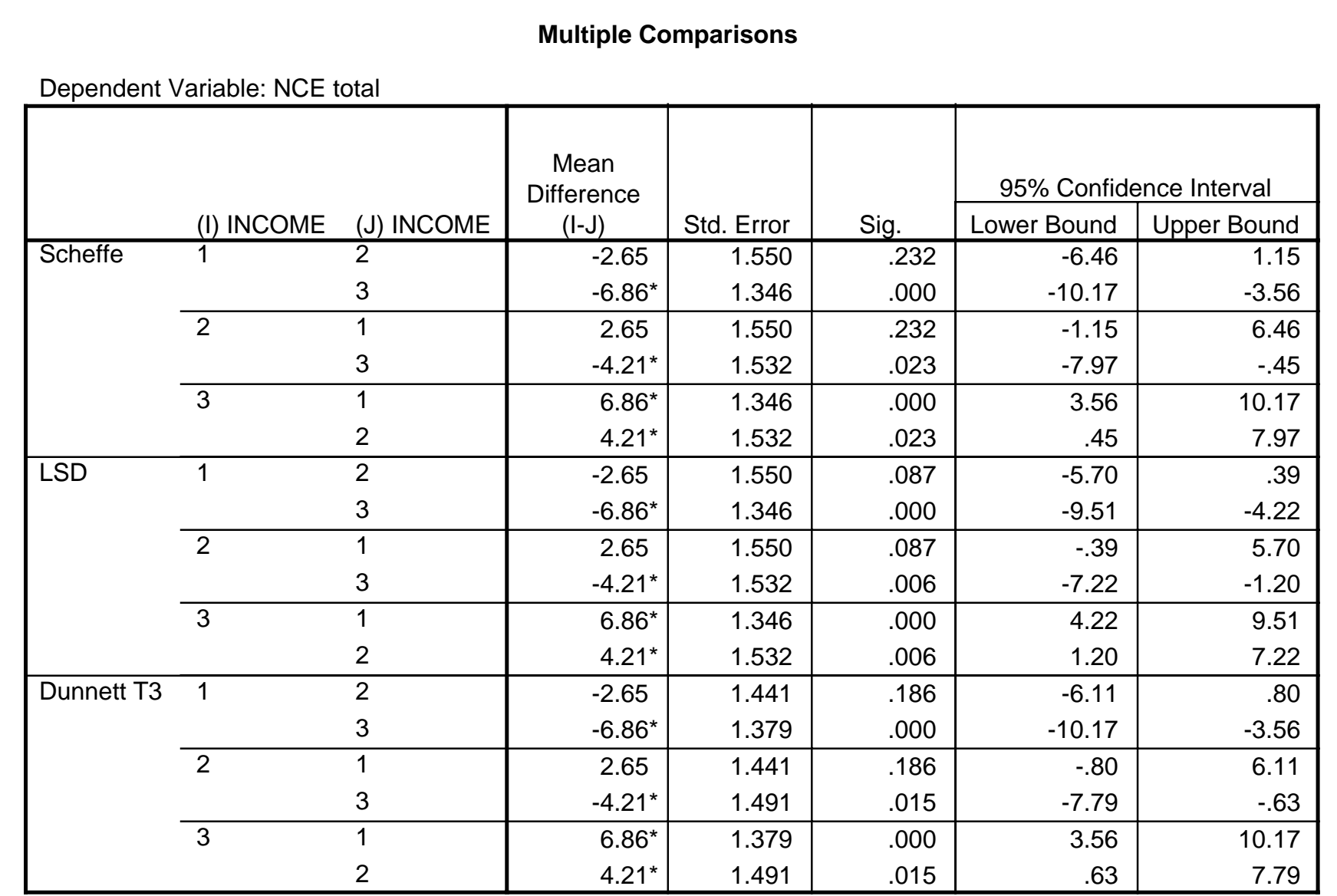

*. The mean difference is significant at the .05 level. 
APPENDIX T - One-Way ANOVA for Factors A, B, \& C (cont.)

Homogeneous Subsets

NCE total

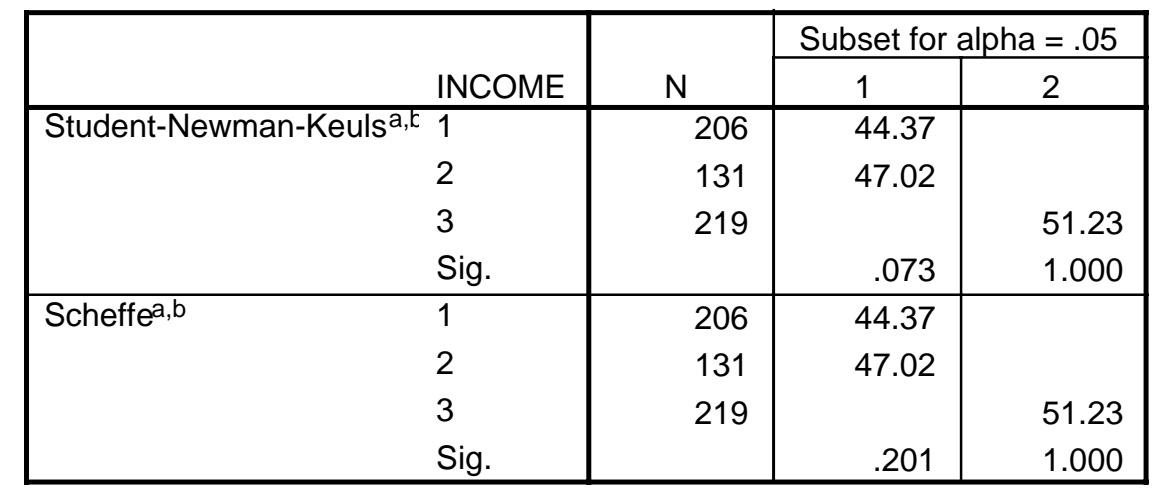

Means for groups in homogeneous subsets are displayed.

a. Uses Harmonic Mean Sample Size $=175.910$.

b. The group sizes are unequal. The harmonic mean of the group sizes is used. Type I error levels are not guaranteed. 
APPENDIX T - One-Way ANOVA for Factors A, B, \& C (cont.)

One-way ANOVA for Factor A (Education)

Descriptives

\begin{tabular}{|c|c|c|c|c|c|c|c|c|}
\hline & \multirow[b]{2}{*}{$\mathrm{N}$} & \multirow[b]{2}{*}{ Mean } & \multirow[b]{2}{*}{ Std. Deviation } & \multirow[b]{2}{*}{ Std. Error } & \multicolumn{2}{|c|}{$\begin{array}{l}\text { 95\% Confidence Interval for } \\
\text { Mean }\end{array}$} & \multirow[b]{2}{*}{ Minimum } & \multirow[b]{2}{*}{ Maximum } \\
\hline & & & & & Lower Bound & Upper Bound & & \\
\hline 1 & 321 & 44.29 & 12.938 & .722 & 42.87 & 45.71 & 5 & 76 \\
\hline 2 & 235 & 52.36 & 14.472 & .944 & 50.50 & 54.22 & 14 & 90 \\
\hline Total & 556 & 47.70 & 14.168 & .601 & 46.52 & 48.88 & 5 & 90 \\
\hline
\end{tabular}

Test of Homogeneity of Variances

NCE total
\begin{tabular}{|r|r|r|c|}
\hline $\begin{array}{c}\text { Levene } \\
\text { Statistic }\end{array}$ & df1 & df2 & Sig. \\
\hline 3.983 & & 554 & .046 \\
\hline
\end{tabular}
ANOVA

NCE total
\begin{tabular}{|l|l|r|r|r|r|}
\hline & $\begin{array}{l}\text { Sum of } \\
\text { Squares }\end{array}$ & \multicolumn{1}{c|}{ df } & Mean Square & F & Sig. \\
\hline Between Groups & 8837.631 & 1 & 8837.631 & 47.733 & .000 \\
Within Groups & 102571.6 & 554 & 185.147 & & \\
Total & 111409.2 & 555 & & & \\
\hline
\end{tabular}


APPENDIX U - Fully Crossed and Balanced A\&B\&C Factorial ANOVA

Univariate Analysis of Variance

Between-Subjects Factors

\begin{tabular}{|ll|r|}
\hline & & \multicolumn{1}{|c|}{ N } \\
\hline INTERNET & 0 & 114 \\
& 1 & 114 \\
INCOME & 1 & 76 \\
& 2 & 76 \\
& 3 & 76 \\
Education & 1 & 114 \\
& 2 & 114 \\
\hline
\end{tabular}

\section{Levene's Test of Equality of Error Variances}

Dependent Variable: NCE

\begin{tabular}{|l|r|r|r|}
\hline $\mathrm{F}$ & $\mathrm{df} 1$ & $\mathrm{df} 2$ & Sig. \\
\hline 1.248 & 11 & 216 & .257 \\
\hline
\end{tabular}

Tests the null hypothesis that the error variance of the dependent variable is equal across groups.

a. Design:

Intercept+INTERNET+INCOME+EDUCATIO+INTERNET

* INCOME+INTERNET * EDUCATIO+INCOME *

EDUCATIO+INTERNET * INCOME * EDUCATIO 
APPENDIX U - Fully Crossed and Balanced A\&B\&C Factorial ANOVA (cont.)

Descriptive Statistics

Dependent Variable: NCE

\begin{tabular}{|c|c|c|c|c|c|}
\hline INTERNET & INCOME & Education & Mean & Std. Deviation & $\mathrm{N}$ \\
\hline \multirow[t]{12}{*}{0} & \multirow[t]{3}{*}{1} & 1 & 40.84 & 12.549 & 19 \\
\hline & & 2 & 54.42 & 14.968 & 19 \\
\hline & & Total & 47.63 & 15.262 & 38 \\
\hline & \multirow[t]{3}{*}{2} & 1 & 45.32 & 12.356 & 19 \\
\hline & & 2 & 50.37 & 8.858 & 19 \\
\hline & & Total & 47.84 & 10.909 & 38 \\
\hline & \multirow[t]{3}{*}{3} & 1 & 45.95 & 11.759 & 19 \\
\hline & & 2 & 49.84 & 15.872 & 19 \\
\hline & & Total & 47.89 & 13.918 & 38 \\
\hline & \multirow[t]{3}{*}{ Total } & 1 & 44.04 & 12.223 & 57 \\
\hline & & 2 & 51.54 & 13.508 & 57 \\
\hline & & Total & 47.79 & 13.367 & 114 \\
\hline \multirow[t]{12}{*}{1} & \multirow[t]{3}{*}{1} & 1 & 45.58 & 13.385 & 19 \\
\hline & & 2 & 46.32 & 13.204 & 19 \\
\hline & & Total & 45.95 & 13.119 & 38 \\
\hline & \multirow[t]{3}{*}{2} & 1 & 47.37 & 14.664 & 19 \\
\hline & & 2 & 49.05 & 12.295 & 19 \\
\hline & & Total & 48.21 & 13.374 & 38 \\
\hline & \multirow[t]{3}{*}{3} & 1 & 47.89 & 14.479 & 19 \\
\hline & & 2 & 56.74 & 16.865 & 19 \\
\hline & & Total & 52.32 & 16.138 & 38 \\
\hline & \multirow[t]{3}{*}{ Total } & 1 & 46.95 & 13.967 & 57 \\
\hline & & 2 & 50.70 & 14.692 & 57 \\
\hline & & Total & 48.82 & 14.395 & 114 \\
\hline \multirow[t]{12}{*}{ Total } & \multirow[t]{3}{*}{1} & 1 & 43.21 & 13.020 & 38 \\
\hline & & 2 & 50.37 & 14.515 & 38 \\
\hline & & Total & 46.79 & 14.161 & 76 \\
\hline & \multirow[t]{3}{*}{2} & 1 & 46.34 & 13.415 & 38 \\
\hline & & 2 & 49.71 & 10.590 & 38 \\
\hline & & Total & 48.03 & 12.124 & 76 \\
\hline & \multirow[t]{3}{*}{3} & 1 & 46.92 & 13.047 & 38 \\
\hline & & 2 & 53.29 & 16.527 & 38 \\
\hline & & Total & 50.11 & 15.133 & 76 \\
\hline & \multirow[t]{3}{*}{ Total } & 1 & 45.49 & 13.147 & 114 \\
\hline & & 2 & 51.12 & 14.056 & 114 \\
\hline & & Total & 48.31 & 13.870 & 228 \\
\hline
\end{tabular}


APPENDIX U - Fully Crossed and Balanced A\&B\&C Factorial ANOVA (cont.)

Tests of Between-Subjects Effects

\begin{tabular}{|c|c|c|c|c|c|c|c|c|}
\hline Source & $\begin{array}{l}\text { Type III Sum } \\
\text { of Squares }\end{array}$ & df & Mean Square & $\mathrm{F}$ & Sig. & $\begin{array}{l}\text { Partial Eta } \\
\text { Squared }\end{array}$ & $\begin{array}{l}\text { Noncent. } \\
\text { Parameter }\end{array}$ & $\begin{array}{l}\text { Observed } \\
\text { Power }^{\mathrm{a}}\end{array}$ \\
\hline Corrected Model & $3767.772^{b}$ & 11 & 342.525 & 1.854 & .047 & .086 & 20.398 & .868 \\
\hline Intercept & 532053.491 & 1 & 532053.491 & 2880.381 & .000 & .930 & 2880.381 & 1.000 \\
\hline INTERNET & 61.070 & 1 & 61.070 & .331 & .566 & .002 & .331 & .088 \\
\hline INCOME & 426.772 & 2 & 213.386 & 1.155 & .317 & .011 & 2.310 & .252 \\
\hline EDUCATIO & 1807.737 & 1 & 1807.737 & 9.787 & .002 & .043 & 9.787 & .876 \\
\hline INTERNET * INCOME & 366.772 & 2 & 183.386 & .993 & .372 & .009 & 1.986 & .222 \\
\hline INTERNET * EDUCATIO & 200.860 & 1 & 200.860 & 1.087 & .298 & .005 & 1.087 & .180 \\
\hline INCOME * EDUCATIO & 151.895 & 2 & 75.947 & .411 & .663 & .004 & 822 & .116 \\
\hline $\begin{array}{l}\text { INTERNET * INCOME * } \\
\text { EDUCATIO }\end{array}$ & 752.667 & 2 & 376.333 & 2.037 & .133 & .019 & 4.075 & .417 \\
\hline Error & 39898.737 & 216 & 184.716 & & & & & \\
\hline Total & 575720.000 & 228 & & & & & & \\
\hline Corrected Total & 43666.509 & 227 & & & & & & \\
\hline
\end{tabular}

a. Computed using alpha $=.05$

b. $\mathrm{R}$ Squared $=.086$ (Adjusted R Squared $=.040$ ) 
APPENDIX U - Fully Crossed and Balanced A\&B\&C Factorial ANOVA (cont.)

\section{Estimated Marginal Means}

\section{Grand Mean}

Dependent Variable: NCE

\begin{tabular}{|c|r|r|r|}
\hline & & \multicolumn{2}{|c|}{$95 \%$ Confidence Interval } \\
\cline { 3 - 4 } Mean & Std. Error & Lower Bound & Upper Bound \\
\hline 48.307 & .900 & 46.533 & 50.081 \\
\hline
\end{tabular}

\section{INTERNET}

Dependent Variable: NCE

\begin{tabular}{|l|r|r|r|r|}
\hline & & & \multicolumn{2}{|c|}{ 95\% Confidence Interval } \\
\cline { 4 - 5 } INTERNET & Mean & Std. Error & Lower Bound & Upper Bound \\
\hline 0 & 47.789 & 1.273 & 45.281 & 50.298 \\
1 & 48.825 & 1.273 & 46.316 & 51.333 \\
\hline
\end{tabular}

\section{INCOME}

Dependent Variable: NCE

\begin{tabular}{|l|r|r|r|r|}
\hline & & & \multicolumn{2}{|c|}{$95 \%$ Confidence Interval } \\
\cline { 4 - 5 } INCOME & Mean & Std. Error & Lower Bound & Upper Bound \\
\hline 1 & 46.789 & 1.559 & 43.717 & 49.862 \\
2 & 48.026 & 1.559 & 44.954 & 51.099 \\
3 & 50.105 & 1.559 & 47.032 & 53.178 \\
\hline
\end{tabular}

\section{Education}

Dependent Variable: NCE

\begin{tabular}{|l|c|r|r|r|}
\hline \multirow{2}{*}{ Education } & & & \multicolumn{2}{|c|}{ 95\% Confidence Interval } \\
\cline { 4 - 5 } & Mean & Std. Error & Lower Bound & Upper Bound \\
\hline 1 & 45.491 & 1.273 & 42.982 & 48.000 \\
2 & 51.123 & 1.273 & 48.614 & 53.632 \\
\hline
\end{tabular}

\section{INTERNET * INCOME}

Dependent Variable: NCE

\begin{tabular}{|ll|r|r|r|r|}
\hline & & & & \multicolumn{2}{|c|}{$95 \%$ Confidence Interval } \\
\cline { 5 - 6 } INTERNET & INCOME & Mean & Std. Error & Lower Bound & Upper Bound \\
\hline 0 & 1 & 47.632 & 2.205 & 43.286 & 51.977 \\
& 2 & 47.842 & 2.205 & 43.497 & 52.188 \\
& 3 & 47.895 & 2.205 & 43.549 & 52.240 \\
\hline 1 & 1 & 45.947 & 2.205 & 41.602 & 50.293 \\
& 2 & 48.211 & 2.205 & 43.865 & 52.556 \\
& 3 & 52.316 & 2.205 & 47.970 & 56.661 \\
\hline
\end{tabular}


APPENDIX U - Fully Crossed and Balanced A\&B\&C Factorial ANOVA (cont.)

\section{INTERNET * Education}

Dependent Variable: NCE

\begin{tabular}{|ll|r|r|r|r|}
\hline \multirow{2}{*}{ INTERNET } & & & \multirow{2}{|c|}{$95 \%$ Confidence Interval } \\
\cline { 5 - 6 } & Education & Mean & Std. Error & Lower Bound & Upper Bound \\
\hline 1 & 1 & 44.035 & 1.800 & 40.487 & 47.583 \\
& 2 & 51.544 & 1.800 & 47.996 & 55.092 \\
\hline 1 & 1 & 46.947 & 1.800 & 43.399 & 50.496 \\
& 2 & 50.702 & 1.800 & 47.154 & 54.250 \\
\hline
\end{tabular}

\section{INCOME * Education}

Dependent Variable: NCE

\begin{tabular}{|ll|r|r|r|r|}
\hline & & & & \multicolumn{2}{|c|}{$95 \%$ Confidence Interval } \\
\cline { 5 - 6 } INCOME & Education & Mean & Std. Error & Lower Bound & Upper Bound \\
\hline 1 & 1 & 43.211 & 2.205 & 38.865 & 47.556 \\
& 2 & 50.368 & 2.205 & 46.023 & 54.714 \\
\hline 2 & 1 & 46.342 & 2.205 & 41.997 & 50.688 \\
& 2 & 49.711 & 2.205 & 45.365 & 54.056 \\
\hline 3 & 1 & 46.921 & 2.205 & 42.575 & 51.267 \\
& 2 & 53.289 & 2.205 & 48.944 & 57.635 \\
\hline
\end{tabular}

\section{INTERNET * INCOME * Education}

Dependent Variable: NCE

\begin{tabular}{|c|c|c|c|c|c|c|}
\hline \multirow[b]{2}{*}{ INTERNET } & \multirow[b]{2}{*}{ INCOME } & \multirow[b]{2}{*}{ Education } & \multirow[b]{2}{*}{ Mean } & \multirow[b]{2}{*}{ Std. Error } & \multicolumn{2}{|c|}{ 95\% Confidence Interval } \\
\hline & & & & & Lower Bound & Upper Bound \\
\hline \multirow[t]{6}{*}{0} & 1 & 1 & 40.842 & 3.118 & 34.697 & 46.988 \\
\hline & & 2 & 54.421 & 3.118 & 48.275 & 60.567 \\
\hline & 2 & 1 & 45.316 & 3.118 & 39.170 & 51.461 \\
\hline & & 2 & 50.368 & 3.118 & 44.223 & 56.514 \\
\hline & 3 & 1 & 45.947 & 3.118 & 39.802 & 52.093 \\
\hline & & 2 & 49.842 & 3.118 & 43.697 & 55.988 \\
\hline \multirow[t]{6}{*}{1} & 1 & 1 & 45.579 & 3.118 & 39.433 & 51.725 \\
\hline & & 2 & 46.316 & 3.118 & 40.170 & 52.461 \\
\hline & 2 & 1 & 47.368 & 3.118 & 41.223 & 53.514 \\
\hline & & 2 & 49.053 & 3.118 & 42.907 & 55.198 \\
\hline & 3 & 1 & 47.895 & 3.118 & 41.749 & 54.040 \\
\hline & & 2 & 56.737 & 3.118 & 50.591 & 62.882 \\
\hline
\end{tabular}




\section{APPENDIX U - Fully Crossed and Balanced A\&B\&C Factorial ANOVA (cont.)}

\section{Post Hoc Tests}

\section{INCOME}

Multiple Comparisons

Dependent Variable: NCE

\begin{tabular}{|c|c|c|c|c|c|c|c|}
\hline & \multirow[b]{2}{*}{ (I) INCOME } & \multirow[b]{2}{*}{ (J) INCOME } & \multirow{2}{*}{$\begin{array}{c}\text { Mean } \\
\text { Difference } \\
(\mathrm{I}-\mathrm{J}) \\
\end{array}$} & \multirow[b]{2}{*}{ Std. Error } & \multirow[b]{2}{*}{ Sig. } & \multicolumn{2}{|c|}{ 95\% Confidence Interval } \\
\hline & & & & & & Lower Bound & Upper Bound \\
\hline \multirow[t]{6}{*}{ Scheffe } & \multirow[t]{2}{*}{1} & 2 & -1.24 & 2.205 & .854 & -6.67 & 4.20 \\
\hline & & 3 & -3.32 & 2.205 & .325 & -8.75 & 2.12 \\
\hline & \multirow[t]{2}{*}{2} & 1 & 1.24 & 2.205 & .854 & -4.20 & 6.67 \\
\hline & & 3 & -2.08 & 2.205 & .642 & -7.51 & 3.36 \\
\hline & \multirow[t]{2}{*}{3} & 1 & 3.32 & 2.205 & .325 & -2.12 & 8.75 \\
\hline & & 2 & 2.08 & 2.205 & .642 & -3.36 & 7.51 \\
\hline \multirow[t]{6}{*}{ LSD } & \multirow[t]{2}{*}{1} & 2 & -1.24 & 2.205 & .575 & -5.58 & 3.11 \\
\hline & & 3 & -3.32 & 2.205 & .134 & -7.66 & 1.03 \\
\hline & \multirow[t]{2}{*}{2} & 1 & 1.24 & 2.205 & .575 & -3.11 & 5.58 \\
\hline & & 3 & -2.08 & 2.205 & .347 & -6.42 & 2.27 \\
\hline & \multirow[t]{2}{*}{3} & 1 & 3.32 & 2.205 & .134 & -1.03 & 7.66 \\
\hline & & 2 & 2.08 & 2.205 & .347 & -2.27 & 6.42 \\
\hline \multirow[t]{6}{*}{ Dunnett T3 } & \multirow[t]{2}{*}{1} & 2 & -1.24 & 2.138 & .916 & -6.40 & 3.93 \\
\hline & & 3 & -3.32 & 2.377 & .417 & -9.05 & 2.42 \\
\hline & \multirow[t]{2}{*}{2} & 1 & 1.24 & 2.138 & .916 & -3.93 & 6.40 \\
\hline & & 3 & -2.08 & 2.224 & .726 & -7.45 & 3.29 \\
\hline & \multirow[t]{2}{*}{3} & 1 & 3.32 & 2.377 & .417 & -2.42 & 9.05 \\
\hline & & 2 & 2.08 & 2.224 & .726 & -3.29 & 7.45 \\
\hline
\end{tabular}

Based on observed means. 
APPENDIX U - Fully Crossed and Balanced A\&B\&C Factorial ANOVA (cont.)

Homogeneous Subsets

NCE

\begin{tabular}{|ll|r|r|}
\hline & & & \multicolumn{1}{|c|}{ Subset } \\
\cline { 4 - 4 } & INCOME & $\mathrm{N}$ & \multicolumn{1}{|c|}{1} \\
\hline Student-Newman-Keuls, & 1 & 76 & 46.79 \\
& 2 & 76 & 48.03 \\
& 3 & 76 & 50.11 \\
Sig. & & .291 \\
\hline Scheffe ${ }^{\mathrm{a}, \mathrm{b}}$ & 1 & 76 & 46.79 \\
& 2 & 76 & 48.03 \\
& 3 & 76 & 50.11 \\
& Sig. & & .325 \\
\hline
\end{tabular}

Means for groups in homogeneous subsets are displayed.

Based on Type III Sum of Squares

The error term is Mean Square(Error) $=184.716$.

a. Uses Harmonic Mean Sample Size $=76.000$.

b. Alpha $=.05$. 


\section{APPENDIX V - One-Way ANOVA - Balanced Data}

One-way ANOVA on Factor A (Internet) calculated from Balanced Data

Descriptives

\begin{tabular}{|c|c|c|c|c|c|c|c|c|}
\hline & \multirow[b]{2}{*}{$\mathrm{N}$} & \multirow[b]{2}{*}{ Mean } & \multirow[b]{2}{*}{ Std. Deviation } & \multirow[b]{2}{*}{ Std. Error } & \multicolumn{2}{|c|}{$\begin{array}{l}\text { 95\% Confidence Interval for } \\
\text { Mean }\end{array}$} & \multirow[b]{2}{*}{ Minimum } & \multirow[b]{2}{*}{ Maximum } \\
\hline & & & & & Lower Bound & Upper Bound & & \\
\hline 0 & 114 & 47.79 & 13.367 & 1.252 & 45.31 & 50.27 & 18 & $\overline{78}$ \\
\hline 1 & 114 & 48.82 & 14.395 & 1.348 & 46.15 & 51.50 & 14 & 84 \\
\hline Total & 228 & 48.31 & 13.870 & .919 & 46.50 & 50.12 & 14 & 84 \\
\hline
\end{tabular}

\section{Test of Homogeneity of Variances}

NCE
\begin{tabular}{|r|r|r|c|}
\hline $\begin{array}{c}\text { Levene } \\
\text { Statistic }\end{array}$ & df1 & df2 & Sig. \\
\hline 1.684 & 1 & 226 & .196 \\
\hline
\end{tabular}

ANOVA

NCE
\begin{tabular}{|l|r|r|r|r|r|}
\hline & \multicolumn{1}{|c|}{$\begin{array}{c}\text { Sum of } \\
\text { Squares }\end{array}$} & \multicolumn{1}{c|}{ df } & Mean Square & \multicolumn{1}{c|}{ F } & Sig. \\
\hline Between Groups & 61.070 & 1 & 61.070 & .317 & .574 \\
Within Groups & 43605.439 & 226 & 192.944 & & \\
Total & 43666.509 & 227 & & & \\
\hline
\end{tabular}


APPENDIX V - One-Way ANOVA - Balanced Data (cont.)

One-way ANOVA on Factor B (income) calculated from Balanced Data

\section{Descriptives}

\begin{tabular}{|c|c|c|c|c|c|c|c|c|}
\hline & \multirow[b]{2}{*}{$\mathrm{N}$} & \multirow[b]{2}{*}{ Mean } & \multirow[b]{2}{*}{ Std. Deviation } & \multirow[b]{2}{*}{ Std. Error } & \multicolumn{2}{|c|}{$\begin{array}{c}\text { 95\% Confidence Interval for } \\
\text { Mean }\end{array}$} & \multirow[b]{2}{*}{ Minimum } & \multirow[b]{2}{*}{ Maximum } \\
\hline & & & & & Lower Bound & Upper Bound & & \\
\hline 1 & 76 & 46.79 & 14.161 & 1.624 & 43.55 & 50.03 & 18 & 78 \\
\hline 2 & 76 & 48.03 & 12.124 & 1.391 & 45.26 & 50.80 & 21 & 75 \\
\hline 3 & 76 & 50.11 & 15.133 & 1.736 & 46.65 & 53.56 & 14 & 84 \\
\hline Total & 228 & 48.31 & 13.870 & .919 & 46.50 & 50.12 & 14 & 84 \\
\hline
\end{tabular}

Test of Homogeneity of Variances

NCE
\begin{tabular}{|c|c|c|c|}
\hline $\begin{array}{c}\text { Levene } \\
\text { Statistic }\end{array}$ & df1 & df2 & Sig. \\
\hline 2.097 & 2 & 225 & .125 \\
\hline
\end{tabular}
ANOVA

NCE
\begin{tabular}{|l|r|r|r|l|c|}
\hline & \multicolumn{1}{|c|}{$\begin{array}{c}\text { Sum of } \\
\text { Squares }\end{array}$} & \multicolumn{1}{c|}{ df } & Mean Square & \multicolumn{1}{c|}{ F } & Sig. \\
\hline Between Groups & 426.772 & 2 & 213.386 & 1.110 & .331 \\
Within Groups & 43239.737 & 225 & 192.177 & & \\
Total & 43666.509 & 227 & & & \\
\hline
\end{tabular}


APPENDIX V - One-Way ANOVA - Balanced Data (cont.)

Post Hoc Tests

\section{Multiple Comparisons}

\begin{tabular}{|c|c|c|c|c|c|c|c|}
\hline & \multirow[b]{2}{*}{ (I) INCOME } & \multirow[b]{2}{*}{ (J) INCOME } & \multirow{2}{*}{$\begin{array}{c}\text { Mean } \\
\text { Difference } \\
(\mathrm{I}-\mathrm{J})\end{array}$} & \multirow[b]{2}{*}{ Std. Error } & \multirow[b]{2}{*}{ Sig. } & \multicolumn{2}{|c|}{ 95\% Confidence Interval } \\
\hline & & & & & & Lower Bound & Upper Bound \\
\hline \multirow[t]{6}{*}{ Scheffe } & \multirow[t]{2}{*}{1} & 2 & -1.24 & 2.249 & .860 & -6.78 & 4.30 \\
\hline & & 3 & -3.32 & 2.249 & .339 & -8.86 & 2.23 \\
\hline & \multirow[t]{2}{*}{2} & 1 & 1.24 & 2.249 & .860 & -4.30 & 6.78 \\
\hline & & 3 & -2.08 & 2.249 & .653 & -7.62 & 3.46 \\
\hline & \multirow[t]{2}{*}{3} & 1 & 3.32 & 2.249 & .339 & -2.23 & 8.86 \\
\hline & & 2 & 2.08 & 2.249 & .653 & -3.46 & 7.62 \\
\hline \multirow[t]{6}{*}{ LSD } & \multirow[t]{2}{*}{1} & 2 & -1.24 & 2.249 & .583 & -5.67 & 3.19 \\
\hline & & 3 & -3.32 & 2.249 & .142 & -7.75 & 1.12 \\
\hline & \multirow[t]{2}{*}{2} & 1 & 1.24 & 2.249 & .583 & -3.19 & 5.67 \\
\hline & & 3 & -2.08 & 2.249 & .356 & -6.51 & 2.35 \\
\hline & \multirow[t]{2}{*}{3} & 1 & 3.32 & 2.249 & .142 & -1.12 & 7.75 \\
\hline & & 2 & 2.08 & 2.249 & .356 & -2.35 & 6.51 \\
\hline \multirow[t]{6}{*}{ Dunnett T3 } & \multirow[t]{2}{*}{1} & 2 & -1.24 & 2.138 & .916 & -6.40 & 3.93 \\
\hline & & 3 & -3.32 & 2.377 & .417 & -9.05 & 2.42 \\
\hline & \multirow[t]{2}{*}{2} & 1 & 1.24 & 2.138 & .916 & -3.93 & 6.40 \\
\hline & & 3 & -2.08 & 2.224 & .726 & -7.45 & 3.29 \\
\hline & \multirow[t]{2}{*}{3} & 1 & 3.32 & 2.377 & .417 & -2.42 & 9.05 \\
\hline & & 2 & 2.08 & 2.224 & .726 & -3.29 & 7.45 \\
\hline
\end{tabular}




\section{APPENDIX V - One-Way ANOVA - Balanced Data (cont.)}

Homogeneous Subsets

NCE

\begin{tabular}{|ll|r|r|}
\hline & & & $\begin{array}{c}\text { Subset } \\
\text { for alpha } \\
=.05\end{array}$ \\
\cline { 4 - 4 } & & & 1 \\
\hline Student-Newman-Keuls $^{\mathrm{a}}$ & INCOME & $\mathrm{N}$ & \multicolumn{1}{c|}{} \\
& 2 & 76 & 46.79 \\
& 3 & 76 & 48.03 \\
& Sig. & 76 & 50.11 \\
& 1 & & .305 \\
\hline Scheffe $^{\mathrm{a}}$ & 2 & 76 & 46.79 \\
& 3 & 76 & 48.03 \\
& Sig. & 76 & 50.11 \\
& & & .339 \\
\hline
\end{tabular}

Means for groups in homogeneous subsets are displayed.

a. Uses Harmonic Mean Sample Size $=76.000$. 


\section{APPENDIX V - One-Way ANOVA - Balanced Data (cont.)}

One-way ANOVA on Factor B (Education) calculated from Balanced Data

\section{Descriptives}

\begin{tabular}{|c|c|c|c|c|c|c|c|c|}
\hline & \multirow[b]{2}{*}{$\mathrm{N}$} & \multirow[b]{2}{*}{ Mean } & \multirow[b]{2}{*}{ Std. Deviation } & \multirow[b]{2}{*}{ Std. Error } & \multicolumn{2}{|c|}{$\begin{array}{l}\text { 95\% Confidence Interval for } \\
\text { Mean }\end{array}$} & \multirow[b]{2}{*}{ Minimum } & \multirow[b]{2}{*}{ Maximum } \\
\hline & & & & & Lower Bound & Upper Bound & & \\
\hline 1 & 114 & 45.49 & 13.147 & 1.231 & 43.05 & 47.93 & 18 & 71 \\
\hline 2 & 114 & 51.12 & 14.056 & 1.316 & 48.51 & 53.73 & 14 & 84 \\
\hline Total & 228 & 48.31 & 13.870 & .919 & 46.50 & 50.12 & 14 & 84 \\
\hline
\end{tabular}

Test of Homogeneity of Variances

NCE
\begin{tabular}{|r|r|r|r|}
\hline Levene & df1 & df2 & Sig. \\
\hline Statistic & df 1 & 226 & .942 \\
\hline .005 & & 1
\end{tabular}

ANOVA

NCE
\begin{tabular}{|l|c|r|r|r|r|}
\hline & \multicolumn{1}{|c|}{ Sum of } \\
& Squares & df & Mean Square & F & Sig. \\
\hline Between Groups & 1807.737 & 1 & 1807.737 & 9.760 & .002 \\
Within Groups & 41858.772 & 226 & 185.216 & & \\
Total & 43666.509 & 227 & & & \\
\hline
\end{tabular}


the End 